FABRÍCIO JUNQUEIRA

\title{
MODELAGEM E SIMULAÇÃO DISTRIBUÍDA DE SISTEMAS PRODUTIVOS
}

Tese apresentada à Escola Politécnica da Universidade de São Paulo para a obtenção do título de Doutor em Engenharia.

São Paulo 
FABRÍCIO JUNQUEIRA

\section{MODELAGEM E SIMULAÇÃO DISTRIBUÍDA DE SISTEMAS PRODUTIVOS}

Tese apresentada à Escola Politécnica da Universidade de São Paulo para a obtenção do título de Doutor em Engenharia.

Área de Concentração:

Engenharia de Controle e Automação Mecânica

Orientador:

Prof. Dr. Paulo Eigi Miyagi

São Paulo 
Este exemplar foi revisado e alterado em relação à versão original sob responsabilidade única do autor e com a anuência de seu orientador.

São Paulo, 20 de julho de 2006

Fabrício Junqueira (autor) Paulo Eigi Miyagi (orientador)

\section{FICHA CATALOGRÁFICA - EDIÇÃO REVISADA}

\section{Junqueira, Fabrício}

Modelagem e simulação distribuída de sistemas produtivos, São Paulo / F. Junqueira. - São Paulo, 2006.

222p.

Tese (Doutorado) - Escola Politécnica da Universidade de São Paulo. Departamento de Engenharia Mecatrônica e de Sistemas Mecânicos.

1. Rede de Petri 2. Simulação distribuída 3. Programação orientada a objetos 4. Algoritmos (Otimização) I.Universidade de São Paulo. Escola Politécnica. Departamento de Engenharia Mecatrônica e de Sistemas Mecânicos II.t. 
Aos meus pais, Osvaldo e Maria José, e ao meu irmão Leonardo. 


\section{AGRADECIMENTOS}

Ao meu orientador, Prof. Dr. Paulo Eigi Miyagi, pela sua constante orientação e incentivo para o desenvolvimento deste trabalho.

Ao CNPq pela bolsa-auxílio.

Aos meus pais, professores, através dos quais agradeço todos os professores que de forma direta ou indireta contribuiram para a minha formação.

Ao Leonardo, meu irmão, ao qual tenho profunda admiração e carinho.

À Erica, pelo seu amor e carinho.

Aos professores e alunos do Laboratório de Automação de Sistemas - LAS pelas sugestões e contribuições - em especial à Emília, à Gladys, ao Luis Alberto, ao Roger, ao David e ao Percy, pelo apoio e pela amizade.

À Escola Politecnica da USP, em especial ao Departamento de Engenharia Mecatrônica e de Sistemas Mecânicos, que institucionalmente viabilizaram este trabalho.

A todos aqueles que, mesmo não tem sido aqui citados nominalmente, colaboraram, direta ou indiretamente, de maneira não menos importante, na produção deste trabalho. 


\section{SUMÁRIO}

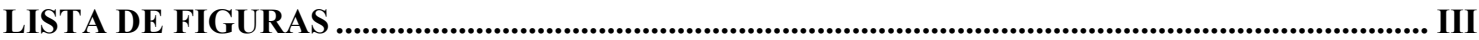

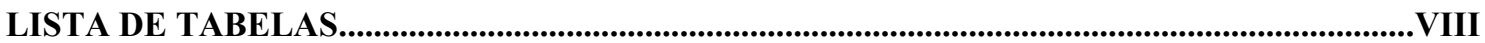

LISTA DE PALAVRAS RESERVADAS...................................................................................................

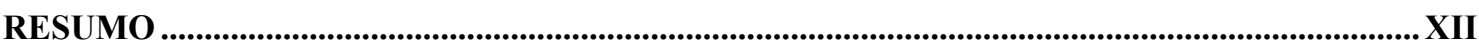

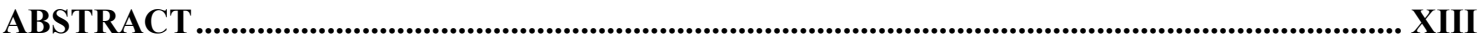

1. INTRODUÇÃO .............................................................................................................................................. 1

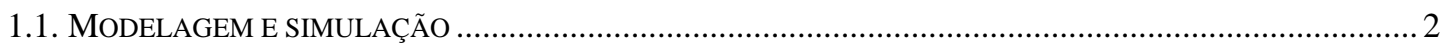

1.2. PERSPECTIVAS FUTURAS NO CAMPO DA SIMULAÇÃO, EM ESPECIAL A DISTRIBUÍDA.............................. 4

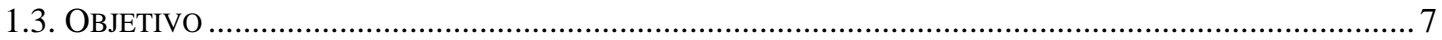

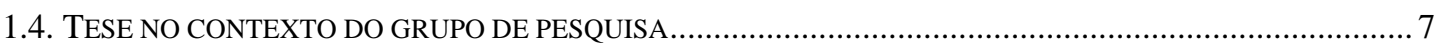

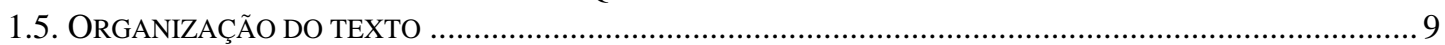

2. MODELAGEM DE SISTEMAS PRODUTIVOS, DE FORMA DISTRIBUÍDA, EM REDE DE

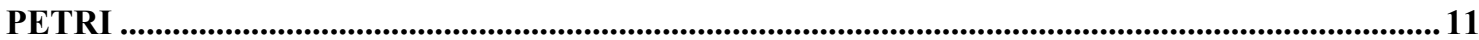

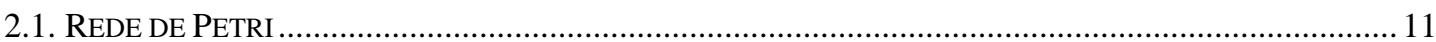

2.2. SiMULAÇÃo DistRIBUídA E A REDE DE PETRI ............................................................................ 15

2.3. ESTUDO DAS INTERFACES ENTRE MODELOS EM REDE DE PETRI ..................................................... 17

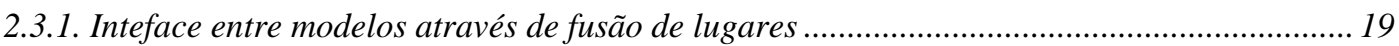

2.3.2. Inteface entre modelos através de fusão de transições............................................................2

2.3.3. Inteface entre modelos através de arcos habilitadores............................................................ 23

2.4. PROPOSTA DE UM MÉTODO PARA A CONSTRUÇÃO DE MODELOS EM RDP PARA SIMULAÇÃO

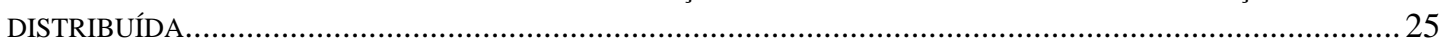

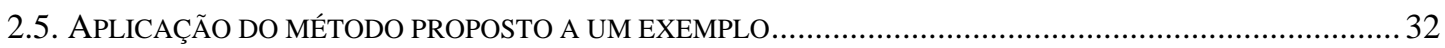

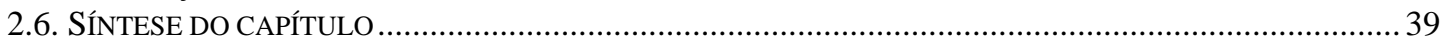

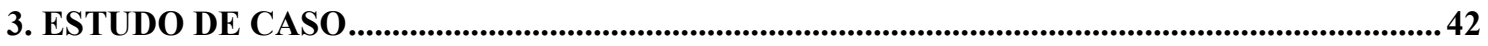

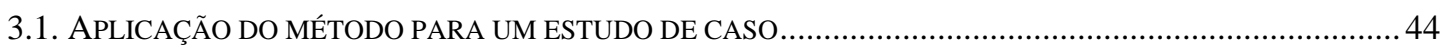

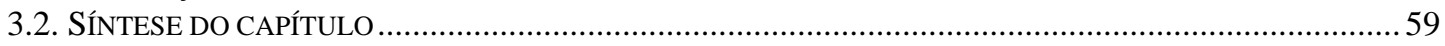

4. MECANISMO DE SINCRONIZAÇÃO DA SIMULAÇÃO.........................................................61

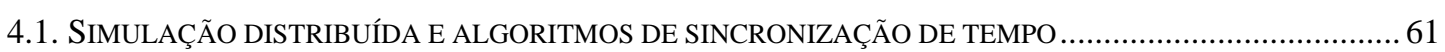

4.2. PROTOCOLO TOKEN RING DE GERENCIAMENTO DE REDE DE COMUNICAÇÃO ......................................64

4.3. PROPOSTA DE UM MECANISMO PARA O GERENCIAMENTO DA SIMULAÇÃO DISTRIBUÍDA ....................67

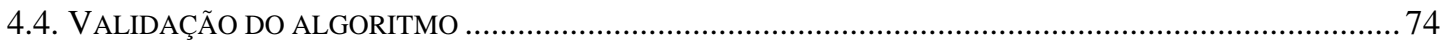

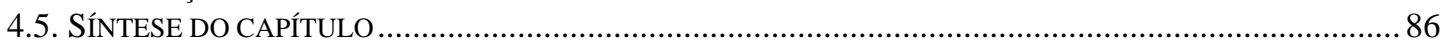

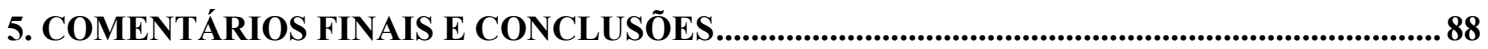

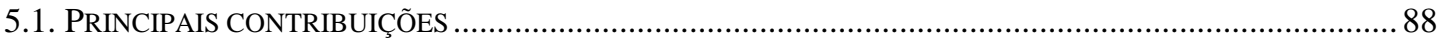

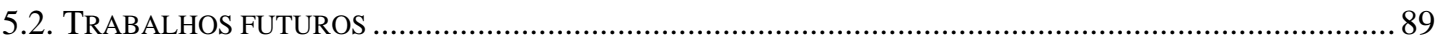

ANEXO A - PFS (PRODUCTION FLOW SCHEMA) ...................................................................91

ANEXO B - OBJETOS E UMA ABORDAGEM ORIENTADA À OBJETOS ....................................93

ANEXO C - UML (UNIFIED MODELING LANGUAGE) ...........................................................95

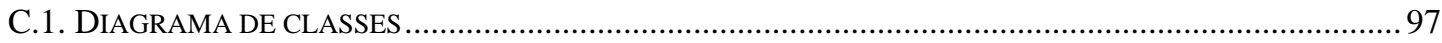

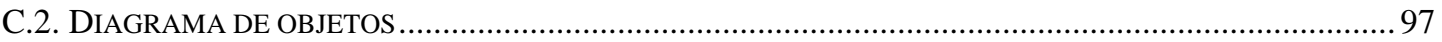

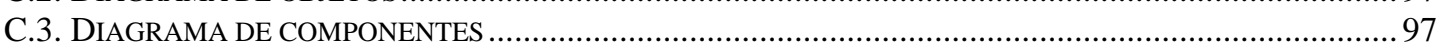

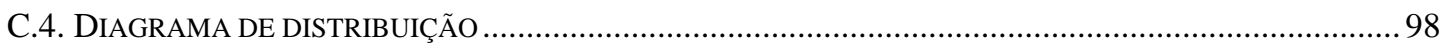

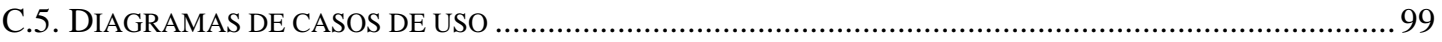




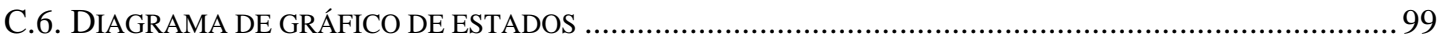

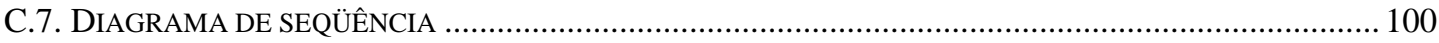

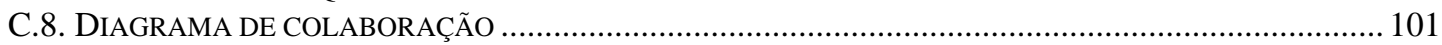

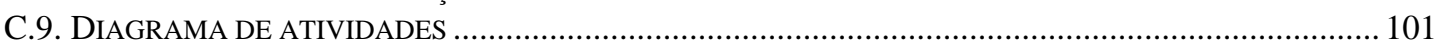

ANEXO D - UTILIZAÇÃO DE XML PARA ARMAZENAMENTO E COMPARTILHAMENTO

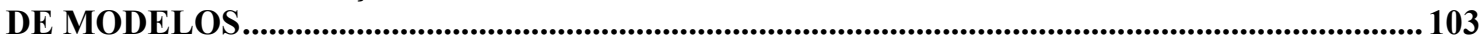

D.1. DESCRIÇÃO EM XML DOS MODELOS DA SEÇÃO 2.5 …………………………………………....114

ANEXO E - ESTUDO DE CASO (OUTROS MODELOS DO CAPÍTULO 3) ...................................118

ANEXO F - OPEN AND DISTRIBUTED PROCESSING (ODP) ..................................................... 162

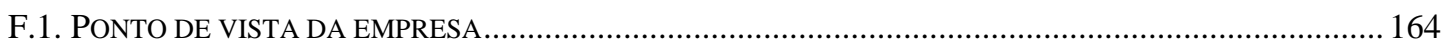

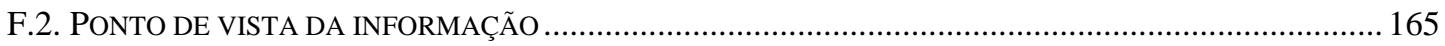

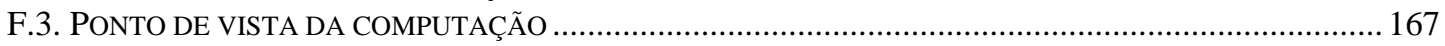

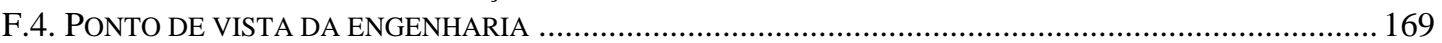

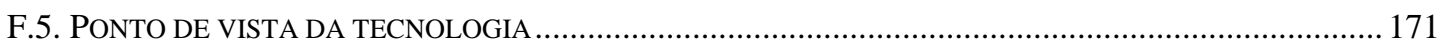

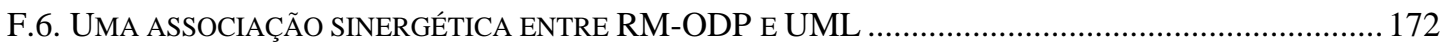

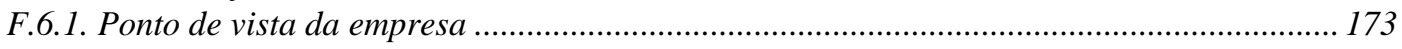

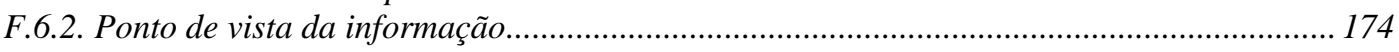

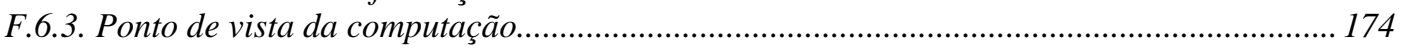

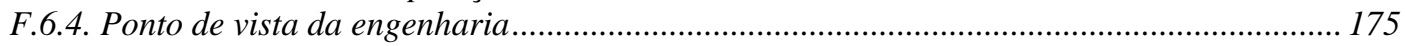

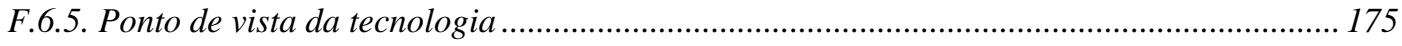

ANEXO G - PROPOSTA DE UM SISTEMA COMPUTACIONAL PARA MODELAGEM E SIMULAÇÃO DISTRIBUÍDAS DE MODELOS EM REDE DE PETRI ..........................................176

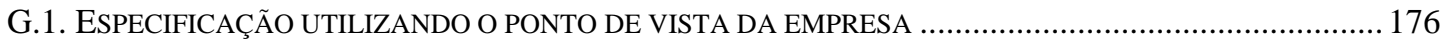

G.2. ESPECIFICAÇÃO UTILIZANDO O PONTO DE VISTA DA INFORMAÇÃO................................................... 179

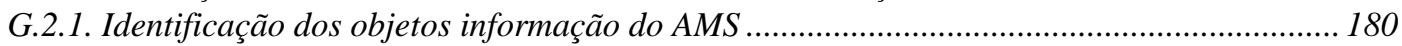

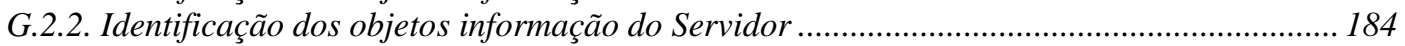

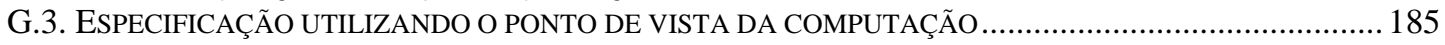

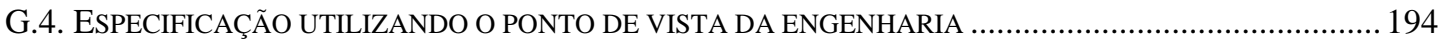

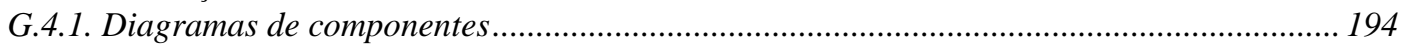

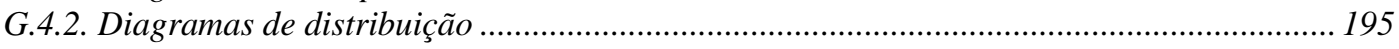

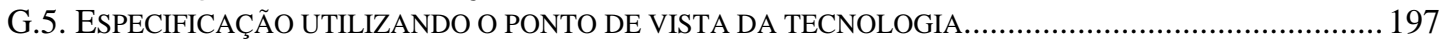

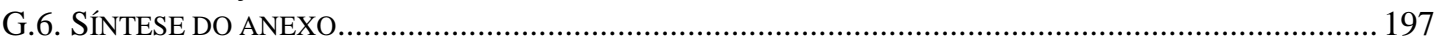

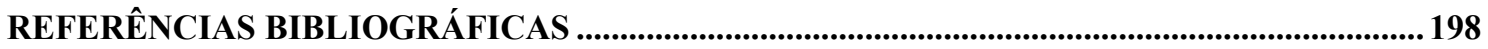




\section{LISTA DE FIGURAS}

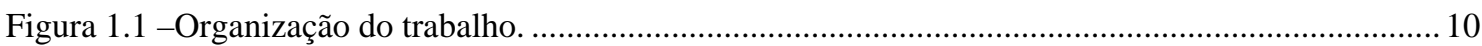

Figura 2.1 - Representação de uma Rede de Petri (adaptado de PETERSON, 1981). ............................. 12

Figura 2.2 - Exemplo de disparo de uma transição......................................................................... 14

Figura 2.3 - (a) Modelo requistante requista uma funcionalidade do modelo requisitado e aguarda por uma resposta, enquanto; (b) modelo requistante requisita uma funcionalidade do modelo requisitado e não aguarda uma resposta.

18

Figura 2.4 - Possíveis relações entre modelos: (a) diferentes modelos requisitantes poderem requisitar a funcionalidade de um modelo requisitado através de um mesmo tipo de interface; (b) a não possibilidade de se utilizar uma mesma interface para requisitar funcionalidade de modelos distintos; e (c) a possibilidade de se requisitar funcionalidades distintas através de interfaces

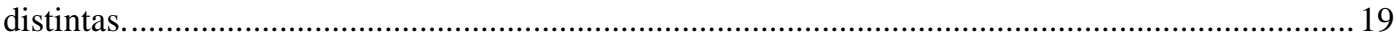

Figura 2.5 - Exemplo de troca de informações entre dois modelos em RdP utilizando-se "fusão de

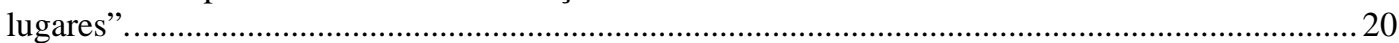

Figura 2.6 - Dois modelos distintos requisitando a mesma funcionalidade de um terceiro através da fusão de lugares......

21

Figura 2.7 - Exemplo de troca de informações entre dois modelos em RdP utilizando-se "fusão de transições”.

22

Figura 2.8 - Exemplo de troca de informações entre dois modelos em RdP utilizando-se “arcos habilitadores".

24

Figura 2.9 - (a) Introdução de arcos habilitadores no sentido contrário da chamada para garantir a seqüência de disparo desejada; (b) introdução de novos elementos, responsáveis pela comunicação

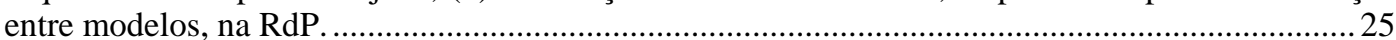

Figura 2.10 - Diagrama com o método de modelagem de sistemas produtivos.......................................26

Figura 2.11 - Uma classe, implementada em Redes de Petri............................................................... 27

Figura 2.12 - Constituição de componentes através do agrupamento de dois ou mais objetos baseados nas classes definidas na etapa 3.

29

Figura 2.13 - Exemplo de uso do relacionamento estático: (a) representação esquemática; e (b) representação em Rede de Petri com fusão de transições................................................................ 30

Figura 2.14 - Exemplo de uso do relacionamento dinâmico.................................................................3 30

Figura 2.15 - Constituição de aplicativo a partir de dois ou mais componentes.......................................31

Figura 2.16 - Representação do sistemas de movimentação de materiais. .............................................. 33

Figura 2.17 - Representação do deslocamento do transportador no trilho, deslocando-se de forma circular

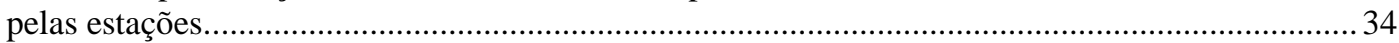

Figura 2.18 - Modelo em Rede de Petri do tranporte entre duas estações. .............................................. 34

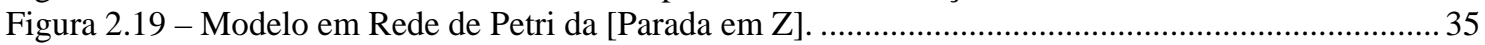

Figura 2.20 - Modelo em Rede de Petri da Interface com o Transportador.............................................. 35

Figura 2.21 - Modelo em Rede de Petri da Estação............................................................................... 35

Figura 2.22 - Modelo em Rede de Petri do Transportador. ................................................................... 36

Figura 2.23 - Ilustração do relacionamento entre os modelos da [Parada] e [Estação], através de fusão de

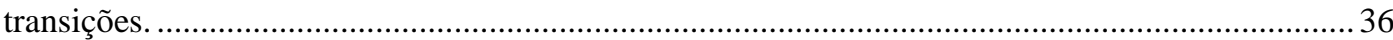

Figura 2.24 - Ilustração do relacionamento entre os modelos da [Interface com o Transportador] e [Transportador], através de fusão de transições............................................................................ 37

Figura 2.25 - Aplicação de técnicas para simplificação de modelos. .....................................................37

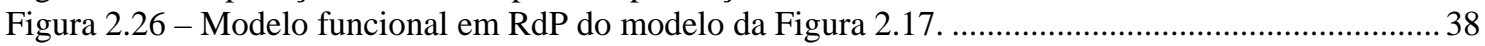

Figura 2.27 - Objetos gerados a partir das classes definidas na etapa 3. .............................................38

Figura 2.28 - Componente Célula de Manufatura. ........................................................................... 39

Figura 3.1 - Célula de Manufatura FESTO: (a) foto da célula; e (b) diagrama com a estrutura da célula. 43

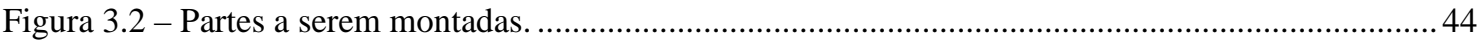

Figura 3.3 - Primeiro nível de detalhamento da Célula de Manufatura................................................. 45

Figura 3.4 - Segundo nível de detalhamento: PFS da Célula de Manufatura. ..........................................46

Figura 3.5 - Terceiro nível de detalhamento: PFS da atividade [Controle da estação de alimentação]..... 47

Figura 3.6 - Terceiro nível de detalhamento: PFS da atividade [Atuadores] ..........................................48

Figura 3.7 - Modelo em RdP lugar-transição da atividade [Ordens de produção]...................................48

Figura 3.8 - Modelo em RdP lugar-transição da atividade [Controle da estação de alimentação]. ........... 49

Figura 3.9 - Modelo em RdP lugar-transição da [Eletro-válvula]. ....................................................... 51 
Figura 3.10 - Modelo em RdP lugar-transição do [Cilindro pneumático]. ...............................................52

Figura 3.11 - Modelo em RdP lugar-transição da [Ventosa] ..............................................................53

Figura 3.12 - Modelo em RdP lugar-transição do [Motor de passo]. ..................................................... 53

Figura 3.13 - Modelo em RdP colorida da atividade [Estação de alimentação]......................................54

Figura 3.14 - Objeto Ordem_Produção gerado a partir da classe [Ordens de produção]......................... 55

Figura 3.15 - Objetos Atuador_Buffer_Cilindro_Base e Atuador_Transporte gerados a partir da classe

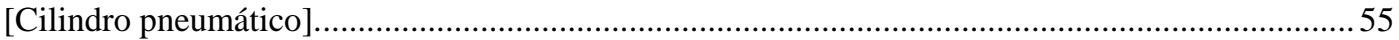

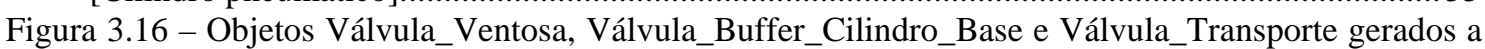

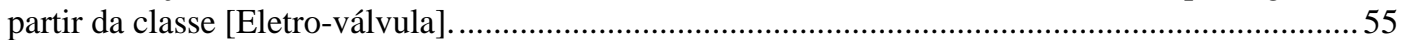

Figura 3.17 - Objeto Ventosa gerado a partir da classe [Ventosa]....................................................... 56

Figura 3.18 - Objeto Controle_Alimentação gerado a partir da classe [Controle da estação de alimentação]. ................................................................................................................... 56

Figura 3.19 - Objeto Planta_Alimentação gerado a partir da classe [Estação de alimentação]. ................56

Figura 3.20 - Componente Sistema Supervisório Ordem composto pelo objeto Ordem_Produção.......... 57

Figura 3.21 - Componente Alimentação composto pelo objeto Controle_Alimentação. ..........................5 57

Figura 3.22 - Componente Planta Alimentação............................................................................... 58

Figura 3.23 - Aplicativo Célula de Manufatura composto pelos componentes Sistema Supervisório Ordem, Alimentação e Planta Alimentação................................................................................ 59

Figura 4.1 - Exemplo de funcionamento de uma rede Token Ring (GÖHRING \& KAUFFELS, 1994). . 66

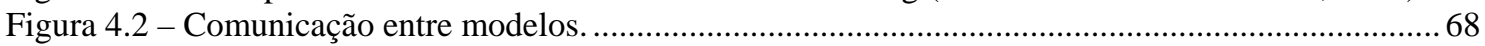

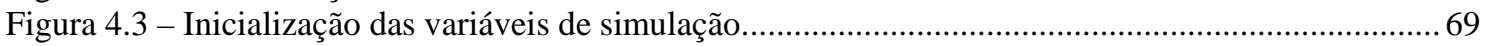

Figura 4.4 - Algoritmo de tratamento do token. ..............................................................................69

Figura 4.4 - Algoritmo de tratamento do token (continuação). .......................................................... 70

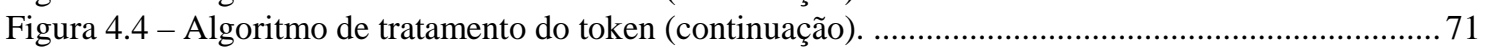

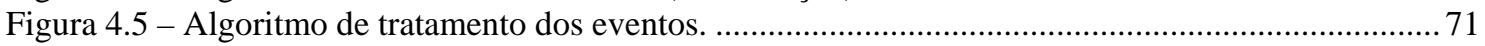

Figura 4.6 - Modelo simplificado em Rede de Petri para ilustrar o algoritmo. ...................................... 72

Figura 4.7 - Diagrama UML de seqüência para o exemplo..............................................................73

Figura 4.8 - Software de simulação implementado para validar o algoritmo. ......................................... 75

Figura 4.9 - Tempos de processamento e de circulação do token.....................................................76

Figura 4.10 - Listas de eventos utilizadas nos ensaios.................................................................. 76

Figura 4.11 - Influência do número de simuladores o número de passagens do token para processar 100

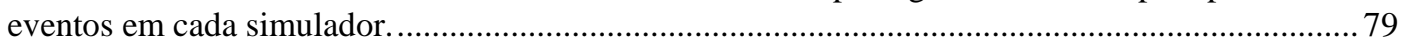

Figura 4.12 - Influência do número de simuladores sobre o TC do token............................................. 79

Figura 4.13 - Influência do número de simuladores sobre o número de passagens do token entre duas evoluções consecutivas do tempo (do simulador).

Figura 4.14 - Influência do número de simuladores sobre o número de passagens do token entre duas evoluções consecutivas do tempo, ponderando-se pelo número total de eventos processados.......... 81

Figura 4.15 - Influência do número de simuladores no tempo entre duas evoluções consecutivas de tempo (do simulador)

Figura 4.16 - Influência do número de eventos instantâneos sobre o TC do token..............................84

Figura 4.17 - Influência do número de eventos instantâneos sobre o número de passagens do token entre duas evoluções consecutivas do tempo (do simulador).

Figura 4.18 - Influência do número de eventos instantâneos sobre $\alpha$ para que se tenha uma equivalência entre o número de mensagens nulas trocadas para evolução do tempo no algoritmo proposto e no algoritmo tradicional.

Figura 4.19 - Influência do eventos instantâneos no tempo entre duas evoluções consecutivas de tempo (do simulador)

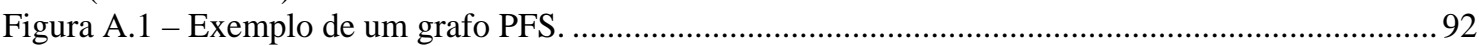

Figura C.1 - Ilustração da estrutura de uma classe ........................................................................... 95

Figura C.2 - Ilustração das formas de associações. ...........................................................................96

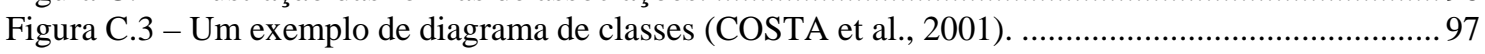

Figura C.4 - Um exemplo de diagrama de componentes (AMBLER, 2002) ........................................98

Figura C.5 - Um exemplo de diagrama de distribuição (AMBLER, 2002)...........................................98

Figura C.6 - Um exemplo de um diagrama de caso de uso (COSTA et al., 2001)................................99

Figura C.7 - Um exemplo de diagrama de estados (COSTA et al., 2001)............................................ 100

Figura C.8 - Um exemplo de diagrama de seqüência (COSTA et al., 2001)....................................... 100

Figura C.9 - Um exemplo de diagrama de colaboração (DOUGLASS, 1998)..................................... 101

Figura C.10 - Um exemplo de diagrama de atividades (COSTA et al., 2001). .................................... 102

Figura D.1 - Uso de tabelas para o armazenamento de modelos em Rede de Petri............................... 103 
Figura D.2 - Uso de XML para o armazenamento de modelos em Rede de Petri. 104

Figura D.3 - Uso de XML para o armazenamento de modelos em Rede de Petri................................ 104

Figura D.4 - Exemplo de Rede de Petri descrita utilizando-se a notação PNML...................................105

Figura D.5 - Descrição da estrutura de uma classe (em Rede de Petri) utilizando XML Schema........... 107

Figura D.5 - Descrição da estrutura de uma classe (em Rede de Petri) utilizando XML Schema. (continuação).

108

Figura D.5 - Descrição da estrutura de uma classe (em Rede de Petri) utilizando XML Schema. (continuação).

109

Figura D.6 - Descrição da estrutura de um componente utilizando XML Schema. ................................ 110

Figura D.6 - Descrição da estrutura de um componente utilizando XML Schema (continuação)........... 111

Figura D.7 - Descrição, baseada na notação XML, da estrutura do aplicativo......................................112

Figura D.8 - Exemplo de Rede de Petri descrita utilizando-se a notação proposta para modelagem de classes.

Figura D.9 - Modelo em XML da classe [Estação] (Figura 2.21). ................................................... 114

Figura D.10 - Modelo em XML da classe [Transportador] (Figura 2.22). .......................................... 115

Figura D.11 - Modelo em XML da classe da Malha de movimentação (Figura 2.26). ........................... 115

Figura D.11 Modelo em XML da classe Malha de movimentação (Figura 2.26) (continuação)............. 116

Figura D.12 - Modelo em XML do componente CelulaDeManufatura (Figura 2.28)........................... 117

Figura E.1 - Segundo nível de detalhamento: PFS da Célula de Manufatura........................................118

Figura E.2 - Terceiro nível de detalhamento: PFS da atividade [Controle da estação de inspeção]......... 119

Figura E.3 - Terceiro nível de detalhamento: PFS da atividade [Controle da estação de transporte]......119

Figura E.4 - Terceiro nível de detalhamento: PFS da atividade [Controle da estação de montagem]..... 120

Figura E.5 - Quarto nível de detalhamento - detalhamento em PFS da atividade [Prepara demais partes para a montagem].

120

Figura E.6 - Modelo em RdP colorida da atividade [Supervisão do transporte]. ..................................121

Figura E.7 - Modelo em RdP colorida da atividade [Controle da estação de inspeção]......................... 122

Figura E.8 - Modelo em RdP colorida da atividade [Controle da estação de transporte] .......................125

Figura E.9 - Modelo em RdP lugar-transição da atividade [Pega palete na estação de transporte] do [Controle da estação de montagem].

Figura E.10 - Modelo em RdP lugar-transição da atividade [Põe palete sobre a bancada] do [Controle da estação de montagem].

Figura E.11 - Modelo em RdP lugar-transição tanto para a atividade [Alimenta com mola] como para a atividade [Alimenta com tampa] do [Prepara demais partes para a montagem] do [Controle da estação de montagem].

Figura E.12 - Modelo em RdP lugar-transição da atividade [Alimenta com pino] do [Prepara demais partes para a montagem] do [Controle da estação de montagem].

Figura E.13 - Modelo em RdP lugar-transição da atividade [Pega cilindro base do palete] do [Controle da estação de montagem].

Figura E. 14 - Modelo em RdP lugar-transição da atividade [Põe cilindro base na posição de montagem] do [Controle da estação de montagem].

Figura E.15 - Modelo em RdP lugar-transição da atividade [Pega a mola] do [Controle da estação de montagem].

Figura E.16 - Modelo em RdP lugar-transição da atividade [Monta a mola] do [Controle da estação de montagem].

Figura E.17 - Modelo em RdP lugar-transição da atividade [Pega o pino] do [Controle da estação de montagem].

Figura E.18 - Modelo em RdP lugar-transição da atividade [Monta Pino] do [Controle da estação de montagem].

Figura E.19 - Modelo em RdP lugar-transição da atividade [Pega a tampa] do [Controle da estação de montagem].

Figura E.20 - Modelo em RdP lugar-transição da atividade [Monta a tampa] do [Controle da estação de montagem].

Figura E.21 - Modelo em RdP lugar-transição da atividade [Sobe cilindro montado] do [Controle da estação de montagem].

Figura E.22 - Modelo em RdP lugar-transição da atividade [Põe cilindro montado no palete] do [Controle da estação de montagem].

Figura E.23 - Modelo em RdP lugar-transição da atividade [Pega palete] do [Controle da estação de montagem]. 
Figura E.24 - Modelo em RdP lugar-transição da atividade [Põe palete na estação de transporte] do

[Controle da estação de montagem].

Figura E.25 - Modelo em RdP lugar-transição para as atividades [Avança o braço], [Recua o braço] e [Desliga motor]

Figura E.26 - Modelo em RdP lugar-transição para as atividades [Abre a garra], [Fecha a garra], [Desce o braço] e [Sobe o braço]...

Figura E.27 - Modelo em RdP colorida da atividade [Estação de inspeção]........................................ 146

Figura E.28 - Modelo em RdP colorida da atividade [Estação de transporte] ........................................ 148

Figura E.29 - Modelo em RdP colorida da atividade [Estação de montagem]. .................................... 150

Figura E.30 - Objeto Supervisão_Transporte. ............................................................................ 152

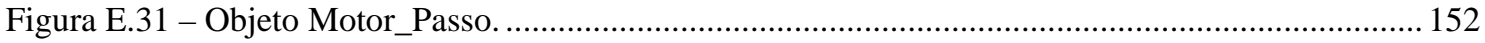

Figura E.32 - Objeto Controle_Inspeção................................................................................... 153

Figura E.33 - Objeto Controle_Montagem................................................................................... 153

Figura E.34 - Objeto Controle_Transporte. .............................................................................. 154

Figura E.35 - Objeto Planta_Inspeção................................................................................... 154

Figura E.36 - Objeto Planta_Transporte.................................................................................... 155

Figura E.37 - Objeto Planta_Montagem................................................................................ 155

Figura E.38 - Componente Sistema Supervisório Transporte......................................................... 156

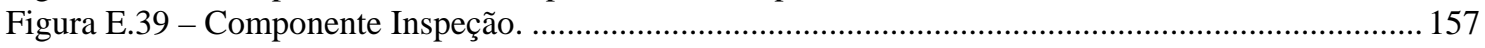

Figura E.40 - Componente Transporte. ....................................................................................... 157

Figura E.41 - Componente da Montagem................................................................................. 157

Figura E.42 - Componente Planta Inspeção.............................................................................. 158

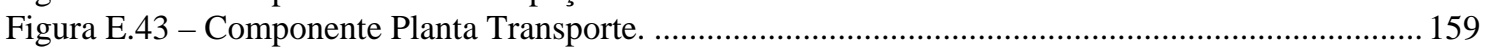

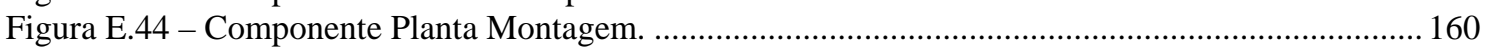

Figura E.45 - Aplicativo. .................................................................................................... 161

Figura F.1 - Relacionamento entre objetos, interfaces e objetos de ligação (PUTMAN, 2001)............. 168

Figura F.2 - Relação entre os elementos do ponto de vista da engenharia (PUTMAN, 2001)............... 170

Figura F.3 - Modelo do canal. ................................................................................................... 171

Figura F.4 - Relacionamento entre os diagramas UML e os pontos de vista da ODP (KANDÉ et al., 1998).

Figura G.1 - (a) Um exemplo de dois modelos (em Rede de Petri) interagindo entre si no mesmo AMS; (b) - Um exemplo de dois modelos (em Rede de Petri), cada um sendo executado em um AMS, interagindo entre si através do servidor.

Figura G.2 - Um exemplo de projeto usando modelos de diferentes domínios, todos pertencentes à uma

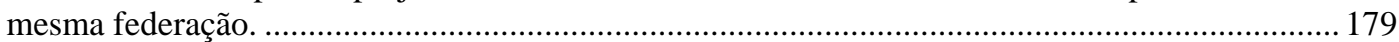

Figura G.3 - Diagrama de casos de uso referente ao sistema computacional proposto. ......................... 180

Figura G.4 - Diagrama UML de classe do Ambiente de Modelagem e Simulação (AMS).................... 180

Figura G.5 - Diagrama UML de Classes da Janela de Desenvolvimento............................................. 183

Figura G.6 - Diagrama UML de Classes do Painel da Janela de Desenvolvimento................................ 184

Figura G.7 - Diagrama UML de Classes do Servidor................................................................... 185

Figura G.8 - Diagrama de seqüência ilustrando a seqüência de atividades necessárias para sair do modo de edição e entrar no modo de simulação para quando se simula um modelo do tipo classe......... 186

Figura G.9 - Diagrama de seqüência ilustrando a seqüência de atividades necessárias para sair do modo de simulação e voltar para o modo de edição quando se simula um modelo do tipo classe........... 186

Figura G.10 - Diagrama de seqüência ilustrando a seqüência de atividades necessárias para iniciar a simulação quando se simula um modelo do tipo classe ............................................................ 187

Figura G.11 - Diagrama de seqüência ilustrando a seqüência de atividades necessárias para simular passo a passo quando se simula um modelo do tipo classe .............................................................. 187

Figura G.12 - Diagrama de seqüência ilustrando a seqüência de atividades necessárias para pausar a simulação quando se simula um modelo do tipo classe ............................................................ 188

Figura G.13 - Diagrama de seqüência ilustrando a seqüência de atividades necessárias para entrar no modo de simulação e sair do modo de edição quando se simula um modelo diferente de classe Parte I - AMS “mestre”.

Figura G.14 - Diagrama de seqüência ilustrando a seqüência de atividades necessárias para entrar no modo de simulação e sair do modo de edição quando se simula um modelo diferente de classe Parte II - Servidor.

Figura G.15 - Diagrama de seqüência ilustrando a seqüência de atividades necessárias para entrar no modo de simulação e sair do modo de edição quando se simula um modelo diferente de classe Parte III - AMS “escravo”. 
Figura G.16 - Diagrama de seqüência ilustrando a seqüência de atividades necessárias para sair do modo de simulação e voltar para o modo de edição quando se simula um modelo diferente de classe Parte I - AMS “mestre".

Figura G.17 - Diagrama de seqüência ilustrando a sequiência de atividades necessárias para sair do modo de simulação e voltar para o modo de edição quando se simula um modelo diferente de classe Parte II - Servidor

Figura G.18 - Diagrama de seqüência ilustrando a seqüência de atividades necessárias para iniciar a simulação quando se simula um modelo diferente de classe.

Figura G.19 - Diagrama de seqüência ilustrando a seqüência de atividades necessárias para pausar a simulação quando se simula um modelo diferente de classe.

Figura G.20 - Diagrama de seqüência ilustrando a seqüência de atividades que se dá durante a chamada de métodos (através de fusão de transições).

Figura G.21 - Diagrama de componentes ilustrando os componentes (Macro AMS e Macro Janela de Desenvolvimento) utilizados para a geração de modelos em Redes de Petri, bem como sua relação de dependência. 195

Figura G.22 - Diagrama de componentes ilustrando o componente Macro Servidor responsável pelo gerenciamento do Domínio e a Base de Dados. 195

Figura G.23 - Diagrama de distribuição para o Nó Estação. 196

Figura G.24 - Diagrama de distribuição para o Nó Servidor. 196

Figura G.25 - Exemplo de relação entre os nós durante a simulação. 196 


\section{LISTA DE TABELAS}

Tabela 2.1 - Objetos que constituem o componente Célula de Manufatura e as classes de que derivam. . 38

Tabela 3.1 - Descrição dos elementos do modelo em RdP da atividade [Controle da estação de alimentação]. 50

Tabela 3.1 - Descrição dos elementos do modelo em RdP da atividade [Controle da estação de alimentação] (continuação)........................................................................................................... 51

Tabela 3.2 - Descrição dos elementos do modelo em RdP da [Eletro-válvula]......................................5 51

Tabela 3.2 - Descrição dos elementos do modelo em RdP da [Eletro-válvula] (continuação)..................5 52

Tabela 3.3 - Descrição dos elementos do modelo em RdP do [Cilindro pneumático]...............................52

Tabela 3.4 - Descrição dos elementos do modelo em RdP da [Ventosa]. ...............................................53

Tabela 3.5 - Descrição dos elementos do modelo em RdP do [Motor de passo]......................................53

Tabela 3.6 - Descrição dos elementos do modelo em RdP da atividade [Estação de alimentação]...........54

Tabela 4.1. Possíveis valores para o campo de status ........................................................................69

Tabela 4.2. Resultado da simulação distribuída dos modelos. ...............................................................77

Tabela 4.3. Influência do número de simuladores sobre o TC do token. ............................................ 78

Tabela 4.4. Influência do número de simuladores sobre o número de passagens do token entre duas evoluções consecutivas do tempo (do simulador).

Tabela 4.5. Influência do número de simuladores no tempo entre duas evoluções consecutivas de tempo (do simulador).

81

Tabela 4.6. Influência da rede de comunicação no TC do token.........................................................82

Tabela 4.7. Influência da rede de comunicação sobre o número de passagens do token entre duas evoluções consecutivas do tempo (do simulador).

Tabela 4.8. Influência da rede de comunicação no tempo entre duas evoluções consecutivas de tempo (do simulador).

Tabela 4.9. Influência do número de eventos instantâneos no TC do token. .........................................84

Tabela 4.10. Influência do número de eventos instantâneos sobre o número de passagens do token entre duas evoluções consecutivas do tempo (do simulador). ................................................................ 84

Tabela 4.11. Influência da do número de eventos instantâneos no tempo entre duas evoluções consecutivas de tempo (do simulador)..

Tabela D.1 - Descrição dos tags utilizados na Figura D.5................................................................. 109

Tabela D.1 - Descrição dos tags utilizados na Figura D.5 (continuação). ............................................. 110

Tabela D.2 - Descrição dos tags utilizados na Figura D.6.............................................................. 111

Tabela D.3 - Descrição dos tags utilizados na Figura D.7 ................................................................ 113

Tabela E.1 - Descrição dos elementos do modelo em RdP da atividade [Controle da estação de inspeção].

Tabela E.1 - Descrição dos elementos do modelo em RdP da atividade [Controle da estação de inspeção].

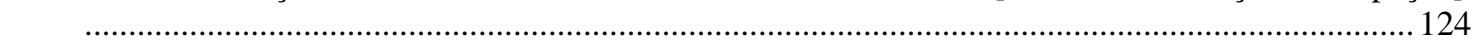

Tabela E.2 - Descrição dos elementos do modelo em RdP da atividade [Controle da estação de transporte]....................................................................................................................... 125

Tabela E.2 - Descrição dos elementos do modelo em RdP da atividade [Controle da estação de transporte] (continuação) ...................................................................................................... 126

Tabela E.2 - Descrição dos elementos do modelo em RdP da atividade [Controle da estação de transporte] (continuação) ....................................................................................................... 127

Tabela E.2 - Descrição dos elementos do modelo em RdP da atividade [Controle da estação de transporte] (continuação) ........................................................................................................ 128

Tabela E.3 - Descrição dos elementos do modelo em RdP da atividade [Pega palete na estação de transporte].

Tabela E.4 - Descrição dos elementos do modelo em RdP da atividade [Põe palete sobre a bancada]... 130

Tabela E.5 - Descrição dos elementos do modelo em RdP da atividade [Alimenta com mola] e [Alimenta com tampa].

Tabela E.6 - Descrição dos elementos do modelo em RdP da atividade [Alimenta com pino]............... 132

Tabela E.7 - Descrição dos elementos do modelo em RdP da atividade [Pega cilindro base do palete]. 133

Tabela E.8 - Descrição dos elementos do modelo em RdP da atividade [Põe cilindro base na posição de

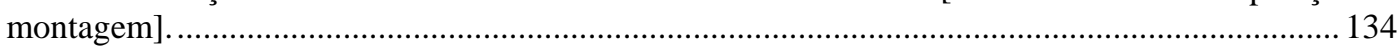

Tabela E.9 - Descrição dos elementos do modelo em RdP da atividade [Pega a mola].........................135

Tabela E.10 - Descrição dos elementos do modelo em RdP da atividade [Monta a mola]. .................... 136 
Tabela E.11 - Descrição dos elementos do modelo em RdP da atividade [Pega o pino]. 137

Tabela E.12 - Descrição dos elementos do modelo em RdP da atividade [Monta pino].

Tabela E.13 - Descrição dos elementos do modelo em RdP da atividade [Pega a tampa].

Tabela E.14 - Descrição dos elementos do modelo em RdP da atividade [Monta a tampa].....

Tabela E.15 - Descrição dos elementos do modelo em RdP da atividade [Sobe cilindro montado]. ...... 141

Tabela E.16 - Descrição dos elementos do modelo em RdP da atividade [Põe cilindro montado no palete].

Tabela E.17 - Descrição dos elementos do modelo em RdP da atividade [Pega palete].

Tabela E.18 - Descrição dos elementos do modelo em RdP da atividade [Põe palete na estação de transporte]....

Tabela E.19 - Descrição dos elementos do modelo em RdP das atividades [Avança o braço], [Recua o braço] e [Desliga motor].

Tabela E.20 - Descrição dos elementos do modelo em RdP das atividades [Abre a garra], [Fecha a garra],

[Desce o braço] e [Sobe o braço].

Tabela E.21 - Descrição dos elementos do modelo em RdP da atividade [Estação de inspeção].............147

Tabela E.22 - Descrição dos elementos do modelo em RdP da [Estação de transporte].........................148

Tabela E.22 - Descrição dos elementos do modelo em RdP da [Estação de transporte] (continuação). . 149

Tabela E.23 - Descrição dos elementos do modelo em RdP da [Estação de montagem].

Tabela E.23 - Descrição dos elementos do modelo em RdP da [Estação de montagem] (continuação) . 151 


\section{LISTA DE PALAVRAS RESERVADAS}

\section{Redes de Petri (Fonte: Ariel 10 pontos)}

$>\operatorname{Arco}(\mathrm{s})$ (orientado (s), habilitador (es) ou inibidor (es))

$>$ Atributo (s)

$>$ Capacidade (s)

$>$ Conflito (s)

$>$ Disparo (s)

$>$ Disparável (eis)

$>$ Estado

$>$ Lugar (es)

$>$ Marca (s)

$>$ Marcação

$>$ Marcado (s) (desmarcado (s))

$>$ Pré (pós) condição (ões)

> Transição (ões) (habilitada (s), desabilitada (s), instantânea (s), temporizada (s))

Token Ring (Fonte: Courier New 12 pontos)

$$
\text { Anel }
$$

$>$ Estação ativa

$>$ Frame

> Monitor (ativo, principal, de reserva, reservas)

$>$ Pacote

$>$ Prioridade

$>$ Quadro

$>$ Reserva

$>$ Token (ring, prioritário (s))

Orientação a Objetos e UML (Fonte: Comic Sans MS 10 pontos)

$>$ Atributo (s)

$>$ Classe (s)

$>$ Componente (s)

> Diagrama de (casos de uso, classe, componente, distribuição, seqüência)

$>$ Encapsular (encapsulamento)

$>$ Interface (s) 
$>$ Objeto (s)

$>$ Operação (ões)

$>$ Relacionamento $(s)$

$>$ Semântica (s)

ODP (Fonte: Tahoma 10 pontos)

$>$ Ator (es)

$>\operatorname{Binder}(\mathrm{s})$

$>$ Canal (is)

$>$ Cluster (s)

$>$ Comunidade (s)

$>$ Domínio (s)

$>$ Esquema (estático, invariante e dinâmico)

$>$ Federação (ões)

$>$ Fluxo

> Gerenciador (de cápsula, de grupo)

$>$ Grupo

$>$ Interceptador (es)

$>$ Interface (s) computacional (is)

$>$ Nó (s)

> Objeto (s) (básico de engenharia, da empresa, empresa, de informação, computacional (is), de engenharia, de ligação, protocolo)

$>$ Operação

$>$ Ponto (s) de vista (s) (empresa, informação, computação, engenharia e tecnologia)

$>$ Sinal

$>\operatorname{Stub}(\mathrm{s})$

Do método de modelagem proposto (Fonte: Times New Roman, 12, negrito, itálico, verde)

$>$ Classe (s)

$>$ Objeto (s)

> Componente (s)

$>$ Aplicativo (s) 


\section{RESUMO}

As tecnologias da informação, telecomunicações e mobilidade aliadas às mudanças econômicas e sociais acarretaram uma grande reestruturação da indústria. Entre estas mudanças, verifica-se um maior nível de descentralização e especialização das unidades produtivas, o aumento da automação dos processos e, em conseqüência, uma maior quantidade e complexidade nas interações de seus sub-sistemas. De forma a lidar com esta complexidade e facilitar o estudo e projeto de novos sistemas, faz-se necessário o uso de modelos, que são analisados por exemplo, através de simulação. Entre elas destaca-se a simulação distribuída, a qual trata da evolução de situações/cenários do sistema em computadores fisicamente dispersos, conectados através de uma rede de comunicação, visando, por exemplo, a redução do tempo de simulação, a simulação de grandes modelos(composto por muitos elementos), maior tolerânica a falhas e mesmo a distribuição geográfica. Visando contribuir para uma maior aplicabilidade das técnicas de modelagem e simulação, em especial a distribuída, propõe-se nesta tese (1) um novo método para a modelagem hierárquica de sistemas produtivos; e (2) um novo algoritmo para a sincronização da evolução do tempo de simulação de diferentes simuladores interagindo através de redes de comunicação (LAN, WAN). No método de modelagem proposto, utiliza-se uma abordagem top-down para a decomposição do sistema, partindo-se de um nível de abstração para um de maior detalhamento, permitindo, assim, um maior nível de conhecimento quanto ao comportamento dos elementos e suas interações. No nível de detalhamento desejado, utiliza-se a Rede de Petri na modelagem dos elementos básicos do sistema, que são, assim como na orientação a objetos, denominados “classes”. Em seguida, através de uma abordagem bottom-up, estes modelos são agrupados, formando modelos mais complexos: “componentes” e “aplicativos”. A fim de garantir a interação entre estes elementos, foram definidos um conjunto de interfaces, bem como suas regras de relacionamento. Este método foi aplicado a um estudo de caso para comprovar sua eficácia. No que diz respeito ao algoritmo proposto para sincronizar os tempos de simulação, utiliza-se como subsidio o mecanismo de gerenciamento da transmissão de dados em redes conhecido como Token Ring. Um simulador de eventos, distribuído, foi implementado com a finalidade de validar o algoritmo proposto. 


\section{ABSTRACT}

Evolution on the information technology, telecommunications and transport systems, associated to social and economic changes around the world have caused a significative reorganization of the industry. In this context, a high level of decentralization and specialization of the productive units, as well as an increment of the automation level used in productive processes have been verified. It results on the increase of the amount and the complexity of the enterprise subsystems interactions. Modeling techniques are used with simulation to deal with the complexity, to analysis, and to design new productive systems. Among the simulation approaches, distributed simulation is distinguished. It deals with the execution of simulation in physically dispersed computers connected through a LAN (Local Area Network), providing, for example, the reduction of the simulation time, huge simulation models (models with many elements), fault tolerance, as well as geographic dispersion. To contribute for the evolution of modeling and simulation techniques, in special the distributed one, it is proposed on this work: (1) a new method for the hierarchical modeling of productive systems; and (2) a new time synchronization algorithm used to manage the time evolution of a set of distributed simulation software. On the proposed modeling method it is used a top-down approach to decompose the system in basic elements, starting in a high-level abstraction model, and ending with a set of basic models with high level of detail. Then, these models are modeled using Petri net. As well as on object-oriented languages, each model is called “class”. After that, using a bottom-up approach, these basic models are grouped to generate more complex models: "component" and "application". A set of interfaces, as well as its relationship rules had been defined to guarantee the interaction among these elements. This method was applied to a case study to confirm its effectiveness. About the time synchronization algorithm, the token ring protocol is used as subsidy. An event based distributed simulator was implemented with the purpose to validate the proposed algorithm. 


\section{INTRODUÇÃO}

Observa-se ao longo da história uma profunda reestruturação da indústria e da economia. Esta reestruturação se refere a mudanças na forma como bens e serviços são projetados, desenvolvidos e produzidos. Os principais fatores que impulsionaram estas mudanças são a evolução da tecnologia de comunicação e transporte, o acelerado ritmo de transferência de tecnologia, as reformas sociais e econômicas e as modificações nos hábitos de consumo dos países, gerando uma intensa competição global entre empresas (SHI; GREGORY, 1998; LEE; LAU, 1999).

Nos sistemas produtivos, as mudanças são caracterizadas por uma gradual migração do paradigma “fordista” de produção para um novo modelo, onde as economias de escala são substituídas por economias de escopo, a competição por preço é substituída por competição por inovação, a padronização e automação via hardware por tecnologias programáveis e mais flexíveis, hierarquias e camadas de gerência por equipes autônomas, e a integração vertical pela integração da cadeia de suprimentos (LEE; LAU, 1999).

Uma vez que os mercados estão se tornando mais globais e independentes de barreiras geográficas, um maior número de indústrias de manufatura tem se estabelecido de forma distribuída e dispersa, aproveitando o crescimento das redes de comunicação e da Tecnologia da Informação e Comunicação (TIC), permitindo uma maior cooperação transnacional. O sistema global de pesquisa, produção e distribuição da empresa DELL (DELL, 2005) é um exemplo onde os componentes são produzidos não apenas em diferentes plantas mas em diferentes países. Estes componentes são então movimentados entre as plantas para a montagem dos produtos finais.

Observa-se também mudanças na forma como as pessoas consideram atualmente os sistemas produtivos. Novas tecnologias e abordagens permitem que administradores e engenheiros possuam uma visão mais integrada e dinâmica de um sistema produtivo, abandonando o foco de que a empresa é uma entidade isolada, passando a considerar a atuação da empresa dentro de uma rede corporativa internacional de fábricas (SHI; GREGORY, 1998).

Em geral estas novas “forças” - oportunidades num mercado global e novos padrões de competição - requerem uma nova geração de redes de relacionamentos que vão além da tradicional seqüência de transformação. As características dos novos 
sistemas produtivos devem envolver uma grande perspectiva, cobrindo a dispersão geográfica, coordenação interdependente, além do tradicional foco em diversas plantas produtivas. Estas novas perspectivas requerem novos conhecimentos quanto à natureza dos sistemas produtivos e quanto às formas com que os desempenhos esperados possam ser alcançados.

A incorporação da TI nos processos produtivos também vem permitindo a integração dos diversos sistemas da empresa, em seus diferente níveis (SANZ; ALONSO, 2001). Como exemplo, pode-se citar os sistemas de supervisão e controle, responsáveis pelas operações do chão de fábrica, típicos em uma instalação moderna de médio e grande porte que são compostos por uma coleção heterogênea de hardwares e softwares distribuídos em um conjunto de plataformas (estações de operação, unidades remotas, controladores programáveis, etc.). A necessidade de integração de sistemas heterogêneos implica um aumento da complexidade e diversidade dos sistemas.

De forma a facilitar o estudo e projeto de sistemas ${ }^{1}$, faz-se uso de modelos, sejam estes físicos, matemáticos, mentais, computacionais, etc. Neste contexto, um modelo é considerado uma abstração e representação simplificada do sistema, onde se busca representar os seus componentes mais importantes e a forma como eles interagem (EYKHOFF, 1974).

\subsection{Modelagem e simulação}

A modelagem de sistemas pode ser definida como a prática de se construir modelos para representar sistemas reais existentes, ou sistemas hipotéticos, e realizar experimentos com estes modelos para: (1) explicar o comportamento dos sistemas; (2) construir teorias ou hipóteses que consideram o comportamento observado; (3) aumentar o desempenho do sistema; (4) projetar novos sistemas com o desempenho desejado; e/ou (5) descrever comportamentos futuros ou o efeito produzido por mudanças no conjunto das entradas (KHOSHNEVIS, 1994; PIDD, 1994; SARGENT, 1994; CENTENO, 1996).

Uma das técnicas para se analisar e validar os modelos, e que vem sendo empregada desde 1950, é a simulação (GARCIA, 1997). Através desta técnica o modelo 
é submetido a entradas similares às do sistema real de forma a verificar se a sua dinâmica corresponde à observada no sistema real, produzindo resultados coerentes aos deste.

Sobre outras técnicas, como por exemplo a análise matemática, a simulação possui algumas vantagens das quais pode-se citar (CENTENO, 1996; FISHBURN et al., 1995; SEILA, 1995; EVANS; OLSON, 1998):

$>$ a capacidade de analisar modelos de complexidade arbitrária, ou seja, é uma técnica flexível pois os modelos não precisam de muitas simplificações como nos modelos analíticos;

o custo dos resultados obtidos através de simulação são relativamente menores do que os obtidos através do sistema real;

a análise por simulação pode ser desempenhada com o mínimo risco para o cliente pois é possível realizar mudanças no projeto de um sistema antes que este seja implementado, com apenas uma fração do custo que se teria caso o sistema tivesse sido implementado.

possuir credibilidade frente aos responsáveis pela tomada de decisões, visto que recursos, como animação, podem ser utilizados para ilustrar quão o modelo se aproxima da realidade; e

um mesmo conjunto de métodos de simulação poder ser utilizado para analisar diversos sistemas.

O aumento da complexidade dos sistemas e seus respectivos modelos também exige o desenvolvimento de novas soluções. Entre elas destaca-se a utilização da simulação paralela e distribuída. A simulação paralela trata da execução de programas de simulação em computadores paralelos, enquanto a simulação distribuída trata da execução de simulações em computadores geograficamente dispersos, conectados através de uma LAN (Local Area Network) ou WAN (Wide Area Network), obtendo-se um super computador virtual. Em ambos os casos a execução de um único modelo de simulação é distribuído entre múltiplos processadores (FUJIMOTO, 1999; BANKS et al., 2000).

\footnotetext{
${ }^{1}$ De acordo com Seila (1995), um sistema é um conjunto de componentes ou entidades interagindo de forma cooperativa de modo a atingirem um objetivo maior do que seus objetivos individuais.
} 
Sistemas simples (com poucos elementos), porém com um alto grau de interação, também podem ser analisados mais rapidamente utilizando-se as simulações paralela e distribuída quando comparado com a simulação sequencial. Misra (1986) cita, como exemplo, um switch telefônico que gera em torno de 100 mensagens internas para completar uma única chamada local. Cada um deste switches pode receber 100 ou mais chamadas por segundo. Assim, a simulação de 15 minutos de funcionamento de um switch telefônico requer a simulação de aproximadamente 10 milhões de mensagens, o que requer várias horas de uso de um processador alta velocidade.

Dentre as várias razões para se distribuir a execução da simulação entre múltiplos computadores (FUJIMOTO, 1999), cita-se:

$>$ redução do tempo de execução - através da subdivisão de um modelo de simulação entre vários processadores, executando-as concorrentemente, pode-se reduzir o tempo de execução da simulação por um fator menor ou igual ao número de processadores utilizados;

$>$ distribuição geográfica - executando o programa de simulação em um conjunto de computadores geograficamente distribuídos, pode-se criar mundos virtuais com muitos participantes que podem estar em diferentes localidades geográficas. Isto alivia drasticamente os custos com viagens destinadas à criação de exercícios conjuntos envolvendo participantes de diferentes localidades;

$>$ integração de simuladores (simulações) combinando simulações que são executadas em máquinas de diferentes fabricantes;

tolerância à falhas - se um processador falhar, permite-se que os demais processadores continuem a simulação.

\subsection{Perspectivas futuras no campo da simulação, em especial a} distribuída

Como destacado em Venkateswaran, et al., (2001), a distribuição da simulação pode trazer outras vantagens, como a possibilidade de se criar empresas virtuais. Uma empresa virtual é uma organização onde várias companhias se juntam para produzir um produto ou uma linha de produtos. Participar de uma empresa virtual permite que uma companhia use seus conhecimentos, recursos, e seu próprio conhecimento do negócio 
para levar vantagem nas oportunidades de negócio que existem na produção em larga escala, comparado ao que teria se estivesse só.

Para facilitar a criação de empresas virtuais, os potenciais parceiros devem ser capazes de avaliar rapidamente quando será vantajoso para eles participar de tal empresa. Novamente, a tecnologia da simulação, em geral, e a tecnologia distribuída de simulação, em particular, pode auxiliar no processo de avaliação. Cada parceiro pode utilizar a simulação de suas instalações para verificar se este possui capacidade para desempenhar sua função individual na empresa virtual. Em seguida, estes modelos de simulação podem ser integrados para uma simulação distribuída e completa da empresa virtual, sendo usada para prever a viabilidade e os possíveis lucros desta colaboração. O uso da tecnologia de simulação distribuída permite que cada parceiro em potencial esconda as informações que julgar confidencial/proprietária na implementação da simulação individual, ao mesmo tempo que permite que estas informações sejam usadas na avaliação da empresa como um todo (VENKATESWARAN, et al., 2001).

Além do uso da internet na simulação distribuída, outras vantagens podem ser obtidas, entre elas a possibilidade de interação entre o modelista e o cliente, o compartilhamento e revisão de modelos, ou mesmo o acompanhamento do processo de modelagem e simulação através da internet, sem a necessidade que o cliente ou o modelista se desloquem (BANKS, 2000).

Kachitvichyanukul (2001) e Banks et al. (2000) prevêm a necessidade de se utilizar modelos “componentizados”, que possam ser facilmente selecionados de uma biblioteca, tendo como fim o seu uso imediato, ou serem agrupados, servindo de intermediários para a geração de novos modelos. Com relação à modelagem, Daum e Sargent (1999) e Kachitvichyanukul (2001), entre outros autores, destacam a modelagem hierárquica como uma forma de se lidar com sistemas complexos (composto por muitos elementos). Ela permite que o modelista particione os sistemas complexos em sub-sistemas (e conseqüentemente sub-modelos) melhor gerenciáveis, onde trabalha-se com a geração de modelos em diferentes níveis de abstração, que podem ajudar na verificação e validação dos mesmos.

Ainda com relação a Kachitvichyanukul (2001), destaca-se a necessidade de desenvolvimento de padrões para intercâmbio de modelos, baseados, por exemplo, no padrão XML; e o desenvolvimento de bibliotecas de modelos/componentes que possam ser facilmente selecionados e agrupados de modo a formarem novos modelos. 
Durante a pesquisa bibliográfica, identificou-se a oportunidade de se propor novos algoritmos de sincronização de simuladores no contexto da simulação distribuída pois observa-se, por exemplo em Misra (1986) e Fujimoto (1999) que, em um primeiro momento, as pesquisas nesta área procuram adaptar os algoritmos utilizados na simulação paralela para a distribuída.

Outros fatores que influenciaram esta tese derivam dos trabalhos desenvolvimentos por Yen-Tsang; Villani; Miyagi (2000), Villani (2000) e Junqueira (2001). Nestes trabalhos, detectou-se a existência de poucas ferramentas apropriadas (ou mesmo nenhuma) para a modelagem e simulação dos sistemas produvitos em estudo. Nos trabalhos de Yen-Tsang; Villani; Miyagi (2000) e Villani (2000), o objeto de estudo é o sistema de ar condicionado, que apresentam características híbridas (contínuas e discretas). Existia, assim, a necessidade de uma ferramenta que permitisse a modelagem, em Rede de Petri, de ambas características, bem como sua simulação.

No trabalho de Junqueira (2001) abordou-se o sistema de movimentação de materiais em ambiente fabril, um sistema com caracterísicas predominantemente discretas. Apesar de existirem muitos simuladores a eventos discretos para Rede de Petri, este trabalho apresenta um método orientado a objetos para a modelagem de sistemas de movimentação de materiais. Assim, até aquela data, não existiam ferramentas apropriadas que permitissem a modelagem em Rede de Petri utilizando o paradigma orientado a objetos.

Com base nas necessidades apresentadas por estes trabalhos, bem como nas já citadas anteriormente, propôs-se em Junqueira; Villani; Miyagi (2005a, 2005b) o desenvolvimento de um sistema para a modelagem e simulação de sistemas produtivos de forma distribuída. Este sistema deveria ter como características permitir a modelagem hierárquica dos elementos que compõem o sistema produtivo, o uso do paradigma de orientação a objetos na elaboração e interação entre os modelos, a possibilidade de distribuição da simulação entre diferentes processadores, e a possibilidade do uso de diferentes variantes da Rede de Petri na modelagem dos elementos que compõem o sistema. 


\subsection{Objetivo}

No contexto que se apresenta, ou seja, o aumento da complexidade dos sistemas produtivos, onde se fazem necessários o uso da modelagem e da simulação, em particular a distribuída, para o fim de verificar se estes (sistemas produtivos) atendem os objetivos para os quais foram propostos, tem-se por objetivo neste trabalho:

propor um método para a modelagem de sistemas produtivos;

> propor um mecanismo de sincronização do tempo de simulação de modelos distribuídos por um conjunto de computadores interligados em rede.

A opção pelos itens elencados como objetivo desta tese tem como justificativa a mudança de paradigma que se pretende, ou seja, de uma simulação isolada, para uma simulação distribuída. Esta mudança introduz um novo fator a se considerar no processo de modelagem: a interação entre os modelos que estão sendo simulados em simuladores distintos. Esta mudança de paradigma também faz com que haja a preocupação com a sincronização do tempo entre os simuladores de forma que o resultado obtido seja o mesmo que se teria utilizando um simulador isolado.

\subsection{Tese no contexto do grupo de pesquisa}

O grupo de pesquisa em que se insere este trabalho é o Labaratório de Sistemas de Automação (http://www.pmr.poli.usp.br/lsa/). Neste grupo, uma das linhas de projeto envolve a sistematização de técnicas necessárias para a concepção e implementação de sistemas de controle para automação balanceada, isto é, desenvolvimento de uma metodologia para a especificação de sistemas de controle a eventos discretos (sistemas com estados discretos e eventos instantâneos) e/ou híbridos (sistemas onde co-existem estados discretos, eventos instantâneos e variáveis continuas) dentro do contexto de sistemas antropocêntricos (humam centered systems) e balanceados (balanced automation systems). Este projeto envolve os seguintes temas:

\section{A. Integração de sistemas e atividades em edifícios inteligentes}

Este tema visa a caracterização e desenvolvimento de um sistema integrado e modular para a gestão, controle e monitoração de edifícios inteligentes, com infra- 
estrutura sensorial assistida por computador. Considera-se que os edifícios inteligentes podem ser tratados como um sistema a eventos discretos onde o conceito de sistemas abertos de automação tem papel fundamental.

Nesta linha de pesquisa destacam-se os trabalhos de Bastidas Gustin (2000) apresentando uma metodologia para a modelagem de sistemas de elevadores, e Villani (2000) enfocando os sistemas de ar condicionado, ambos para edifícios interligentes, considerando sua integração com outros sistemas prediais. Ainda nesta linha, Bastidas Gustin (2005) propõe uma abordagem para a modelagem e análise de sistemas distribuídos e abertos para automação predial que permita a integração efetiva dos sistemas prediais em edifícios inteligentes.

Em relação ao sistema de controle, tem-se o trabalho de Arakaki (2004) que trata do problema de degeneração do software de controle de edifícios.

\section{B. Sistemas supervisórios híbridos}

Este tema visa o estudo e desenvolvimento de metodologias de modelagem, análise e especificação de sistemas supervisórios híbridos. O enfoque é baseado nas ferramentas de modelagem e análise de sistemas a eventos discretos como as redes de Petri estendidas para tratamento das variáveis contínuas. Neste contexto Villani (2004) propõe um método para a elaboração de modelos para sistemas supervisórios híbridos. Em Villani et al. (2004). Villani et al. (2005) e Villani; Miyagi; Valette (2006), este método é testado para diferentes tipos de sistemas e um procedimento semi-automático de análise é desenvolvido.

Ainda nesta linha, em Villani, Kaneshiro; Miyagi (2006) é introduzido o conceito de incerteza nestes sistemas.

\section{Sistemas flexíveis (inteligentes) de produção}

Este tema visa o desenvolvimento de metodologias e sistemas de apoio para a concepção, análise e controle de sistemas de fabricação e montagem. Considera-se que estes sistemas podem ser estudados sob o enfoque de sistemas a eventos discretos e assim, investiga-se a efetividade de técnicas baseadas em redes de Petri e suas extensões como o PFS/MFG (Production Flow Schema / Mark Flow Graph). Os pontos investigados são o gerenciamento remoto de sistemas automatizados e o processo de detecção e tratamento de falhas. 
Em relação a modelagem e análise destes sistemas, o trabalho de Arata (2006) discute sobre os requisitos para os sistemas de apoio ao projeto desta classe de sistemas.

Na área de falhas em sistemas produtivos, Martinez Riascos (2002) propõe uma metodologia de modelagem e análise que considera a detecção e o tratamento de falhas junto com os processos "normais" de produção; e Lira Nuñez; Junqueira; Miyagi (2005) propõem um processo de modelagem e diagnóstico de falhas em sistemas flexíveis de montagem de peças. Na área de sistemas automatizados, Junqueira (2001) propõe uma metodologia para a modelagem de sistemas flexíveis de movimentação de materiais e partes em ambiente fabril, onde conceitos de orientação a objetos são utilizados juntamente aos de Rede de Petri de forma a migrar do tradicional paradigma de orientação a processos para orientação a objetos.

É neste contexto que se insere o presente trabalho, propiciando meios para que novas pesquisas sejam desenvolvidas na área de gerenciamento remoto de sistemas automatizados.

Destaca-se como pontos em comum dos trabalhos desenvolvidos neste grupo de pesquisa o enfoque nos sistemas produtivos, sejam estes tradicionais como as instalações fabris, seja no sentido mais amplo, como é o caso dos edifícios (inteligentes); e também o enfoque no uso da Rede de Petri e suas variações na modelagem e análise de sistemas produtivos.

\subsection{Organização do texto}

Propõe-se no capítulo 2 um método, baseado em Rede de Petri e Orientação a Objetos, para a modelagem hierárquica de sistemas podutivos. Para tanto, utiliza-se como embasamento teórico conceitos de Rede de Petri; formas de se realizar, através do uso de interfaces, a troca de informações entre modelos em Rede de Petri; a simulação distribuída de modelos em Rede de Petri. Outros conceitos como PFS (Production Flow Schema), Orientação a Objetos e UML (Unified Modeling Language) também são utilizados.

No capítulo 3 é apresentado um estudo de caso onde o método proposto no capítulo 2 é aplicado a um sistema produtivo real. 
No capítulo 4 é proposto um algoritmo para a sincronização do tempo de simulação de modelos distribuídos em uma rede de computadores, como alternativa aos algoritmos existentes. Para tanto a pesquisa sobre algoritmos de sincronização de tempo e sobre o protocolo de gerenciamento de redes de comunicação Token Ring são apresentados no início do capítulo.

No capítulo 5 são apresentados os comentários finais, conclusões e propostas de trabalhos futuros.

A Figura 1.1 ilustra a organização da tese.

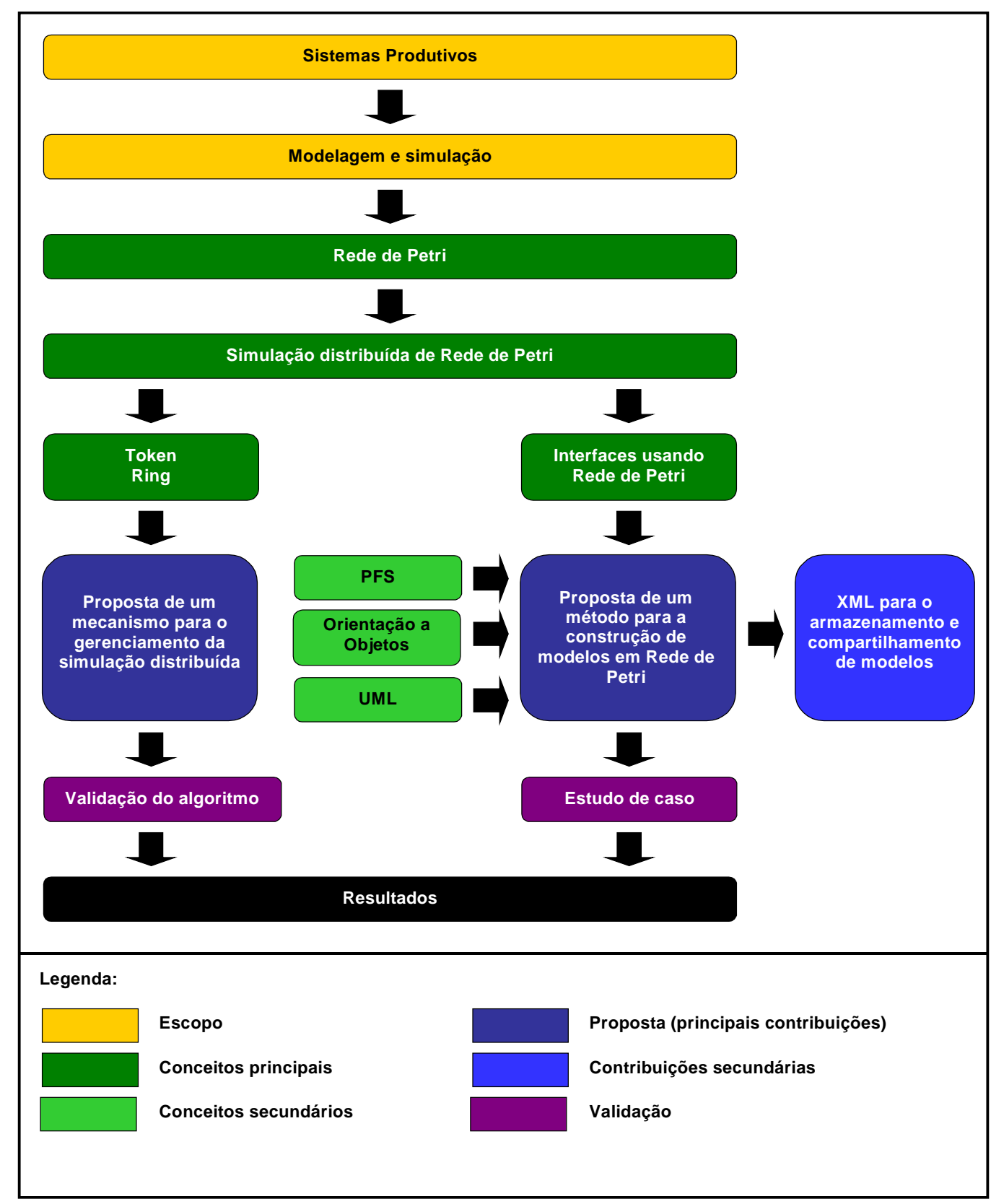

Figura 1.1 -Organização do trabalho. 


\section{MODELAGEM DE SISTEMAS PRODUTIVOS, DE FORMA DISTRIBUÍDA, EM REDE DE PETRI}

Considerando-se o aumento da complexidade dos sistemas produtivos dispersos, destaca-se a necessidade de se propor novas forma de se conceber, avaliar, operar estes sistemas. Desta forma, neste capítulo é proposto um método hierárquico para a modelagem de sistemas produtivos deste tipo (seção 2.4).

Assim, como base teórica para este proposta, na seção 2.1 é apresentada a Rede de Petri, uma técnica de modelagem e simulação que vem sendo exitosamente aplicada na modelagem de sistemas produtivos em geral. Na seção 2.2 aborda-se algumas pesquisas na área da simulação distribuída utilizando-se modelos em Rede de Petri, onde destaca-se como uma das principais necessidades o estudo de meios para se particionar o problema/modelo entre os processadores. Na seção 2.3 é apresentada uma pesquisa procurando-se apresentar diferentes formas de se realizar a interface entre modelos em Rede de Petri.

Como teorias secundárias que servem de respaldo para a pesquisa, apresenta-se nos Anexos A, B e C, respectivamente, uma breve apresentação do PFS (Production Flow Schema), Objeto e Orientação a Objetos, e UML (Unified Modeling Language).

Na seção 2.5 é apresentado um exemplo onde o método proposto na seção 2.4 é aplicado.

Na seção 2.6 são discutidas as principais conclusões do capítulo.

\subsection{Rede de Petri}

Modelos baseados em sistemas a eventos discretos (SEDs) são intensamente usados para descrever, analisar e controlar processos em sistemas produtivos, como por exemplo em ambientes de rede de computadores e manufatura, pois o que caracteriza este processo é o fato de sua dinâmica ser governada pela ocorrência de eventos instantâneos. Assim, a evolução de estados destes sistemas é baseada em regras que definem as condições para a ocorrência de eventos e o resultado da ocorrência destes eventos (CASSANDRAS; STRICKLAND, 1992).

A Rede de Petri (RdP) é uma técnica de modelagem gráfica e matemática originalmente desenvolvida por Carl Adam Petri em meados de 1960 para caracterizar 
operações de concorrência em computadores (MOORE; BRENNAN, 1996). Desde então ela tem sido utilizada para a modelagem de sistemas dinâmicos em diversas áreas (SRINIVASAN; VENKATASUBRAMANIAN, 1998), como por exemplo: protocolos de comunicação, algoritmos distribuídos, arquiteturas de computadores, interação homem/máquina (ELKOUTBI; KELLER, 1998).

A RdP é conhecida como uma poderosa ferramenta para modelagem e análise de sistemas concorrentes, assíncronos, distribuídos e paralelos (MURATA, 1989; CARDOSO; VALETTE, 1997; REISIG, 1992; INAMASU, 1995) e é de interpretação relativamente simples e fácil devido a sua representação gráfica, quando comparada a outras técnicas, como a modelagem matemática.

A RdP (originalmente definida e também chamada Rede de Petri Ordinária) é um grafo composto de lugares (representados por círculos), transições (representado por barras), arcos orientados interligando os componentes anteriores e marcas (que são utilizadas para definir o estado de uma RdP). São também consideradas multigrafos direcionados bipartidos (Figura 2.1) pois vários arcos orientados podem sair de um nó (lugar ou transição) para os demais, existindo a restrição de que os arcos só interligam elementos de natureza diferente (PETERSON, 1981; MURATA, 1989; SRINIVASAN; VENKATASUBRAMANIAN, 1998).

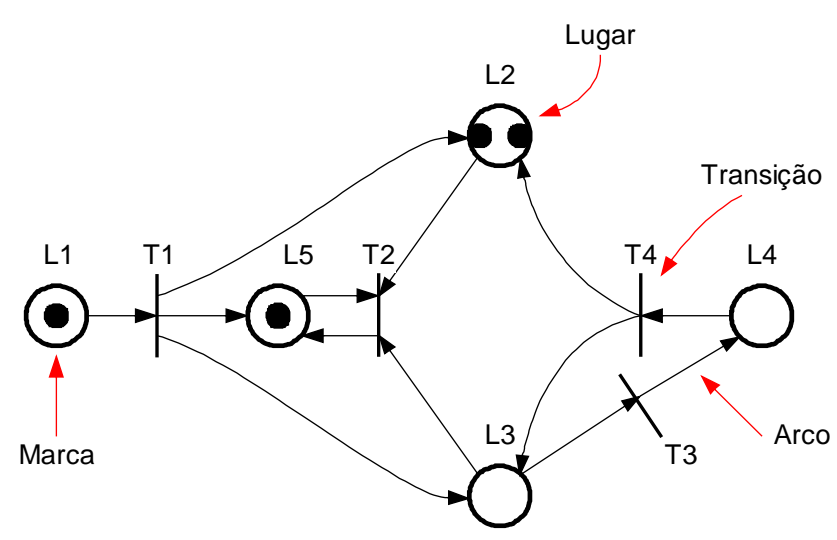

Figura 2.1 - Representação de uma Rede de Petri (adaptado de PETERSON, 1981).

A execução de uma RdP é definida pelo número de marcas e sua distribuição no grafo que é alterada com o disparo de transições. As marcas residem nos lugares e condicionam o disparo das transições da RdP. Uma transição dispara removendo as 
marcas dos seus lugares de entrada (pré-condições) e criando novas marcas em seus lugares de saída (pós-condições) (Figura 2.2 (a) e (b)).

As principais características da RdP, segundo INAMASU (1995) são:

permitir a representação de diferentes tipos de sistemas;

$>$ ser um modelo que pode ser formalizado matematicamente;

> ser um modelo gráfico de aprendizado relativamente fácil, funcionando como linguagem de comunicação entre especialistas de diversas áreas;

$>$ permitir a representação de paralelismo e sincronização;

> representar aspectos estáticos e dinâmicos;

possuir métodos e ferramentas de análise, inclusive comerciais.

MOORE e BRENNAN (1996) apresentam mais algumas características da RdP: pode-se considerar regras de tempo associadas com transições para representar o tempo requerido para completar uma atividade. Esta regra pode ser estocástica, baseada em uma função de probabilidade, um valor computado, ou uma constante. Regras de decisão podem ser associadas com os lugares e resolvem casos onde mais de uma transição está habilitada pela mesma marca ou conjunto de marcas (Figura 2.2 (c) (transições em conflito);

$>$ pode-se considerar atributos nas marcas para especificar um conjunto de características associadas com a marca. O valor destes atributos pode ser mudado nas transições e podem ser passados para algoritmos externos e o resultado incorporado ao modelo de RdP;

pode-se considerar outros tipos de arcos, que proporcionam uma lógica adicional à transição: o arco habilitador, que habilita a transição caso o lugar a que se refere esteja marcado, sem consumir a marca; e o arco inibidor, que desabilita a transição caso o lugar a que se refere esteja marcado.

No entanto, a representação de complexos (grande número de elementos e/ou interações entre estes elementos) sistemas através da RdP pode envolver um nível de detalhamento inaceitável. Como conseqüência, muitos usuários da RdP desenvolveram extensões para suprir suas necessidades, incluindo atributos, relações de tempo e eventos estocásticos, porém mantendo-se a simplicidade conceitual do grafo (GUSTAVSON; TÖRN, 1995; MOORE; BRENNAN, 1996). 

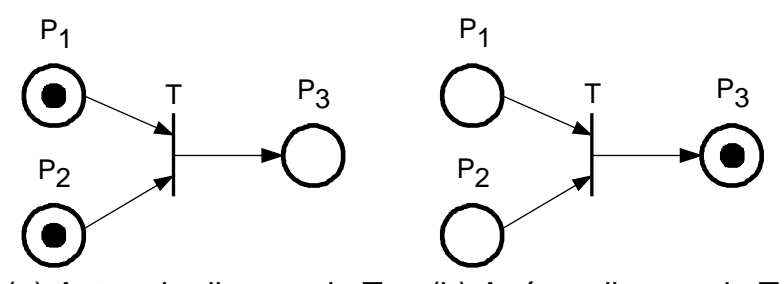

(a) Antes do disparo de T

(b) Após o disparo de T
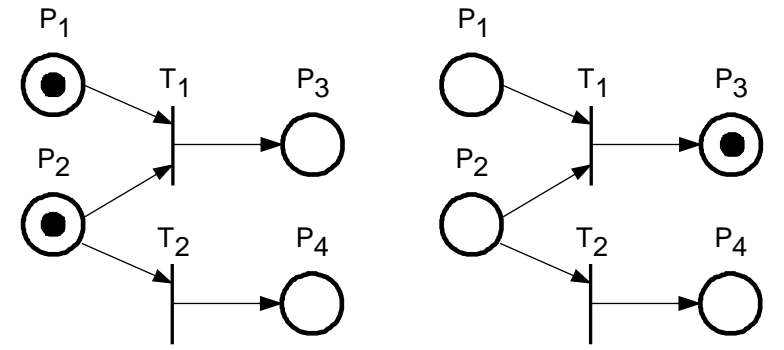

T1 e T2 estão habilitadas Disparo de T1 disabilita T2

(c) Exemplo de transições em conflito

Figura 2.2 - Exemplo de disparo de uma transição.

Pode-se citar como alguns exemplos destas variações (MURATA, 1989; CHEUNG, 1996):

RdP “ordinária” - onde, o seu elemento lugar possui capacidade ilimitada para marcas;

RdP Lugar/Transição (limitada) - ao contrário da RdP “ordinária” esta rede possui capacidade finita em seu elemento lugar;

$>$ RdP temporizada - as transições neste caso, possuem um parâmetro que representa o tempo que a marca leva para sair da pré-condição até atingir a pós-condição. Como evolução desta variante, tem-se a RdP estocástica;

RdP numérica - associa-se variáveis numéricas às transições, lugares e marcas e condições para o disparo das transições.

$>\mathrm{RdP}$ colorida $(\mathrm{CPN})$ - é uma RdP com marcas individualizadas possibilitando que as transições se comportem de forma diferenciada de acordo com o tipo das marcas individualizadas.

$>$ RdP orientada a objetos - é uma RdP que inclui recursos para descrever propriedades e entidades que ocorrem na abordagem orientada a objetos.

Dentre as RdP propostas (conforme as necessidades dos sistemas modelados/estudados), a RdP orientada a objetos têm recebido atenção por parte dos 
pesquisadores. Existem diferentes enfoques para RdP orientadas a objetos como os apresentados por (BASTIDE, 1995; KRENA; VOJNAR; 2001), mas a que cobre a maior diversidade de características/conceitos de objetos é a OPN (Object Petri Net) proposta por LAKOS $(1994,1995)$.

A OPN apresenta uma completa integração entre os conceitos de RdP e orientação a objetos, resultando na possibilidade de se modelar diretamente sistemas com níveis arbitrários de atividade, bem como apresentar flexibilidade na especificação da interface dos objetos, sejam elas síncronas ou assíncronas.

Assim como na CPN, a OPN possui arcos habilitadores e inibidores que facilitam a definição de funções de acesso que provêem informações sobre o estado do objeto sem alterá-lo. A utilização destas funções pode facilitar significativamente a modularização dos projetos em RdP.

Ainda com relação à OPN, cada RdP pode ser definida como uma classe, que pode ser instanciada em um diferente número de contextos (inclusive como marcas). Desta forma, uma marca pode encapsular uma sub-rede. Isso implica que a OPN suporta a possibilidade de múltiplos níveis de atividade na rede e o projetista é livre para decidir como várias atividades devem ser compostas (se um objeto em particular deve ser ativo $^{2}$, passivo ${ }^{3}$ ou ambos).

Ainda nesta linha, trabalhos como os de Bastidas Gustin et al. (2003), Junqueira; Miyagi (2000, 2006), Junqueira; Villani; Miyagi (2005a, 2005b), Villani et al. (2004, 2005), apresentam resultados vantajosos da utilização conjunta de Rede de Petri e Orientação a Objetos à sistemas produtivos.

\subsection{Simulação Distribuída e a Rede de Petri}

Com o aumento da complexidade dos sistemas produtivos modelados, seja quanto ao número de elementos considerados na modelagem, seja quanto ao nível de detalhe destes elementos, diversos trabalhos (FUJIMOTO, 1990; NICOL; ROY, 1991; CHIOLA; FERSCHA, 1993; KUMAR; KOHLI, 1997; BERALDI; NIGRO, 1999; NKETSA; VALETTE, 2001) apresentam alternativas para o problema de desempenho dos sistemas computacionais durante as operações de simulação. Estes trabalhos

\footnotetext{
${ }^{2}$ Que requisita/invoca uma ação.
} 
sugerem a computação paralela, em sua maioria utilizando computadores com vários processadores, podendo ou não utilizar memória compartilhada, como uma forma de acelerar o processo de simulação. Nketsa; Valette (2001), por outro lado, utilizam um conjunto de computadores que trocam mensagens entre si através de uma rede de comunicação para a simulação distribuída.

Os relatos encontrados sobre simulação paralela aplicada à RdP se dão, em geral, em relação à RdP temporizada (CHIOLA; FERSCHA, 1993; KUMAR; KOHLI, 1997), porém outras RdP também são utilizadas (NKETSA; VALETTE, 2001).

Na computação paralela aplicada à RdP, ao invés de se trabalhar com uma lista global das transições (DJEMAME et al., 1998) disparáveis, ordenada pelo tempo em que os disparos devem ocorrer (CHIOLA; FERSCHA, 1993), particiona-se o problema de modo que cada processador administra uma lista local de transições disparáveis. A forma como os modelos são particionados pode gerar conflitos (exemplo onde um lugar administrado por um processador é pré ou pós-condição para uma transição administrada por outro processador) e desta forma os processadores devem trocar mensagens a fim de solucionarem estes conflitos antes de procederem ao disparo das transições. Há também a necessidade de troca de mensagens entre os processadores de forma que a relação de causalidade seja respeitada, ou seja, que um processo lógico (PL) não receba eventos com timestamp ${ }^{4}$ inferior ao timestamp de um ou mais eventos já processados.

Outro problema inerente à simulação distribuída reside no particionamento dos modelos entre os processadores. Nevison (1990) apud (FUJIMOTO, 1990) faz uso do conhecimento prévio do modelo para otimizar a simulação. Porém, quando se trabalha com ferramentas flexíveis de modelagem, como a RdP, que permitem o estudo de diferentes sistemas produtivos sem o conhecimento prévio do sistema bem como do número de processadores a serem utilizados na simulação, a otimização do algoritmo de gerenciamento da simulação com base nestes fatores torna-se algo impraticável.

Neste sentido, apresenta-se na seção 2.4 um método para a modelagem hierárquica de sistemas produtivos distribuídos, o que garante uma solução para o problema de particionamento dos modelos entre os processadores. A modelagem hierárquica é apresentada por vários autores, entre eles Daum e Sargent (1999) e

\footnotetext{
${ }^{3}$ Que realiza uma ação/atividade solicitada por outro objeto.

${ }^{4}$ Atributo da mensagem que indica o instante em que esta foi gerada no PL que a enviou.
} 
Kachitvichyanukul (2001), como uma forma de se lidar com sistemas complexos ${ }^{5}$. Ela permite que o modelista particione os sistemas complexos em sub-sistemas (e conseqüentemente sub-modelos) mais facilmente gerenciáveis, onde trabalha-se com a geração de modelos em diferentes níveis de abstração, e que ajudam na verificação e validação dos mesmos (DAUM; SARGENT, 1999).

\subsection{Estudo das interfaces entre modelos em Rede de Petri}

Inicialmente, apresenta-se uma nomenclatura que é utilizada ao longo deste capítulo para que as formas de comunicação entre modelos em RdP possam ser expostas e comparadas. Neste sentido, define-se:

$>$ modelo requisitante $\left(\mathbf{M o d}_{1}\right)$ - modelo em RdP que, através de uma interface (lugar, transição ou arco habilitador), requisita a funcionalidade de um segundo modelo;

$>$ modelo requisitado $\left(\mathbf{M o d}_{2}\right)$ - modelo em RdP que, através de uma interface (lugar, transição ou arco habilitador), disponibiliza uma funcionalidade para que outros modelos possam utilizá-la;

$>$ interface requisitante ( $\mathbf{a z u l}^{\mathbf{6}}$ ) - interface utilizada para chamar a funcionalidade desejada no modelo requistado ou a interface utilizada para retornar a resposta do modelo requisitado para o modelo requisitante;

$>$ interface requisitada (vermelho ${ }^{7}$ ) - interface utilizada para receber chamadas requisitando uma funcionalidade no modelo requisitado ou a interface utilizada, no modelo requisitante, para receber a resposta enviada pelo modelo requisitado.

Além destas definições, destaca-se ainda que as requisições de tais funcionalidades possam ser de dois tipos: (1) funções; e (2) procedimentos, como nas linguagens convencionais de programação. Nas requisições do tipo “função” o modelo requisitante aguarda por uma resposta do modelo requistado após a requisição ter sido feita. Na requisção do tipo “procedimento” o modelo requisitante não aguarda por uma resposta. A Figura 2.3 ilustra um exemplo de requisição do tipo função (Figura 2.3 (a)) e um do tipo procedimento (Figura 2.3 (b)).

\footnotetext{
${ }^{5}$ Composto por muitos eleementos.

${ }^{6}$ Nos modelos, os elementos de interface serão destacados em azul.

${ }^{7}$ Nos modelos, os elementos de interface serão destacados em vermelho.
} 


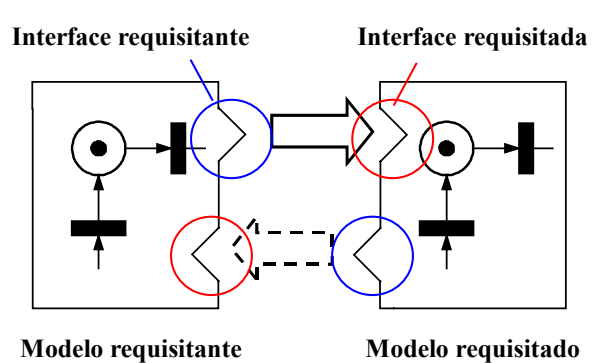

(a)

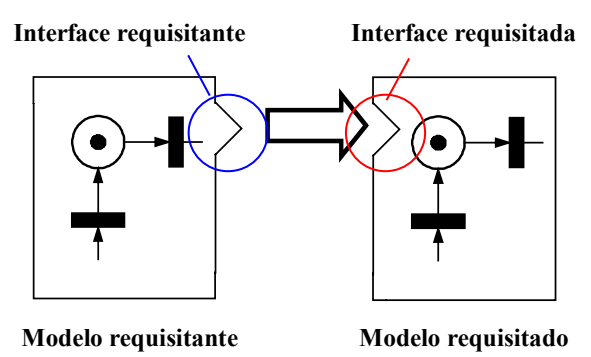

(b)

Figura 2.3 - (a) Modelo requistante requista uma funcionalidade do modelo requisitado e aguarda por uma resposta; enquanto em (b) o modelo requistante requisita uma funcionalidade do modelo requisitado e não aguarda uma resposta.

Outras características referentes às linguagens de programação também adotadas neste trabalho são que:

cada uma das funcionalidades de um modelo deve ser disponibilizada através de uma interface requisitada, existindo ou não uma interface requisitante para a resposta no caso de ser uma função ou procedimento, respectivamente;

> uma funcionalidade do modelo requisitado pode ser solicitada por um ou mais modelos requisitantes, ou seja, é uma relação [1..n] para 1 (Figura 2.4 (a));

cada interface de requisição de um modelo requisitante só pode ser utilizada para requisitar a funcionalidade de um pré-determinado tipo de modelo requisitado. Para requisitar funcionalidades distintas de modelos requisitados distintos (ou até de um mesmo modelo), deve-se ter interfaces de requisição distintas (Figura 2.4 (b) e (c)).

Nas linguagens de programação do tipo seqüencial, cada função (ou procedimento) é executada isoladamente. Nas linguagens que permitem processos em paralelo, como algumas linguagens orientadas a objetos, quando uma função (ou procedimento) é requisitada simultaneamente por duas ou mais partes do programa, este cria uma cópia da função (ou procedimento) para atender cada uma das requisições, paralelamente. Neste trabalho, para que uma funcionalidade de um modelo possa ser utilizada simultaneamente, por dois ou mais modelos requisitantes, o mesmo deve ser explicitado no modelo em RdP pois, do contrário, cada requisição é atendida conforme a disponibilidade da funcionalidade requisitada, na ordem em que os modelos a requisitam. 


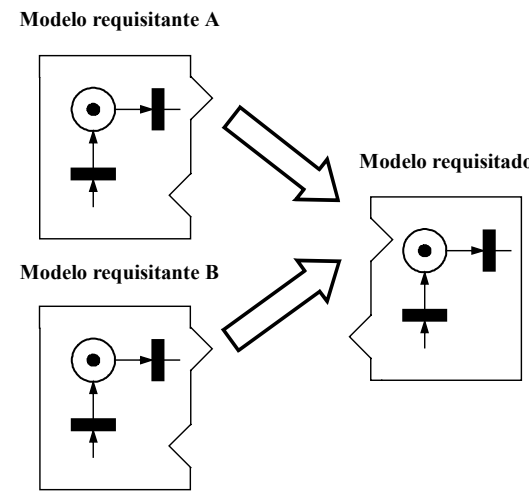

(a)

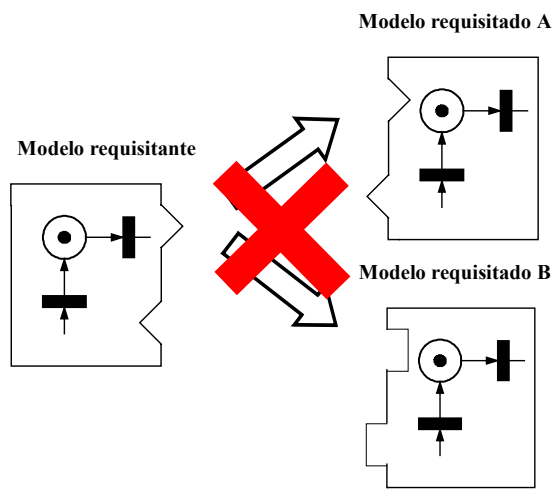

(b)

Modelo requisitado B
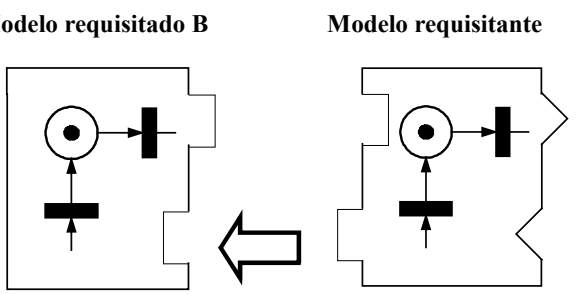

Modelo requisitado A

(c)

Figura 2.4 - Possíveis relações entre modelos: (a) diferentes modelos requisitantes poderem requisitar a funcionalidade de um modelo requisitado através de um mesmo tipo de interface; (b) a não possibilidade de se utilizar uma mesma interface para requisitar funcionalidade de modelos distintos; e (c) a possibilidade de se requisitar funcionalidades distintas através de interfaces distintas.

Uma vez apresentadas as formas como podem se dar as relações entre os modelos através de interfaces, passa-se à análise das possíveis formas de modelar a interface através de elementos da RdP. Alguns autores utilizam diferentes elementos da RdP (lugar e transição) simultaneamente (BASTIDE, 1995; LAKOS, 1995; WANG, 1998) para representar as interfaces entre os modelos. Visando padronizar a forma como a interface é modelada, ou seja, utilizar apenas um tipo de elemento da RdP, este estudo baseou-se em SIBERTIN-BLANC (1993) e focou em: (1) fusão de lugares; (2) fusão de transições; e (3) comunicação por arcos habilitadores.

\subsubsection{Inteface entre modelos através de fusão de lugares}

A Figura 2.5 ilustra a comunicação entre dois modelos em RdP através da fusão de lugares. Nesta abordagem, dois lugares pertencentes a modelos distintos se comportam como se fossem um mesmo lugar. Pode-se notar na Figura 2.5 (b) que quando a transição $\mathbf{M o d}_{\mathbf{1}} \cdot \mathbf{T}_{\mathbf{1}}$ dispara, além do lugar $\mathbf{M o d}_{\mathbf{2}} \cdot \mathbf{L}_{\mathbf{2}}$ receber uma marca, outros dois lugares (de interface) também recebem marcas. O mesmo se observa na Figura 2.5 
(e) onde o $\mathbf{M o d}_{2}$ sinaliza para o $\operatorname{Mod}_{1}$ que a operação foi finalizada. Da mesma forma que os dois lugares (de interface) da Figura 2.5 (b) foram marcados simultaneamente com o disparo da transição $\mathbf{M o d}_{\mathbf{1}} . \mathbf{T}_{\mathbf{1}}$, ambos são desmarcados, também simultaneamente, com o disparo da transição $\mathbf{M o d}_{\mathbf{2}}$. $\mathbf{1}$ (Figura 2.5 (c)).
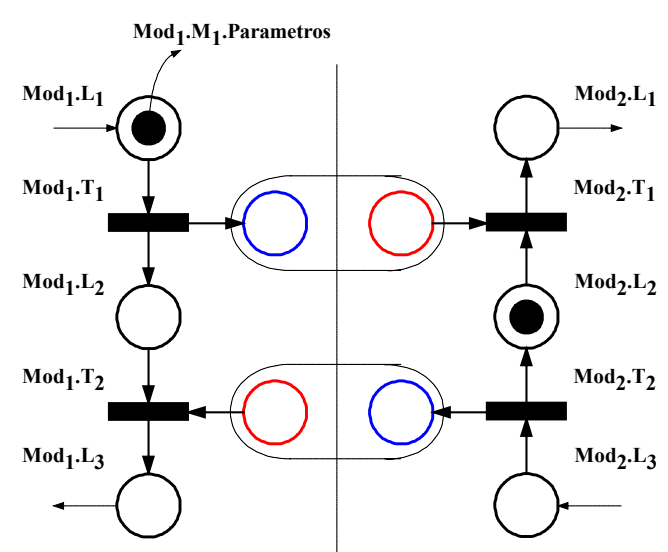

(a)

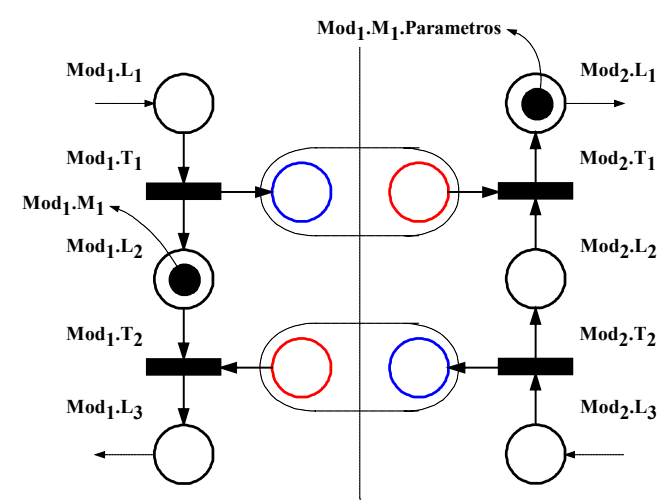

(c)

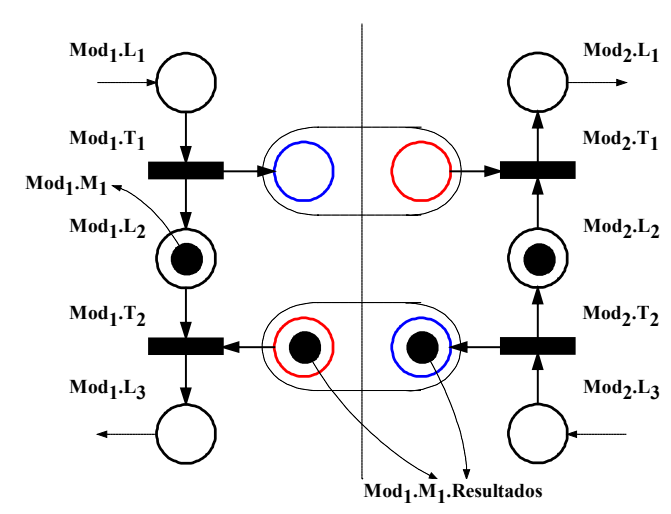

(e)

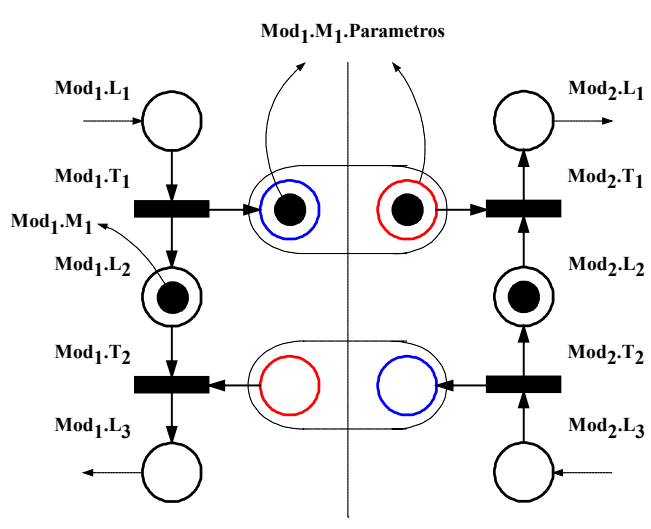

(b)

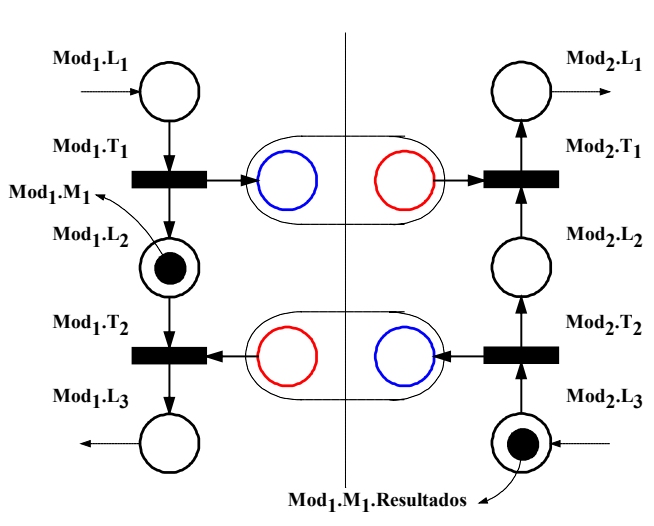

(d)

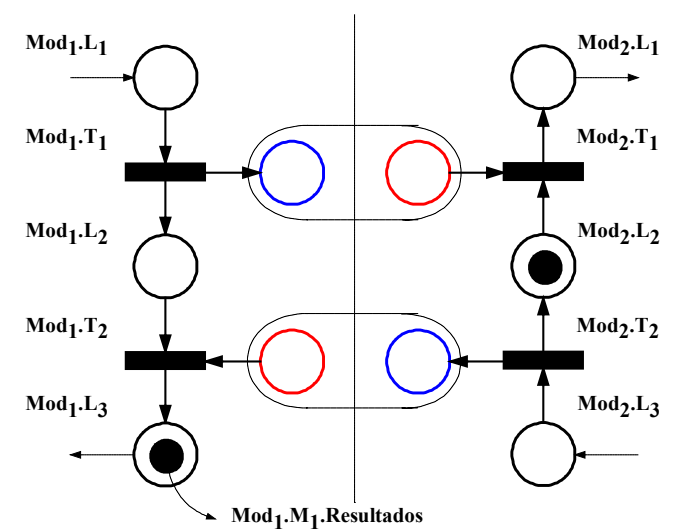

(f)

Figura 2.5 - Exemplo de troca de informações entre dois modelos em RdP utilizando-se "fusão de lugares". 
A abordagem por fusão de lugares apresenta como desvantagem a forma como a marcação nos lugares de interface deve ser administrada. Este caso pode ser ilustrado com um exemplo. Supõe-se que os modelos $\operatorname{Mod}_{\mathbf{1}} \mathbf{A}$ e $\operatorname{Mod}_{1} \mathbf{B}$ requisitem uma funcionalidade do $\operatorname{Mod}_{2}$. No caso de ambos $\left(\operatorname{Mod}_{1} \mathbf{A}\right.$ e $\left.\operatorname{Mod}_{1} \mathbf{B}\right)$ requisitarem simultaneamente $\mathbf{M o d}_{\mathbf{2}}$ (Figura 2.6), o conjunto das marcações nos três modelos torna dúbia a interpretação de qual destes $\left(\operatorname{Mod}_{1} \mathbf{A}\right.$ ou $\left.\mathbf{M o d}_{1} \mathbf{B}\right)$ está efetivamente requisitando $\operatorname{Mod}_{2}$.

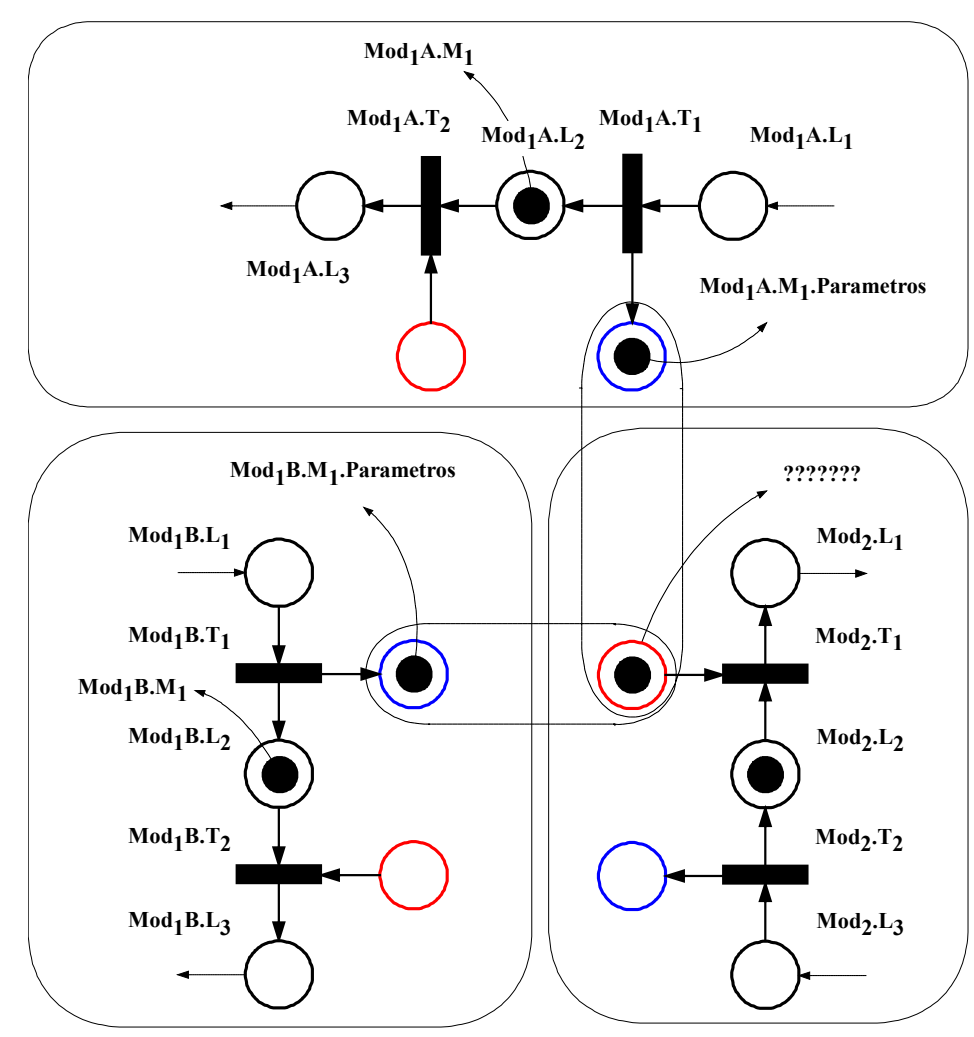

Figura 2.6 - Dois modelos distintos requisitando a mesma funcionalidade de um terceiro através da fusão de lugares.

\subsubsection{Inteface entre modelos através de fusão de transições}

A Figura 2.7 ilustra a mesma comunicação abordada na Figura 2.5, porém utilizando-se a fusão de transições. Neste caso, duas transições pertencentes a modelos em RdP distintos comportam-se como se fossem a mesma transição. Desta forma, para que a transição dispare, é necessário que tanto as pré quanto as pós-condições de ambas as transições (de ambos modelos) estejam satisfeitas.

Ao se utilizar a fusão de transições, quando as pré e pós condições da transição de requisição $\operatorname{Mod}_{1} \cdot \mathbf{T}_{1}$ estão satisfeitas, esta envia uma mensagem para a transição 
requisitada $\operatorname{Mod}_{2} \cdot \mathbf{T}_{\mathbf{1}}$. Quando todas as condições de $\mathbf{M o d}_{\mathbf{2}} \cdot \mathbf{T}_{\mathbf{1}}$ estiverem satisfeitas, esta dispara, enviando uma mensagem de volta para $\operatorname{Mod}_{\mathbf{1}} \cdot \mathbf{T}_{\mathbf{1}}$ para que esta também dispare.

Graficamente, a fusão de transições apresenta-se mais simples que a fusão de lugares por utilizar menor número de elementos. Esta abordagem se destaca sobre a fusão de lugares pois ao contrário do apresentado na Figura 2.6, na fusão de transições a marcação só evolui quando as transições de interface dos modelos requisitante e requisitado estão disponíveis. Desta forma evita-se dúvidas quanto ao modelo que efetivamente requisitou primeiro o modelo requisitado.

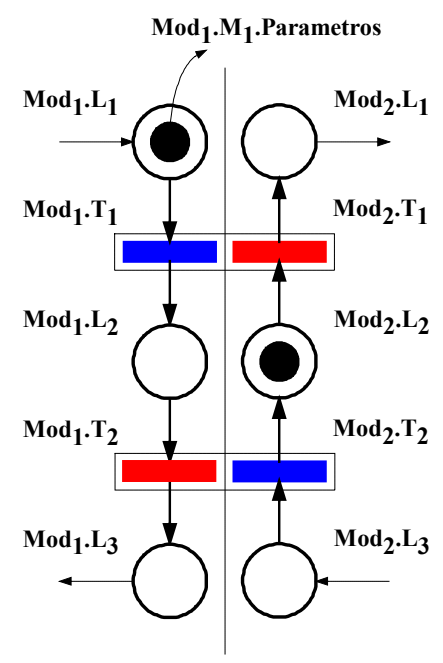

(a)

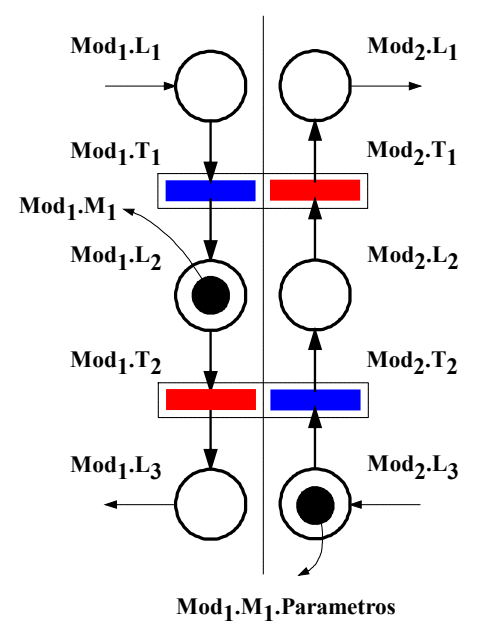

(c)

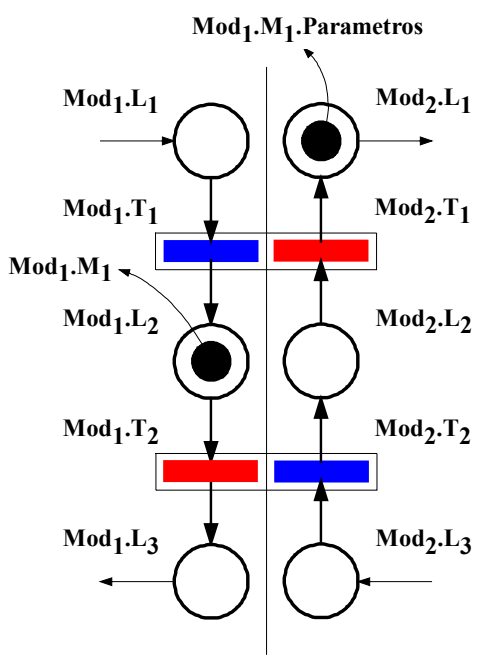

(b)

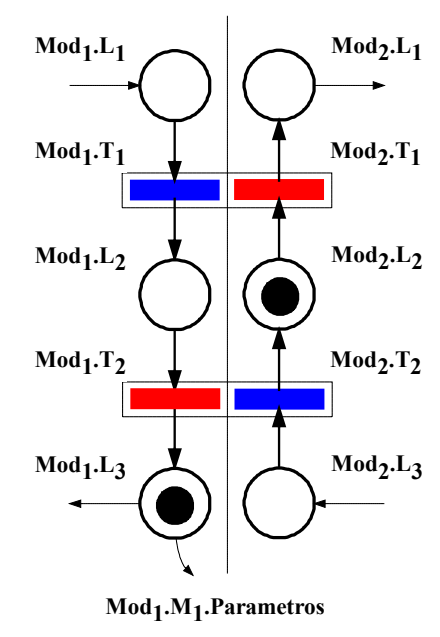

(d)

Figura 2.7 - Exemplo de troca de informações entre dois modelos em RdP utilizando-se "fusão de transições". 


\subsubsection{Inteface entre modelos através de arcos habilitadores}

A terceira forma de comunicação abordada neste trabalho é através de arcos habilitadores. A Figura 2.8 ilustra a comunicação similar às das Figuras 2.5 e 2.7. A disponibilidade de $\mathbf{M o d}_{\mathbf{2}}\left(\mathbf{M o d}_{\mathbf{2}} \cdot \mathbf{L}_{\mathbf{2}}\right.$ marcado) juntamente com um requisição do $\mathbf{M o d}_{\mathbf{1}}$ $\left(\operatorname{Mod}_{1} \cdot \mathbf{L}_{1}\right.$ marcado) (Figura 2.8 (a)) permitem que a transição $\mathbf{M o d}_{2} \cdot \mathbf{T}_{1}$ dispare, resultando na configuração da Figura 2.8 (b).

Na comunicação entre modelos utilizando arcos habilitadores, observa-se que a passagem do estado apresentado na Figura 2.8 (a) para (b) pode não ocorrer uma vez que a habilitação da transição $\mathbf{M o d}_{2} \cdot \mathbf{T}_{1}$ não implica na inibição de $\operatorname{Mod}_{1} \cdot \mathbf{T}_{1}$, ou seja, qualquer uma pode disparar primeiro. Desta forma, a utilização de arcos habilitadores como está apresentada não se mostra eficaz para a representação da interface entre modelos.

Como alternativa, pode-se utilizar um outro arco habilitador partindo de $\operatorname{Mod}_{\mathbf{2}} \cdot \mathbf{L}_{\mathbf{1}}$ para $\operatorname{Mod}_{1} \cdot \mathbf{T}_{\mathbf{1}}$ (Figura 2.9 (a)), impedindo que $\mathbf{M o d}_{\mathbf{1}} \cdot \mathbf{T}_{\mathbf{1}}$ dispare antes de $\mathbf{M o d}_{\mathbf{2}} \cdot \mathbf{T}_{\mathbf{1}}$. Outra alternativa é a introdução de um novo elemento (responsável pela comunicação) à RdP, gerenciando a comunicação entre os modelos (Figura 2.9 (b)). No primeiro caso, apesar de ser uma solução possível, frente às alternativas anteriormente expostas, esta se mostra mais complexa devido à necessidade de criar arcos habilitadores nos dois sentidos da comunicação. O segundo caso, além de se apresentar igualmente complexo frente às opções anteriormente apresentadas, introduz um novo elemento à rede, tornando-a incompatível com as ferramentas existentes de modelagem e análise baseadas em RdP.

Considerando as características das três abordagens, optou-se neste trabalho pela fusão de transições. 


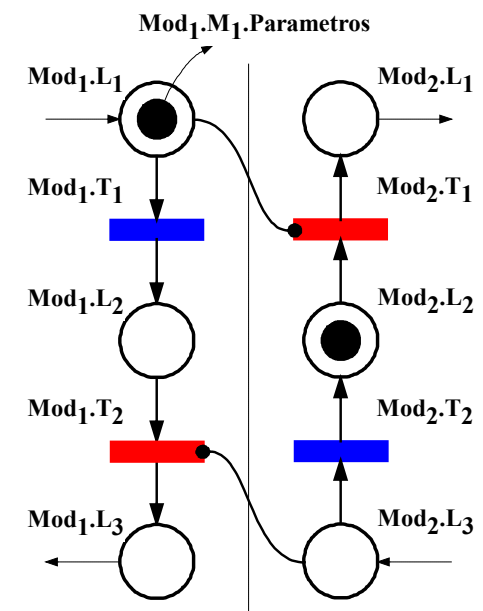

(a)

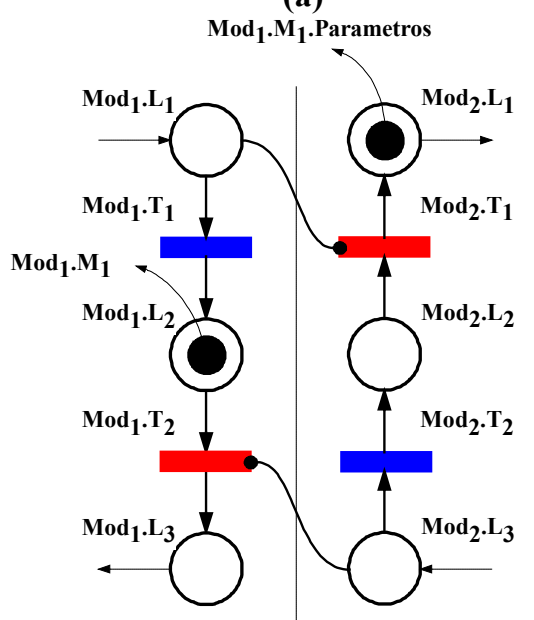

(c)

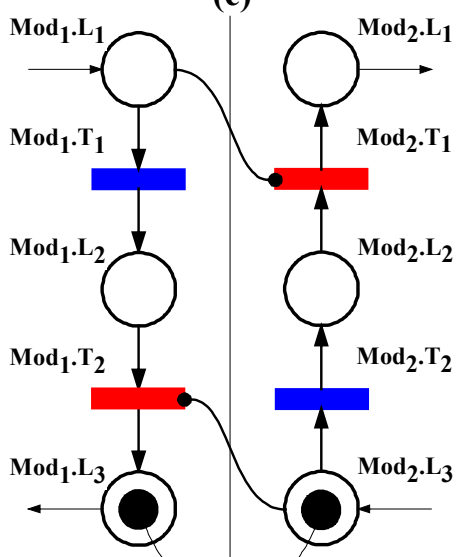

$\operatorname{Mod}_{1} \cdot \mathbf{M}_{1} \cdot$ Parametros

(e)

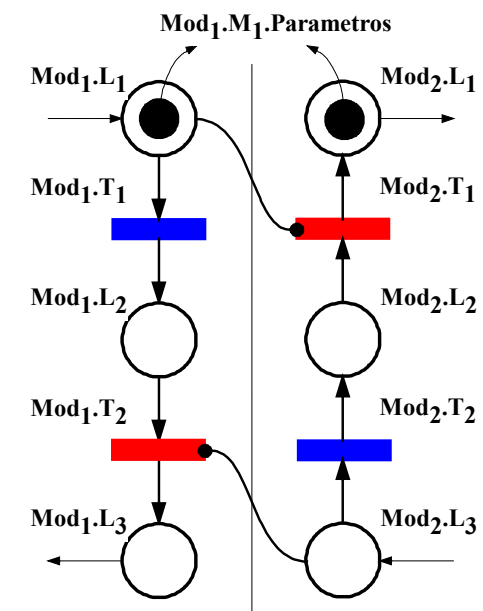

(b)

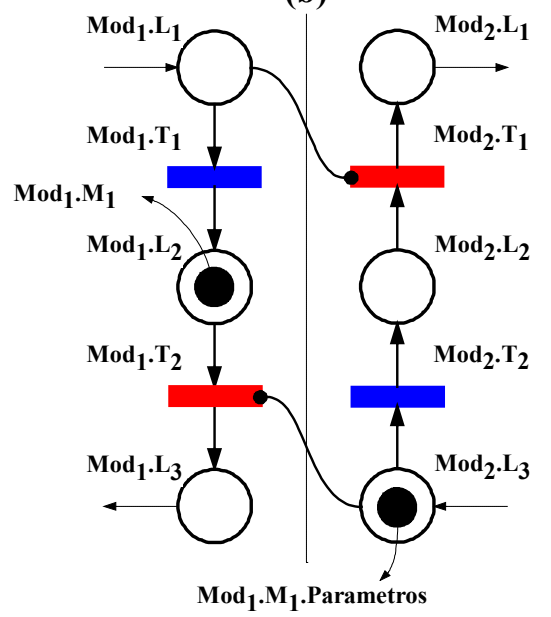

(d)

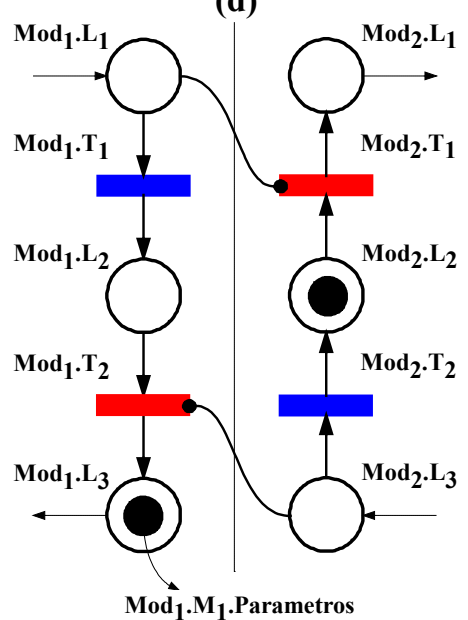

(f)

Figura 2.8 - Exemplo de troca de informações entre dois modelos em RdP utilizando-se "arcos habilitadores". 


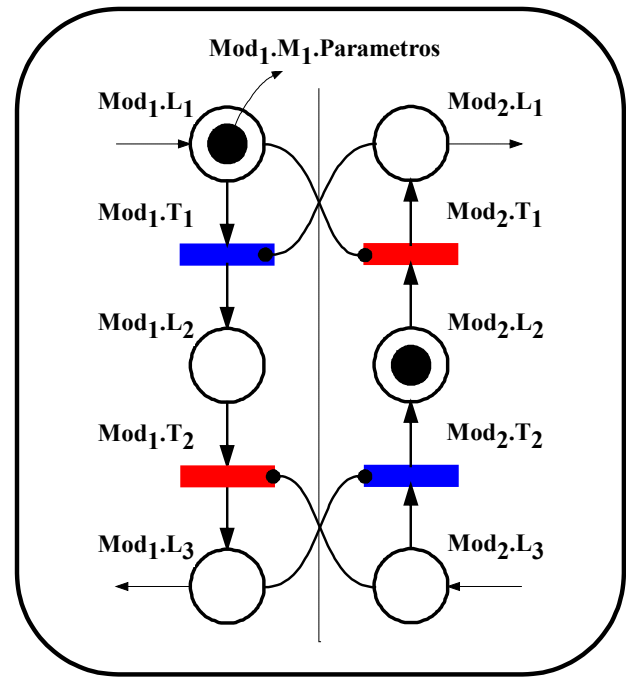

(a)

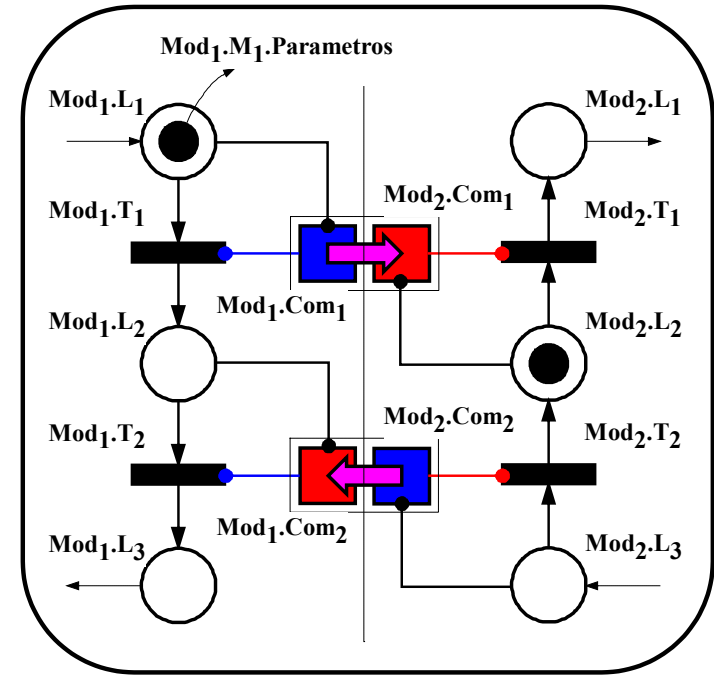

(b)

Figura 2.9 - (a) Introdução de arcos habilitadores no sentido contrário da chamada para garantir a seqüência de disparo desejada; (b) introdução de novos elementos, responsáveis pela comunicação entre modelos, na RdP.

\subsection{Proposta de um método para a construção de modelos em RdP para simulação distribuída}

A forma como um sistema produtivo é modelado depende tanto de fatores inerentes a este, como sua complexidade, bem como de fatores pessoais, como estilo, forma/nível de abstração e experiência do projetista. Porém observa-se que a equipe de projeto deve conseguir visualizar o sistema produtivo (ou a parte que lhe é de interesse) como um todo, as partes que o compõem, seu funcionamento e a relação entre as partes (suas interfaces). Apresenta-se na Figura 2.10 uma abordagem para a modelagem de sistemas produtivos e cujas etapas são genericamente discutidas a seguir (os detalhes da aplicação prática do método são apresentados na seção 2.5):

\section{Etapa 1 - Definição do problema delimitando o escopo do sistema produtivo em estudo}

Nesta etapa o modelista deve delimitar o escopo do sistema produtivo em estudo, ou seja, quais departamentos, equipamentos e pessoas (ambos podendo ser vistos como recursos) são utilizados, quais as funcionalidades/características e processos que se pretende modelar e analisar (através de simulação). Nesta etapa o modelista pode fazer uso do ponto de vista da empresa do RM-ODP (Reference Model Open and Distributed Processing). O ponto de vista da empresa foca nas políticas do 
negócio, políticas de gerenciamento e as funções das pessoas no sistema e no ambiente onde estão inseridas. O uso da palavra empresa não significa que este ponto de vista se limite a apenas uma organização. O modelo construído pode bem descrever as restrições existentes entre várias organizações distintas (SINNOTT; TURNER, 1997; KANDÉ et al., 1998; BOITEN et al., 2000; COSTA et al., 2001). Uma descrição detalhada sobre este ponto de vista, bem como sobre o modelo de referência ODP, é apresentada na seção F.1.

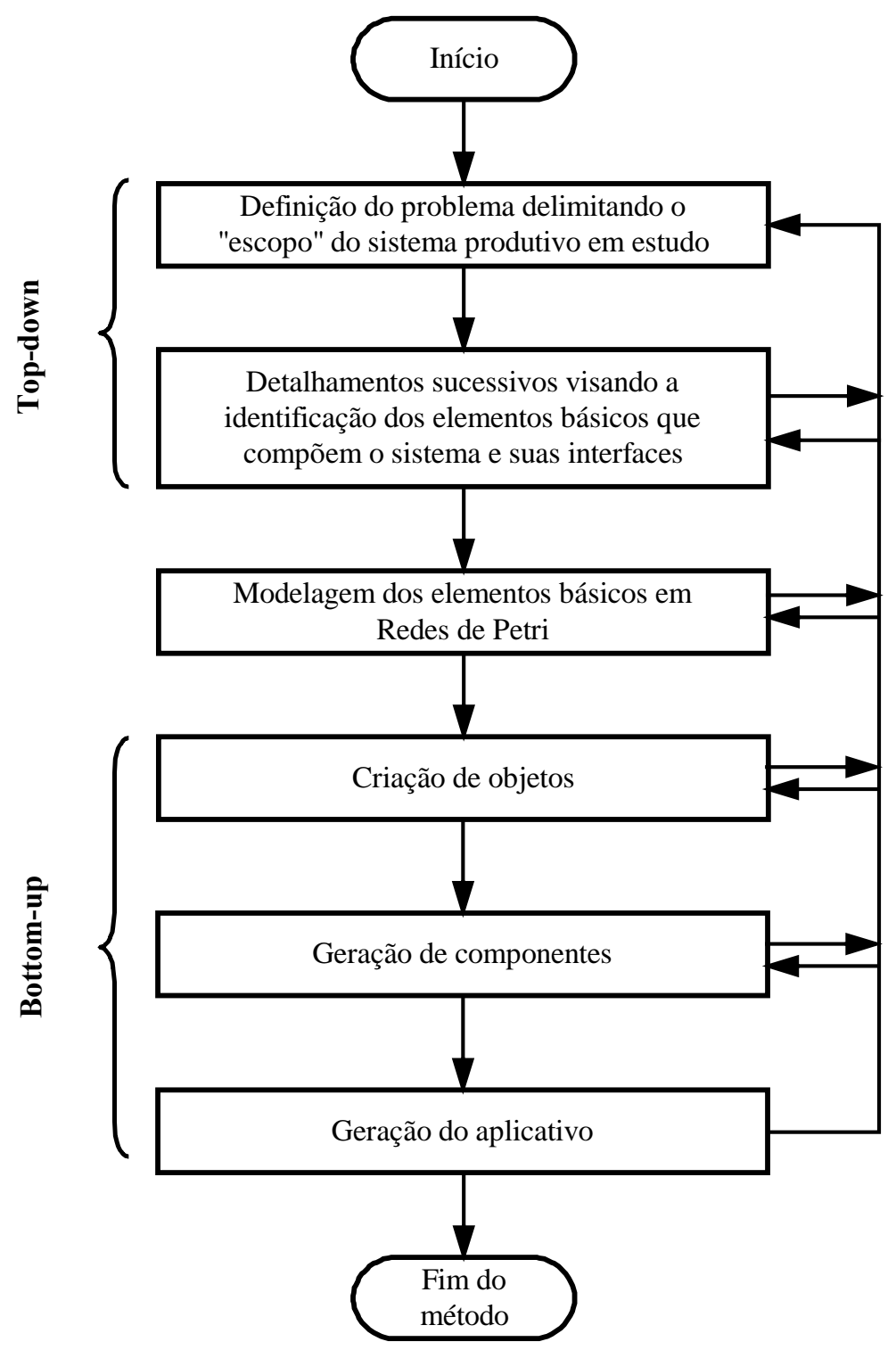

Figura 2.10 - Diagrama com o método de modelagem de sistemas produtivos. 
Etapa 2 - Detalhamentos sucessivos visando a identificação dos elementos básicos ${ }^{8}$ que compõem o sistema e seus relacionamentos

Considera-se nesta fase do projeto uma abordagem top-down, partindo-se de um certo nível de detalhamento no "topo” e chegando-se a níveis maiores de detalhamento nos níveis "inferiores”.

Como apresentado por Miyagi (1996), o uso de técnicas como o PFS (Production Flow Schema) $^{9}$, auxiliam no processo de modelagem dos sistemas produtivos, onde parte-se do modelo conceitual do sistema produtivo e, através de detalhamentos sucessivos, chega-se aos ao nível de abstração desejado.

Deve-se ter, ao final da etapa 2, um conjunto de elementos básicos, dado o nível de detalhamento desejado, que constituem o sistema produtivo, bem como os relacionamentos entre estes, ou seja, suas interfaces, e o formato das mensagens trocadas entre estas.

\section{Etapa 3 - Modelagem dos elementos básicos em Redes de Petri (RdP)}

Nesta etapa, as funcionalidades dos elementos básicos são modeladas com o auxílio da RdP. Cada elemento básico dá origem a um modelo em RdP denominado classe (Figura 2.11). Assim como na orientação a objetos, uma classe é uma descrição de um conjunto de objetos que compartilham os mesmos atributos, operações, relacionamentos e semânticas ${ }^{10}$.

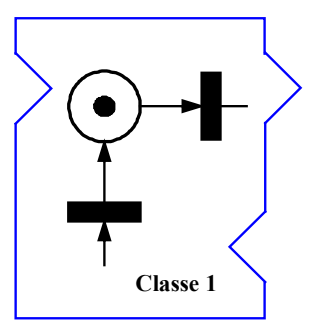

Figura 2.11 - Uma classe, implementada em Redes de Petri.

\footnotetext{
8 Entende-se por elementos básicos as máquinas, transportadores, pessoas, etc. considerados como pertinentes para o estudo e que devem ser modelados, porém sem se ater a detalhes como, por exemplo, quais seus fabricantes ou mesmo características específicas como velocidade de operação. No caso de fresas, por exemplo, mesmo sendo de fabricantes diferentes, estas apresentam características estruturais e funcionais comuns e que são mais relevantes, numa primeira fase de estudo, do que as faixas de velocidade em que podem atuar.

${ }^{9}$ Brevemente descrito no Anexo A e que é utilizado tanto na seção 2.5, como no capítulo 3.

${ }^{10}$ Significado.
} 
Ainda com relação a esta etapa, cada modelo pode ser analisado de forma isolada, o que facilita na sua validação, antes de ser utilizado na composição de novos modelos, mais complexos. Assim, em seguida, pode-se adotar uma abordagem bottomup para a modelagem de elementos mais complexos, partindo-se de modelos simples, que segundo Pidd $(1994,1996)$ são relativamente mais fáceis de modelar e validar, e que são posteriormente agregados para compor o modelo final, mais complexo.

\section{Etapa 4 - Criação de objetos}

Uma vez definidos os elementos básicos, as classes, pode-se iniciar o processo de composição de modelos através de uma abordagem botton-up. Esta é o primeiro passo neste sentido, onde objetos são gerados baseando-se nas classes modeladas na etapa 3.

\section{Etapa 5 - Geração de componentes}

Nesta etapa, o componentes são construídos em três sub-etapas: (5.1) encapsular os objetos em componentes; (5.2) interligar as interfaces internas dos objetos; e (5.3) mapear as interfaces dos objetos como interfaces do componente.

Na sub-etapa 5.1, objetos gerados na etapa 4, que possuem alguma característica em comum e que interagem entre si através de interfaces, podem ser agrupadas constituindo os componentes (Figura 2.12).

Para se agrupar objetos em componentes, sub-etapa 5.2, pode-se dispor de dois tipos de relacionamentos: (1) estático; e (2) dinâmico. No relacionamento estático, a relação entre as transições de interface dos objetos (requisitante e requisitado) é explicitada criando-se um relacionamento interno (setas vermelhas na Figura 2.12) entre elas. A Figura 2.13 ilustra o relacionamento estático entre dois objetos.

Neste exemplo, $\mathbf{O b j} \mathbf{j}_{1}$ requisita $\mathbf{O b j}_{2}$. Desta forma, no componente, cria-se uma ligação entre estes, partindo do $\mathbf{O b j}_{1}$ para o $\mathbf{O b j}_{2}$. Ao se criar esta ligação, os parâmetros associados à transição $\mathbf{O b j}_{1}$. $\mathbf{T}_{\mathbf{1}}$ são preenchidos, alguns durante a modelagem - como o IDCalled e o TCalled (Figura 2.13 (b)) que representam respectivamente o nome do objeto requisitado e a transição para a qual a requisição é direcionada - e um durante a simulação - o IPCalled, que é informado quando os objetos são carregados para a simulação. 


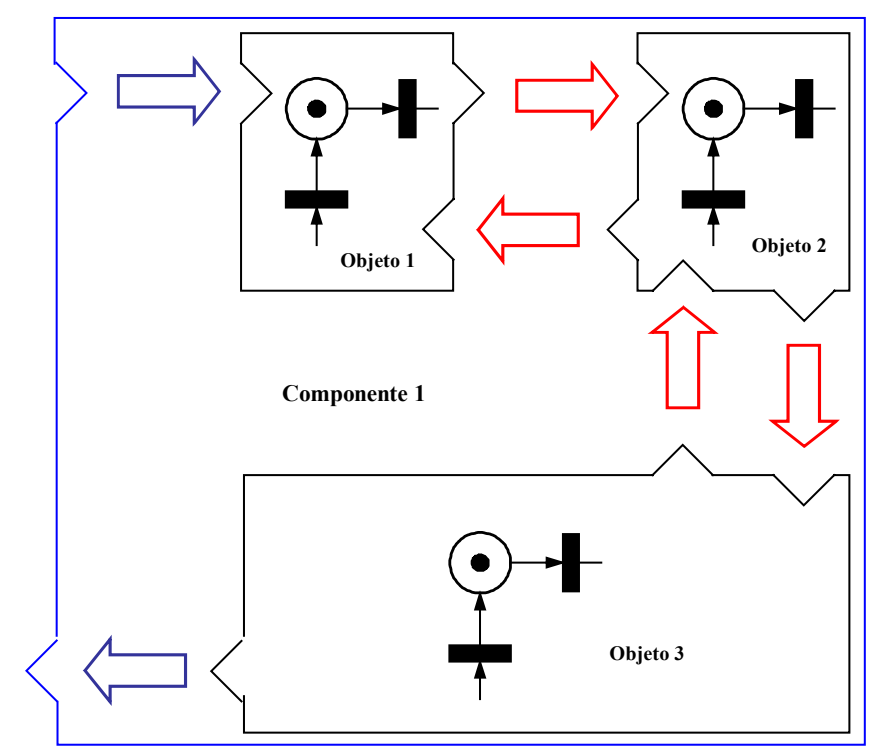

Figura 2.12 - Constituição de componentes através do agrupamento de dois ou mais objetos baseados nas classes definidas na etapa 3 .

Na Figura 2.13 também é possível notar a fusão das transições $\mathbf{O b j}_{1} \cdot \mathbf{T}_{\mathbf{1}}$ e $\mathbf{O b j}_{2} \cdot \mathbf{T}_{1}$. O $\mathbf{O b j} \mathbf{j}_{1}$ informa ao $\mathbf{O b j}_{2}$ a sua localização na rede $(\mathbf{O b j I P}$ - um atributo que indica o Internet Protocol onde o objeto se localiza na rede), a sua identificação (ObjID - um atributo que o identifica univocamente naquele IP) e a transição associada à $\mathbf{O b j}_{1} \cdot \mathbf{T}_{1}$ para retorno da resposta, ou seja, $\mathbf{O b j} \mathbf{j}_{1} \cdot \mathbf{T}_{\mathbf{2}}$. Com o disparo de $\mathbf{O b j} \mathbf{j}_{2} \cdot \mathbf{T}_{\mathbf{1}}$, estes parâmetros são armazenados na marca mostrada em $\mathbf{O b j}_{\mathbf{2}} \cdot \mathbf{L}_{\mathbf{2}}$. Estes parâmetros serão utilizados por $\mathbf{O b j} \mathbf{j}_{2} \cdot \mathbf{T}_{2}$ quando este for retornar uma resposta ao objeto requisitante, no caso $\mathbf{O b j}_{1}$.

No relacionamento dinâmico, as informações quanto ao objeto a ser requisitado, ao invés de ficaram armazenadas na transição requisitante, ficam armazenadas na marca. A Figura 2.14 ilustra este relacionamento. Neste caso, ao invés de se fazer um relacionamento interno explícito entre os objetos, como apresentado na Figura 2.13 (b), os parâmetros quanto ao objeto requisitado são inseridos na marca (neste caso mostrada em $\mathbf{O b j} \mathbf{j}_{1} \cdot \mathbf{L}_{1}$ ) durante a modelagem, seja na classe (que representa o modelo) na qual o objeto se baseia, seja durante a modelagem do componente.

A vantagem em se utilizar o relacionamento dinâmico reside na possibilidade se requisitar objetos diferentes, porém baseados em uma mesma classe, através de uma mesma interface. Um exemplo de aplicação seria um Sistema de Controle que requisita um entre vários Transportadores, iguais, para transportar uma peça da Máquina A para a Máquina B, sem ter que criar uma interface distinta para requisitar cada 
Transportador. Ainda com relação a este exemplo, seria necessário trabalhar com uma RdP que permita inscrições (atributos) nas marcas, como a RdP colorida, afim de distinguir os transportadores.

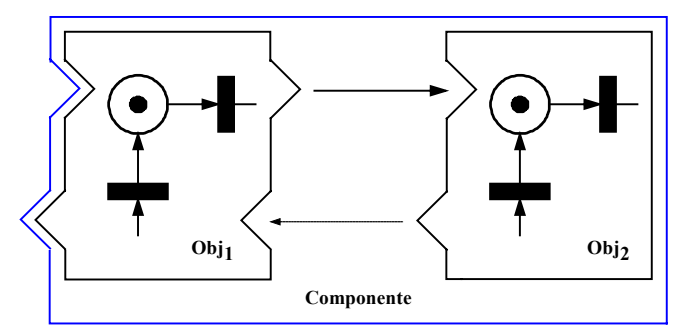

(a)

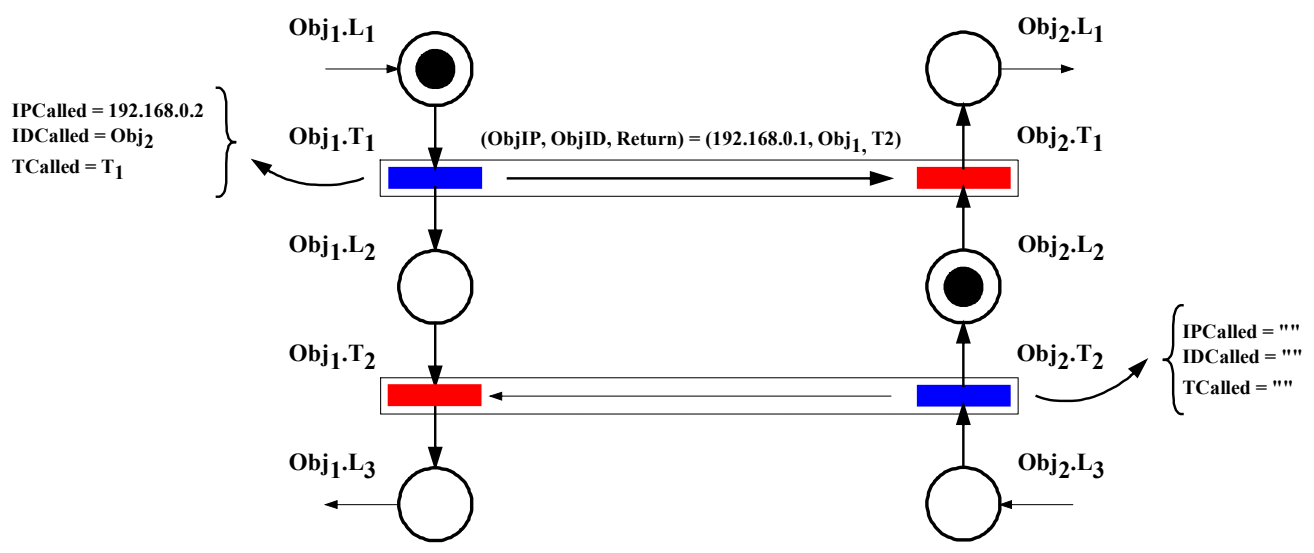

(b)

Figura 2.13 - Exemplo de uso do relacionamento estático: (a) representação esquemática; e (b) representação em Rede de Petri com fusão de transições - neste relacionamento os parâmetros da chamada estão na transição requisitante do objeto requisitante.

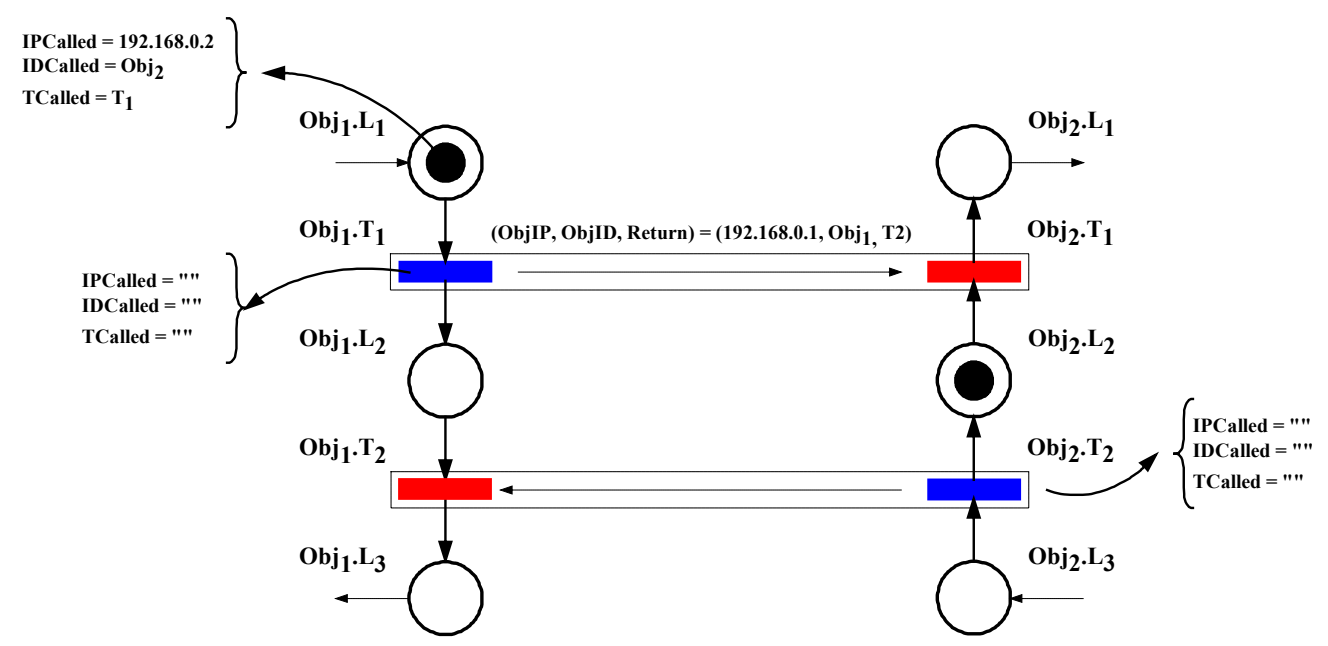

Figura 2.14 - Exemplo de uso do relacionamento dinâmico- neste relacionamento os parâmetros da chamada estão na marca do objeto requisitante. 
Feitos os relacionamentos internos entre os objetos dos componentes, a próxima sub-etapa (5.3) é mapear as interfaces dos objetos para o mundo externo. Isso se dá mapeando as interfaces do objetos como sendo as próprias interfaces dos componentes (setas azuis na Figura 2.12).

\section{Etapa 6 - Geração do aplicativo}

Esta etapa se assemelha à anterior. Porém, suas diferenças residem em dois fatos: (1) dado o nível de complexidade do sistema que se está modelando, pode ser que não haja a necessidade de se gerar um aplicativo; e (2) nesta etapa não existe o mapeamento das interfaces do componente como interfaces do aplicativo. Fazendo uma analogia com os elementos de software, pode-se dizer que o componente é um elemento semi-acabado, que isoladamente não possui utilidade, ao passo que o aplicativo é um produto acabado com uma finalidade bem definida.

Nesta etapa, agrupando-se dois ou mais componentes, criam-se os aplicativos (Figura 2.15). Para se agrupar os componentes em aplicativos, pode-se dispor apenas dos relacionamentos estáticos pois neste nível de abstração não existe o conceito de marca.

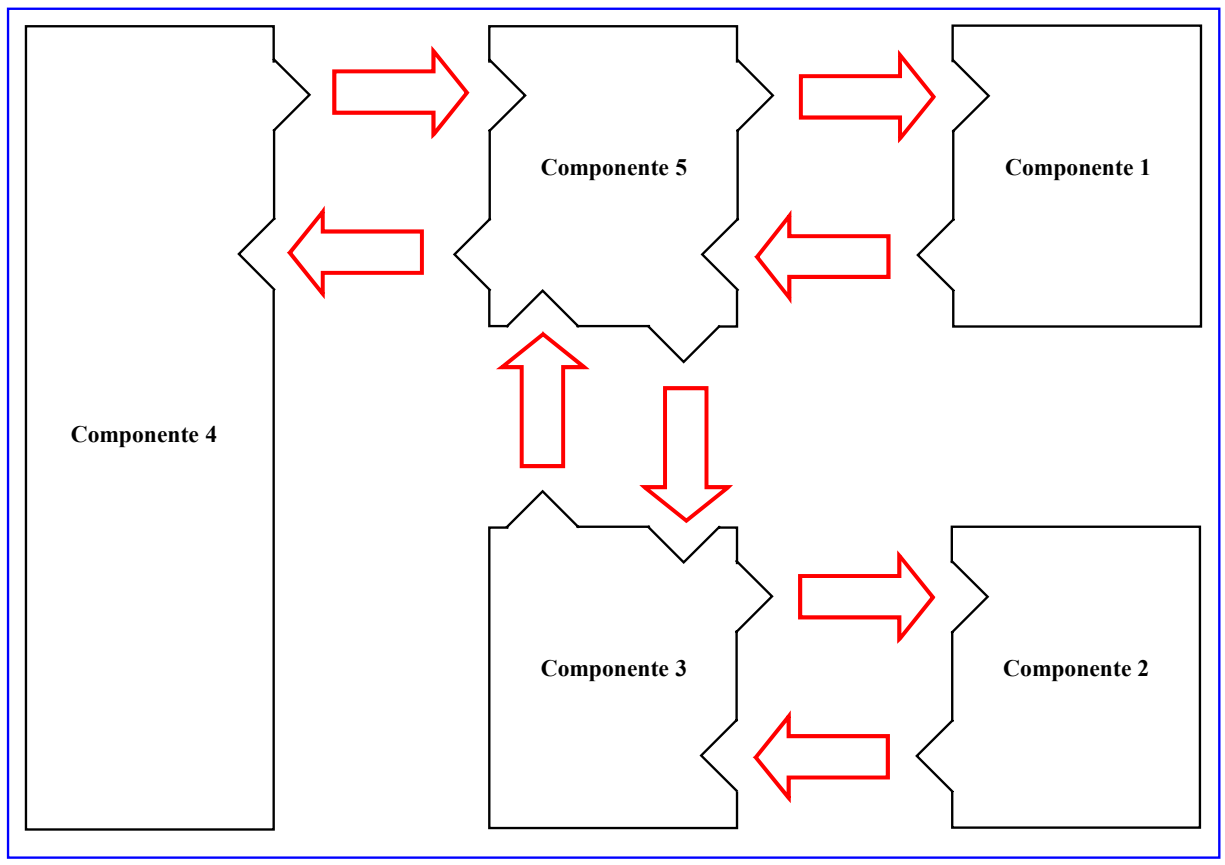

Figura 2.15 - Constituição de aplicativo a partir de dois ou mais componentes. 
Deve-se ter, ao final das etapas de modelagem: (1) os elementos básicos modelados em RdP, as classes; (2) os componentes, que são agrupamentos de classes; e (3) o (s) aplicativo (s), que são agrupamentos de componentes.

\subsection{Aplicação do método proposto a um exemplo}

A fim de demonstrar o emprego do método proposto, apresenta-se nesta seção um exemplo de sistema de movimentação de materiais. Através deste exemplo pretende-se evidenciar ol processo de identificação dos elementos que compõem o sistema, o seu detalhamento, a modelagem dos elementos básicos, e o agrupamento destes de forma a constituir os componentes.

\section{Etapa 1 - Definição do problema delimitando o escopo do sistema em estudo}

Este sistema de movimentação de materiais é composto por quatro estações de trabalho produtoras ou consumidoras de peças. A Estação $\boldsymbol{A}$ fornece peças para a Estação B e a Estação C fornece peças para a Estação D.

Para a movimentação das peças, o sistema conta com um trilho por onde circula um transportador, o qual transporta uma peça por vez. Apresenta-se uma representação do sistema objeto de estudo na Figura 2.16.

Por simplificação, não fazem parte do objeto de estudo a alimentação das Estações $\boldsymbol{A}$ e $\boldsymbol{C}$ e nem a remoção de peças em $\boldsymbol{B}$ e $\boldsymbol{D}$. Considera-se que nenhuma delas utiliza o transportador para esta finalidade.

Cada estação possui um tempo de processamento correspondente à operação desempenhada nas peças. $\boldsymbol{A}$ e $\boldsymbol{C}$ só liberam (e $\boldsymbol{B}$ e $\boldsymbol{D}$ só aceitam) a peça assim que tiverem terminado seu processamento.

Desconsidera-se no modelo o (s) mecanismo (s) responsável (eis) por transferir as peças do transportador para as estações e vice-versa. No entando, considera-se que o tempo necessário para tal operação seja uma característica ao transportador, ou seja, um tempo que este obrigatoriamente deve permanecer parado até que a operação de transferência seja concluída.

Etapa 2 - Detalhamentos sucessivos e a identificação dos elementos básicos que compõem o sistema e seus relacionamentos 
Com base na representação do sistema apresentada na Figura 2.16, utiliza-se o PFS para refinar o modelo através de detalhamentos sucessivos. A Figura 2.17 apresenta a transcrição do sistema da Figura 2.16 para PFS, representando o deslocamento do transportador no trilho pelas estações. Neste modelo, pode-se distinguir as atividades: (1) o [transporte entre entre duas estações]; (2) [a parada na estação] (para que a peça seja carregada ou descarregada); (3) o [transportador]; e (4) [estação]. Além disso, apresentam-se os fluxos secundários de informação entre as paradas e as estações (em azul) e, entre as paradas e o transportador (em vermelho).

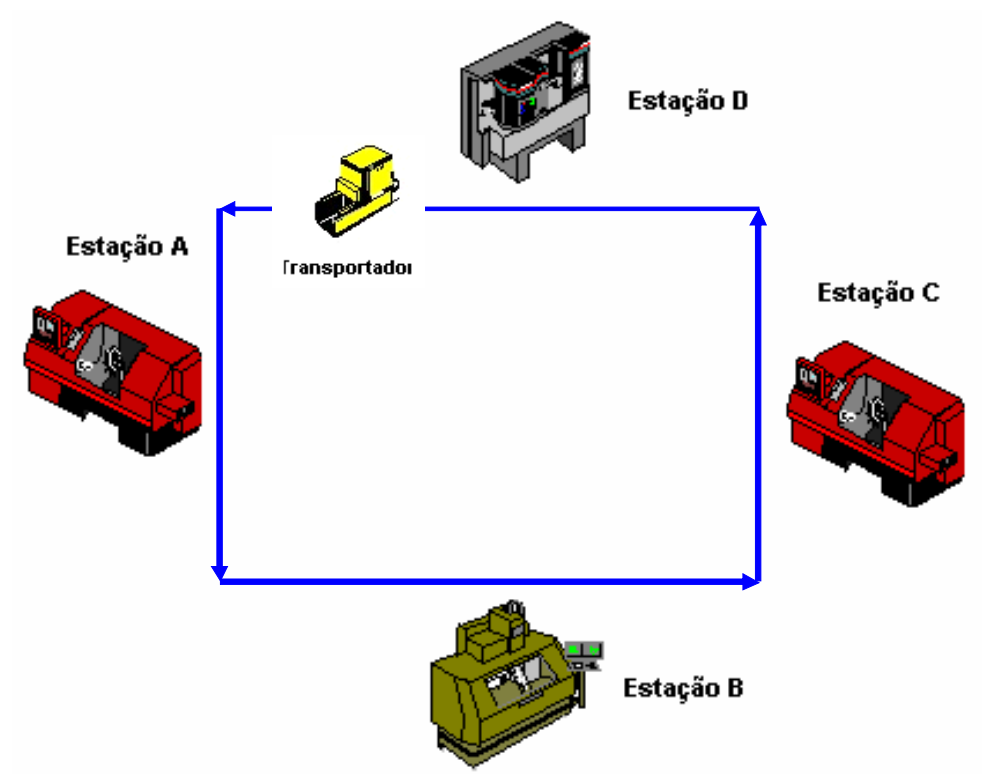

Figura 2.16 - Representação do sistemas de movimentação de materiais.

Dado que este é um modelo simples frente a um modelo real ${ }^{11}$, não são necessárias muitas etapas para se passar do modelo conceitual em PFS para o modelo funcional em RdP. Desta forma, passa-se para a Etapa 3.

\section{Etapa 3 - Modelagem dos elementos básicos em Redes de Petri (RdP)}

Nesta etapa, cada uma das atividades identificados na Etapa 2 é detalhada em RdP.

A Figura 2.18 apresenta a modelagem, em RdP referente ao transporte que ocorre entre duas estações, identificadas genericamente por X (origem) e Y (destino),

\footnotetext{
${ }^{11}$ Uma vez que é composto por poucos elementos e possui poucas interações entre estes.
} 
enquanto que a Figura 2.19 apresenta a modelagem das paradas nas estações, neste caso representada genericamente pela letra $\mathrm{Z}$.

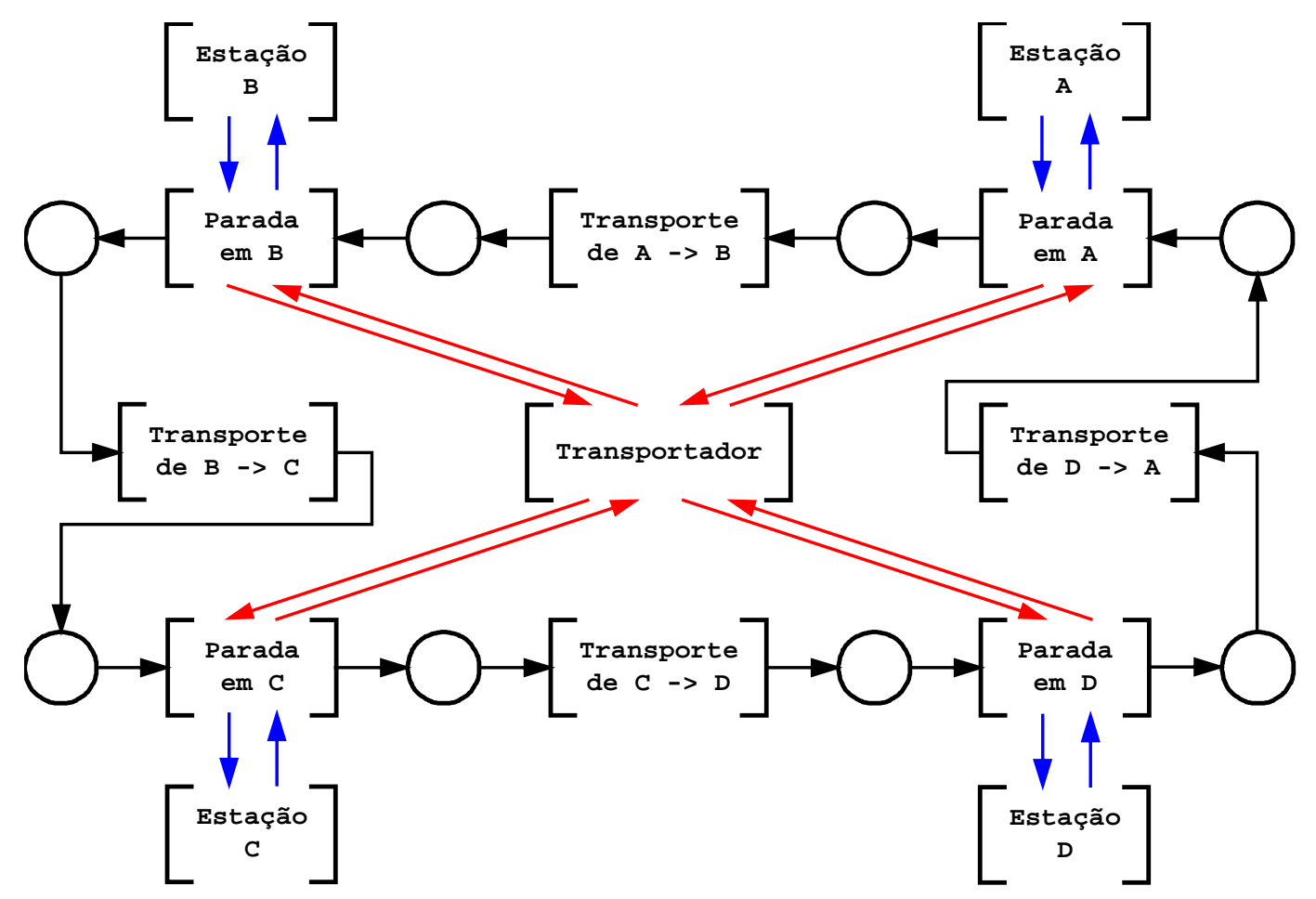

Figura 2.17 - Representação do deslocamento do transportador no trilho, deslocando-se de forma circular pelas estações.

Na Figura 2.18, o lugar L1 indica a pré-condição para realizar o trajeto entre a Parada X e a Parada Y. A transição T1 indica o tempo necessário para se sair de X e se chegar a Y e o lugar L2 indica a pós-condição desta operação.

No modelo da [Parada em Z] (Figura 2.19), o lugar L1 representa a chegada do transportador à estação. A transição T1 indica o início da operação de (des) carregamento da peça, enquanto T2 indica o final desta operação. O lugar L2 indica a manutenção do estado de (des) carregamento e L3 o final da operação de (des) carregamento.

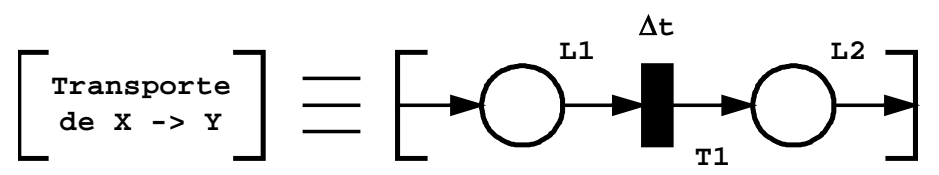

Figura 2.18 - Modelo em Rede de Petri do transporte entre duas estações. 


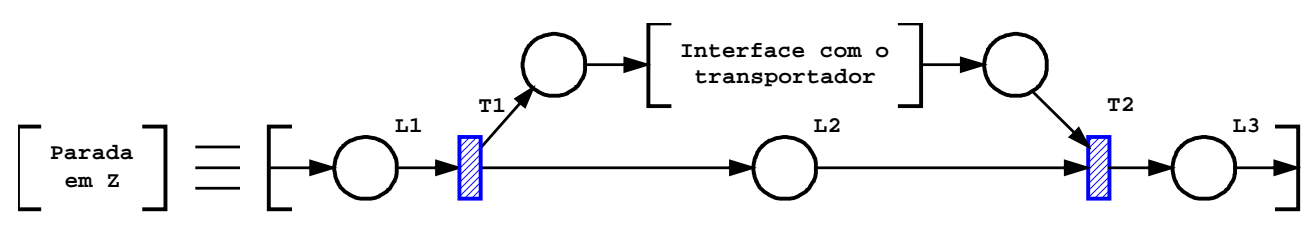

Figura 2.19 - Modelo em Rede de Petri da [Parada em Z].

A Figura 2.20 detalha a atividade [Interface com o transportador]. Nela L1 indica o estado inicial de (des) carregamento, L2 a manutenção da operação de (des) carregamento e L3 o estado final da operação de (des) carregamento. A transição T1 representa o início do (des) carregamento e T2 é a finalização desta operação.

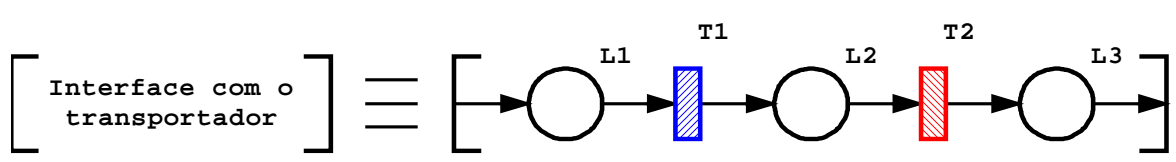

Figura 2.20 - Modelo em Rede de Petri da Interface com o Transportador.

As Figuras 2.21 e 2.22 ilustram respectivamente os modelos em RdP da estação e do transportador. Na Figura 2.21, as transições T1 e T2 representam as interfaces com o modelo da [Parada em Z], que são o início e o fim do (des) carregamento, respectivamente, enquanto T3 representa o tempo envolvido na operação da [Estação]. O lugar L1 representa o estado de espera da estação enquanto aguarda o (des) carregamento da peça. L3 e L2, respectivamente, o estado durante a operação e o estado ao final desta.

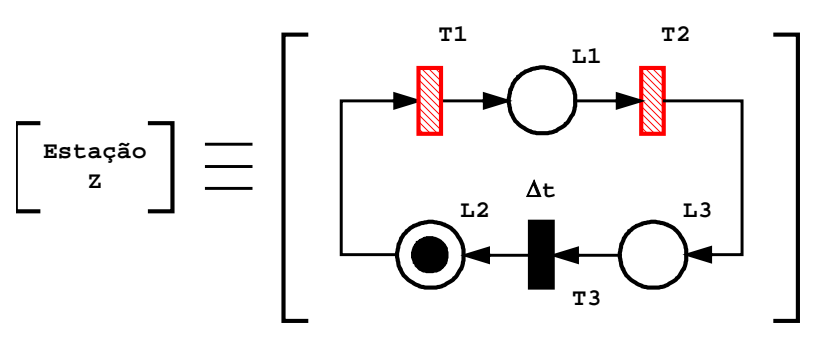

Figura 2.21 - Modelo em Rede de Petri da Estação.

Na Figura 2.22, apesar de aparentemente similar à Figura 2.21, seus elementos possuem interpretações distintas. O lugar L1 modela o estado em que o transportador está em movimento, enquanto L2 é o estado inicial da operação de (des) carregamento e L3 o estado de término da operação. T1 é a transição de interface que representa a parada do transportador e o início da operação de (des) carregamento. T3 representa o 
tempo de (des) carregamento e T2 é a interface associada à [Interface com o transportador] que representa a finalização da operação.

A Figura 2.23 ilustra a relação existente entre a atividade [Parada em Z] e [Estação Z], onde destaca-se a fusão das transições T1 de [Parada em Z] e T1 de [Estação Z], fazendo com que atuem como uma única. O mesmo ocorre para as transições T2 de [Parada em Z] e T2 de [Estação Z].

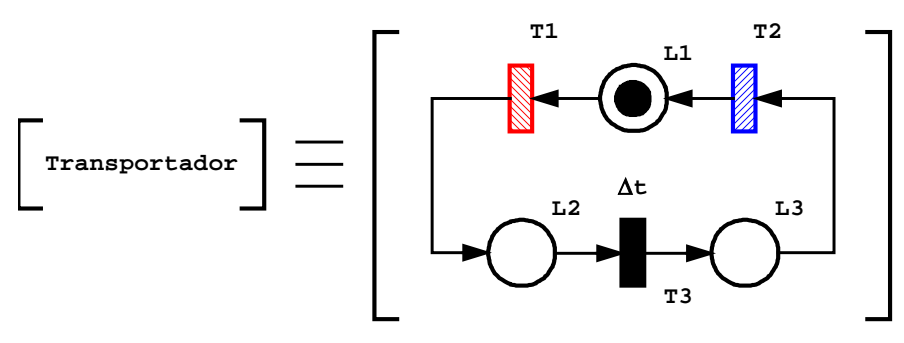

Figura 2.22 - Modelo em Rede de Petri do Transportador.

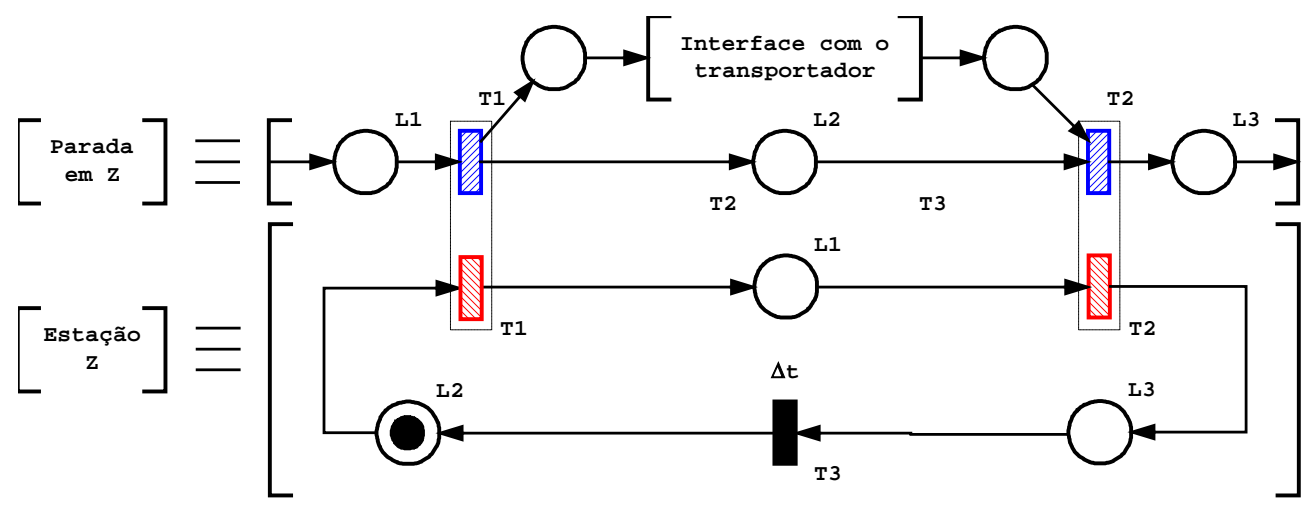

Figura 2.23 - Ilustração do relacionamento entre os modelos da [Parada] e [Estação], através de fusão de transições.

De forma similar à Figura 2.23, na Figura 2.24 ilustra-se a fusão de transições existente entre os modelos do [Transportador] e da [Interface com o Transportador] onde a fusão das transições T1 de ambos os modelos, bem como T2, funcionam como se fossem uma única transição.

Analisando as Figuras 2.17, 2.18 e 2.19, pode-se destacar uma parte do modelo (Figura 2.25 (a)) onde uma simplificação pode ser aplicada. Neste exemplo, os lugares L2 de [Parada em Z] e L1 de [Transporte de $\mathbf{X} \rightarrow \mathbf{Y}$ ] (Figura 2.25 (b)), por exemplo, podem ser fundidos no lugar L1 do modelo na Figura 2.25 (c). 


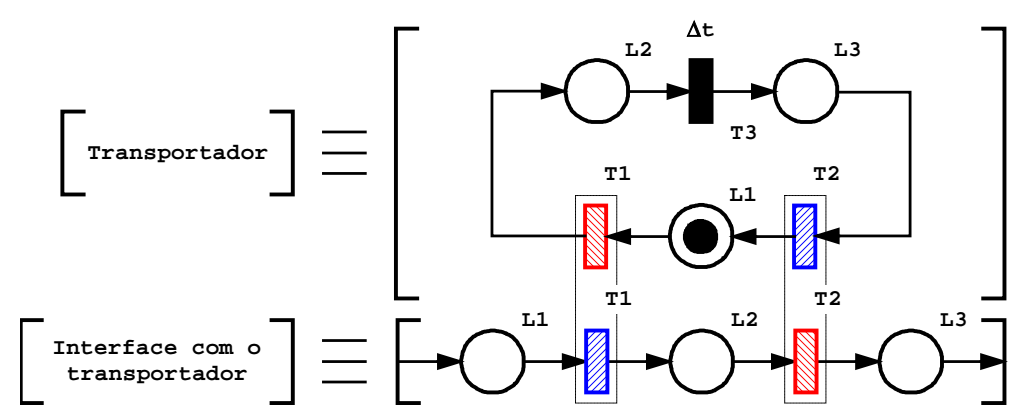

Figura 2.24 - Ilustração do relacionamento entre os modelos da [Interface com o Transportador] e [Transportador], através de fusão de transições.
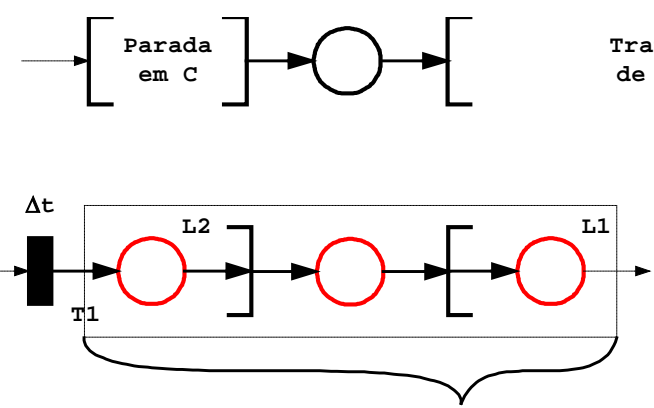

Transporte de $C \rightarrow D$

(a)
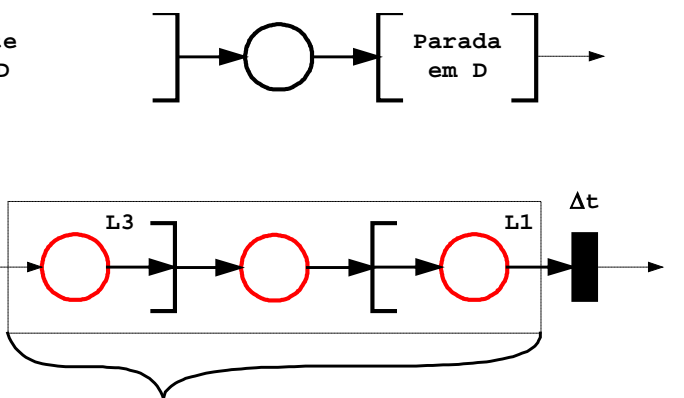

(b)

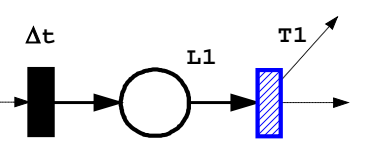

(c)

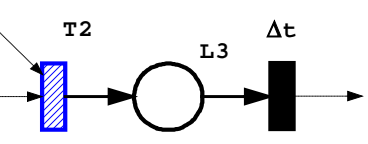

Figura 2.25 - Aplicação de técnicas para simplificação de modelos.

Desta forma, aplicando-se a simplificação apresentada (Figura 2.25), pode-se reestruturar o modelo da Figura 2.17 gerando o modelo na Figura 2.26, o qual é denominado [Malha de Movimentação]. Outra simplificação adotada neste exemplo é utilizar apenas um par de interfaces, isto é, a comunicação entre o modelo da [Malha de Movimentação] e do [Transportador]. Assim, conflitos por recursos são evidenciados no modelo e a composição de componentes (etapa 4) é simplificada.

\section{Etapa 4 - Criação de objetos}

Nesta etapa são gerados os objetos com base nas classes definidas na etapa anterior. A Tabela 2.1 ilustra os objetos gerados e as classes de que derivam. As Figura 2.27 (a), (b) e (c) ilustram, respectivamente, os objetos Transp (baseado na classe Transportador), Estação A (B, C e D) (baseado na classe Estação), e Rota (baseado na classe Malha de Movimentação). 


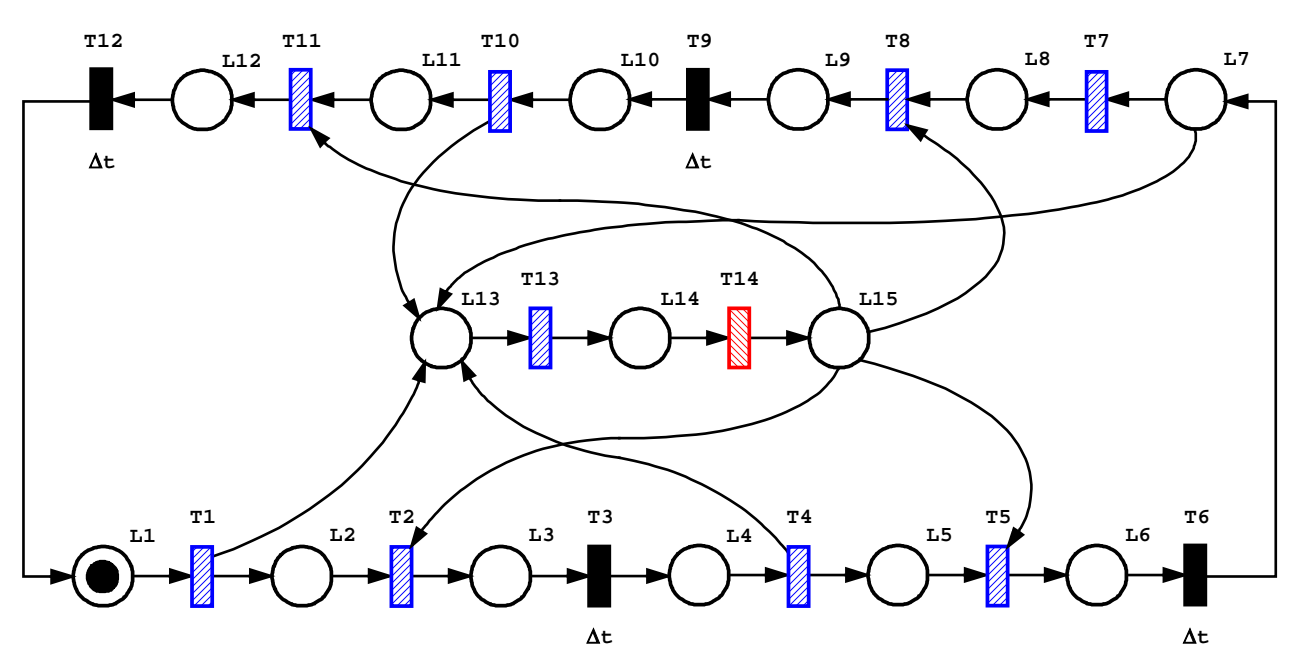

Figura 2.26 - Modelo funcional em RdP do modelo da Figura 2.17.

Tabela 2.1 - Objetos que constituem o componente Célula de Manufatura e as classes de que derivam.

\begin{tabular}{|l|l|}
\hline Objeto & Classe \\
\hline Estação A & Estação \\
\hline Estação B & Estação \\
\hline Estação C & Estação \\
\hline Estação D & Estação \\
\hline Rota & Malha de movimentação \\
\hline Transp & Transportador \\
\hline
\end{tabular}

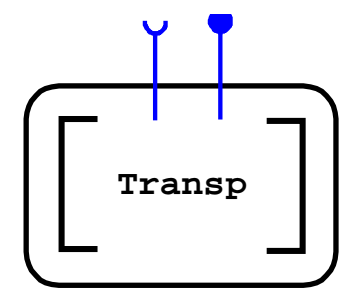

(a)

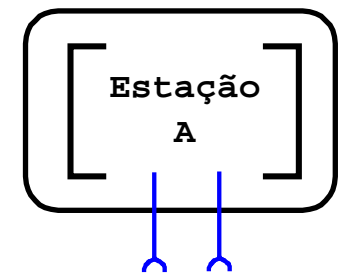

(b)

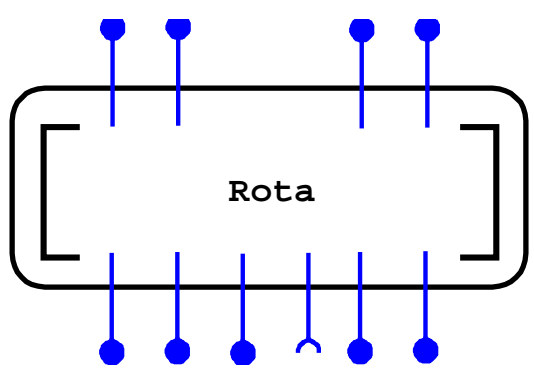

(c)

Figura 2.27 - Objetos gerados a partir das classes definidas na etapa 3 .

\section{Etapa 5 - Geração de componentes}

Nesta etapa, os objetos gerados na etapa 4 são então agrupados, constituindo o componente Célula de Manufatura (Figura 2.28). Nestas Figuras (2.27 e 2.28), utilizouse a notação de interfaces de entrada e saída do diagrama de componentes da UML ${ }^{12}$ para ilustrar as interface e os fluxos de informações entre os objetos do componente Célula de Manufatura.

\footnotetext{
${ }^{12}$ Vide Anexo C.
} 


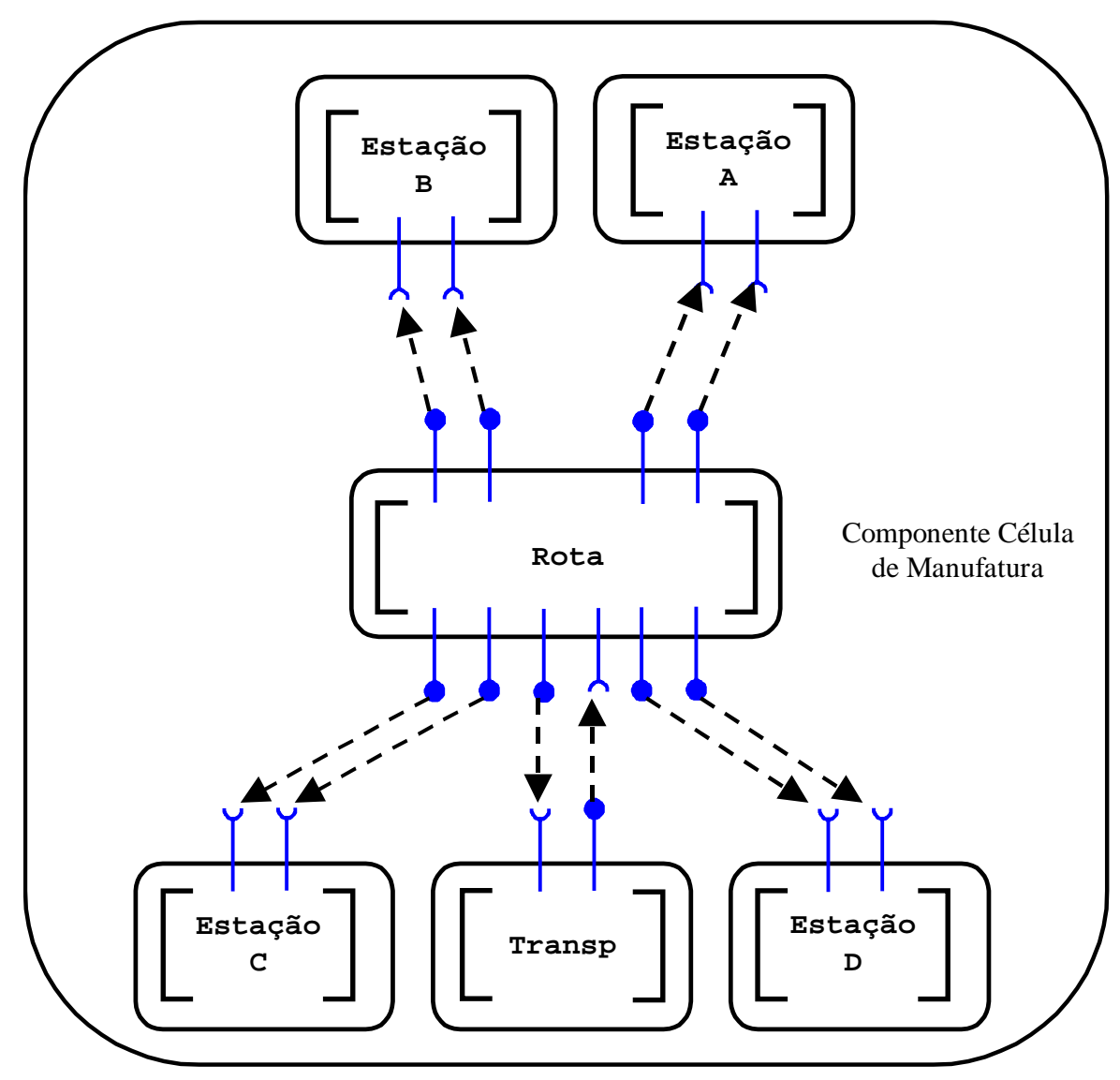

Figura 2.28 - Componente Célula de Manufatura.

\section{Etapa 6 - Geração do aplicativo}

Pela simplicidade do exemplo, o aplicativo é o próprio componente apresentado na Figura 2.28. No capítulo 3 é apresentado um estudo de caso onde um aplicativo é gerado a partir da união vários componentes.

\subsection{Síntese do capítulo}

Neste capítulo apresentou-se a Rede de Petri (RdP) (e algumas de suas variações), uma técnica utilizada com sucesso na modelagem e simulação de sistemas produtivos (seção 2.1). Abordou-se também a simulação de RdP de forma paralela e distribuída (seção 2.2). Através dos trabalhos pesquisados, nota-se que tem prevalecido o foco no uso de computadores paralelos quando comparado ao uso de um conjunto de computadores ligados em rede trabalhando como se fossem um único computador. Destes trabalhos também se observa que um dos principais problemas enfrentados é o particionamento dos modelos, uma vez que este influencia no desempenho da 
simulação. Visando particionar os modelos, na seção 2.3 são apresentados os resultados de uma análise quanto as formas de se realizar a troca de mensagens entre modelos (em RdP). Através desta pesquisa, três diferentes formas se mostraram atrativas: fusão de lugares, fusão de transições e por arcos habilitadores. Estas se sobressaem sobre outras formas pesquisadas por utilizarem um mesmo elemento da RdP como interface, bem como não introduzirem novos elementos na RdP, garantindo que suas propriedades não fossem alteradas.

Como observado na seção 1.2 por Daum e Sargent (1999), Kachitvichyanukul et al. (2001) e Banks et al. (2000), são necessárias pesquisas na área de modelagem e simulação no sentido de se propor técnicas que permitam a modelagem hierárquica de sistemas produtivos bem como a reutilização de modelos. Neste sentido, na seção 2.4 foi proposto um novo método para a modelagem de sistemas produtivos, onde as pesquisas apresentadas nas seções 2.1 a 2.3 serviram de subsídio.

Neste método, adotou-se uma abordagem top-down de compreensão e detalhamento do sistema em estudo, divididas em duas etapas:

Etapa 1 - Definição do problema delimitando o escopo do sistema produtivo em estudo;

Etapa 2 - Detalhamentos sucessivos visando a identificação dos elementos básicos que compõem o sistema e seus relacionamentos.

Na etapa 3, cada um dos elementos básicos obtidos é modelado em RdP. Nesta etapa, cada modelo pode ser validado de forma isolada antes de ser utilizado na composição de novos modelos, mais complexos. Ainda com relação a esta etapa, cada modelo é tratado como uma classe, como na orientação a objetos.

Em seguida adota-se uma abordagem bottom-up de estruturação dos modelos, a qual é arranjada em três etapas:

$>$ Etapa 4 - Criação de objetos, onde um ou mais objetos são gerados a partir de uma mesma classe;

$>$ Etapa 5 - Geração de componentes através da união de dois ou mais objetos com uma finalidade em comum;

Etapa 6 - Geração do aplicativo através da união de componentes. 
Outra contribuição deste capítulo é a apresentação de duas abordagens para o relacionamento entre modelos - (1) estático; e (2) dinâmico - bem como o contexto onde cada uma pode ser melhor utilizada.

O Anexo D apresenta uma contribuição secundária derivada deste capítulo: a utilização do XML para descrever, armazenar e compartilhar de modelos (classes, componentes e aplicativos).

De forma a ilustrar a aplicação do método, na seção 2.5 utilizou-se como exemplo um sistema hipotético de movimentação de materiais. No capítulo 3, o método proposto é aplicado na modelagem de um sistema real. 


\section{ESTUDO DE CASO}

Modela-se neste caso uma Célula de Manufatura da empresa FESTO (FESTO, 2005) (Figura 3.1) e que está instalada e em operação no Departamento de Engenharia Mecatrônica e Sistemas Mecânicos da EPUSP. A escolha deste equipamento como estudo de caso se deu em face aos seguintes fatores:

$>$ acessibilidade, o que permite estudar o seu comportamento, realizando experimentos e, desta forma, permitir o desenvolvimento de modelos detalhados de um sistema real;

$>$ o equipamento ser composto por um conjunto de estações de trabalho (apresentadas e descritas posteriormente) que se comunicam através de uma rede industrial (Profibus);

$>$ os equipamentos utilizados nesta Célula de Manufatura são, na prática, os mesmo utilizados em processos industriais, o que permite considerar que se o método apresentado na seção 2.4 se mostrar eficaz na modelagem desta célula, será eficaz na modelagem de sistemas de maior porte como os encontrados nas empresas;

o sistema supervisório que monitora esta Célula de Manufatura está instalado localmente, porém, utilizando-se as tecnologias disponíveis atualmente para a transmissão de dados via rede de comunicação, é possível a supervisão remota da Célula. No caso de uma instalação industrial, o sistema supervisório poderia não apenas estar relacionado a uma planta produtiva, mas a múltiplas instalações, permitindo, por exemplo, a adoção e execução de políticas globais de planejamento e controle da produção;

este estudo de caso permite mostrar que uma mesma ferramenta pode ser empregada na modelagem simultânea de elementos de natureza diferente: físicos como cilindros pneumáticos e válvulas; software para CLP (Controlador Lógico Programável); software para microcomputadores (para o sistema supervisório, por exemplo);

pretender-se em trabalhos futuros, relacionados ao projeto TIDIA, modalidade KyaTera (FAPESP, 2005), disponibilizar este equipamento para monitoramento e controle de forma remota, ou seja, via internet de alta velocidade (transmissão de dados na ordem de terabps). 
Assim, neste estudo de caso pretende-se demonstrar a efetividade do método proposto na seção 2.4 aplicando-o da modelagem da Célula de Manufatura.

Através da aplicação do método, pretende-se identificar os elementos que compõem a Célula de Manufatura em seus diferentes níveis de abstração, ou seja, partindo-se da Célula de Manufatura como um todo, identificar seus componentes, e os dispositivos que constituem os componentes, bem como as interações que existem nos diferentes níveis de abstração. Ainda, pretende-se demonstrar que com a aplicação do método, elementos com características em comum possam ser representados por um mesmo modelo, e este ser utilizado em diferentes componentes deste sistema.

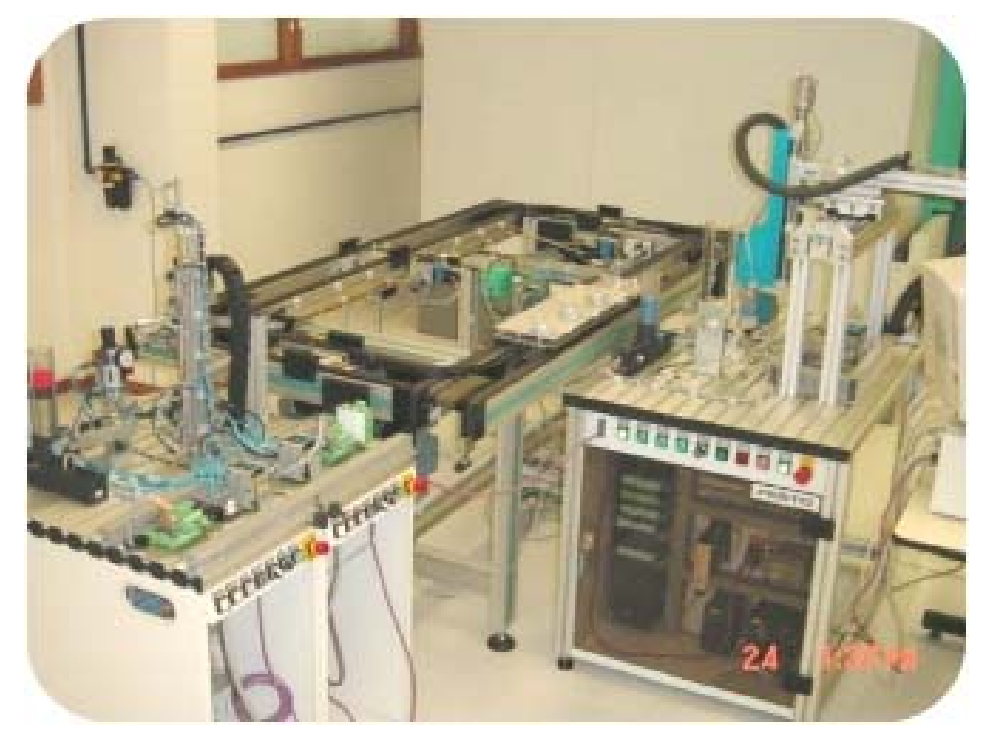

(a)

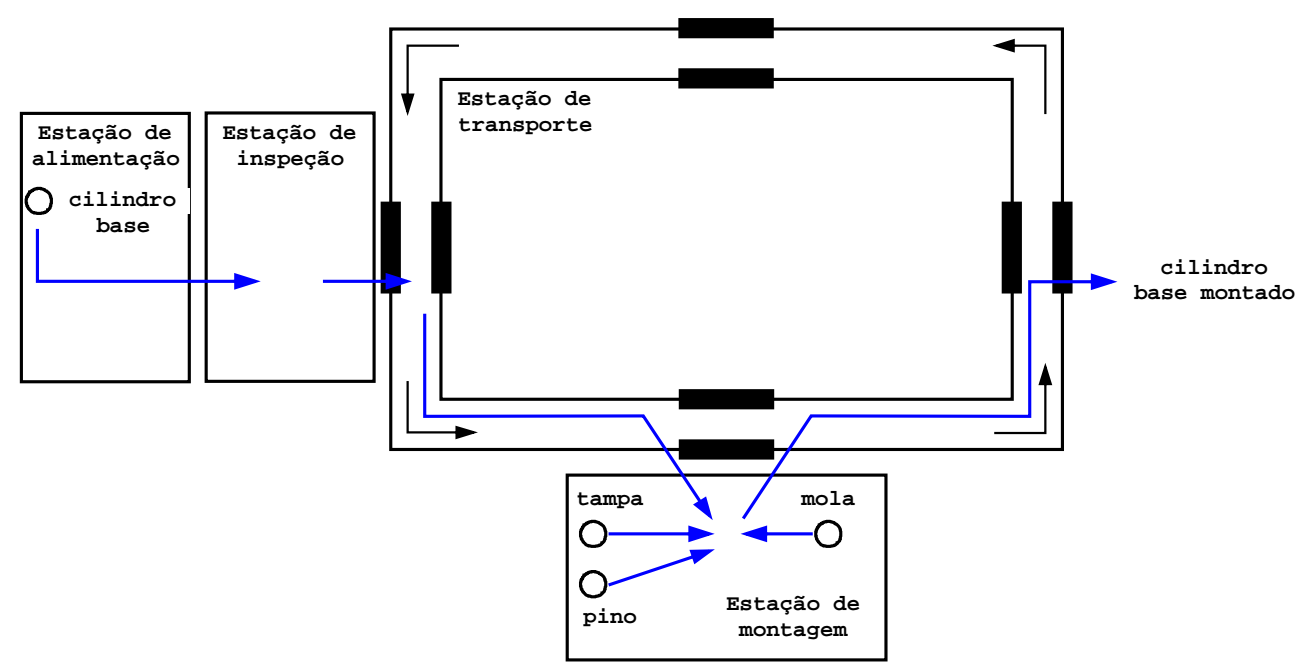

(b)

Figura 3.1 - Célula de Manufatura FESTO: (a) foto da célula; e (b) diagrama com a estrutura da célula. 
A seguir, para ilustrar as principais características do método, um exemplo é apresentado.

\subsection{Exemplo de aplicação do método proposto}

A seguir, as etapas da metodologia apresentada na seção 2.4 são aplicadas na modelagem da Célula de Manufatura da Figura 3.1.

\section{Etapa 1 - Definição do problema delimitando o escopo do sistema em estudo}

A Célula de Manufatura da Figura 3.1 é responsável pela montagem de produtos compostos por quatro partes (Figura 3.2): um cilindro base, uma mola, um pino e uma tampa.

Existem cilindros bases de três diferentes cores: preta, rosa ou prata. Todos os cilindros base são de material plástico, porém o cilindro prata recebe um tratamento superficial que lhe concede propriedades metálicas. Quanto aos pinos, são de duas cores: preto ou prata. Os pinos prateados são montados com cilindros base pretos, enquanto os demais cilindros são montados com pino preto. Molas e tampas são as mesmas à todas as montagens.

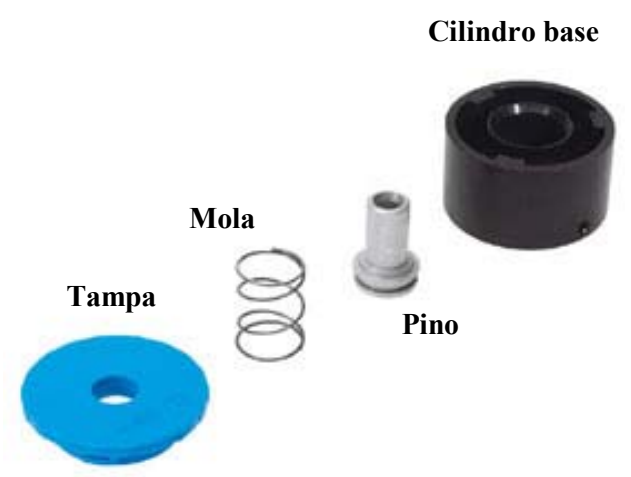

Figura 3.2 - Partes a serem montadas.

A célula de manufatura é composta por quatro estações de trabalho e um sistema supervisório, a saber:

estação de alimentação - que alimenta a estação de inspeção com cilindros base coloridos (a seqüência de alimentação dos diferentes cilindros base é aleatória); 
estação de inspeção - que recebe um cilindro base por vez da estação de alimentação, identifica a cor do cilindro, bem como realiza o controle dimensional deste, descartando-o ou enviando-o para a estação de transporte;

> estação de transporte - esta estação é composta por um conjunto de esteiras e paletes que transportam os cilindros base da estação de inspeção para a estação de montagem, e transportam os produtos montados desta para a saída do sistema;

$>$ estação de montagem - nesta estação são acoplados ao cilindro base a mola, o pino e a tampa, nesta ordem;

sistema supervisório - responsável pelas ordens de produção (número de produtos a serem produzidos) e o monitoramento da localização de cada palete utilizado no transporte dos cilindros ou produtos montados.

\section{Etapa 2 - Detalhamentos sucessivos visando a identificação dos elementos básicos que compõem o sistema e seus relacionamentos}

Com base na estrutura da célula apresentada na Figura 3.1 e do processo de manufatura do produto, pode-se fazer uso do PFS para desenvolver o modelo de funcionamento da célula e suas partes através de detalhamentos sucessivos. A Figura 3.3 apresenta o primeiro nível de detalhamento do sistema, onde a atividade [Célula de Manufatura] é decomposta em quatro sub-atividades: (1) [Sistema supervisório]; (2) [Sistemas de controle]; (3) [Atuadores]; e (4) [Fluxo físico e sensores].

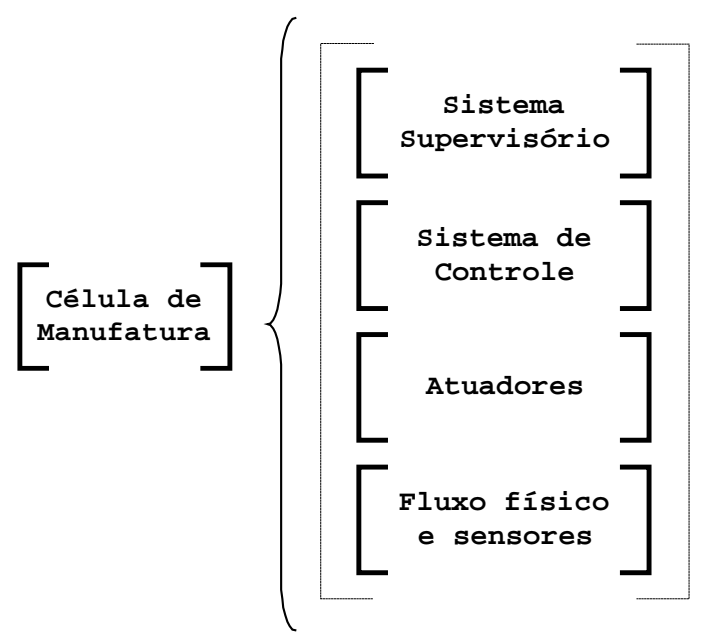

Figura 3.3 - Primeiro nível de detalhamento da Célula de Manufatura. 
O segundo nível de detalhamento é apresentado na Figura 3.4. Nela, cada atividade do PFS é detalhada e os relacionamentos entre elas, tanto em um mesmo nível de atividade como entre os níveis, é explicitado. Desta forma:

[Sistema supervisório] - esta atividade é decomposta na atividade de controle das [Ordens de produção] a serem atendidas, bem como na atividade de [Supervisão do transporte], ou seja, na monitoração da circulação dos paletes. A atividade [Ordens de produção] interage com a atividade de [Controle da estação de alimentação], enquanto a atividade de [Supervisão do transporte] interage com a atividade de [Controle da estação de transporte];

[Sistema de controle] - esta atividade envolve as atividades de controle de cada estação, coletando dados do processo através de sensores e interagindo com este através de seus atuadores;

> [Atuadores] - esta atividade envolve um conjunto de atuadores para cada estação, relacionando-se com esta e seu respectivo sistema de controle;

$>$ [Fluxo físico e sensores] - esta atividade define a seqüência de produção, isto é: [Estação de alimentação] $\rightarrow$ [Estação de inspeção] $\rightarrow$ [Sistema de transporte] $\rightarrow$ [Estação de montagem] $\rightarrow$ [Sistema de transporte] $\rightarrow$ [Saída].

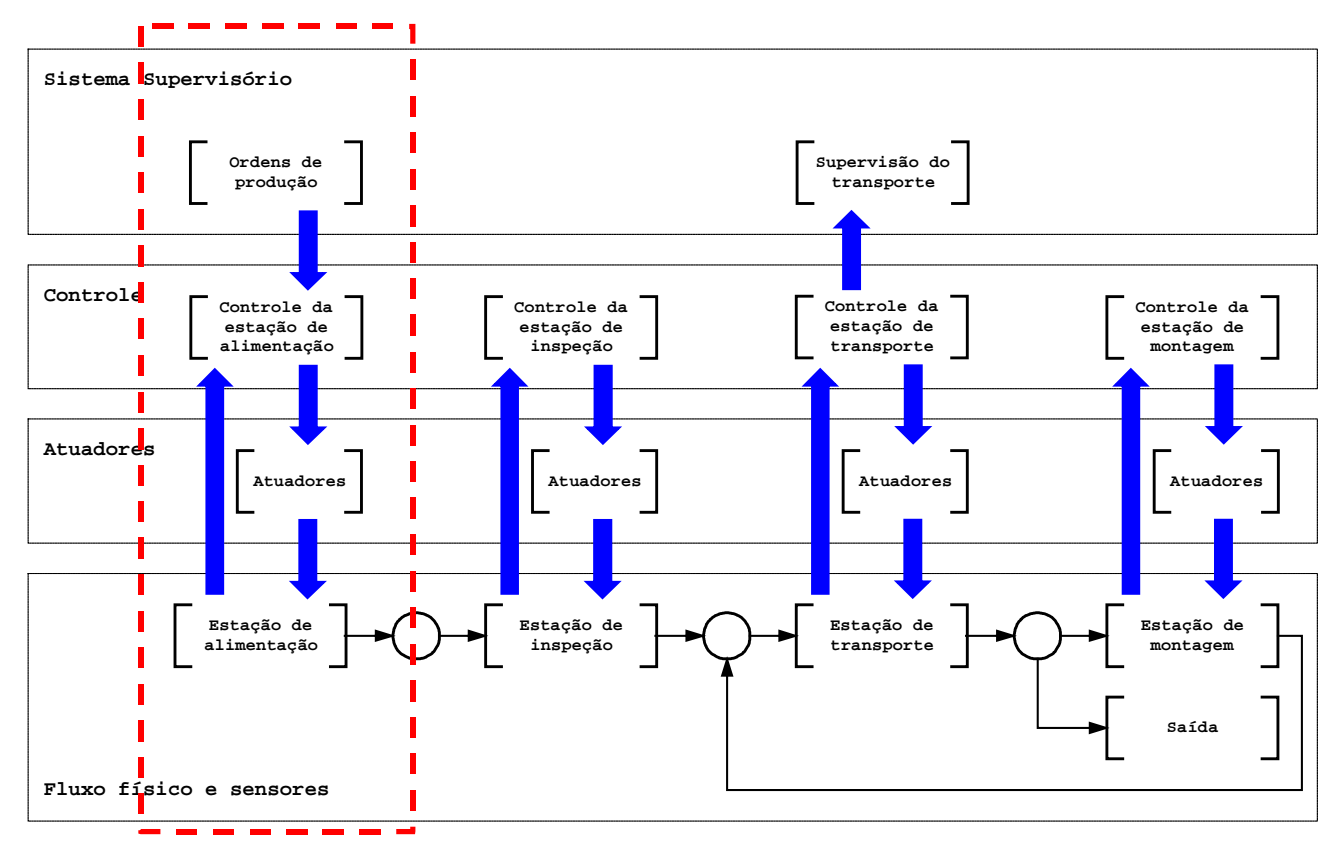

Figura 3.4 - Segundo nível de detalhamento: PFS da Célula de Manufatura. 
Ainda com relação à Figura 3.4, para fins de apresentação, neste capítulo, o processso de detalhamento será aplicado apenas às atividades relacionadas à estação de alimentação. O detalhamento das outras atividades é apresentado no Anexo E.

No terceiro nível de detalhamento são refinadas as atividades de controle da estação de alimentação, assim como dos atuadores. As demais atividades em PFS apresentada na Figura 3.4 não são detalhadas em PFS por serem relativamente simples e, desta forma, já poderem ser modeladas em RdP na Etapa 3.

Na Figura 3.5 é apresentado o detalhamento da atividade [Controle da estação de alimentação]. Neste detalhamento é possível acompanhar a seqüência com que as sub-atividades ocorrem. Primeiro tem-se a sub-atividade [Recebe ordem de produção] e em seguida a sub-atividade [Retira cilindro base do buffer] com o uso de um atuador (pneumático). Em seguida, enquanto se tem a sub-atividade [Recolhe o atuador], realiza-se a sub-atividade [Movimentação do cilindro base para a estação de inspeção], que consiste em [Posiciona o braço (basculante) sobre a estação de alimentação], [Liga a ventosa], [Posiciona o braço (basculante) sobre a estação de inspeção], e por fim [Desliga a ventosa].

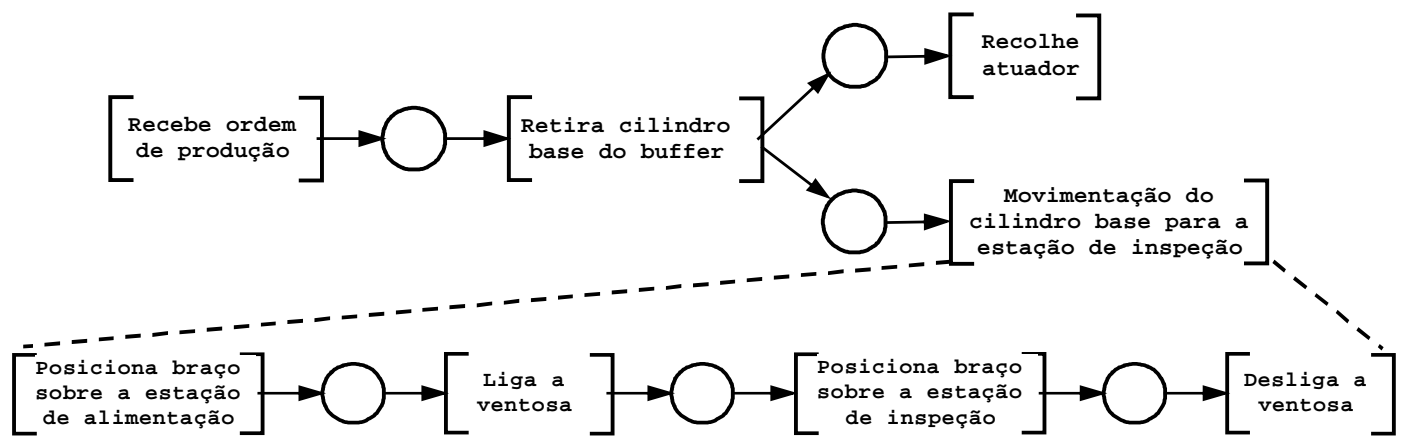

Figura 3.5 - Terceiro nível de detalhamento: PFS da atividade [Controle da estação de alimentação].

Na Figura 3.6 são apresentadas as atividades dos elementos do sistema produtivo que fazem parte da atividade [Atuadores]. São estes: [Eletro válvula], [Cilindro pneumático], [Ventosa] e [Motor de passo] ${ }^{13}$.

${ }^{13} \mathrm{O}$ motor de passo é usado apenas nos modelos apresentados no Anexo E, porém, por ser um modelo simples e para não ficar separado dos demais, este é apresentado neste capítulo. 


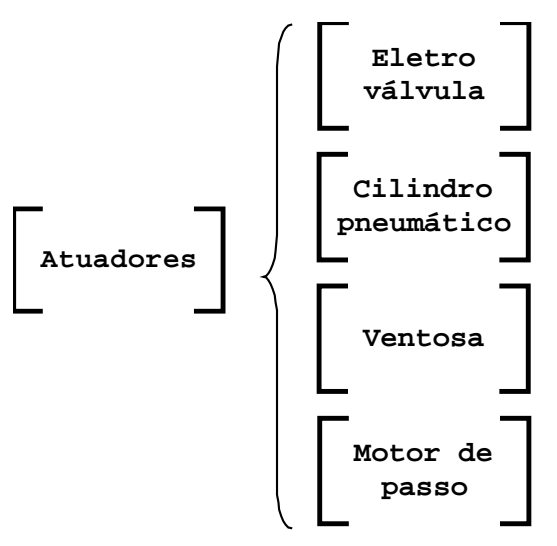

Figura 3.6 - Terceiro nível de detalhamento: PFS da atividade [Atuadores].

\section{Etapa 3 - Modelagem dos elementos básicos em Redes de Petri (RdP)}

Nesta etapa, os modelos já detalhados com o PFS são refinados utilizando a RdP. Procurando facilitar o acompanhamento do refinamento dos modelos, estes foram agrupados conforme o nível a que pertencem no sistema, ou seja: (1) sistema supervisório; (2) controle; (3) atuadores; e (4) fluxo físico e sensores.

\section{i) Elementos do sistema supervisório}

Apresenta-se na Figura 3.7 o modelo em RdP da atividade [Ordens de produção] (Figura 3.4). Este é um modelo relativamente simples por ser composto por apenas um lugar (L1) que modela o estado “número de peças a serem produzidas” e uma transição (T1) requisitante (azul, conforme nomenclatura adotada no capítulo 2.3) responsável por solicitar ao [Controle da estação de alimentação] a fabricação dos cilíndros.

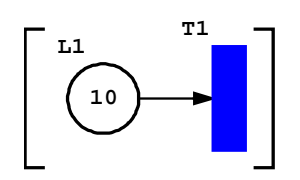

Figura 3.7 - Modelo em RdP lugar-transição da atividade [Ordens de produção].

\section{ii) Elementos do sistema de controle}

A Figura 3.8 apresenta o modelo em RdP lugar-transição da atividade [Controle da estação de alimentação] (Figura 3.5). 


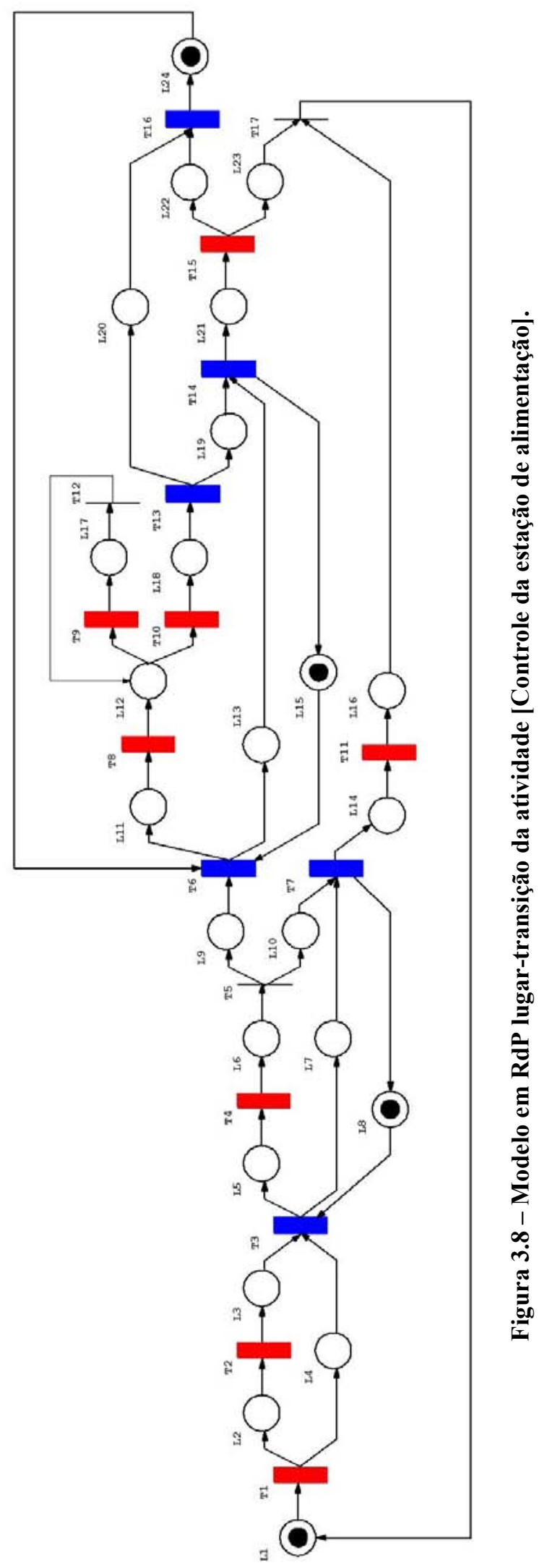


Dada a quantidade de elementos da RdP (lugares e transições) utilizados para descrever as operações de [Controle da estação de alimentação], optou-se descrevêlos na Tabela 3.1.

Tabela 3.1 - Descrição dos elementos do modelo em RdP da atividade [Controle da estação de alimentação].

\begin{tabular}{|c|c|}
\hline Lugar & Descrição \\
\hline L1 & A estação está livre e pronta para produzir \\
\hline $\mathrm{L} 2$ & O controle aguardando o sensor acusar cilindros base no buffer \\
\hline L3 & Foi detectada a presença de cilindros base no buffer \\
\hline L4 & Estado pedido recebido \\
\hline L5 & O atuador responsável por retirar cilindros base do buffer está sendo distendido \\
\hline L6 & O atuador que retira cilindros base do buffer foi totalmente distendido \\
\hline L7 & Válvula está energizada para distender o atuador que retira cilindros base do buffer \\
\hline L8 & Válvula está energizada para recolher o atuador que retira cilindros base do buffer \\
\hline L9 & Lugar auxiliar usado para que as operações sigam em paralelo \\
\hline L10 & Lugar auxiliar usado para que as operações sigam em paralelo \\
\hline L11 & $\begin{array}{l}\text { O atuador de transporte de cilindros base da estação de alimentação para a estação de } \\
\text { inspeção está sendo posicionado sobre a estação de alimentação }\end{array}$ \\
\hline L12 & O atuador usado no transporte está sobre a estação de alimentação \\
\hline L13 & $\begin{array}{l}\text { Válvula está energizada para posicionar o atuador que transporta cilindros base para a } \\
\text { inspeção sobre a estação de alimentação }\end{array}$ \\
\hline L14 & O atuador responsável por retirar cilindros base do buffer está sendo recolhido \\
\hline L15 & Válvula está energizada para posicionar o atuador de transporte sobre a estação de inspeção \\
\hline L16 & $\mathrm{O}$ atuador que retira cilindros base do buffer foi totalmente recolhido \\
\hline L17 & $\begin{array}{l}\text { A estação de inspeção foi informada que o atuador de transporte está sobre a estação de } \\
\text { alimentação }\end{array}$ \\
\hline L18 & A estação de inspeção está livre \\
\hline L19 & Lugar auxiliar \\
\hline L20 & Válvula que liga a ventosa está energizada \\
\hline L21 & O atuador de transporte está sendo posicionado sobre a estação de inspeção \\
\hline L22 & O atuador usado no transporte está sobre a estação de inspeção \\
\hline L23 & Lugar auxiliar com o mesmo significado de L22 \\
\hline L24 & Válvula que liga a ventosa está desenergizada \\
\hline Transição & Descrição \\
\hline T1 & Transição requisitada que representa o recebimento de uma ordem de produção \\
\hline $\mathrm{T} 2$ & $\begin{array}{l}\text { Transição requisitada que representa a confirmação, através de sensor, da presença de } \\
\text { cilindros base no buffer }\end{array}$ \\
\hline T3 & $\begin{array}{l}\text { Transição requisitante que representa a ordem para distender o atuador que retira cilindros } \\
\text { base do buffer }\end{array}$ \\
\hline T4 & $\begin{array}{l}\text { Transição requisitada que representa a confirmação, através de sensor, do cilindro base já } \\
\text { posicionado }\end{array}$ \\
\hline T5 & Transição auxiliar para paralelizar as operações \\
\hline T6 & $\begin{array}{l}\text { Transição requisitante que representa a ordem para posicionar sobre a estação de } \\
\text { alimentação o atuador que transporta cilindros base }\end{array}$ \\
\hline T7 & $\begin{array}{l}\text { Transição requisitante que representa a ordem para recolher o atuador que retira cilindros } \\
\text { base do buffer }\end{array}$ \\
\hline T8 & $\begin{array}{l}\text { Transição requisitada que indica, através de sensor, que o atuador de transporte está sobre a } \\
\text { estação de alimentação }\end{array}$ \\
\hline T9 & $\begin{array}{l}\text { Transição requisitada que indica para a estação de inspeção que o atuador de transporte está } \\
\text { sobre a estação de alimentação }\end{array}$ \\
\hline T10 & Transição requisitada que representa a estação de inspeção livre \\
\hline
\end{tabular}


Tabela 3.1 - Descrição dos elementos do modelo em RdP da atividade [Controle da estação de alimentação] (continuação).

\begin{tabular}{|l|l|}
\hline Transição & Descrição \\
\hline T11 & $\begin{array}{l}\text { Transição requisitada que indica, através de sensor, que o atuador que retira peças do buffer } \\
\text { foi recolhido }\end{array}$ \\
\hline T12 & Transição auxiliar \\
\hline T13 & $\begin{array}{l}\text { Transição requisitante que representa a ordem para posicionar sobre a estação de inspeção o } \\
\text { atuador que transporta cilindros base }\end{array}$ \\
\hline T14 & $\begin{array}{l}\text { Transição requisitante que representa a ordem para posicionar sobre a estação de inspeção o } \\
\text { atuador que transporta cilindros base }\end{array}$ \\
\hline T15 & $\begin{array}{l}\text { Transição requisitada que indica, através de sensor, que o atuador de transporte está sobre a } \\
\text { estação de inspeção }\end{array}$ \\
\hline T17 & Transição auxiliar que restitui o controle da estação de alimentação ao seu estado inicial \\
\hline
\end{tabular}

\section{iii) Elementos dos atuadores}

Neste item são apresentados os modelos dos atuadores, que compreendem as [Eletro-válvula] (Figura 3.9 e Tabela 3.2), [Cilindro pneumático] (Figura 3.10 e

Tabela 3.3), [Ventosa] (Figura 3.11 e Tabela 3.4) e [Motor de passo] (Figura 3.12 e Tabela 3.5).

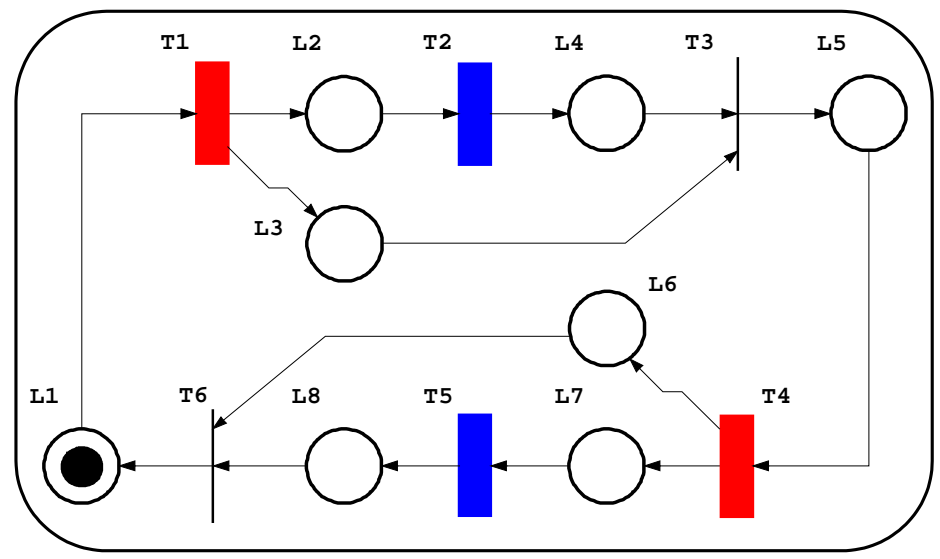

Figura 3.9 - Modelo em RdP lugar-transição da [Eletro-válvula].

Tabela 3.2 - Descrição dos elementos do modelo em RdP da [Eletro-válvula].

\begin{tabular}{|l|l|}
\hline Lugar & Descrição \\
\hline L1 & Eletro-válvula energizada \\
\hline L2 & Pressurizando linha que distende o cilindro pneumático \\
\hline L3 & Energizando eletro-válvula no sentido “distende cilindro pneumático” \\
\hline L4 & Linha que distende o cilindro pneumático pressurizada \\
\hline L5 & Eletro-válvula energizada \\
\hline L6 & Energizando eletro-válvula no sentido “recolhe cilindro pneumático” \\
\hline L7 & Pressurizando linha que recolhe o cilindro pneumático \\
\hline L8 & Linha que recolhe o cilindro pneumático pressurizada \\
\hline Transição & Descrição \\
\hline T1 & $\begin{array}{l}\text { Transição requisitada que representa a energização da eletro-válvula para que esta distenda o } \\
\text { cilindro pneumático }\end{array}$ \\
\hline T2 & $\begin{array}{l}\text { Transição requisitante representa a pressurização da linha para que o cilindro pneumático } \\
\text { seja distendido }\end{array}$ \\
\hline
\end{tabular}


Tabela 3.2 - Descrição dos elementos do modelo em RdP da [Eletro-válvula] (continuação).

\begin{tabular}{|l|l|}
\hline Transição & Descrição \\
\hline T3 & $\begin{array}{l}\text { Transição que representa o fim da operação de energização da eletro-válvula para que esta } \\
\text { distenda o cilindro pneumático }\end{array}$ \\
\hline T4 & $\begin{array}{l}\text { Transição requisitada que representa a energização da eletro-válvula para que esta recolha o } \\
\text { cilindro pneumático }\end{array}$ \\
\hline T5 & $\begin{array}{l}\text { Transição requisitante representa a pressurização da linha para que o cilindro pneumático } \\
\text { seja recolhido }\end{array}$ \\
\hline T6 & $\begin{array}{l}\text { Transição que representa o fim da operação de energização da eletro-válvula para que esta } \\
\text { recolha o cilindro pneumático }\end{array}$ \\
\hline
\end{tabular}

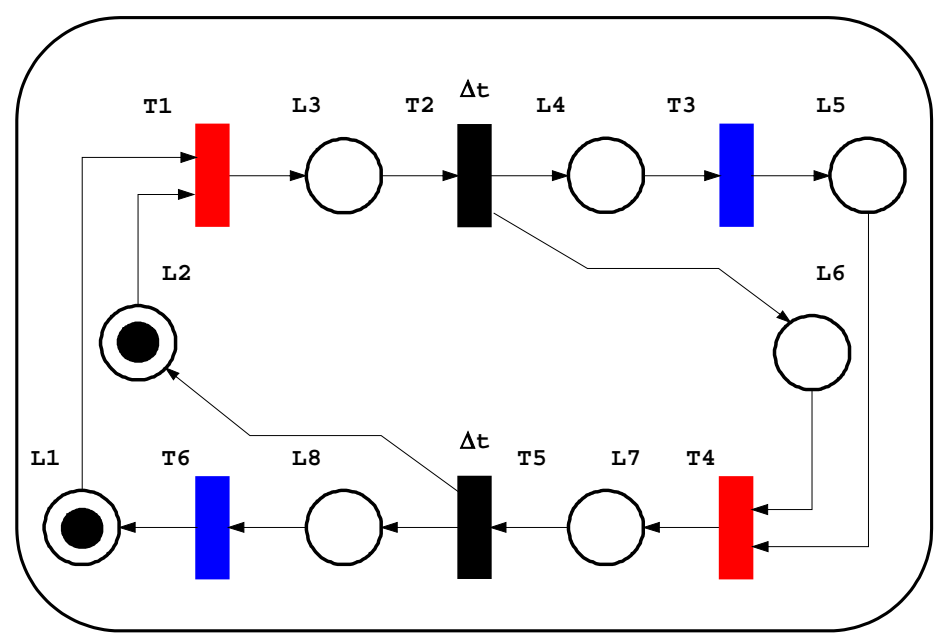

Figura 3.10 - Modelo em RdP lugar-transição do [Cilindro pneumático].

Tabela 3.3 - Descrição dos elementos do modelo em RdP do [Cilindro pneumático].

\begin{tabular}{|l|l|}
\hline Lugar & Descrição \\
\hline L1 & Sinal de que o cilindro foi recolhido foi enviado pelo sensor \\
\hline L2 & Cilindro pneumático recolhido \\
\hline L3 & Cilindro pneumático distendendo \\
\hline L4 & Sensor detectou o cilindro distendido \\
\hline L5 & Sinal de que o cilindro foi distendido foi enviado pelo sensor \\
\hline L6 & Cilindro pneumático distendido \\
\hline L7 & Cilindro pneumático recolhendo \\
\hline L8 & Sensor detectou o cilindro recolhido \\
\hline Transição & Descrição \\
\hline T1 & $\begin{array}{l}\text { Transição requisitada que representa a pressurização da linha que distende o cilindro } \\
\text { pneumático }\end{array}$ \\
\hline T2 & Transição temporizada que representa o tempo de distenção do cilindro pneumático \\
\hline T3 & $\begin{array}{l}\text { Transição requisitante que representa ou a influência do cilindro distendido sobre a planta ou } \\
\text { um sensor fim de curso acoplado ao cilindro }\end{array}$ \\
\hline T4 & $\begin{array}{l}\text { Transição requisitada que representa a pressurização da linha que recolhe o cilindro } \\
\text { pneumático }\end{array}$ \\
\hline T5 & Transição temporizada que representa o tempo de recolhimento do cilindro pneumático \\
\hline T6 & $\begin{array}{l}\text { Transição requisitante que representa ou a influência do cilindro recolhido sobre a planta ou } \\
\text { um sensor fim de curso acoplado ao cilindro }\end{array}$ \\
\hline
\end{tabular}




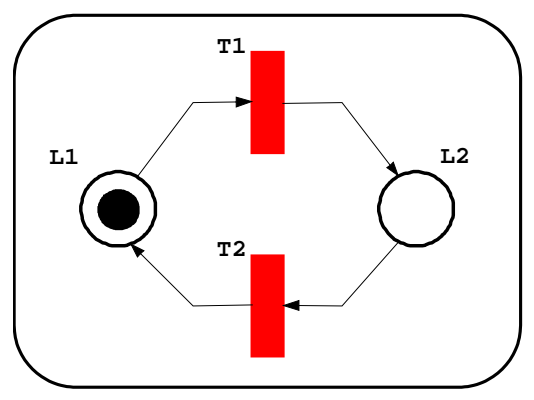

Figura 3.11 - Modelo em RdP lugar-transição da [Ventosa].

Tabela 3.4 - Descrição dos elementos do modelo em RdP da [Ventosa].

\begin{tabular}{|l|l|}
\hline Lugar & Descrição \\
\hline L1 & Ventosa desligada \\
\hline L2 & Ventosa ligada \\
\hline Transição & Descrição \\
\hline T1 & Transição requisitada que representa o comando para ligar a ventosa \\
\hline T2 & Transição requisitada que representa o comando para desligar a ventosa \\
\hline
\end{tabular}

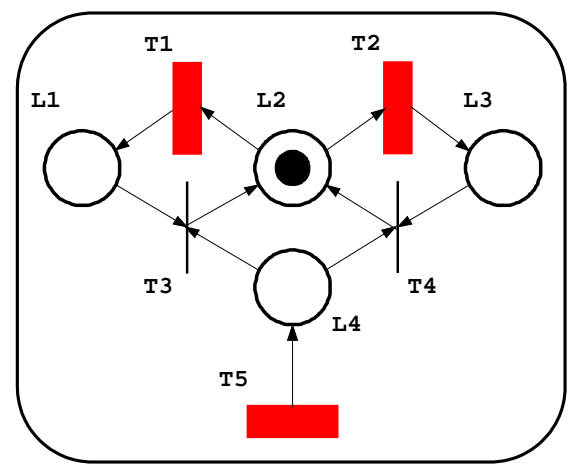

Figura 3.12 - Modelo em RdP lugar-transição do [Motor de passo].

Tabela 3.5 - Descrição dos elementos do modelo em RdP do [Motor de passo].

\begin{tabular}{|l|l|}
\hline Lugar & Descrição \\
\hline L1 & Motor ligado no sentido anti-horário \\
\hline L2 & Motor desligado \\
\hline L3 & Motor ligado no sentido horário \\
\hline L4 & Recebido comando para desligar o motor \\
\hline Transição & Descrição \\
\hline T1 & Transição requisitada que representa o acionamento do motor no sentido anti-horário \\
\hline T2 & Transição requisitada que representa o acionamento do motor no sentido horário \\
\hline T3 & Transição requisitada que representa o recebimento de um comando para desligar o motor \\
\hline
\end{tabular}

\section{iv) Elementos do fluxo físico e sensores}

Neste item são apresentados os modelos relativos ao fluxo físico das peças (cilindro base, mola, pino e tampa ${ }^{14}$ ) e sensores conforme apresentado na Figura 3.4. Ainda com relação à Figura 3.4, este nível é composto pelas atividades [Estação de

\footnotetext{
${ }^{14}$ Mola, pino e tampa são utilizados na estação de montagem e, portanto, tratados no Anexo E.
} 
alimentação], que corresponde ao modelo do fluxo de cilindros base na estação de alimentação e é apresentado na Figura 3.13, com a descrição de seus elementos na Tabela 3.6.

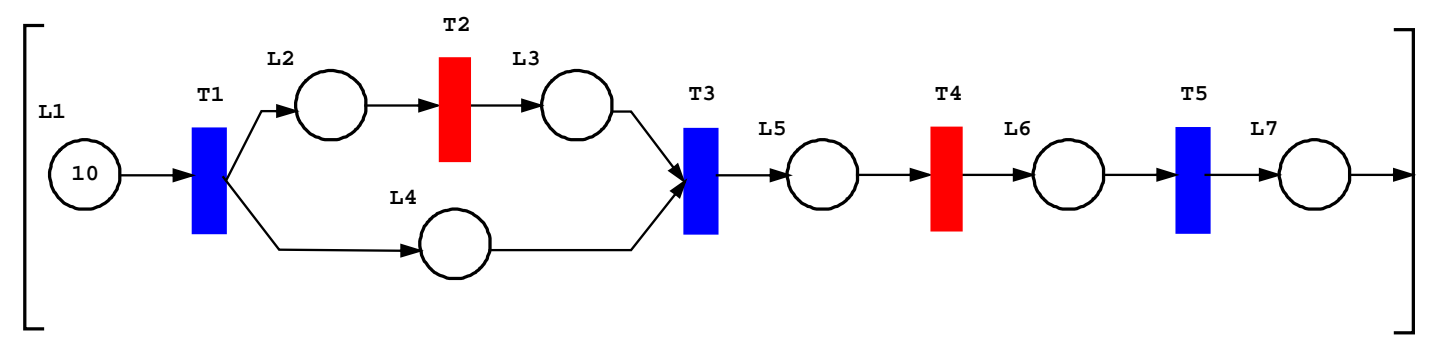

Figura 3.13 - Modelo em RdP colorida da atividade [Estação de alimentação].

Tabela 3.6 - Descrição dos elementos do modelo em RdP da atividade [Estação de alimentação].

\begin{tabular}{|l|l|}
\hline Lugar & Descrição \\
\hline L1 & Representa o buffer, no caso, contendo 10 cilindros base \\
\hline L2 & Lugar auxiliar sem significado físico \\
\hline L3 & Cilindro base sendo retirado do buffer \\
\hline L4 & Lugar auxiliar sem significado físico \\
\hline L5 & Cilindro base pronto para ser transportado para a estação de inspeção \\
\hline L7 & Cilindro base sendo transportado para a estação de inspeção \\
\hline Transição & Cilindro base na estação de inspeção \\
\hline T1 & $\begin{array}{l}\text { Dransição requisitante que representa o envio de informações quanto à presença de cilindros } \\
\text { base no buffer para o controle da estação de alimentação }\end{array}$ \\
\hline T2 & Transição requisitada que representa a ação do atuador retirando o cilindro base do buffer \\
\hline T3 & $\begin{array}{l}\text { Transição requisitante que representa o sensor confirmando o posicionamento do cilindro } \\
\text { base na posição de transporte }\end{array}$ \\
\hline T4 & $\begin{array}{l}\text { Transição requisitada que representa a ação do atuador que transporta o cilindro base para a } \\
\text { estação de inspeção }\end{array}$ \\
\hline T5 & $\begin{array}{l}\text { Transição requisitante que representa o sensor de fim de curso confirmando que o atuador de } \\
\text { transporte está sobre a estação de inspeção }\end{array}$ \\
\hline
\end{tabular}

\section{Etapa 4 - Criação de objetos}

Nesta etapa as classes definidas na etapa 3 servem de referência para a criação de objetos. A Figura 3.14 ilustra o objeto Ordem_Produção (baseado na classe [Ordens de produção]). A classe [Cilindro Pneumático] serve de base para os objetos Atuador_Buffer_Cilindro_Base e Atuador_Transporte (Figura 3.15), enquanto a classe [Eletro-válvula] serve de base para os objetos Válvula_Ventosa, Válvula_Buffer_Cilindro_Base e Válvula_Transporte (Figura 3.16). 


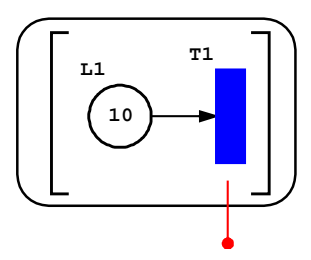

Figura 3.14 - Objeto Ordem_Produção gerado a partir da classe [Ordens de produção].

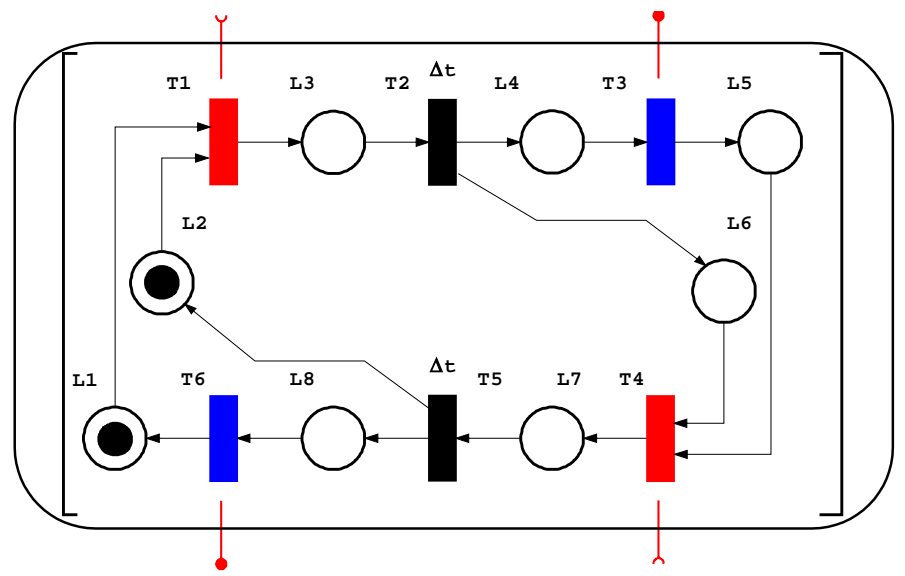

Figura 3.15 - Objetos Atuador_Buffer_Cilindro_Base e Atuador_Transporte gerados a partir da classe [Cilindro pneumático].

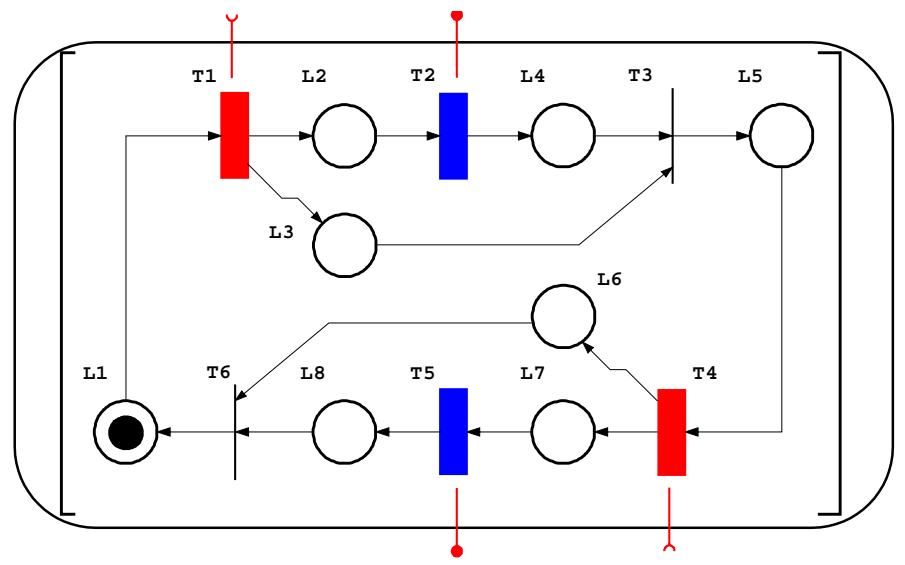

Figura 3.16 - Objetos Válvula_Ventosa, Válvula_Buffer_Cilindro_Base e Válvula_Transporte gerados a partir da classe [Eletro-válvula].

A Figura 3.17 ilustra o objeto Ventosa, baseado na classe de mesmo nome. Os objetos Controle_Alimentação (Figura 3.18) e Planta_Alimentação (Figura 3.19) se baseiam, respectivamente, nas classes [Controle da estação de alimentação] e [Estação de alimentação]. 


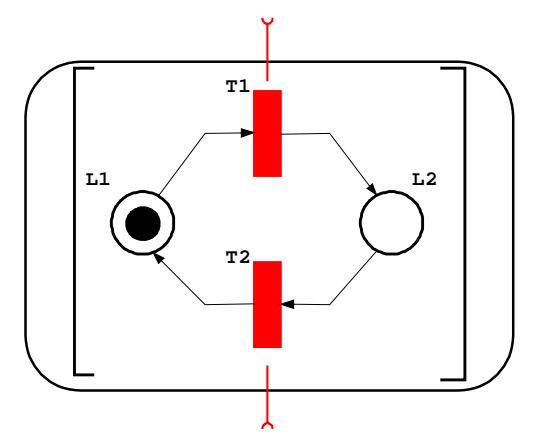

Figura 3.17 - Objeto Ventosa gerado a partir da classe [Ventosa].

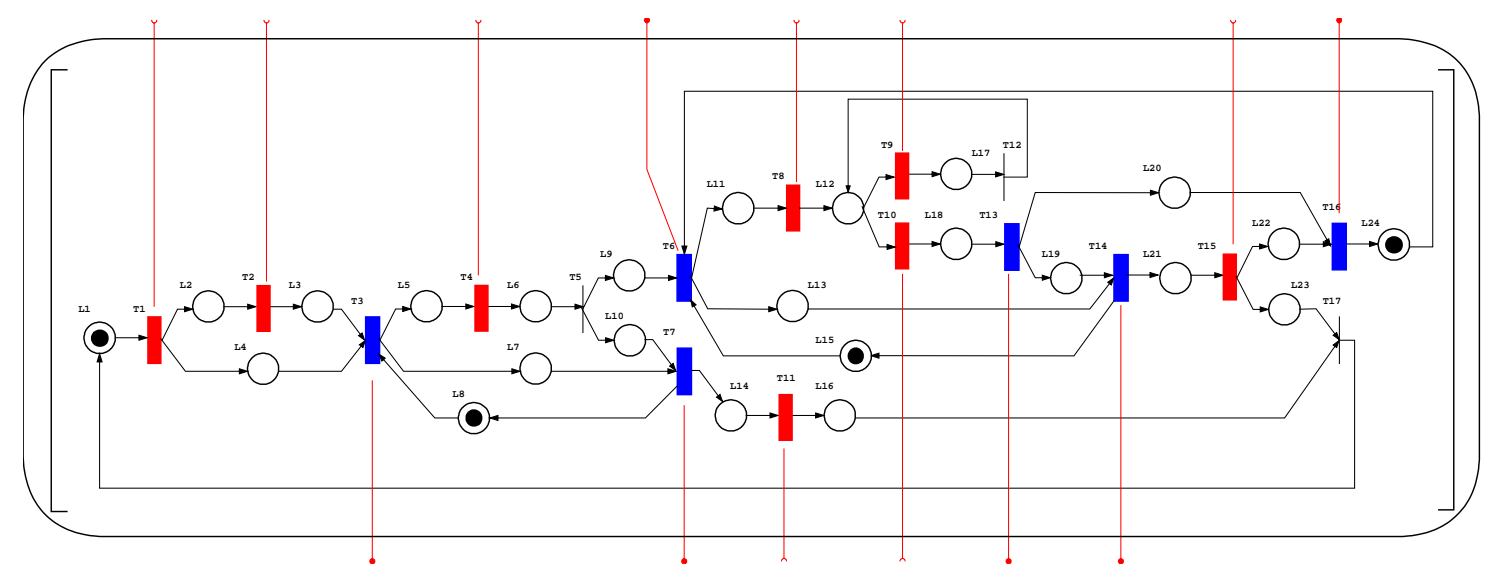

Figura 3.18 - Objeto Controle_Alimentação gerado a partir da classe [Controle da estação de alimentação].

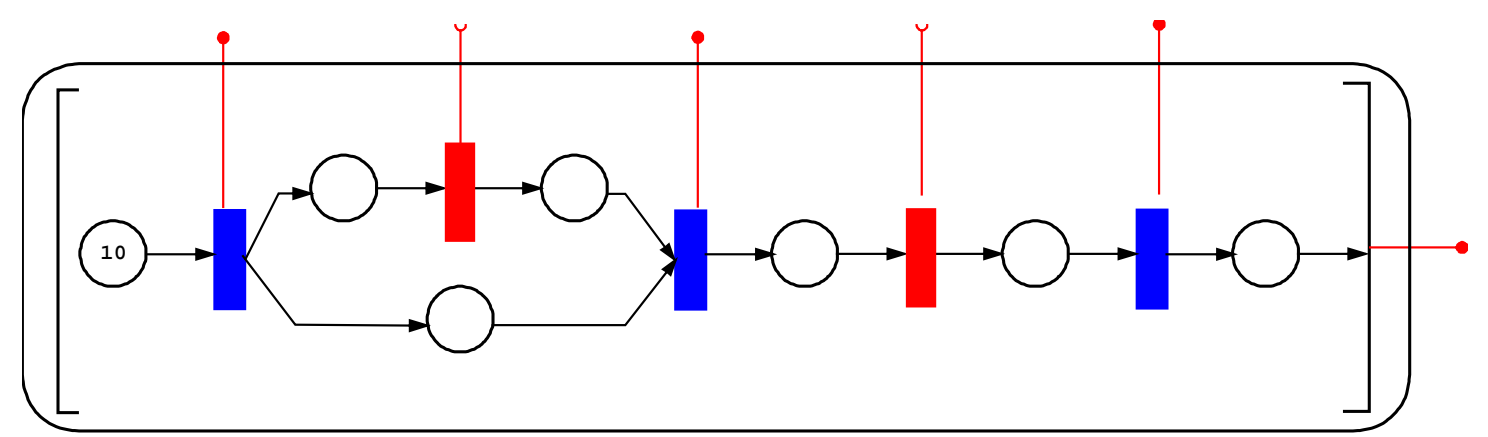

Figura 3.19 - Objeto Planta_Alimentação gerado a partir da classe [Estação de alimentação].

\section{Etapa 5 - Geração de componentes}

Os objetos obtidos na etapa 4 são usados para compor os componentes. Neste estudo de caso, como parte dos modelos estão no Anexo E, serão considerados apenas os modelos deste capítulo para a composição dos componentes e do aplicativo. Assim, sendo, a Figura 3.20 apresenta o componente “Sistema Supervisório Ordem”, composto pelo objeto Ordem_Produção. Por se tratar de um software de acompanhamento das operações da Célula de Manufatura, constituindo-se numa interface entre esta e o usuário, este foi componentizado isoladamente. Ainda, devido à evolução dos 
protocolos de comunicação, o "Sistema Supervisório Ordem” pode ser localmente ou remotamente conectado à Célula de Manufatura, corroborando a componentização adotada.

Na Figura 3.21 apresenta-se o componente "Alimentação" composto pelo objeto Controle_Alimentação. Como critério de componentização, levou-se em consideração que este modelo dê origem a um programa em linguagem de CLP (Controlador Lógico Programável), a ser alocado ao CLP que controla a sua respectiva estação. Assim, com a modelagem do aplicativo, será possível evidenciar o fluxo de sinais entre a planta e cada CLP, bem como entre os CLPs.

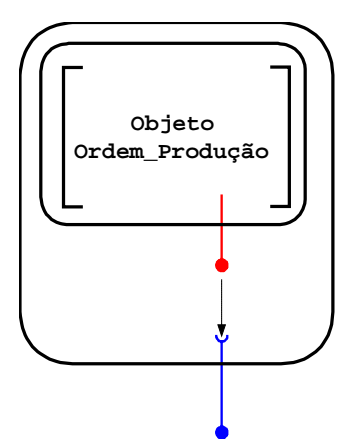

Figura 3.20 - Componente Sistema Supervisório Ordem composto pelo objeto Ordem_Produção.

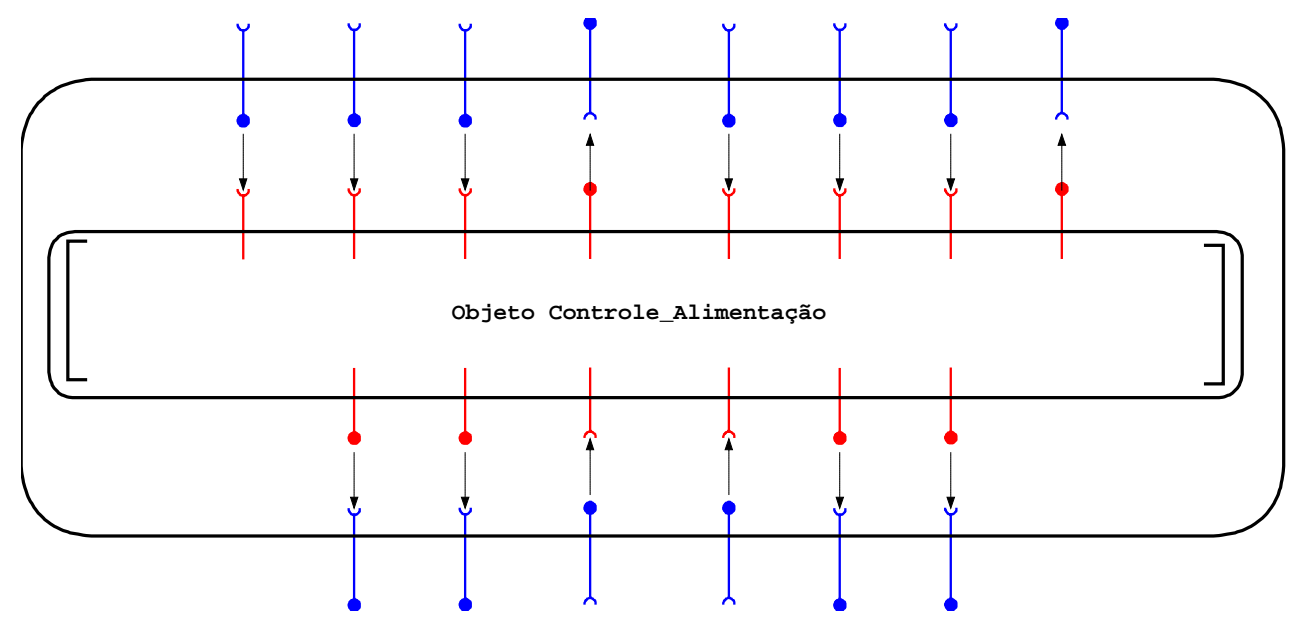

Figura 3.21 - Componente Alimentação composto pelo objeto Controle_Alimentação.

Para a componentização da "Planta Alimentação" (Figura 3.22) utilizou-se como critério o fato de seus elementos representarem entidades físicas (montadas juntas) e o fato de se procurar representar o fluxo do cilindro base bem como das demais peças pelas estações da Célula de Manufatura. Sendo assim, o componente "Planta Alimentação" é composto pelos objetos Atuador_Buffer_Cilindro_Base, 
Atuador_Transporte, Válvula_Ventosa, Válvula_Buffer_Cilindro_Base, Válvula_Transporte, Ventosa e Planta_Alimentação.

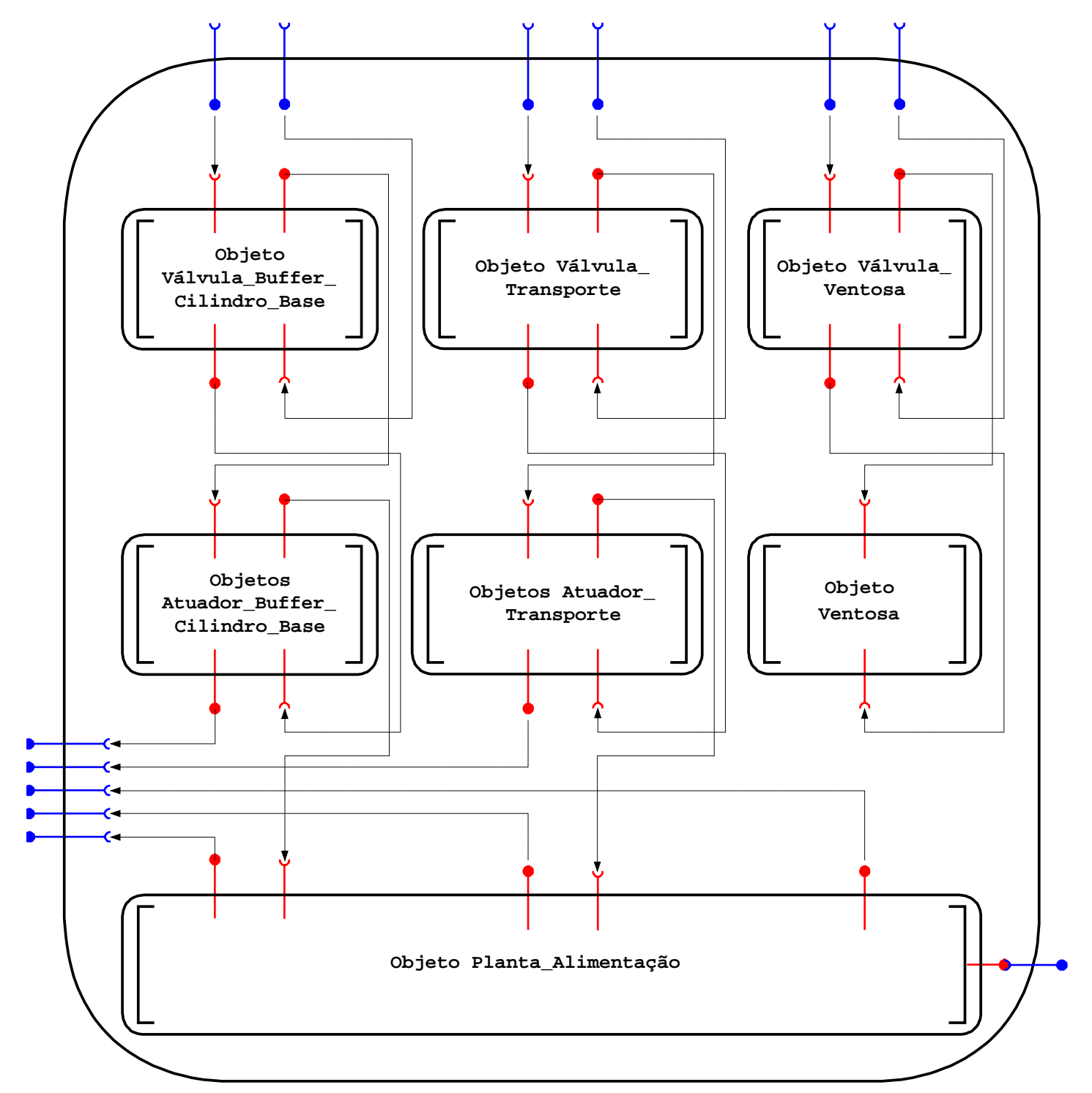

Figura 3.22 - Componente Planta Alimentação.

\section{Etapa 6 - Geração do aplicativo}

Os componentes da etapa 5 são então agrupados de forma a compor o aplicativo “Célula de Manufatura”15. Assim, a Figura 3.23 ilustra o aplicativo "Célula de Manufatura”, seus componentes “Sistema Supervisório Ordem”, “Alimentação” e "Planta Alimentação” e o relacionamento entre eles. 


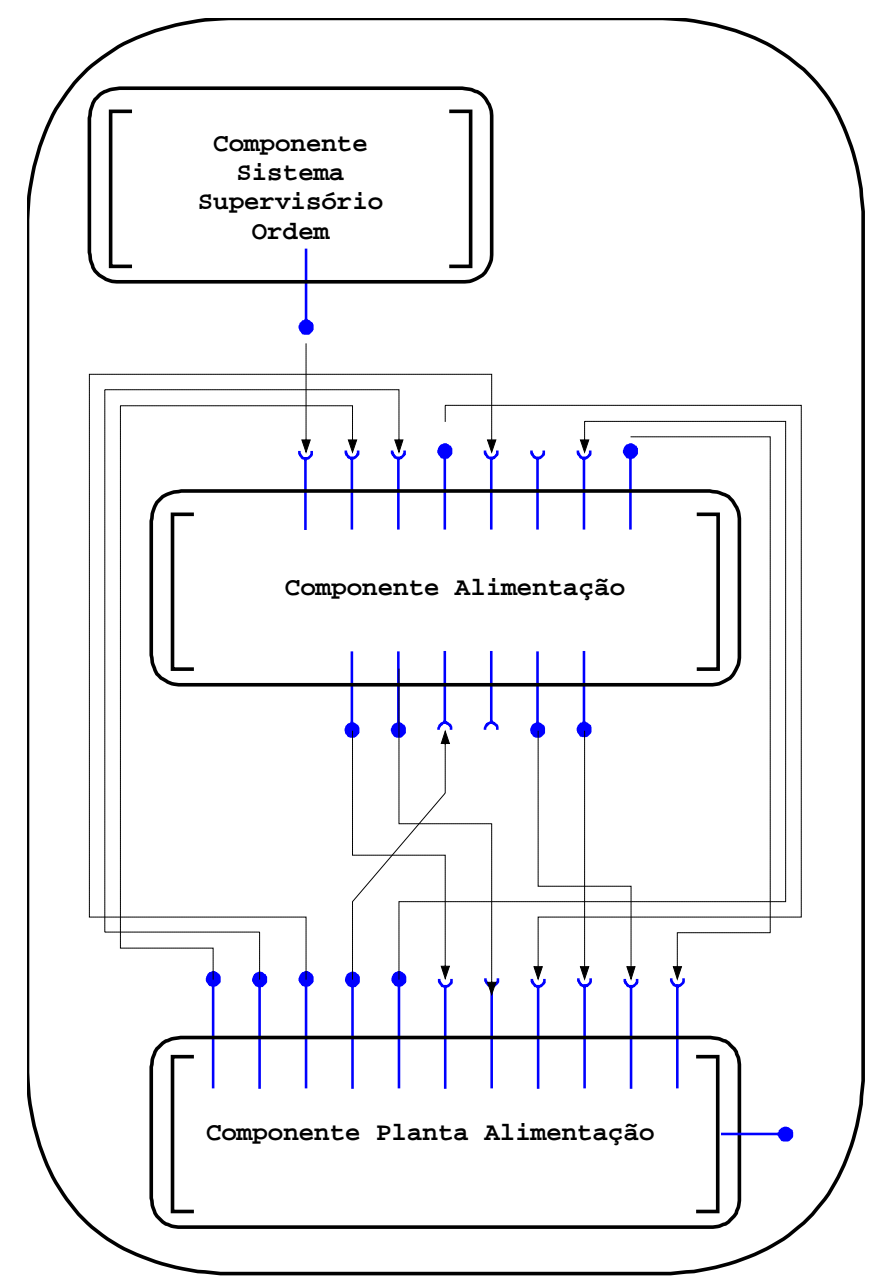

Figura 3.23 - Aplicativo Célula de Manufatura composto pelos componentes Sistema Supervisório Ordem, Alimentação e Planta Alimentação.

\subsection{Síntese do capítulo}

Neste capítulo, empregou-se o método proposto na seção 2.4 na modelagem de um sistema produtivo: a Célula de Manufatura da FESTO e que está instalada e em operação no Departamento de Engenharia Mecatrônica e Sistemas Mecânicos da EPUSP.

Através da aplicação do método, identificou-se os elementos que compõem a Célula de Manufatura em seus diferentes níveis de abstração, ou seja, a Célula de Manufatura como um todo, seus componentes, e os dispositivos que constituem os componentes, bem como as interações que existentes em cada um destes diferentes níveis de abstração.

${ }^{15}$ Apenas a parte referente à estação de alimentação tratada neste capítulo. Os demais componentes da planta são tratados no Anexo E. 
Evidenciou-se ainda a existência de elementos comuns utilizados em diferentes partes do sistema, como por exemplo as válvulas e os cilindros pneumáticos, que foram representados, respectivamente, pelos modelos, em Rede de Petri, das Figuras 3.9 e 3.10. Cada um destes deu origem a diferentes objetos, os quais foram utilizados na constituição do modelo do componente "Planta Alimentação" (Figura 3.22).

Deve-se destacar que podem ser utilizados outros critérios de componentização, diferentes do adotado neste estudo de caso. A experiência do modelista, a necessidade deste com relação ao modelo, bem como outros critérios que forem julgados relevantes podem influir no resultado final. Como exemplo, os sensores e atuadores poderiam ter sido componentizados com seus respectivos sistemas de controle ao invés de tê-los componentizado com a planta. 


\section{MECANISMO DE SINCRONIZAÇÃO DA SIMULAÇÃO}

Uma vez apresentado, no capítulo 2, um novo método para a modelagem de sistemas produtivos passíveis de serem simulados de forma distribuída, na seção 4.1 aprofunda-se o tema de simulação distribuída introduzido na seção 2.2, porém com 0 enfoque nos mecanismo de sincronização de tempo mais conhecidos e utilizados.

Na seção 4.2 é apresentado um protocolo de gerenciamento de redes de comunicação conhecido como Token Ring, o qual serve de base para a proposta deste novo mecanismo de sincronização.

Em seguida é proposto um novo mecanismo de sincronização de processos de simulação distribuída (seção 4.3), inicialmente voltado para o emprego na sincronização da simulação distribuída de modelos em Rede de Petri.

Na seção 4.4 são apresentados os experimentos realizados com o mecanismo proposto. Na seção 4.5 é apresentada a síntese do capítulo com as resultados mais relevantes deste.

\subsection{Simulação distribuída e algoritmos de sincronização de tempo}

Na seção 2.2 abordou-se a simulação distribuída de modelos em Rede de Petri $(\mathrm{RdP})$. Esta seção retoma este assunto, porém tratando das solução utilizadas pelos pesquisadores anteriormente citados (FUJIMOTO, 1990; NICOL; ROY, 1991; CHIOLA; FERSCHA, 1993; KUMAR; KOHLI, 1997; BERALDI; NIGRO, 1999; NKETSA; VALETTE, 2001) e outros em relação à proposta e implementação de algoritmos de sincronização de tempo de simulação.

O algoritmo de sincronização garante que as relações de causalidade do sistema real sejam corretamente reproduzidas na simulação. Com este intuito, os mecanismos conservador e otimista de sincronização foram propostos. Estes mecanismos geralmente assumem que a simulação consiste de uma coleção de processos lógicos (PLs) que se comunicam através da troca de mensagens ou eventos. O objetivo do mecanismo de sincronização é garantir que os PLs processem os eventos na ordem cronológica. Se todos os PLs respeitam a relação de causalidade, a simulação em paralela irá reproduzir os mesmos resultados de uma simulação seqüencial (FUJIMOTO, 1999; POPLAWSKI; NICOL, 1999). 
Cada PL pode ser visto como um simulador seqüencial a eventos discretos. Isto quer dizer que cada PL mantém alguns estados locais e uma lista de eventos ordenados cronologicamente que foi agendada por este PL (inclusive os eventos que este agenda para si próprio), mas que ainda não foram processados. Esta lista de eventos pendentes também deve incluir eventos enviados para este PL por outros PLs. A rotina principal identifica o evento de menor tempo e o executa. Processar um evento significa que uma ou mais variáveis de estado associadas ao PL podem ser modificadas, e o PL pode agendar eventos adicionais para si mesmo ou para outros PLs. Cada PL mantém um relógio para gerenciar seu tempo de simulação que indica o tempo do último evento processado pelo PL. Cada evento agendado pelo PL deve conter um timestamp pelo menos igual ou maior ao tempo indicado neste relógio (FUJIMOTO, 1999).

\section{A) Abordagem conservadora}

A principal atividade de um protocolo conversador é determinar quando é seguro processar um evento, isto é, quando se pode garantir que nenhum evento contendo um timestamp inferior ao relógio do PL será recebido. Um PL não pode processar um evento até que se tenha a garantia que este é seguro (FUJIMOTO, 1999; BERALDI; NIGRO, 1999; CHIOLA; FERSCHA, 1993).

As mensagens que chegam a um PL são armazenadas em uma fila ordenada pela sua ordem cronológica conforme o seu timestamp e não sua ordem efetiva de chegada. Os eventos locais são agendados pelo PL em uma fila. Cada PL possui um relógio cujo tempo corresponde ao do timestamp da mensagem que encabeça a fila, caso a fila contenha mensagens, ou o timestamp da última mensagem, caso esteja vazia (FUJIMOTO, 1999).

Se há relativamente poucos eventos não processados em um PL comparado ao número de PLs que este está conectado, ou se os eventos não processados se tornarem localizados/concentrados em um pequeno grupo de PLs da rede de comunicação, podem ocorrer travamentos. Para que isso não ocorra, é utilizado o artifício de enviar mensagens nulas (CHANDY; MISRA, 1979; MISRA, 1986). Quando um PL finaliza o processamento de um evento ou mensagem nula, ele envia uma mensagem nula para cada um dos PLs que a ele estão conectados, notificando-lhes qual o seu relógio local de simulação (FUJIMOTO, 1999). 


\section{B) Abordagem otimista}

Em contraste com a abordagem conservadora, que previne a violação da relação de causalidade localmente, os métodos otimistas permitem que a violação ocorra, mas estão sujeitas à detecção e recuperação nestes casos (CHIOLA; FERSCHA, 1993; NICOL; ROY, 1991). Esta abordagem oferece duas vantagens importantes sobre as técnicas conservadoras. Primeiro elas podem explorar maiores graus de paralelismo. Se dois eventos podem se afetar mutuamente, mas os cálculos são tais que eles na realidade não o fazem, o mecanismo otimista pode processar os dois concomitantemente, enquanto o método conservador deve executá-los em seqüência. Segundo, o mecanismo conversador geralmente depende de informações específicas da aplicação de forma a poder determinar quais eventos são seguros para serem processados. Apesar o mecanismo otimista poder ser executado de forma mais efetiva de posse desta informação, eles são menos dependentes desta para sua correta execução. Isso permite que a sincronização seja mais transparente para a aplicação, simplificando o desenvolvimento de software. Por outro lado os modelos otimistas possuem maior consumo do computador, acarretando certa degradação do desempenho (BERALDI; NIGRO, 1999; FUJIMOTO, 1999).

O mecanismo Time Warp, proposto por Jefferson (1985), é o método otimista mais conhecido. Quando um PL recebe um evento com timestamp menor a um ou vários eventos já processados, ele desfaz todos os eventos com tempo superior ao do evento recebido e re-processa todos os eventos em ordem cronológica. Desfazer as operações implica em restaurar o estado do PL àquele anterior ao evento recebido (pontos de checagem são usados para isso), e enviar anti-mensagens aos demais PLs. Utiliza-se um relógio virtual global (RVG) como referência para apagar os pontos de checagem gerados num tempo anterior ao RVG, evitando que os eventos seguros ${ }^{16}$ sejam desfeitos, ao mesmo tempo, liberando memória (FUJIMOTO, 1999).

A sincronização é uma área de pesquisa amplamente estudada no campo da simulação paralela discreta. Não há consenso sobre qual abordagem é melhor utilizar. Isto depende da aplicação. No geral, se a aplicação possui boas características de previsão e a aplicação é programada para explorar isso, o método conservador é mais

\footnotetext{
${ }^{16}$ Entende-se por evento seguro aquele que não viola a relação de causalidade.
} 
adequado. De outra forma, o método otimista se mostra mais promissor (FUJIMOTO, 1999).

Com base nas características expostas, pelo fato de que para uma simulação gráfica, onde se apresenta a evolução de uma RdP para o usuário, bem como pelo fato de ter-se considerado a estratégia conservadora mais simples (assim como Poplawski e Nicol (1999)), optou-se por ela para o gerenciamento da simulação de RdP de forma distribuída.

\subsection{Protocolo Token Ring de gerenciamento de rede de comunicação}

Procura-se neste tópico fazer uma breve apresentação sobre o funcionamento das redes de comunicação com protocolo tipo Token Ring e que têm como uma de suas áreas de aplicação a automação da manufatura (GÖHRING; KAUFFELS, 1994). Através deste estudo, pretende-se ressaltar as principais características do protocolo tipo Token Ring, que é utilizado como subsídio para a proposta de um algoritmo para o gerenciamento da simulação de forma distribuída.

Esta é uma técnica de controle de redes de comunicação com topologia em anel proposta originalmente em 1969. É uma técnica baseada na utilização de um token que consiste de uma única série de bits que circula continuamente no anel, passando de uma estação à próxima, controlando o acesso desta estação à rede de comunicação (BIRD, 1995). A esse token existe associada uma prioridade.

Durante a circulação do token (ou mesmo um frame ${ }^{17}$ ) as estações podem fazer a reserva do token, alterando a prioridade deste de $\mathbf{i}$ para $\mathbf{i}+\mathbf{n}^{18}$. Todas as estações no anel podem receber o token, mas apenas uma estação pode transmitir. Isto elimina a possibilidade de colisões de mensagens, pois há apenas um token circulando no anel.

Quando uma estação detecta a passagem do token, se a prioridade do mesmo for menor ou igual à prioridade do frame que deseja enviar, ela captura o token, transforma-o no início do frame a ser transmitido.

\footnotetext{
${ }^{17}$ Frame ou Quadro que é um conjunto de informações de tamanho pré-definido.

${ }^{18}$ A estação que incrementa a prioridade do token de i para i+n é também responsável por decrementála de $\mathbf{i}+\mathbf{n}$ para $\mathbf{i}$.
} 
Supondo a rede de comunicação apresentada na Figura 4.1 onde a estação A deseja transmitir dados para a estação C (GÖHRING; KAUFFELS, 1994; BIRD, 1995): a estação A captura o token e o transforma no início de um frame e o transmite para o anel com o formato: endereço de destino, endereço de origem, os dados, etc;

$>$ os dados são então recebidos pela estação B, que lê o endereço de destino e, como os dados não são para esta estação, devolve-os para o anel sem modificação;

$>$ os dados são recebidos pela estação C que lê o endereço de destino. Como os dados são para ela, esta: (1) copia os dados para o seu buffer interno; (2) devolve os dados para o anel; e (3) marca o frame como “copiado";

$>$ os dados modificados passam pela estação D da mesma forma que pela B;

quando os dados retornam à A, ela lê os endereços de origem e destino. Ela espera o frame voltar pois, como estação de envio corrente, esta deve verificar se os dados foram recebidos com sucesso pela estação de destino, retirando-os do anel em seguida;

durante a passagem do token, as demais estações podem fazer a reserva do token atribuindo ao seu campo de reserva um nível de prioridade. A maior prioridade tem preferência por capturar o token;

$>$ tendo terminado de transmitir seus dados ou esgotado o tempo limite de transmissão concedido a cada estação, esta libera o token alterando a prioridade deste para o nível de prioridade presente no seu campo de reserva.

A rede de comunicação com protocolo tipo Token Ring é monitorada por uma estação denominada monitor ativo, que é usualmente a primeira estação a ser conectada ao anel. Esta estação tem a função de gerar e monitorar o token. As demais estações são introduzidas ao anel como monitores de reserva (em stand by), e se necessário, caso o monitor principal apresente algum problema, uma delas assume imediatamente a função de monitor (GÖHRING; KAUFFELS, 1994). 


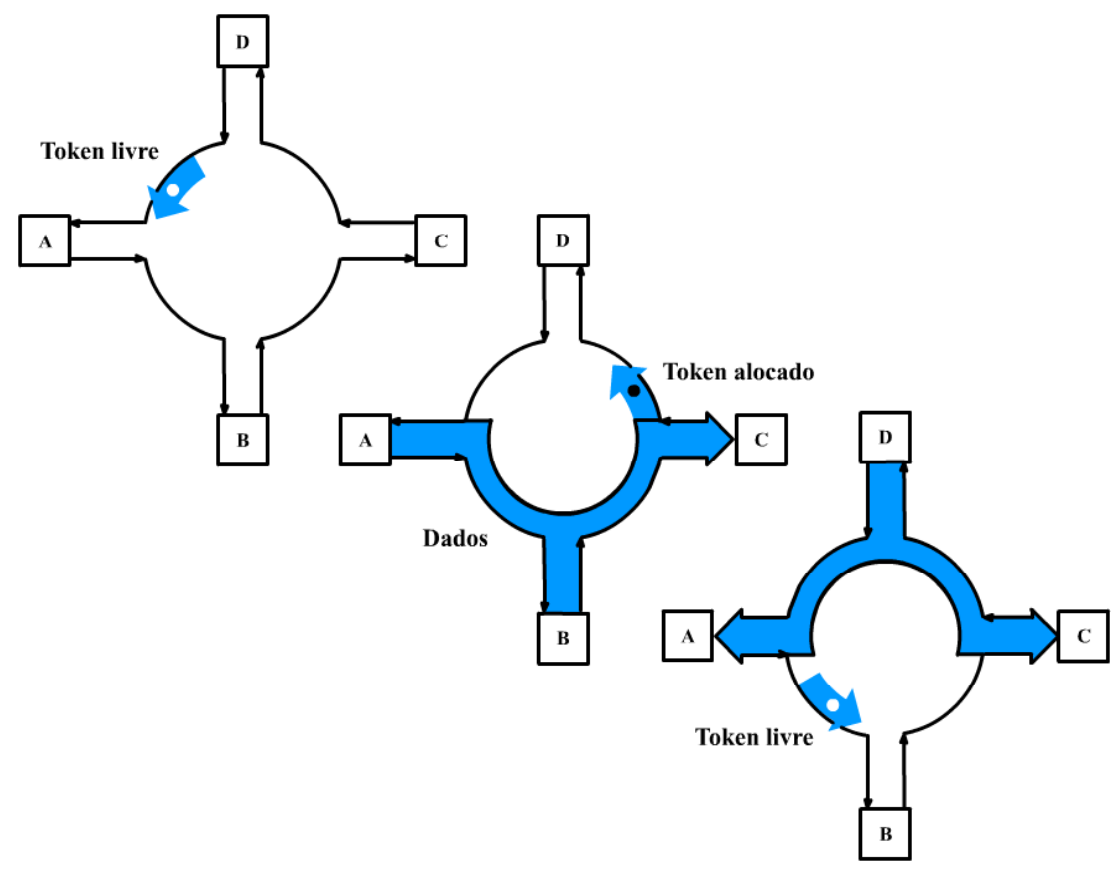

Figura 4.1 - Exemplo de funcionamento de uma rede Token Ring (GÖHRING \& KAUFFELS, 1994).

O monitor verifica os tempos e se assegura que um token ou um frame válido está sempre presente no anel. Ele detecta erros no anel como:

$>$ tokens com falha;

> frames ou tokens prioritários passando mais de uma vez pelo anel - a estação que incrementou sua prioridade apresentou problemas, não decrementando a prioridade do token;

$>$ mais de uma monitor ativo no sistema.

Além destas atribuições, o monitor deve também:

$>$ monitorar o relógio global do anel;

$>$ controlar o tempo de circulação do token (ou frame);

$>$ sincronizar os tempos do anel;

$>$ monitorar a transmissão de tokens e frames;

$>$ reiniciar o anel em caso de falha. 
Algumas falhas detectadas pelo monitor e as soluções adotadas são:

perda de token ou frame: o monitor aguarda o token por um período prédeterminado e, se este não é encontrado, um novo token é gerado. Este tempo é estipulado quando uma nova estação passa a ser monitor;

token ou frame circulando indefinidamente: normalmente a mensagem é removida da rede de comunicação pela estação que a enviou. Desta forma, cada frame deve passar pelo monitor apenas uma vez. Caso seja detectado que este frame ou token tenha passado mais de uma vez, o anel é reiniciado e um novo token é gerado;

duplicação de token ou frame: toda estação ativa verifica o endereço de origem do frame que chega na hora de remove-lo do anel. De acordo com os procedimentos de transmissão, este endereço deve ser seu próprio endereço. Se houver um erro neste endereço, a mensagem não é removida do anel;

> falha do monitor ativo: neste caso, outra estação se torna o monitor, de acordo com alguma regra pré-estabelecida.

Como apresentado, as demais estações são monitores reservas e sua função é verificar o monitor ativo procurando detectar falhas. Sempre que o token passa pelo monitor ativo, este zera um contador. Caso isso não ocorra, as demais estações percebem que o monitor ativo tem problemas (GÖHRING; KAUFFELS, 1994).

O critério para que uma estação se torne o novo monitor ativo pode ser pré-estabelecido através do uso de um algoritmo de "negociação" implementado na rede de comunicação para que as estações restantes elejam o novo monitor ativo.

\subsection{Proposta de um mecanismo para o gerenciamento da simulação distribuída}

Nesta proposta, as estações não estão necessariamente conectadas em uma topologia em anel. No entanto, um anel lógico pode ser construído, imitando o anel físico. Basicamente, cada estação conhece a identidade da próxima estação e o token é enviado entre as estações em uma ordem pré-definida. Simultaneamente, 
mensagens associadas à chamadas de métodos podem ser enviadas pela rede de comunicação (Figura 4.2).

O gerenciamento da simulação de RdP é distribuído entre as estações. O token sincroniza a evolução do tempo de simulação da RdP em todas as estações com base na abordagem conservadora. O token é composto por cinco diferentes campos que podem ser modificados por qualquer uma das estações do anel, a saber:

> campo de identificação da estação (varTokenIdentificacao) - este campo indica a última estação a alterar os valores dos demais campos do token;

> campo de tempo futuro (varTokenTempoFuturo) - este campo contém o tempo de simulação da RdP requisitado pela estação indicada no campo de identificação da estação;

campo de status (varTokenStatus) - este campo contém o status atual da estação indicada no campo de identificação da estação. A Tabela 4.1 apresenta seus possíveis valores;

> campo de instrução (varTokenInstrucao) - este campo é utilizado para enviar instruções para todas as estações, como por exemplo iniciar e parar a simulação da RdP;

> campo de erro (varTokenErro) - este campo é utilizado para gerenciar erros de simulação da RdP, como quando uma estação é desconectada por problemas de comunicação.

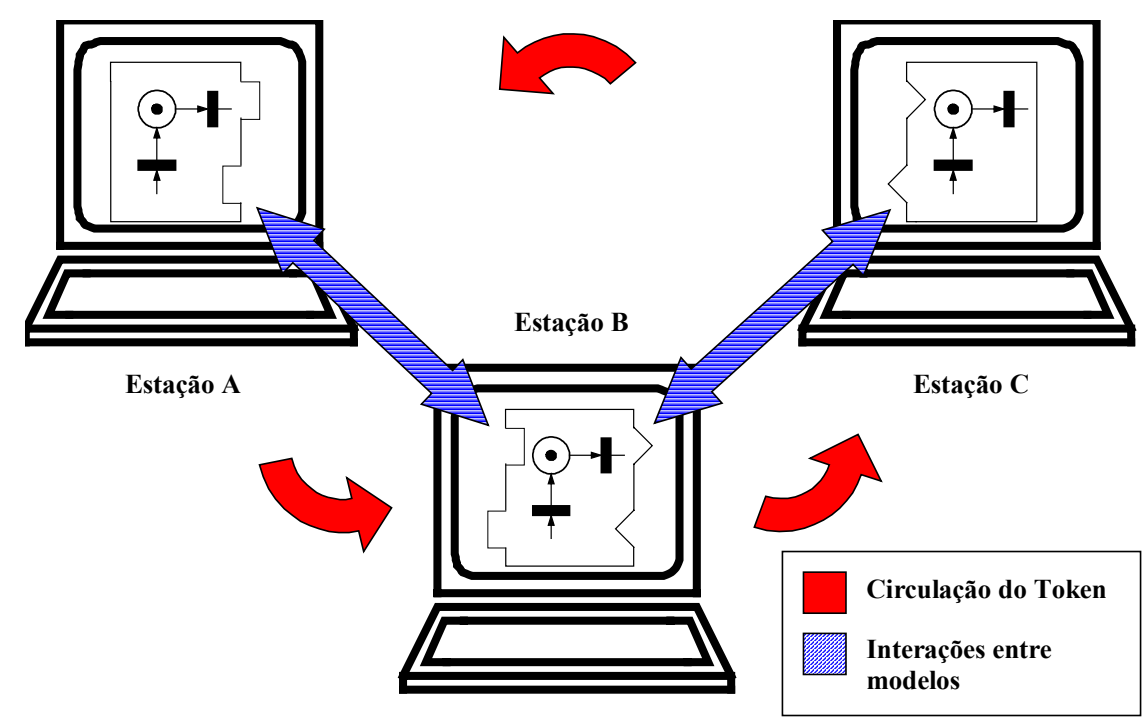

Figura 4.2 - Comunicação entre modelos. 
Tabela 4.1. Possíveis valores para o campo de status

\begin{tabular}{|c|l|}
\hline Valores do campo de status & Significado \\
\hline 0 & --- (nenhuma estação está usando o token) \\
\hline 1 & A estação está verificando o status corrente de outras estações \\
\hline 2 & $\begin{array}{l}\text { A estação está enviando uma ordem para que as demais estações } \\
\text { atualizem seus tempos de simulação com base no campo de tempo futuro }\end{array}$ \\
\hline 3 & A estação entrou em deadlock \\
\hline
\end{tabular}

As Figuras 4.3, 4.4 e 4.5 apresentam, respectivamente, a inicialização das variáveis do ambiente de simulação, o algoritmo de tratamento do token e o algortimo de tratamento dos eventos (o disparo das transições propriamente dito).

// Inicialização das variáveis

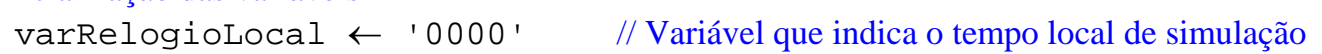

varDeadLock $\leftarrow \odot \quad$ // Variável que indica se a estação está ou não em deadlock

varTemToken $\leftarrow$ False $\quad$ // Variável que indica a presença ou não de token na estação

varTokenIdentificacao $\leftarrow$ ' '

varTokenTempoFuturo $\leftarrow$ '๑७०९'

varTokenstatus $\leftarrow$ ' $\odot$ '

varTokenInstrucao $\leftarrow$ ' 1 '

varTokenErro $\leftarrow$ '

Figura 4.3 - Inicialização das variáveis de simulação.

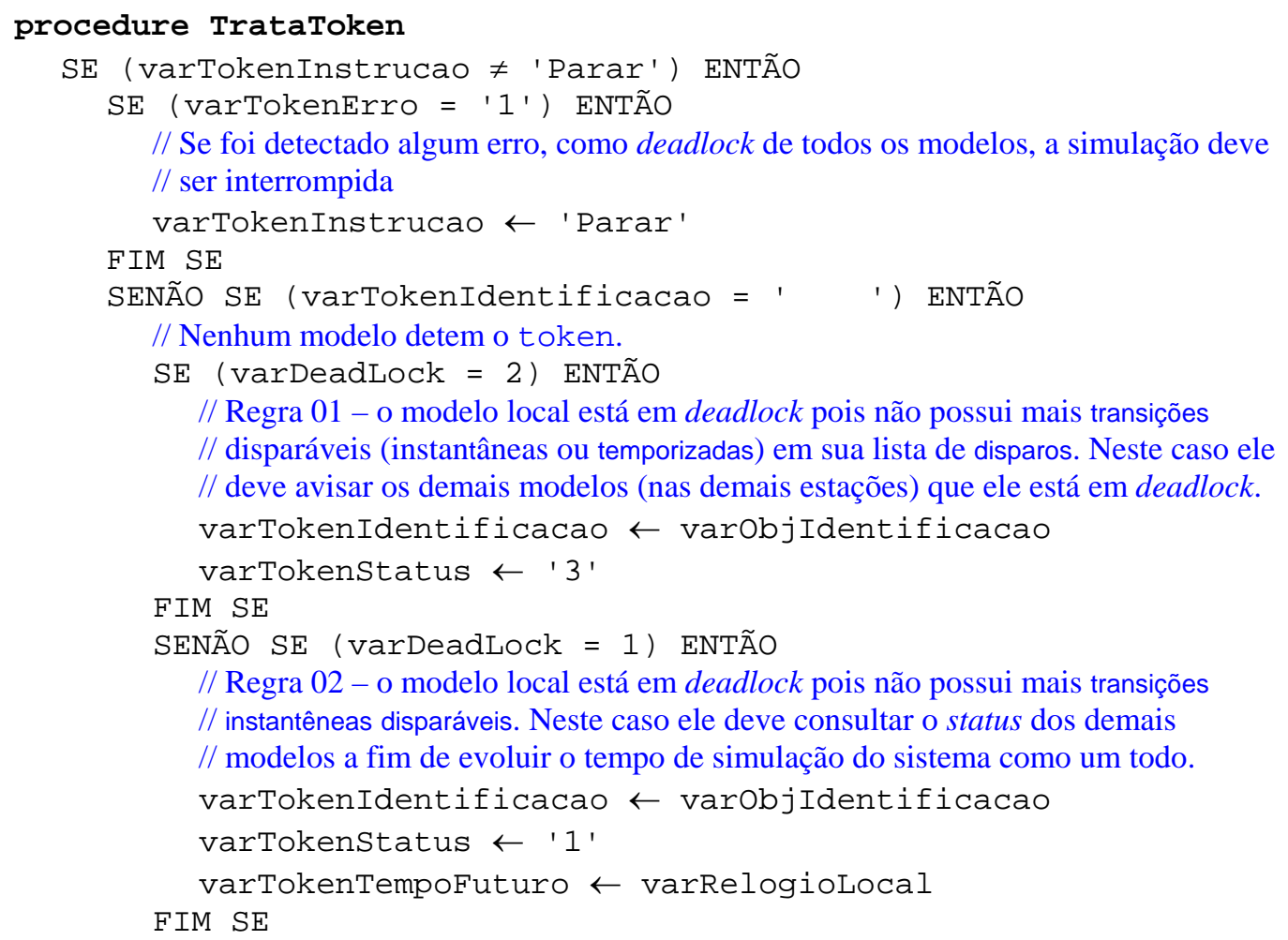

Figura 4.4 - Algoritmo de tratamento do token. 
FIM SE

// O token está sendo usado por um modelo diferente do simulado na presente estação.

SENÃO SE (varTokenIdentificacao $\neq$ varobjIdentificacao) ENTÃO

SE $($ varDeadLock $=0)$ ENTÃO

// Regra 03 - o modelo local não está em deadlock e recebe o token onde um outro // modelo está tentando fazer uma consulta ou avisar que está em deadlock. Neste

// caso ele deve reiniciar os campos do token e informar qual o seu tempo local de

// simulação pois este é o menor tempo entre os modelos.

varTokenIdentificacao $\leftarrow$ ' '

varTokenstatus $\leftarrow$ ' $\odot$ '

varTokenTempoFuturo $\leftarrow$ varRelogioLocal

FIM SE

SENÃO SE ((varDeadLock = 1) E (varTokenstatus = '1') $\mathrm{E}$ (varTokenTempoFuturo > varRelogioLocal)) ENTÃO

// Regra 04 - o modelo local está em deadlock (não possui transições instantâneas // disparáveis) e recebe o token onde um outro modelo, com tempo de simulação

// superior ao local, está tentando fazer uma consulta. Neste caso ele deve

// sobrescrever os campos 'varTokenIdentificacao' e 'varTokenTempoFuturo' com

// seus próprios valores, passando este a fazer a consulta.

varTokenIdentificacao $\leftarrow$ varobjIdentificacao

varTokenTempoFuturo $\leftarrow$ varRelogioLocal

FIM SE

SENÃO SE ( (varDeadLock = 1) E (varTokenStatus = ' 3 ' $)$ ) ENTÃO

// Regra 05 - o modelo local está em deadlock (não possui transições instantâneas

// disparáveis) e recebe o token onde um outro modelo informa que está sem

// transições (instantâneas e temporizadas) disparáveis. Neste caso ele deve

// sobrescrever os campos 'varTokenIdentificacao' e ‘varTokenTempoFuturo' com

// seus próprios valores, e trocar o status (varTokenStatus) do token para consulta,

// informando que ao menos este modelo não está sem transições em sua lista de

// disparos.

varTokenIdentificacao $\leftarrow$ varobjIdentificacao

varTokenstatus $\leftarrow$ ' 1 '

varTokenTempoFuturo $\leftarrow$ varRelogioLocal

FIM SE

SENÃO SE (varTokenstatus $=$ '2') ENTÃO

// Regra 06 - o modelo local recebe uma instrução para atualizar o seu tempo local

// de simulação. Neste caso ele deve atualizar o seu relógio local com o tempo

// informado no token e alterar sua variável de deadlock para zero, a fim de disparar

// suas transições, caso exista alguma disparável neste novo tempo local.

varRelogioLocal $\leftarrow$ varTokenTempoFuturo

varDeadLock $\leftarrow 0$

FIM SE

FIM SE

// O token está sendo usado pelo modelo simulado na presente estação.

SENÃO

SE (varTokenstatus $=$ ' 3 ') ENTÃo

// Regra 07 - o modelo local recebe de volta o token que enviou, sem alterações,

// onde informava aos demais modelos que este se encontrava sem mais transições

// (instatâneas e temporizadas) disparáveis. Neste caso ele deve atualizar o campo de

// erro do token informando que o sistema como um todo está travado e a

// simulação deve ser encerrada.

varTokenErro $\leftarrow$ '1'

FTM SF

Figura 4.4 - Algoritmo de tratamento do token (continuação). 
SENÃO SE (varTokenstatus = '1') ENTÃO

// Regra 08 - o modelo local recebe de volta o token que enviou, sem alterações, // onde fazia uma consulta aos demais modelos de forma a tentar atualizar o seu // tempo local de simulação e, conseqüentemente, o do sistema. Neste caso ele altera // o status do token de forma a informar às demais estações para atualizarem seus

// relógios locais de simulação com o valor utilizado na consulta.

varTokenstatus $\leftarrow$ '2'

FIM SE

SENÃO SE (varTokenstatus $=$ '2') ENTÃO

// Regra 09 - o modelo local recebe de volta o token que enviou. Os

// demais modelos já atualizaram seus relógios locais, restando apenas ele. Assim ele

// libera o token e troca seu status de deadlock para zero, ou seja, o modelo não

// está mais em deadlock, podendo disparar suas transições.

varTokenIdentificacao $\leftarrow$ ' '

varTokenstatus $\leftarrow$ ' $\odot$ '

varDeadLock $\leftarrow 0$

FIM SE

FIM SENÃO

FIM-SE

FIM da procedure TrataToken

Figura 4.4 - Algoritmo de tratamento do token (continuação).

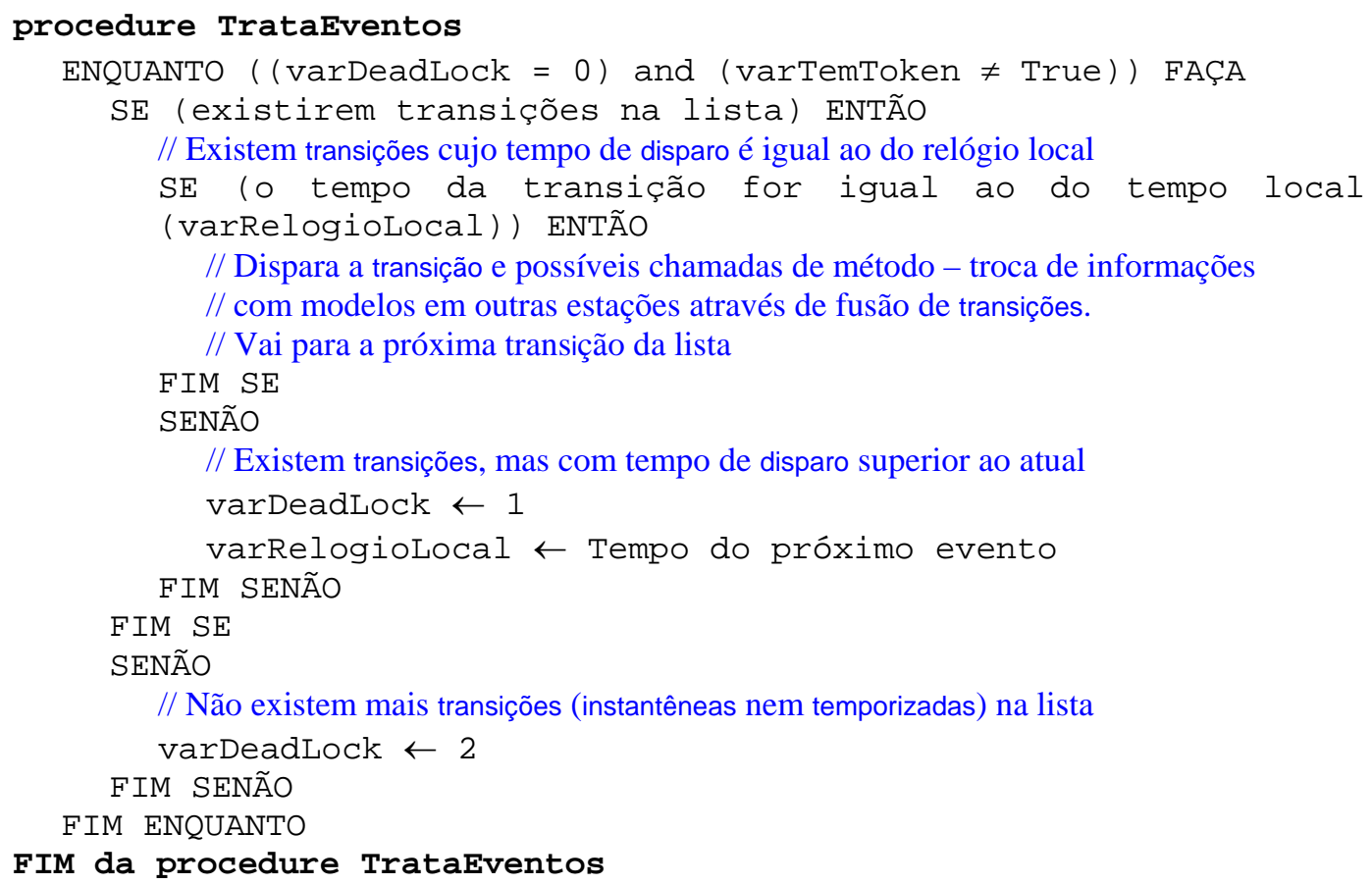

Figura 4.5 - Algoritmo de tratamento dos eventos.

De forma a facilitar o entendimento sobre o funcionamento desta lógica, a seguir é apresentado um exemplo. O modelo da Figura 4.6 ilustra o algoritmo de simulação de RdP. Apesar de sua simplicidade, ele evidencia alguns dos pontos chave do algoritmo, como a passagem do token e as chamadas de método. 
Neste exemplo, o sistema a ser simulado em RdP é composto por três modelos (A, B e C), cada um alocado a uma estação. O Modelo A controla a evolução da simulação da RdP.

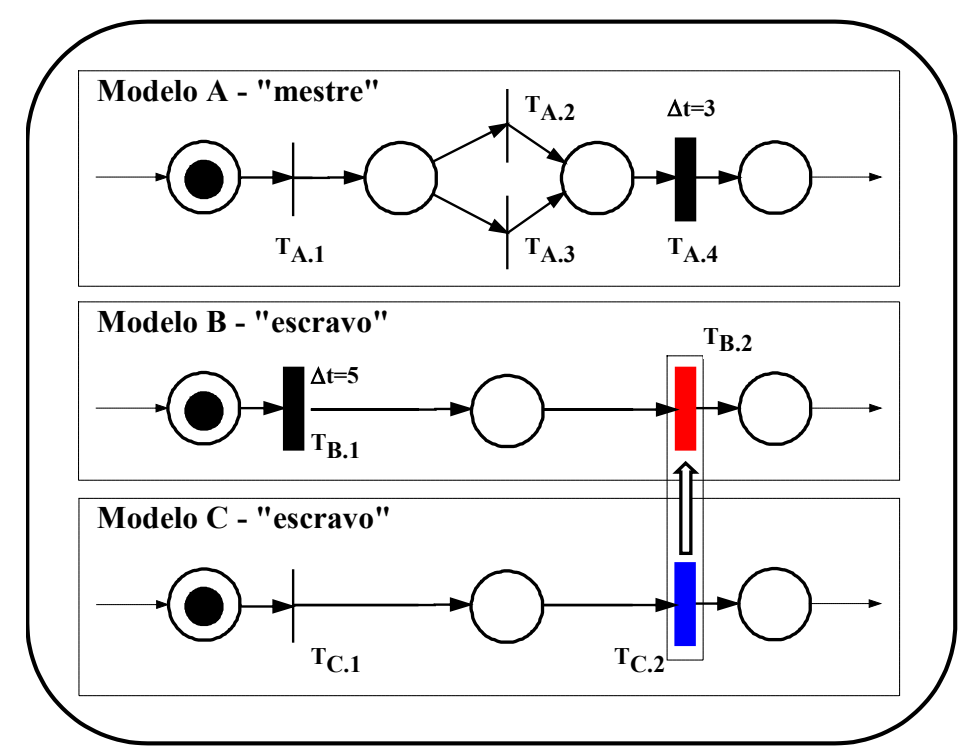

Figura 4.6 - Modelo simplificado em Rede de Petri para ilustrar o algoritmo.

Os principais eventos de uma possível simulação estão ilustrados na Figura 4.7 no diagrama de sequiência da UML. É importante observar que as atividades preliminares para se compor o anel não estão sendo apresentadas no exemplo. Além disso, os intervalos de tempo entre o envio e o recebimento do token bem como entre os disparos das transições foram escolhidos aleatoriamente. Como estes intervalos de tempo dependem das capacidades dos computadores bem como da disponibilidade dos meios de comunicação, eles podem variar de caso para caso.

A simulação é iniciada quando a estação "mestre” envia o token com o campo de instruções marcado com "início”. Após receber o token, cada estação "mestre” ou “escrava” dispara suas transições instantâneas, que são $\mathrm{T}_{\mathrm{A} .1}$ e $\mathrm{T}_{\mathrm{A} .2}$ (ou $\mathrm{T}_{\mathrm{A} .3}$ ) para a estação $A$, e $T_{C .1}$ para a estação $C$. A transição $T_{C .2}$ é uma chamada de método para o Modelo B, mas como este método ainda não está habilitado, a estação C deve aguardar.

Em seguida, o Modelo B faz uma requisição para evoluir o tempo de simulação da RdP para 5 (pois $\mathrm{T}_{\mathrm{B} .1}$ tem $\Delta \mathbf{t}$ igual a 5). Porém, antes de receber o token de volta, o Modelo A altera os campos do token com uma requisição de evolução do tempo para 3 (pois $\mathrm{T}_{\text {A.4 }}$ tem $\Delta \mathbf{t}$ igual a 3). Quando o token circula pelo anel, todas as estações já 
dispararam suas transições instantâneas habilitadas, e desta forma a estação A confirma a atualização do relógio de simulação para 3 (campo de status $\leftarrow 3$ ).

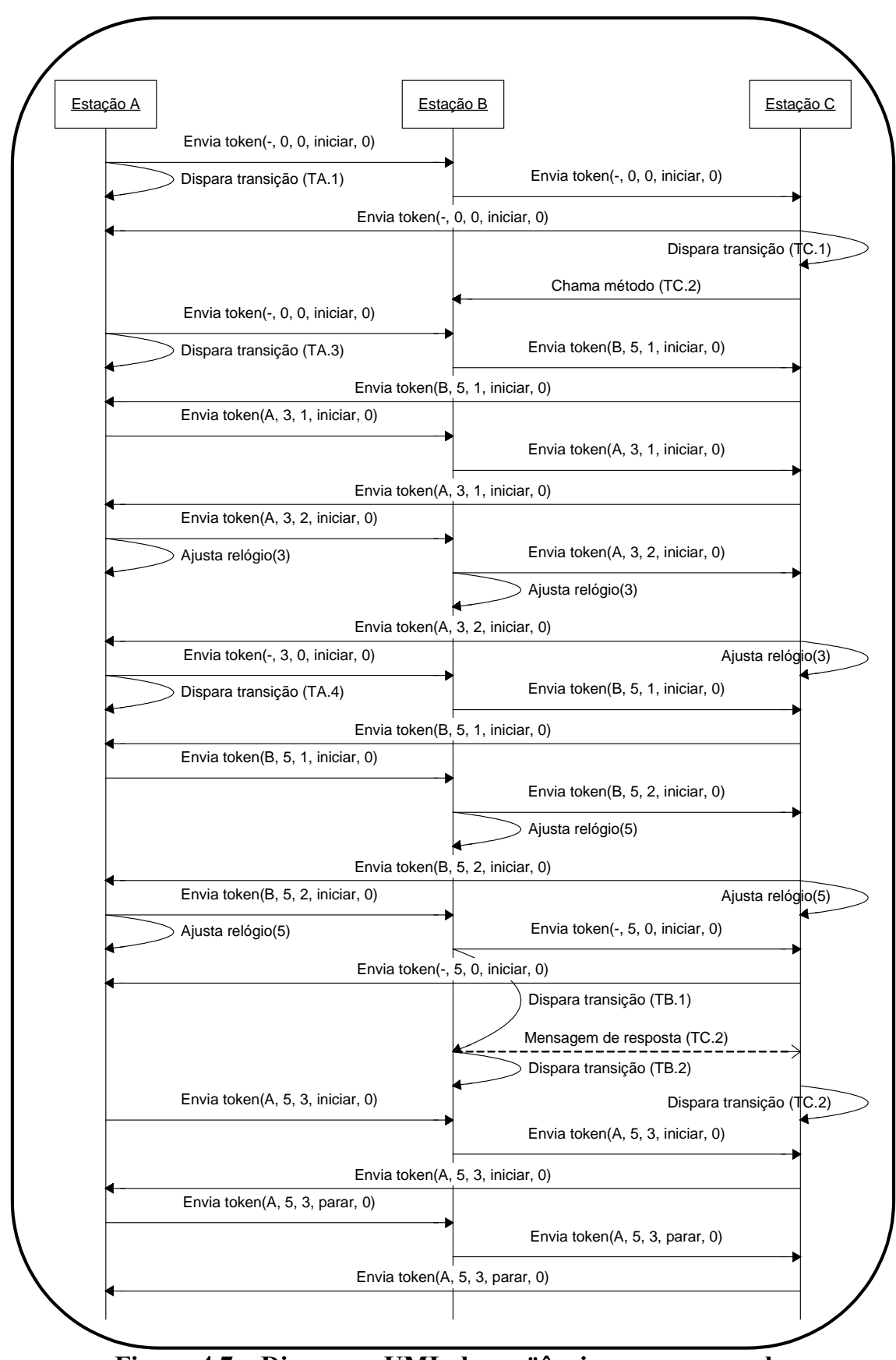

Figura 4.7 - Diagrama UML de seqüência para o exemplo.

Após disparar $\mathrm{T}_{\mathrm{A} .3}$, a estação A alcança um estado de deadlock e envia o token com o campo de status igual a 3. Esta informação é substituída na estação B que novamente requisita a evolução do tempo de simulação para 5. Esta última requisição não é substituída e então o tempo de simulação evolui para 5. A estação B então dispara 
a transição $T_{B .1}$ e então responde à chamada de método, que resulta no disparo de $T_{B .2} e$ $\mathrm{T}_{\mathrm{C} .2 \text {. }}$

Comparando-se as abordagens tradicionais e a abordagem proposta, tem-se que os algoritmos conservadores descritos em Fujimoto (1999) utilizam-se de um conjunto de mensagens (nulas ou não) trocadas entre os modelos para poderem evoluir seus relógios locais. Assim, se uma simulação utiliza N modelos interagindo entre si (o caso mais crítico onde todos trocam mensagens entre si), cada modelo deve enviar N-1 mensagens a fim de determinar quando é seguro evoluir seu tempo de simulação, resultando em $\mathrm{N}(\mathrm{N}-1)$ mensagens trocadas. Considerando-se $\alpha$ o porcentual de mensagens nulas, tem-se $\alpha\left(\mathrm{N}^{2}-\mathrm{N}\right)$ mensagens nulas trocadas a fim de se sincronizar os tempos dos simuladores.

No algoritmo proposto, cada modelo deve monitorar apenas as mensagens referentes ao token. Assim, definindo-se $\beta$ como o número de passagens do token, são necessárias $\beta \mathrm{N}$ mensagens trocadas para negociar a evolução do tempo de simulação do conjunto de simuladores. No caso particular de nenhum outro modelo interferir nos parâmetros do token, são necessárias duas passagens do token (a primeira para consulta e a segunda para atualização dos tempos) por N estações, ou seja, $2 \mathrm{~N}$.

Assim, se $\alpha\left(\mathrm{N}^{2}-\mathrm{N}\right)-\beta \mathrm{N} \leq 0$, a abordagem tradicional é mais vantajosa, do contrário a abordagem proposta o é. Esta expressão pode ser reescrita como:

$$
\mathrm{N} \leq \frac{\beta}{\alpha}+1
$$

\subsection{Validação do algoritmo}

A fim de validar o algoritmo proposto, foi implementado um software de simulação (Figura 4.8). Este simulador foi replicado e executado em diferentes microcomputadores, todos conectados a uma LAN (Local Area Network) com uma taxa de transmissão de dados de 10Mbps. 


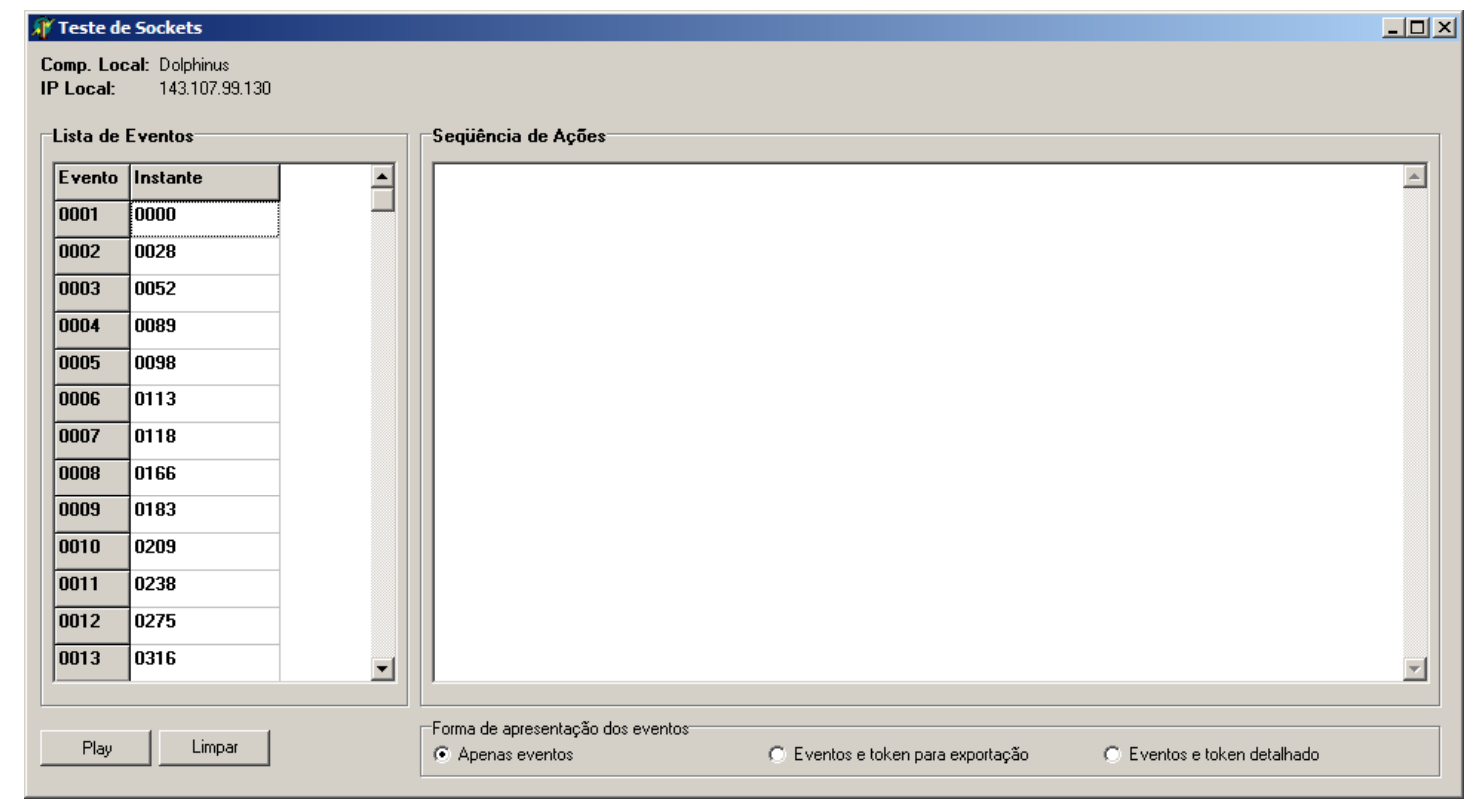

Figura 4.8 - Software de simulação implementado para validar o algoritmo.

Para os ensaios são feitas algumas considerações:

os simuladores, através do uso de sockets, formam um anel lógico entre si;

> cada software simula uma fila de eventos (gerados aleatoriamente em um intervalo de $0 \leq \mathrm{x}<50$ ) ordenada de forma ascendente. O instante do evento $\boldsymbol{i}$ é a soma do instante do evento $\boldsymbol{i}-\mathbf{1}$ ao número aleatório gerado;

a fila de eventos não possui eventos no mesmo instante de tempo ou, se possuir (devido a aleatoriedade), são raros, procurando-se, assim, avaliar o algoritmo no seu caso crítico - estar sempre negociando a evolução do tempo de simulação;

para que os eventos sejam executados, os simuladores, utilizando as regras apresentadas na seção 4.3, negociam a evolução do tempo, registrando esta negociação no campo “Seqüência de ações” (Figura 4.8);

são consideradas duas tomadas de tempo a cada passagem do token: uma correspondendo ao tempo que o token, ao ser enviado para o próximo simulador, leva para ser recebido novamente, que corresponde ao tempo de circulação (TC) do token; e outra referente ao tempo de processamento (TP) do token pelo simulador (Figura 4.9). Desta forma, pode-se eliminar o efeito da implementação dos algoritmos sobre o tempo de circulação do token, obtendo-se o que se denomina tempo de rede (TR). Assim, o TR $=\mathrm{TC}-(\mathrm{N}-1) \mathrm{TP}$, onde $\mathrm{N}$ é o número de microcomputadores que formam o anel. No exemplo da Figura 4.9 o anel é formado por 4 microcomputadores (ilustrados pelos quadrados azuis); 
os tempos são amostrados a cada $5 \mathrm{~ms}$ pois cada amostragem realizada é um eventos que o processador deve atender;

foram utilizados computadores Pentium 4 com um mínimo de 512Mb de memória RAM.

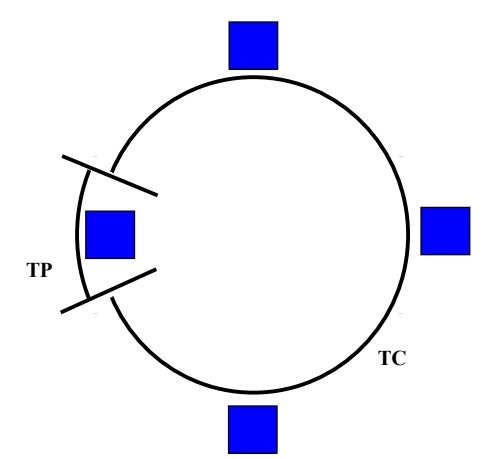

Figura 4.9 - Tempos de processamento e de circulação do token.

A seguir são apresentados os ensaios realizados:

\section{A) Validação do algoritmo}

Neste ensaio são utilizados dois simuladores, cada um contendo uma lista com 10 eventos (Figura 4.10). Pretende-se avaliar a aplicação das regras descritas na seção 4.3 na negociação da evolução do tempo do sistema como um todo. Não será avaliado neste ensaio o tempo de circulação do token.

A Tabela 4.2 apresenta os resultados da simulação.

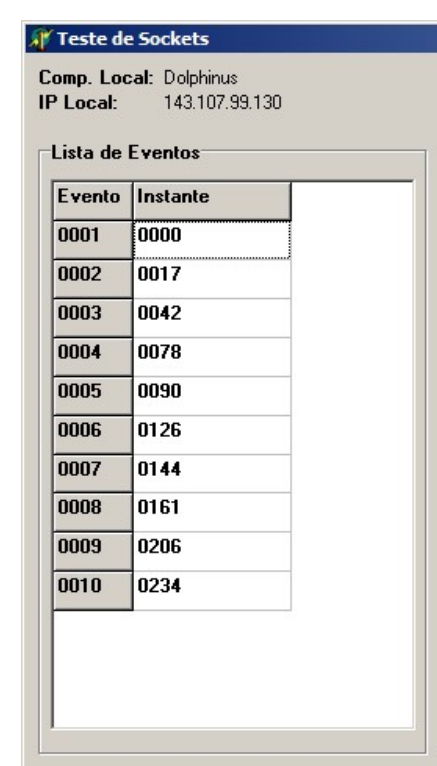

Lista de eventos 1 (Obj1)

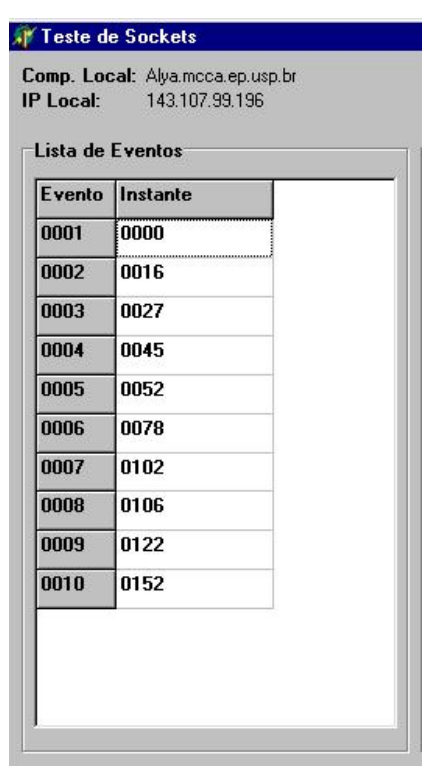

Lista de eventos 2 (Obj2)

Figura 4.10 - Listas de eventos utilizadas nos ensaios. 
Algumas observações quanto à simulação realizada:

no simulador 1 , a passagem do token se inicia em 00 pois é este que inicia a simulação;

a Regra 00 indica a não aplicação de regra alguma;

A Regra03, apesar de implementada, não é executada uma vez que não existem dois ou mais eventos ocorrendo no mesmo instante. O mesmo ocorreria se dois ou mais eventos fossem processados em um tempo inferior ao que o token necessita para dar uma volta no anel.

Tabela 4.2. Resultado da simulação distribuída dos modelos.

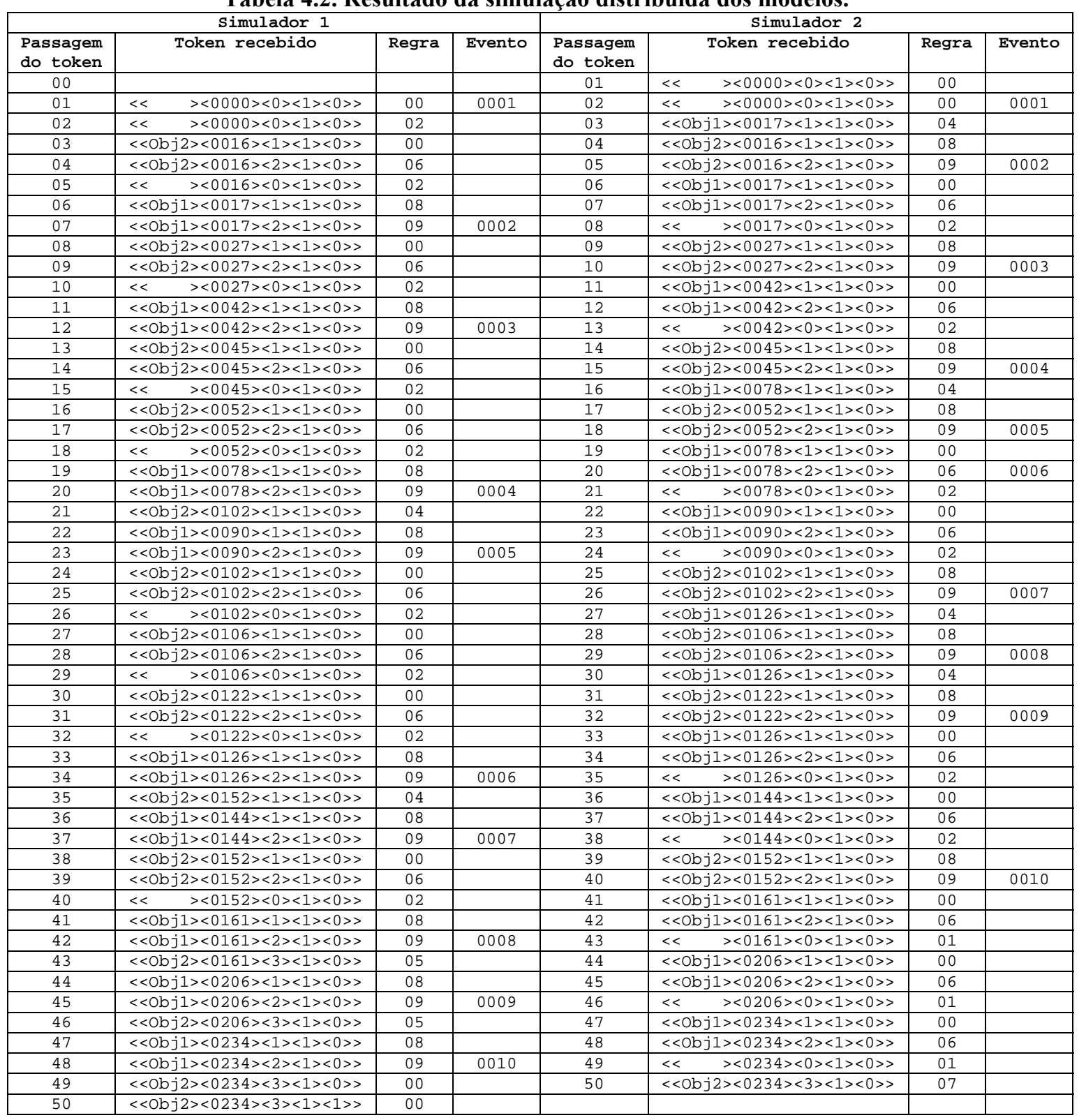


Nos próximos itens são realizados alguns ensaios qualitativos quanto: à influência do número de simuladores utilizados durante o experimento de simulação no desempenho da simulação (item B); à influência da rede de comunicação sobre o desempenho da simulação (item C); e à influência dos eventos instantâneos no desempenho da simulação (item D). Novos ensaios, variando o número de simuladores, características da rede de comunicação, ou outros parâmetros, a fim de mensurar o desempenho do algoritmo, podem ser abordados em trabalhos futuros.

\section{B) A influência do número de simuladores utilizados no desempenho da simulação}

Neste ensaio agendou-se 100 eventos para cada simulador. Pretende-se analisar a influência no número de simuladores $(\mathrm{N})$ sobre quatro parâmetros: (1) o número total de passagens do token para se processar os 100 eventos dos $\mathrm{N}$ simuladores; (2) o tempo de circulação (TC) do token; (3) o número de passagens do token entre duas evoluções consecutivas do tempo (do simulador); e (4) o tempo decorrido entre duas evoluções consecutivas de tempo (do simulador).

A primeira informação obtida é que o tempo de processamento (TP) foi inferior a 5ms (taxa de amostragem), ou seja, este será considerado irrelevante para o experimento.

Apresenta-se na Tabela 4.3 os resultados quanto à influência do número de simuladores sobre: (1) o número de passagens do token (Figura 4.11); e (2) o tempo de circulação do token (Figura 4.12).

Tabela 4.3. Influência do número de simuladores sobre o TC do token.

\begin{tabular}{|c|c|c|c|c|c|c|c|}
\hline \multicolumn{2}{|c|}{} & \multicolumn{7}{|c|}{ Tempos em segundos } \\
\hline $\mathbf{N}$ & Passagens do token & Min & Max & Mediana $^{\mathbf{1 9}}$ & Moda $^{\mathbf{2 0}}$ & Média & $\begin{array}{c}\text { Desvio } \\
\text { padrão }\end{array}$ \\
\hline 2 & 0507 & 0,000 & 1,035 & 0,070 & 0,070 & 0,072 & 0,043 \\
\hline 3 & 0727 & 0,000 & 0,365 & 0,070 & 0,070 & 0,085 & 0,022 \\
\hline 4 & 0952 & 0,000 & 0,095 & 0,070 & 0,070 & 0,070 & 0,004 \\
\hline 5 & 1141 & 0,000 & 0,090 & 0,070 & 0,070 & 0,070 & 0,004 \\
\hline
\end{tabular}

\footnotetext{
${ }^{19}$ A mediana de um conjunto de $\mathrm{M}$ números ordenados em ordem de grandeza é o valor do ponto central (M ímpar) ou a média aritmética dos dois valores centrais (M par).

${ }^{20}$ A moda é o valor mais freqüente em um conjunto de valores numéricos. A moda pode não existir e, mesmo que exista, pode não ser única.
} 
Observa-se que, para o limite de simuladores utilizados, o número de passagens do token (Figura 4.11) necessárias para processar os 100 eventos (por simulador) cresce proporcionalmente ao número de simuladores.

Outra informação obtida da Tabela 4.3 é a de que o tempo de circulação do token praticamente se mantém inalterado (70ms). Nota-se que as médias para 2 e 3 simuladores são superiores a 70ms (Figura 4.12). Porém, obsevando-se suas medianas, bem como seus respectivos desvios padrão frente às outras duas simulações, conclui-se que isto se deve a um número menor de amostras (507 e 727, respectivamente).

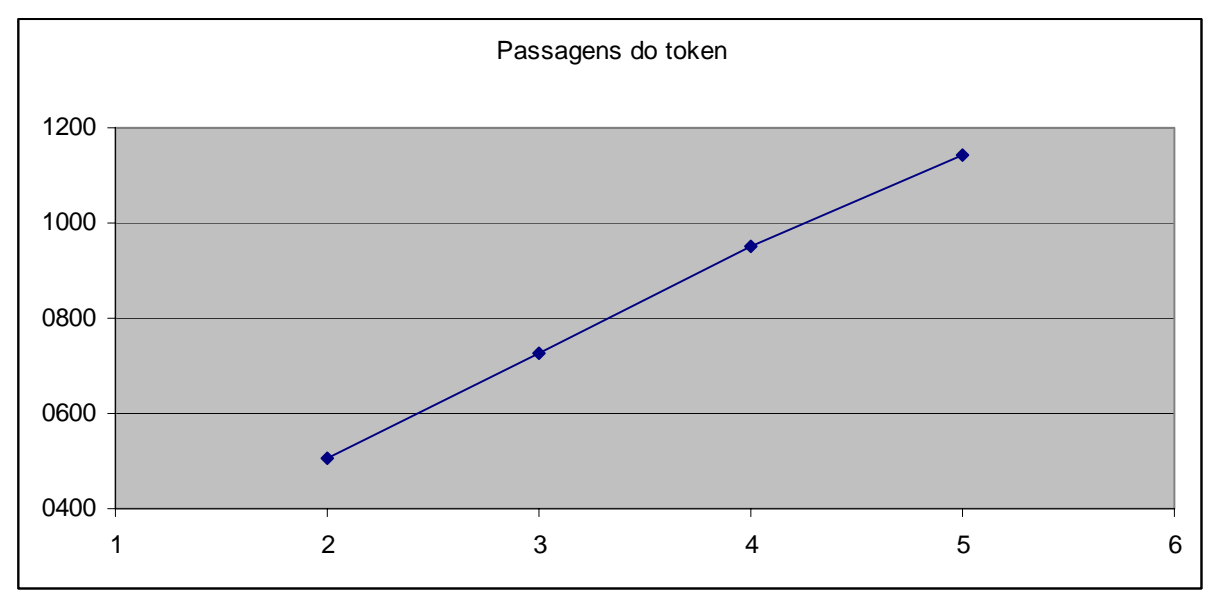

Figura 4.11 - Influência do número de simuladores o número de passagens do token para processar 100 eventos em cada simulador (legenda dos eixos).

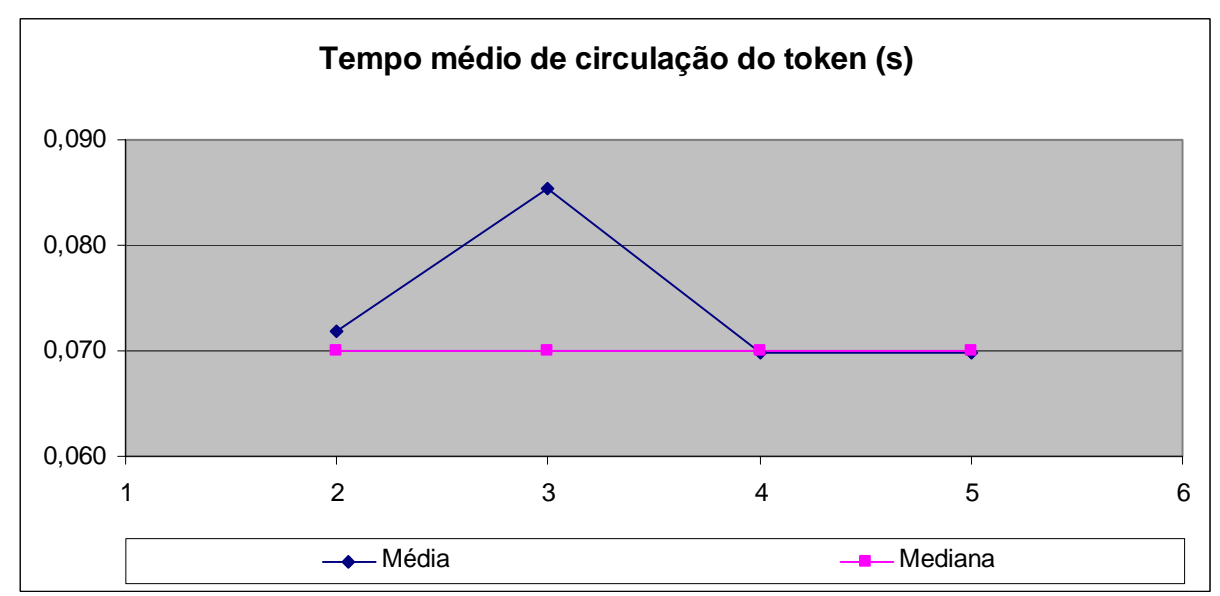

Figura 4.12 - Influência do número de simuladores sobre o TC do token (legenda dos eixos).

Na Tabela 4.4 são apresentados os dados obtidos quanto à influência do número de simuladores sobre o número de passagens do token entre duas evoluções consecutivas do tempo (do simulador), levando-se em consideração apenas os eventos de um simulador, pois, no caso de uma simulação gráfica, são os eventos que o usuário 
de cada simulador consegue monitorar. Para os ensaios realizados, nota-se que o número de passagens do token entre duas evoluções consecutivas de tempo apresentase praticamente linear (Figura 4.13).

Tabela 4.4. Influência do número de simuladores sobre o número de passagens do token entre duas evoluções consecutivas do tempo (do simulador).

\begin{tabular}{|c|c|c|c|c|c|c|c|}
\hline & \multicolumn{7}{|c|}{ Tempos em segundos } \\
\hline $\mathbf{N}$ & Passagens do token & Min & Max & Mediana & Moda & Média & $\begin{array}{c}\text { Desvio } \\
\text { padrão }\end{array}$ \\
\hline 2 & & & & & & & \\
\hline 3 & 0507 & 0,000 & 11,000 & 5,000 & 5,000 & 4,970 & 2,372 \\
\hline 4 & 0727 & 0,000 & 22,000 & 5,000 & 5,000 & 7,140 & 4,584 \\
\hline 5 & 0952 & 0,000 & 23,000 & 8,000 & 5,000 & 9,090 & 4,866 \\
\hline
\end{tabular}

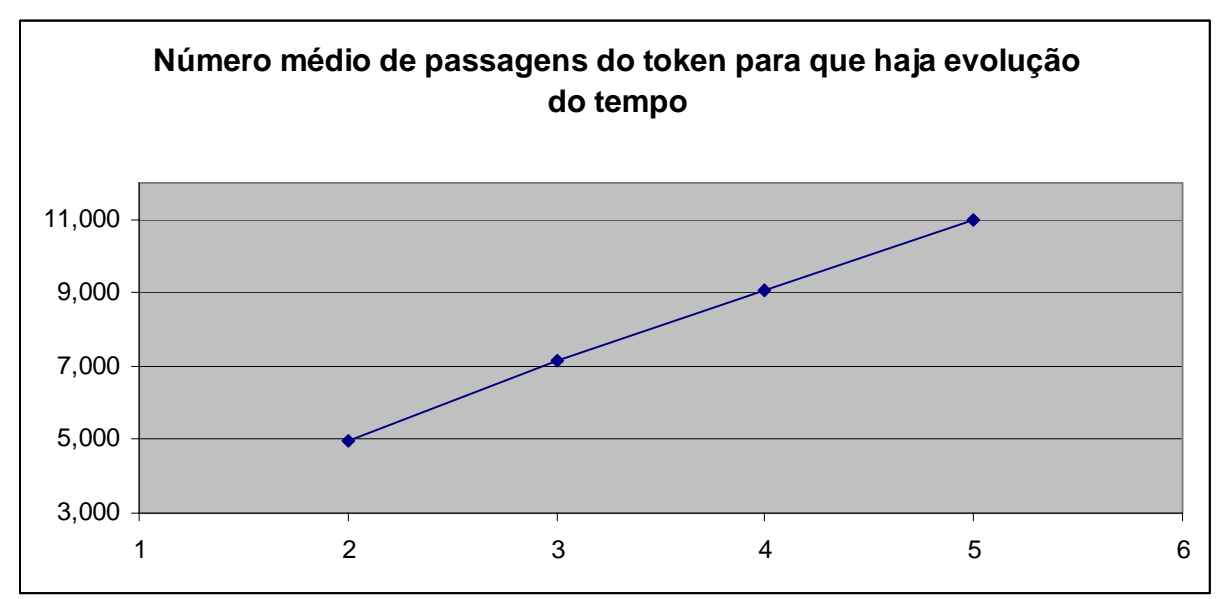

Figura 4.13 - Influência do número de simuladores sobre o número de passagens do token entre duas evoluções consecutivas do tempo (do simulador).

Entretanto, quando se pondera o número de passagens do token pelo número total de eventos processados, observa-se uma redução na média como apresentado na Figura 4.14.

Na Tabela 4.5 são apresentados os dados referentes à influência do número de simuladores sobre o tempo decorrido entre duas evoluções consecutivas de tempo (do simulador). Observa-se uma discrepância quando se utiliza 3 simuladores (Figura 4.15). Atribui-se este comportamento ao número de amostras, como na Figura 4.12. 


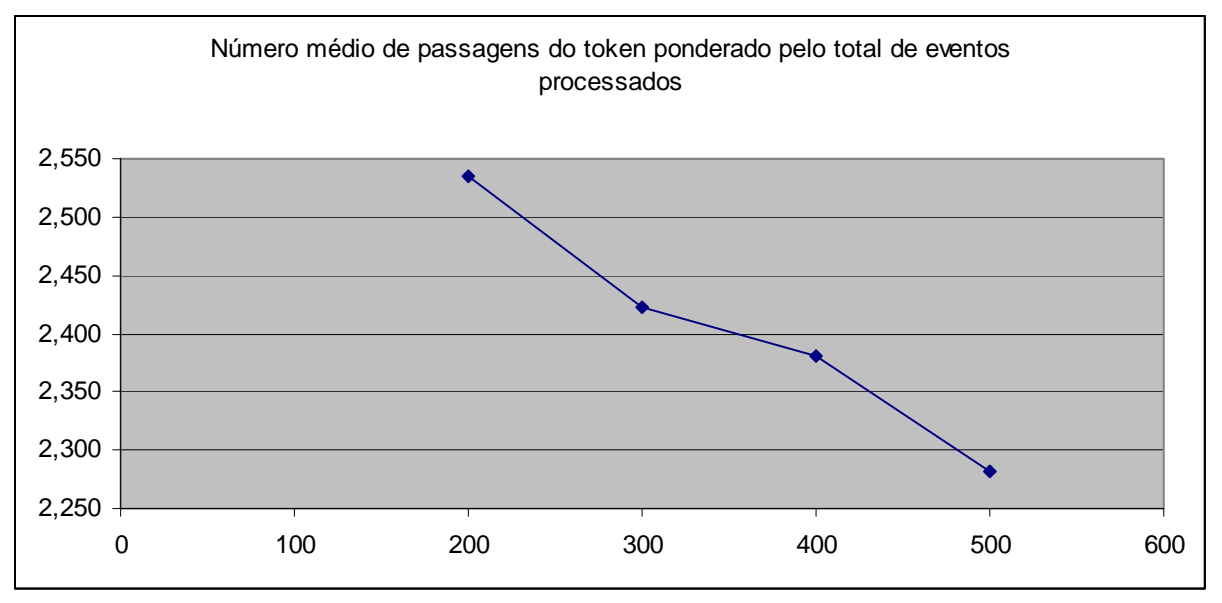

Figura 4.14 - Influência do número de simuladores sobre o número de passagens do token entre duas evoluções consecutivas do tempo, ponderando-se pelo número total de eventos processados.

Tabela 4.5. Influência do número de simuladores no tempo entre duas evoluções consecutivas de tempo (do simulador).

\begin{tabular}{|c|c|c|c|c|c|c|c|}
\hline & \multicolumn{5}{|c|}{ Tempos em segundos } \\
\hline $\mathbf{N}$ & Passagens do token & Min & Max & Mediana & Moda & Média & $\begin{array}{c}\text { Desvio } \\
\text { padrão }\end{array}$ \\
\hline 2 & & & & & & & \\
\hline 3 & 0507 & 0,000 & 1,175 & 0,350 & 0,350 & 0,357 & 0,186 \\
\hline 4 & 0727 & 0,000 & 1,890 & 0,490 & 0,420 & 0,599 & 0,405 \\
\hline 5 & 0952 & 0,000 & 1,605 & 0,560 & 0,350 & 0,635 & 0,342 \\
\hline
\end{tabular}

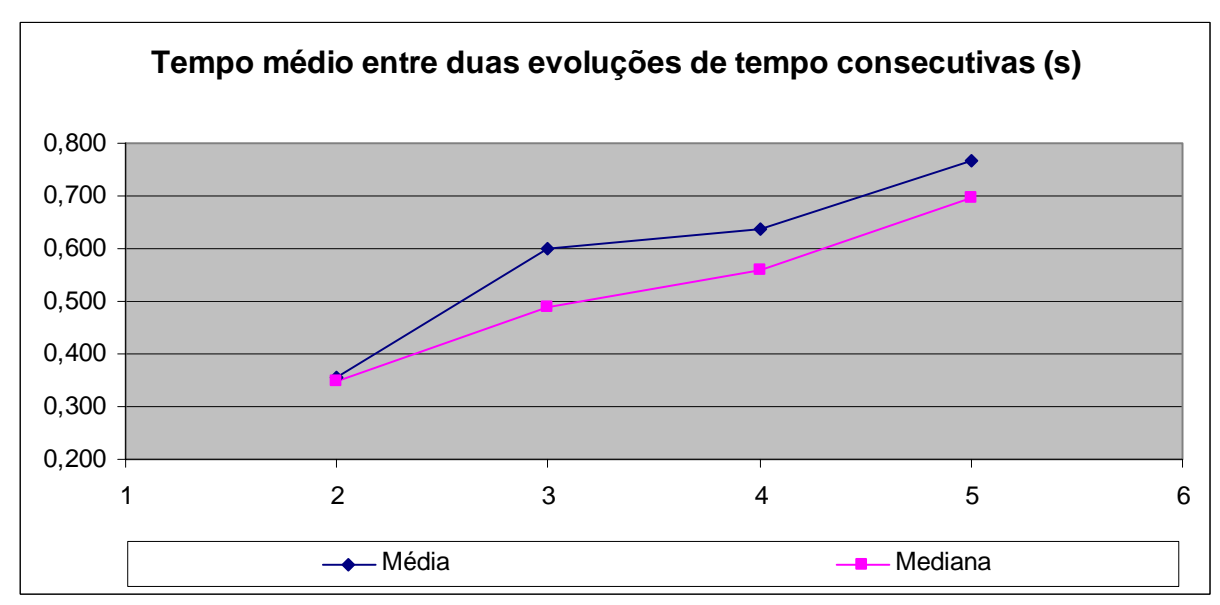

Figura 4.15 - Influência do número de simuladores no tempo entre duas evoluções consecutivas de tempo (do simulador)

Os ensaios são relevantes para avaliar o desempenho da simulação frente à variação do número de simuladores utilizados. Entretanto, os ensaios não são conclusivos pois seria necessário avaliar o uso de um maior número de simuladores a fim de verificar se o comportamento dos parâmetros se mantém linear ou em algum momento se torna exponencial ou logaritmico. 


\section{C) Influência da rede de comunicação no desempenho da simulação}

Assim como no ensaio anterior, foram agendados 100 eventos para cada simulador. Pretende-se analisar a influência rede de comunicação sobre três parâmetros: (1) o tempo de circulação (TC) do token; (2) o número de passagens do token entre duas evoluções consecutivas do tempo (do simulador); e (3) o tempo decorrido entre duas evoluções consecutivas de tempo (do simulador).

Foram considerados:

o uso de 2 simuladores;

em um dos experimentos, um dos simuladores sendo executado em um computador em Neves Paulista (região de São José do Rio Preto, 470Km de São Paulo), com conexão banda larga (conexão wireless entre o computador e o provedor, o qual está conectado ao serviço de banda larga da concessionária de telefonia. Esta por sua vez está conectada à FAPESP, a qual provê serviço para a USP, onde o segundo simulador está sendo executado);

As demais simulações foram realizadas na mesma localidade, alternando-se entre um hub de 10Mbps e um switch de 100Mbps.

Apresenta-se na Tabela 4.6 o resultado quanto à influência do tipo de rede sobre o tempo de circulação do token. Observa-se uma grande diferença no desempenho quando se utiliza uma rede de comunicação de baixo tráfego (10Mbps e 100Mbps) comparado a uma rede de comunicação comercial, sujeita a um maior tráfego, restrições de banda e maior número de interconexões.

Tabela 4.6. Influência da rede de comunicação no TC do token.

\begin{tabular}{|c|c|c|c|c|c|c|c|}
\hline & & \multicolumn{6}{|c|}{ Tempos em segundos } \\
\hline Rede & Passagens do token & Min & Max & Mediana & Moda & Média & $\begin{array}{l}\text { Desvio } \\
\text { padrão }\end{array}$ \\
\hline Telefonica & 0514 & 0,000 & 12,595 & 0,160 & 0,135 & 0,300 & 0,631 \\
\hline 10Mbps & 0507 & 0,000 & 1,035 & 0,070 & 0,070 & 0,072 & 0,043 \\
\hline 100Mbps & 0520 & 0,000 & 0,110 & 0,070 & 0,070 & 0,081 & 0,025 \\
\hline
\end{tabular}

Observa-se na Tabela 4.7 que o número de passagens do token entre duas evoluções consecutivas do tempo (do simulador) é função apenas do número de simuladores envolvidos (e consequentemente eventos), ou seja, a rede de comunicação não tem influência sobre este parâmetro. 
Novamente, como observado para os dados da Tabela 4.6, observa-se a influência do tipo de rede de comunicação no tempo entre duas evoluções consecutivas de tempo (do simulador) (Tabela 4.8), sendo válidas as mesmas observações.

Tabela 4.7. Influência da rede de comunicação sobre o número de passagens do token entre duas evoluções consecutivas do tempo (do simulador).

\begin{tabular}{|c|c|c|c|c|c|c|c|}
\hline \multicolumn{2}{|c|}{} & \multicolumn{6}{|c|}{ Tempos em segundos } \\
\hline Rede & Passagens do token & Min & Max & Mediana & Moda & Média & $\begin{array}{c}\text { Desvio } \\
\text { padrão }\end{array}$ \\
\hline Telefonica & 0514 & 0,000 & 15,000 & 5,000 & 5,000 & 5,040 & 2,498 \\
\hline 10Mbps & 0507 & 0,000 & 11,000 & 5,000 & 5,000 & 4,970 & 2,372 \\
\hline $100 \mathrm{Mbps}$ & 0520 & 1,000 & 17,000 & 5,000 & 5,000 & 5,080 & 2,565 \\
\hline
\end{tabular}

Tabela 4.8. Influência da rede de comunicação no tempo entre duas evoluções consecutivas de

\begin{tabular}{|c|c|c|c|c|c|c|c|}
\hline \multicolumn{2}{|c|}{ tempo (do simulador). } \\
\hline Rede & Passagens do token & Min & Max & Mediana & Moda & Média & $\begin{array}{c}\text { Desvio } \\
\text { padrão }\end{array}$ \\
\hline Telefonica & 0514 & 0,000 & 15,015 & 1,153 & 1,485 & 1,524 & 1,793 \\
\hline $10 \mathrm{Mbps}$ & 0507 & 0,000 & 1,175 & 0,350 & 0,350 & 0,357 & 0,186 \\
\hline $100 \mathrm{Mbps}$ & 0520 & 0,000 & 1,405 & 0,353 & 0,280 & 0,412 & 0,217 \\
\hline
\end{tabular}

Desta forma, pelos ensaios realizados, observa-se que para experimentos de simulação distribuída, deve-se fazer uso de redes de comunicação dedicadas ou de alta disponibilidade, tendo-se poucas interconexões entre os simuladores envolvidos. Entretando, os ensaios não são conclusivos pois seria necessário um maior número de experimentações.

\section{D) Influência do porcentual de eventos instantâneos sobre o desempenho da} simulação

Assim como no ensaio anterior, foram agendados 100 eventos para cada simulador, e foram utilizados dois simuladores. Pretende-se analisar a influência dos eventos instantâneos no desempenho da simulação.

Observa-se pela Tabela 4.9 que o porcentual de eventos instantâneos não tem influência sobre o tempo de circulação do token (Figura 4.16), sendo sua oscilação fruto da aleatoriedade e/ou tráfego local na rede. 
Tabela 4.9. Influência do número de eventos instantâneos no TC do token.

\begin{tabular}{|c|c|c|c|c|c|c|c|}
\hline \multicolumn{2}{|c|}{} & \multicolumn{7}{|c|}{ Tempos em segundos } \\
\hline Passagens & Min & Max & Mediana & Moda & Média & $\begin{array}{c}\text { Desvio } \\
\text { padrão }\end{array}$ \\
\hline 10 & 0414 & 0,020 & 0,405 & 0,105 & 0,105 & 0,097 & 0,034 \\
\hline 30 & 0314 & 0,015 & 0,230 & 0,075 & 0,070 & 0,086 & 0,020 \\
\hline 50 & 0211 & 0,025 & 0,390 & 0,100 & 0,105 & 0,092 & 0,029 \\
\hline 70 & 0107 & 0,040 & 0,120 & 0,070 & 0,070 & 0,071 & 0,009 \\
\hline 90 & 0022 & 0,045 & 0,130 & 0,105 & 0,105 & 0,090 & 0,025 \\
\hline
\end{tabular}

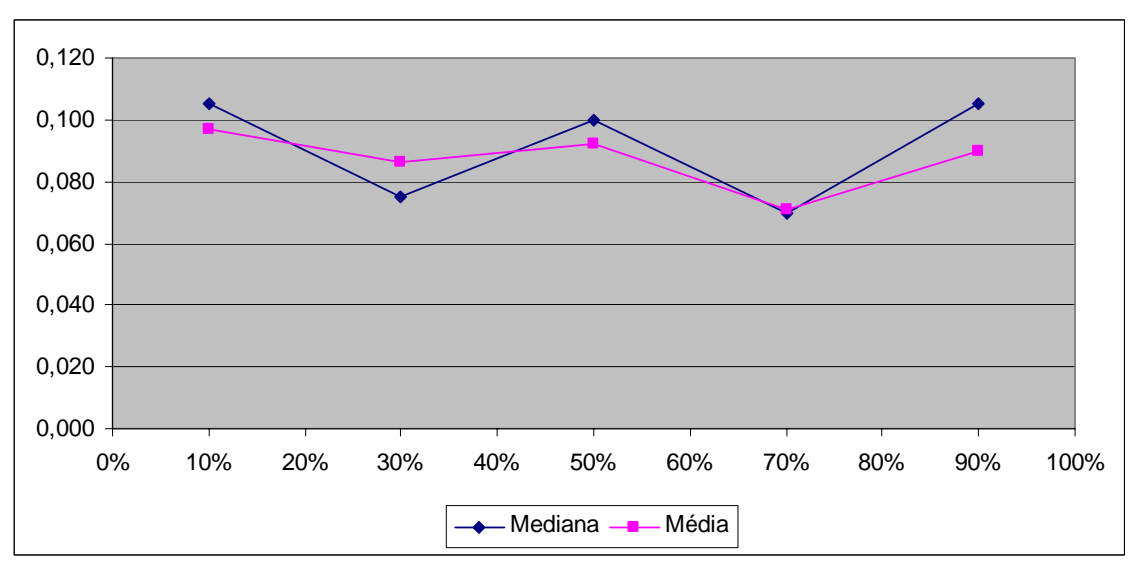

Figura 4.16 - Influência do número de eventos instantâneos sobre o TC do token.

Nota-se, por outro lado, que este tem grande efeito sobre o número de passagens do token entre duas evolução consecutivas do tempo (do simulador) (Tabela 4.10 e Figura 4.17). Nesta caso, quanto maior o porcentual de eventos instantâneos, menor o número médio de passagens do token entre dois eventos consecutivos.

Tabela 4.10. Influência do número de eventos instantâneos sobre o número de passagens do token entre duas evoluções consecutivas do tempo (do simulador).

\begin{tabular}{|c|c|c|c|c|c|c|c|c|}
\hline \multirow[b]{2}{*}{$\%$} & \multirow[b]{2}{*}{$\begin{array}{c}\text { Passagens } \\
\text { do } \\
\text { token }\end{array}$} & \multicolumn{7}{|c|}{ Tempos em segundos } \\
\hline & & Min & Max & Mediana & Moda & Média & $\begin{array}{l}\text { Desvio } \\
\text { padrão }\end{array}$ & $\alpha$ \\
\hline 10 & 0414 & 0 & 14 & 3 & 3 & 4,110 & 2,463 & 4,11 \\
\hline 30 & 0314 & 0 & 11 & 3 & 0 & 3,120 & 2,610 & 3,12 \\
\hline 50 & 0211 & 0 & 11 & 0 & 0 & 2,030 & 2,601 & 2,03 \\
\hline 70 & 0107 & 0 & 8 & 0 & 0 & 1,035 & 1,935 & 1,04 \\
\hline 90 & 0022 & 0 & 3 & 0 & 0 & 0,180 & 0,656 & 0,18 \\
\hline
\end{tabular}

Ainda com relação a este ensaio, calculou-se o $\alpha$ (apresentado no final da seção 4.3). Como $\alpha$ deve ser no máximo igual a 1, ou seja, $100 \%$ de mensagens nulas trocadas no algoritmo tradicional, tem-se que para pequenas variações no porcentual de eventos instantâneos, a partir de 70\%, tem-se, proporcionalmente, um maior descréscimo no 
valor de $\alpha$ (Figura 4.18), lembrando-se que seu efeito foi aferido apenas utilizando-se dois simuladores.

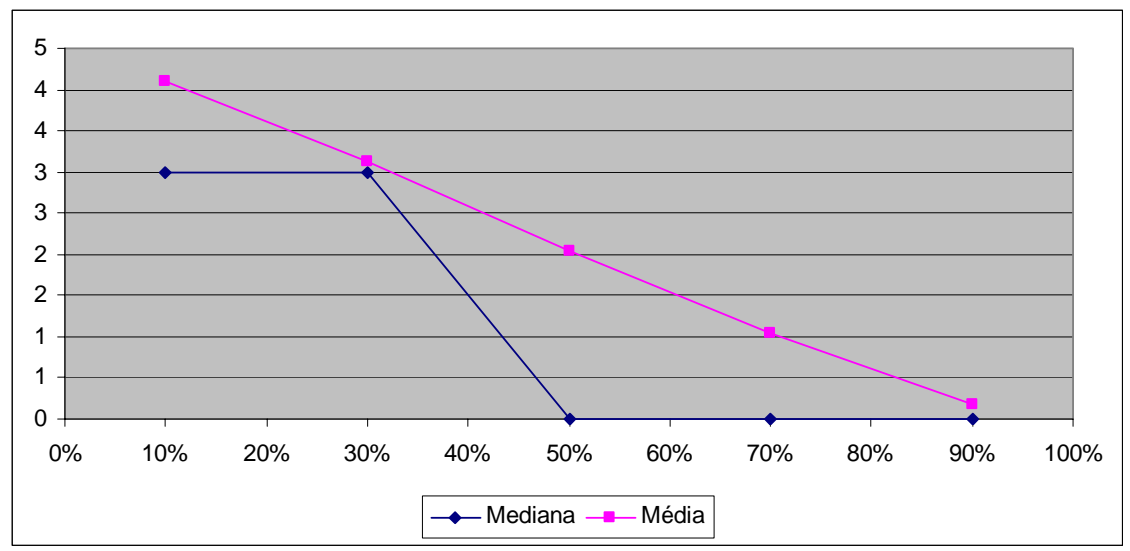

Figura 4.17 - Influência do número de eventos instantâneos sobre o número de passagens do token entre duas evoluções consecutivas do tempo (do simulador).

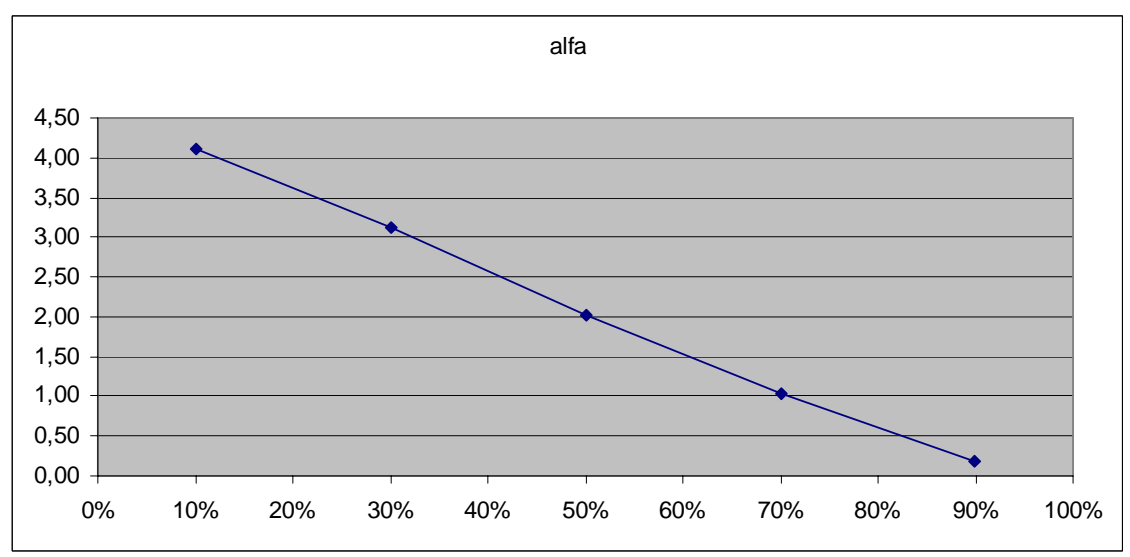

Figura 4.18 - Influência do número de eventos instantâneos sobre $\alpha$ para que se tenha uma equivalência entre o número de mensagens nulas trocadas para evolução do tempo no algoritmo proposto e no algoritmo tradicional.

Na Tabela 4.11 são apresentados os dados referentes à influência do porcentual de eventos instantâneos sobre o tempo decorrido entre duas evoluções consecutivas de tempo (do simulador). Observa-se uma redução linear no tempo ao se aumentar o número de eventos instantâneos (Figura 4.19). 
Tabela 4.11. Influência da do número de eventos instantâneos no tempo entre duas evoluções consecutivas de tempo (do simulador).

\begin{tabular}{|c|c|c|c|c|c|c|c|}
\hline \multicolumn{2}{|c|}{} & \multicolumn{7}{|c|}{ Tempos em segundos } \\
\hline \% & $\begin{array}{c}\text { Passagens } \\
\text { do token }\end{array}$ & Min & Max & Mediana & Moda & Média & $\begin{array}{c}\text { Desvio } \\
\text { padrão }\end{array}$ \\
\hline 10 & 0414 & 0,000 & 1,365 & 0,350 & 0,000 & 0,398 & 0,259 \\
\hline 30 & 0314 & 0,000 & 0,945 & 0,250 & 0,000 & 0,268 & 0,227 \\
\hline 50 & 0211 & 0,000 & 1,015 & 0,000 & 0,000 & 0,186 & 0,244 \\
\hline 70 & 0107 & 0,000 & 0,615 & 0,000 & 0,000 & 0,072 & 0,137 \\
\hline 90 & 0022 & 0,000 & 0,330 & 0,000 & 0,000 & 0,014 & 0,057 \\
\hline
\end{tabular}

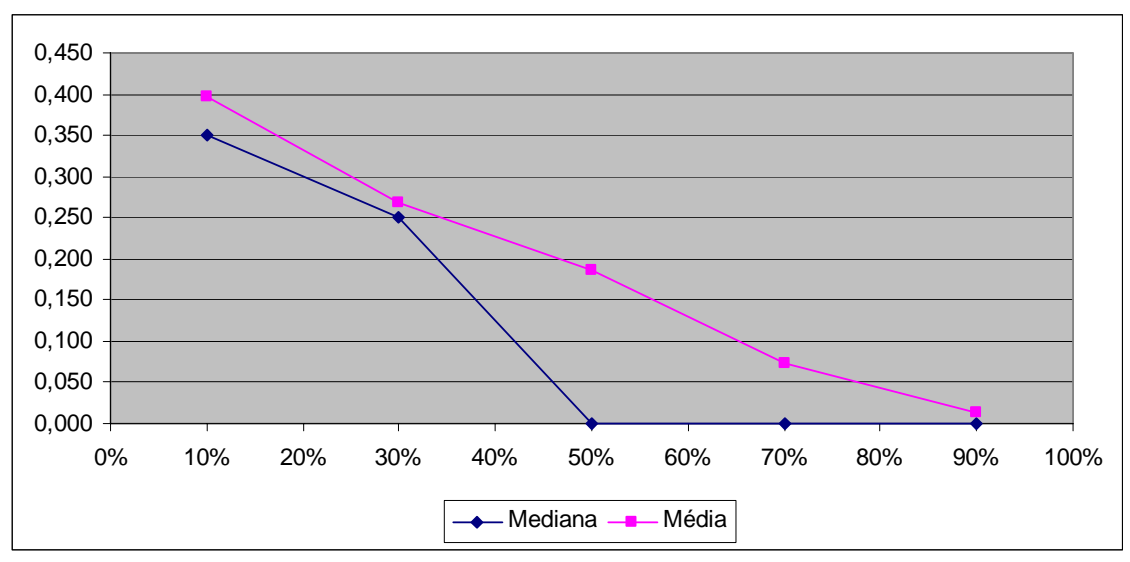

Figura 4.19 - Influência do eventos instantâneos no tempo entre duas evoluções consecutivas de tempo (do simulador)

\subsection{Síntese do capítulo}

Na seção 4.1 foi retomada a discussão a respeito da simulação distribuída abordada na seção 2.2, porém, agora com o foco nos algoritmos de sincronização do tempo de simulação. As abordagens mais conhecidas para sincronizar os tempos de simulação são a conservadora e a otimista. A maior parte dos trabalhos pesquisados aborda a simulação em computadores paralelos. No entanto, o avanço da tecnologia da informação e das redes de comunicação estão contribuindo para o desenvolvimento de pesquisas na área de simulação distribuída (computadores em rede). Observa-se também que em um primeiro momento as pesquisas nesta área procuram adaptar os algoritmos utilizados na simulação paralela para a distribuída. Desta forma, esta área apresenta um potencial de pesquisa onde novos algoritmos podem ser propostos.

Neste sentido, foi introduzido na seção 4.3 um novo algoritmo para a sincronização de tempo em simulação distribuída, ao invés de se trabalhar com computadores em paralelo (que possuem mais de um processador). Optou-se por utilizar uma abordagem conservadora, onde adaptou-se o conceito de gerenciamento da 
comunicação utilizado nas redes de comunicação com protocolo Token Ring. Para tanto, na seção 4.2 realizou-se uma breve revisão sobre os principais aspectos das redes de comunicação baseadas no protocolo Token Ring.

Neste trabalho, ao invés do token ser utilizado para gerenciar o acesso das estações ao meio físico, ele é utilizado para gerenciar a evolução dos relógios locais dos modelos envolvidos no processo de simulação distribuída. Seus principais algoritmos foram apresentados na seção 4.3 .

Através do uso de um simulador implementado para validar o algoritmo proposto, foram realizados alguns ensaios (seção 4.4). Entre estes ensaios, estão a influência do número de simuladores, bem como das características da rede de comunicação, no desempenho da simulação. Os ensaios realizados foram relevantes para avaliar o desempenho da simulação. Entretanto, outros ensaios ainda são necessários, seja quanto ao número de simuladores, seja com relação às redes de comunicação utilizadas, variando-se tanto a taxa de transmissão quanto sua carga (aplicativos utilizando a rede visando deteriorar a qualidade de serviço). Uma limitação das análises realizadas é a falta de material publicado com dados que possam ser utilizados para comparação do desempenho do algoritmo proposto. 


\section{COMENTÁRIOS FINAIS E CONCLUSÕES}

Este trabalho tratou da modelagem de sistemas produtivos discretos para análise através de simulação, em especial no contexto da simulação distribuída, a qual trata da execução de simulações em computadores fisicamente dispersos, conectados através de uma LAN (Local Area Network) ou WAN (Wide Area Network), visando, por exemplo, a redução do tempo de simulação, maior tolerânica a falhas e mesmo a distribuição geográfica.

\subsection{Principais contribuições}

Visando contribuir para a evolução das técnicas de modelagem e simulação, em especial a distribuída, propõe-se neste trabalho (1) um novo método para a modelagem hieráquica de sistemas produtivos; e (2) um novo algoritmo para a sincronização da evolução do tempo de simulação de diferentes simuladores interagindo através de redes de comunicação.

No que se refere ao método de modelagem proposto, este permite que o sistema produtivo em estudo seja detalhado e compreendido em etapas, através de detalhamentos sucessivos. Esta abordagem permite uma melhor caracterização dos elementos que compõem o sistema bem como os relacionamentos existentes entre eles. Elementos que possuem características em comum, mesmo que utilizados em contextos distintos no sistema produtivo, podem ser representados através de um único modelo, garantindo a sua reusabilidade ao mesmo tempo que permite a criação de uma biblioteca de modelos. Neste nível, os elementos podem ser verificados quanto a suas propriedades e funcionalidades. A partir da composição destes elementos, pode-se criar elementos mais complexos, permitindo que sub-sistemas sejam gerados e validados quanto a sua funcionalidade dentro do sistema produtivo como um todo. Através de sucessivas composições, obtém-se o modelo completo do sistema produtivo. O método proposto foi aplicado a estudos de caso onde foi possível comprovar a efetividade do método proposto.

Quanto ao algoritmo para a sincronização da evolução do tempo de simulação, o algoritmo proposto neste trabalho baseia-se no conceito de gerenciamento da comunicação utilizado nas redes de comunicação com protocolo Token Ring, o qual 
foi adaptado com êxito para esta finalidade, como pôde ser comprovado através de ensaios realizados com o auxílio de um simulador implementado para esta finalidade. Entretando, destaca-se a necessidade de se realizar novos ensaios com maior número de simuladores bem como com redes de comunicação, variando-se tanto a taxa de transmissão quanto sua carga (aplicativos utilizando a rede visando deteriorar a qualidade de serviço).

Observa-se ainda que em um primeiro momento as pesquisas nesta área procuram adaptar os algoritmos utilizados na simulação paralela para a distribuída. Desta forma, esta área apresenta um potencial de pesquisa onde novos algoritmos podem ser propostos e dados relativos a seus desempenhos, publicados, pois uma limitação das análises realizadas é a falta de material publicado com dados que possam ser utilizados para comparação do desempenho do algoritmo.

\subsection{Trabalhos futuros}

Dentre trabalhos correlacionados que podem ser desenvolvidos, pode-se citar: projeto e implementação de um ambiente de modelagem e simulação que permita o estudo de sistemas produtivos através da simulação distribuída. Neste sentido, no anexo G é apresentado um esboço de como este ambiente poderia ser estruturado;

> estudo da simulação distribuída quanto ao tempo e carga dos modelos, avaliando as vantagens em se utilizar um repositório de modelos centralizadou ou disperso, ou seja, cada simulador teria seu próprio repositório de modelos, bem como quanto ao acompanhamento da dinâmica dos modelos simulados, bem como a consolidação e visualização dos resultados;

estudo de formas de se realizar a migração de modelos entre estações durante a simulação, permitindo que em caso de sobrecarga ou mesmo falha de algum estação o modelo seja transferido de uma estação para outra da rede de comunicação, de forma transparente para o usuário;

estudo de formas de se realizar o balanceamento de carga entre os processadores e a rede de comunicação, levando-se em consideração a complexidade dos modelos, a quantidade de informações trocadas com outros modelos durante a simulação, bem como a freqüência com que este é requisitado pelos demais; 
estudo de formas de se recuperar o estado de modelos em caso falhas (falta de energia, reset forçado pelo usuário, problemas de comunicação, etc.), durante a simulação, e de forma transparente para o usuário. 


\section{ANEXO A - PFS (PRODUCTION FLOW SCHEMA)}

Em sistemas de pequeno porte observa-se com facilidade o relacionamento entre as partes e o desenvolvimento de modelos destes sistema utilizando Rede de Petri (RdP) torna-se uma tarefa fácil. Porém, a medida em que os sistemas vão se tornando maiores e mais complexos, as relações entre os componentes deste deixam de ser tão visíveis. Para sanar esta dificuldade, foi proposta por Miyagi (1996) uma metodologia denominada PFS (Production Flow Schema), que ao invés de se desenvolver diretamente a estratégia de controle do sistema a eventos discretos, isto é, o modelo em nível detalhado, adota-se primeiro a modelagem do sistema em nível conceitual e em seguida passa-se a detalhar gradativamente cada elemento, indo de um nível macro até o seu nível mais detalhado, ou seja, até se atingir um nível de detalhamento que se possa representar suas funcionalidades com, por exemplo, a RdP.

No PFS não existe o conceito de marcas ou marcações. As inscrições em seus elementos indicam quando (em relação a outros elementos) e como estas operam (por indicação textual). As redes PFS têm como objetivo principal mostrar explicitamente os componentes que formam o sistema e quais relações existem entre cada um deles.

O PFS pode ser representado por três elementos básicos (Figura A.1), que são:

elementos ativos - correspondente às atividades (macro eventos que representam a realização de operações como processamento, montagem, desmontagem);

$>$ elementos passivos - correspondente às inter-atividades (locais onde material, energia ou informações entram, ficam temporariamente armazenados e saem);

arcos - que representam as relações entre os elementos ativos e passivos e indicam o sentido do fluxo de itens (materiais, informações, etc.). Este não representa necessariamente um elemento real do sistema, em geral, descreve uma relação lógica, abstrata entre os elementos. 


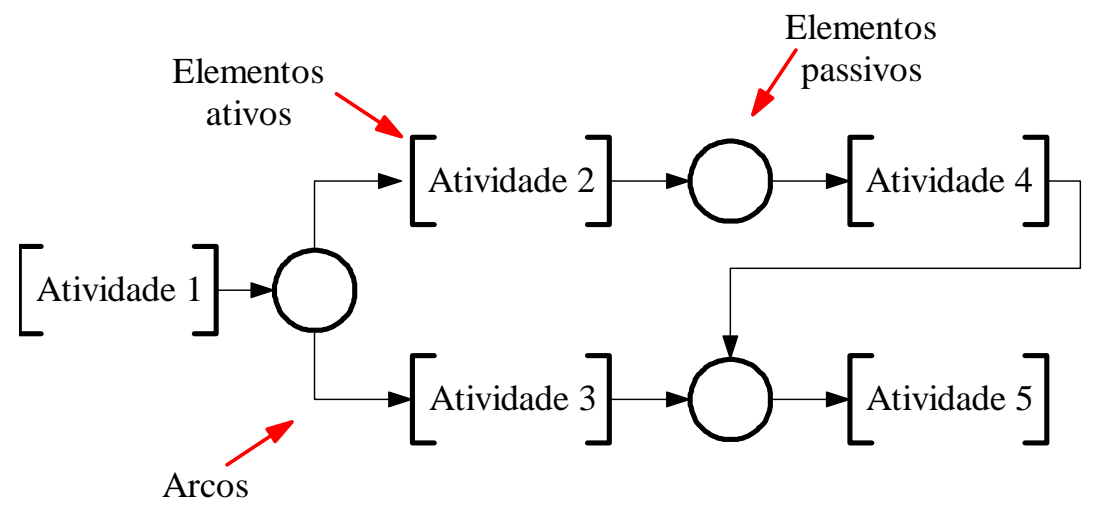

Figura A.1 - Exemplo de um grafo PFS. 


\section{ANEXO B - OBJETOS E UMA ABORDAGEM ORIENTADA À OBJETOS}

O conceito de objetos foi adotado inicialmente na estruturação de projetos de softwares. Ele surgiu como uma evolução da forma de se pensar sistemas e veio a substituir o paradigma estruturado ${ }^{21}$ (DOUGLASS, 1999).

Dentre as vantagens de se utilizar orientação a objetos no projeto de sistemas, frente a outras técnicas, pode-se citar (DOUGLASS, 1998, 1999; COSTA et al., 2001):

$>$ aumento da capacidade de se abstrair problemas - modelos estruturados possuem algumas facilidade de abstração e encapsulamento limitadas mas forçam uma separação artificial entre estrutura e comportamento. Já a modelagem orientada à objetos mantém uma forte relação entre os dados e os itens que os manipulam;

$>$ maior facilidade de reutilização de modelos - a modelagem orientada a objetos inclui dois meios táticos para permitir o reuso: generalização e refinamento. A generalização suporta o reuso através da adição e extensão dos componentes existentes sem mudanças em seu código fonte. Refinamento é similar à generalização mas permite que os objetos não necessitem ser completamente especificados, permitindo que possam ser refinados, adicionando-se as partes “faltantes";

> melhor suporte para confiança e segurança - devido a sua forma de abstração e encapsulamento, a interação entre diferentes componentes orientados a objetos pode ser limitada a poucas interfaces ${ }^{22}$ bem definidas. Isso aumenta a confiança pois é possível controlar como os componentes interagem;

suporte inerente à concorrência - métodos estruturados não possuem a noção de concorrência, gerenciamento ou mesmo sincronização de tarefas. Os sistemas orientados a objetos são inerentemente concorrentes, e os detalhes das sincronizações das tarefas podem ser representados através de diagramas.

Objetos representam entidades que possuem tanto atributos como comportamentos. Objetos podem representar entidades do mundo real (como tornos,

\footnotetext{
${ }^{21}$ Os métodos estruturados tratam o sistema como uma coleção de funções decompostas em mais funções primitivas. Os dados são secundários do ponto de vista estruturado.
} 
fresas, robôs, sensores, etc.), representar entidades puramente conceituais (pacotes de dados, por exemplo) ou mesmo entidades visuais (como histogramas, gráficos, polígonos linhas ou círculos). Todas estas entidades possuem aspectos, tais como (DOUGLASS, 1998, 1999):

$>$ identidade (identificação) - um nome para o objeto;

$>$ atributo (s) -refere-se aos dados encapsulados em um objeto;

$>$ comportamento (operação ou método) - são serviços que outros objetos podem requisitar através da (s) interface (s) do objeto;

$>$ estado (s) - a forma como este é apresentado ou ainda, uma memória;

$>$ responsabilidades - as responsabilidades de um objeto são funções que este desempenha no sistema. A interface e o comportamento provêem os meios pelos quais as responsabilidades são localizadas, mas não as define.

A idéia chave dos objetos é que este combina estas propriedades em uma única unidade (une dados e funções), enquanto a abordagem estruturada para o projeto de softwares lida com dados e funções de forma separada. O objeto é a unidade fundamental de decomposição em programação orientada a objetos.

\footnotetext{
${ }^{22}$ Uma interface é a forma como um objeto se apresenta para os demais (a "cara” do objeto). Ela deve refletir as características essenciais de um objeto e que são necessárias à outros objetos. Os detalhes que não são essenciais para os demais objetos podem ser escondidos, ou seja, podem ser encapsulados.
} 


\section{ANEXO C - UML (UNIFIED MODELING LANGUAGE)}

Neste anexo procura-se fazer uma breve revisão sobre UML (Unified Modeling Language). A UML é uma ferramenta que emergiu dos métodos para análise e projeto de sistemas orientados a objetos e que, em 1997, foi reconhecida e aceita pela OMG (Object Management Group) como uma potencial notação padrão para modelar múltiplas perspectivas do sistemas (COSTA et al., 2001).

As classes são os elementos mais importantes no projeto de sistemas orientados a objetos. Uma classe é uma descrição de um conjunto de objetos que compartilham os mesmos atributos, operações, relacionamentos e semânticas. Uma classe implementa uma ou mais interfaces. Elas podem ser usadas para representar partes de software, de hardware ou elementos puramente conceituais (DOUGLASS, 1998; BOOCH et al., 1999).

Graficamente, uma classe é representada por um retângulo (Figura C.1). Além disso esta possui:

$>$ um nome - que a distingue de outras classes;

$>$ atributo (s) - que é uma propriedade identificada de uma classe que pode assumir um conjunto específico de valores;

operação (ões) - que é a implementação de serviços que pode ser requisitada de qualquer objeto da classe e que pode afetar seu comportamento.

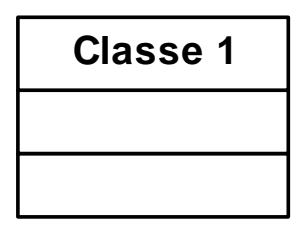

Figura C.1 - Ilustração da estrutura de uma classe.

Para que um objeto troque mensagens com outros, é necessário que exista algum tipo de associação (relacionamento) entre eles. Na UML, estas associações são feitas entre as classes, podendo ser de cinco tipos (DOUGLASS, 1998; BOOCH et al., 1999):

associações - são manifestações que permitem a troca de mensagens entre objetos. As associações são representadas por uma linha conectando duas classes; 
agregação - é usada quando um elemento possui outro de modo lógico ou físico (ex: um avião possui asas). Associações de agregação são ilustradas inserindo-se um losango na extremidade da conexão ligada ao proprietário do relacionamento;

composição - é um tipo específico de agregação onde o proprietário é explicitamente responsável por criar e destruir o objeto agregado;

generalização - define o relacionamento entre um elemento genérico e um elemento mais específico (melhor detalhado). É ilustrado por um retângulo na extremidade ligada à classe geral;

refinamento -suporta elaborações de modelos cujas classes não tenham sido completamente especificadas. O refinamento é apresentado da mesma forma que a generalização, porém em linha tracejada.

A Figura C.2 ilustra as formas de associações apresentadas.

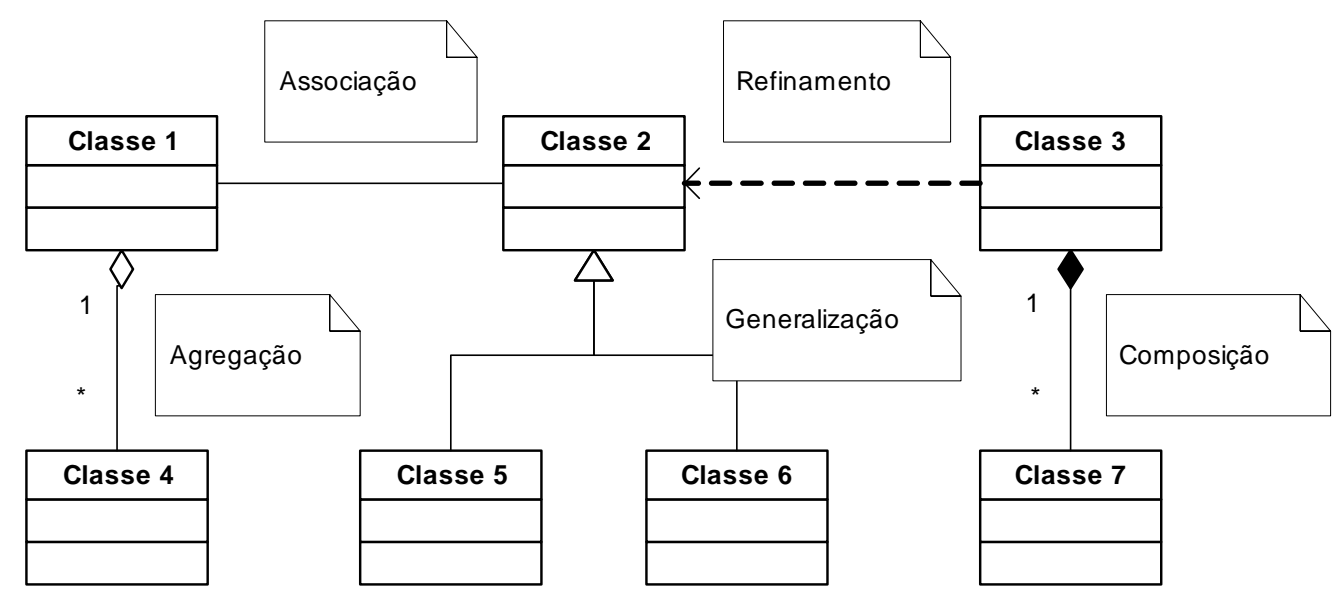

Figura C.2 - Ilustração das formas de associações.

De forma a auxiliar no projeto/modelagem de sistemas, a UML define um conjunto de diagramas que permitem representar graficamente um conjunto de elementos do sistema.

A UML incluí nove tipos de diagramas, sendo os quatro primeiros utilizados para se visualizar as partes estáticas do sistema, e os demais para se observar as partes dinâmicas deste (BOOCH et al., 1999; COSTA et al., 2001; AMBLER, 2002): 


\section{C.1. Diagrama de classes}

Diagramas de classes (Figura C.3) representam a estrutura interna das classes, que podem ser descritas pelo seu nome, atributos (documentados com uma descrição sobre o que eles contêm) e métodos (documentados com uma descrição sobre sua lógica), e seu relacionamento com outras classes, que são descritos através de relacionamentos do tipo herança, associação ou agregação.

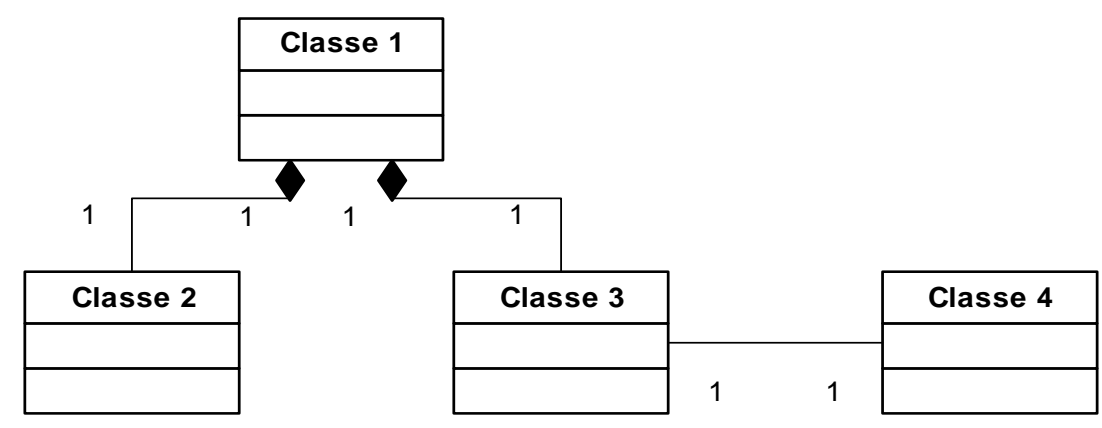

Figura C.3 - Um exemplo de diagrama de classes (COSTA et al., 2001).

\section{C.2. Diagrama de objetos}

O diagrama de objetos mostra um conjunto de objetos e seus relacionamentos. $\mathrm{O}$ diagrama de objetos representa a visão estática de instâncias de entidades representadas nos diagramas de classes.

\section{C.3. Diagrama de componentes}

O diagrama de componentes (Figura C.4) mostra um conjunto de componentes ${ }^{23} \mathrm{e}$ seus relacionamentos. Usa-se o diagrama de componentes para ilustrar de forma estática a implementação do sistema. Os diagramas de componentes se relacionam aos diagramas de classes visto que um componente é composto por uma ou mais classes, interfaces e colaborações;

\footnotetext{
${ }^{23} \mathrm{Um}$ componente pode ser qualquer item maior - tal como um subsistema ou uma aplicação orientada a objetos (Ambler, 2002).
} 


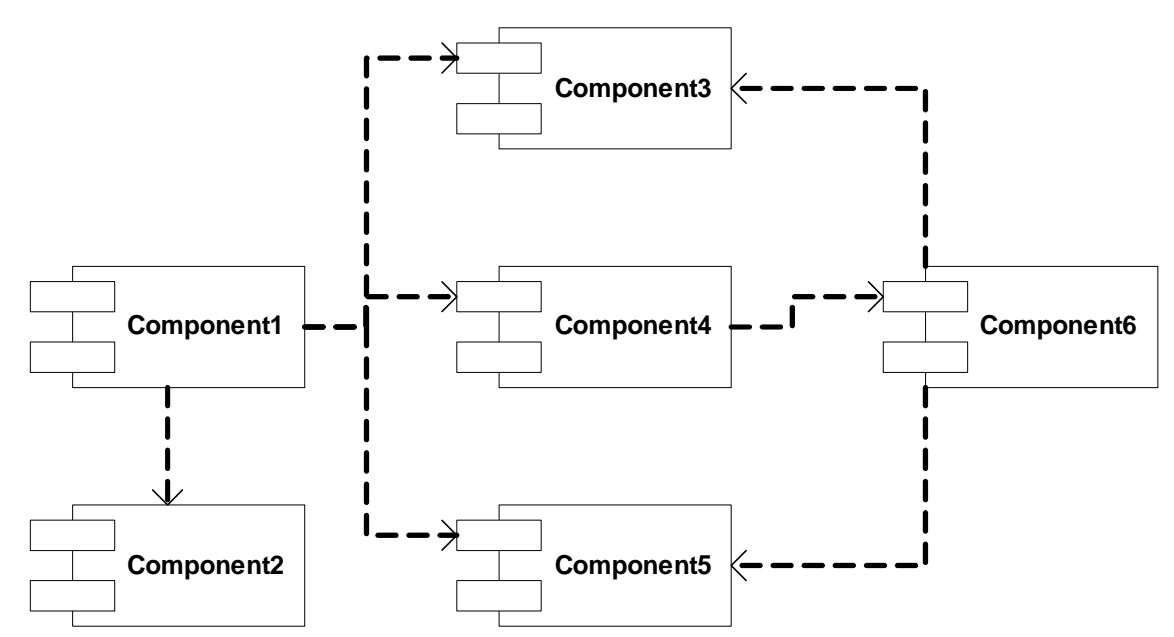

Figura C.4 - Um exemplo de diagrama de componentes (AMBLER, 2002).

\section{C.4. Diagrama de distribuição}

Este diagrama mostra a configuração dos nós e seus relacionamentos entre os componentes e a forma como eles interagem em tempo real. Os diagramas de distribuição (Figura C.5) estão relacionados aos diagramas de componentes pois um nó é composto por um ou mais componentes.

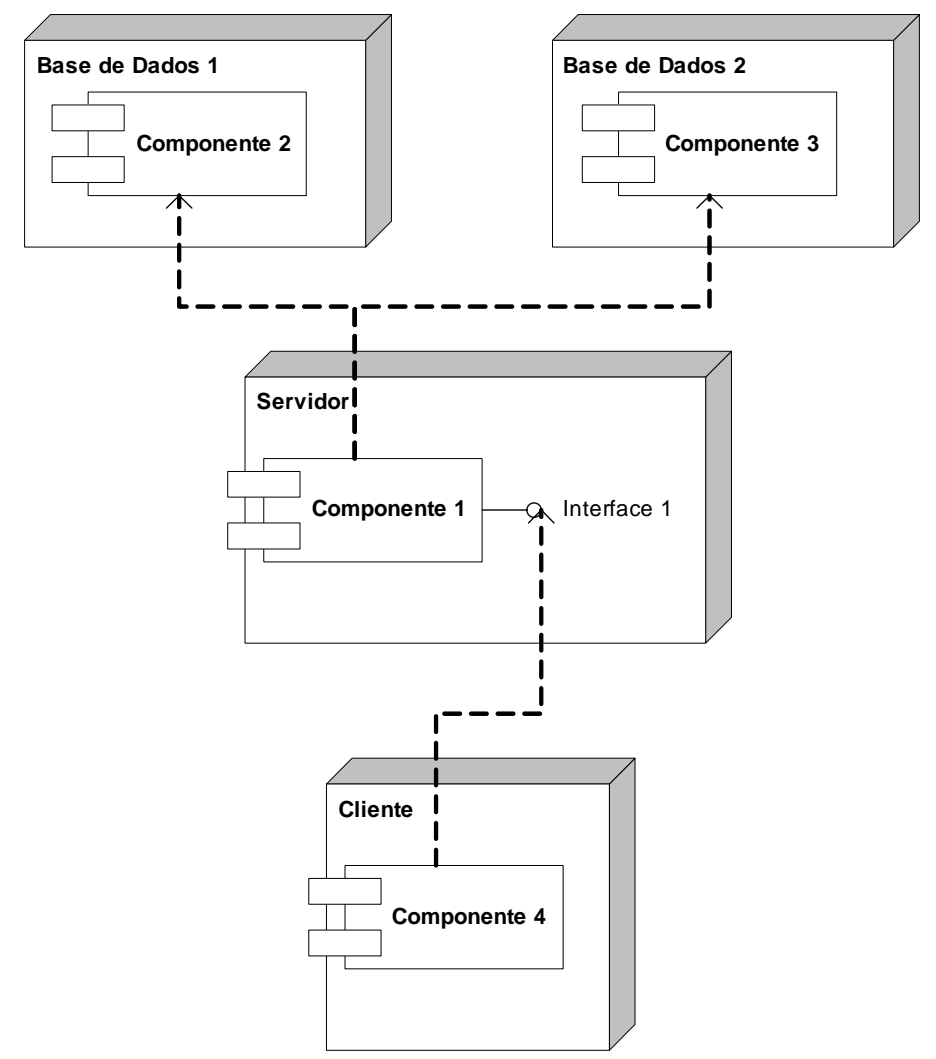

Figura C.5 - Um exemplo de diagrama de distribuição (AMBLER, 2002). 


\section{C.5. Diagramas de casos de uso}

Este diagrama mostra a forma como um ator (uma pessoa, organização ou sistema externo, que representa um estímulo externo ao sistema, ação) do mundo real interage com a aplicação. Eles abordam a visão estática do caso de uso do sistema. Estes diagramas são especialmente importantes para organizar e modelar o comportamento do sistema.

Os casos de uso representam as funcionalidades de alto nível do sistema, descrevendo “o que o sistema deveria fazer”. A descrição através de casos de uso provê informações que ajudam quando se especifica as propriedades (atributos e métodos) das classes necessárias para atuar como um caso de uso. A Figura C.6 ilustra um exemplo de diagrama de caso de uso.

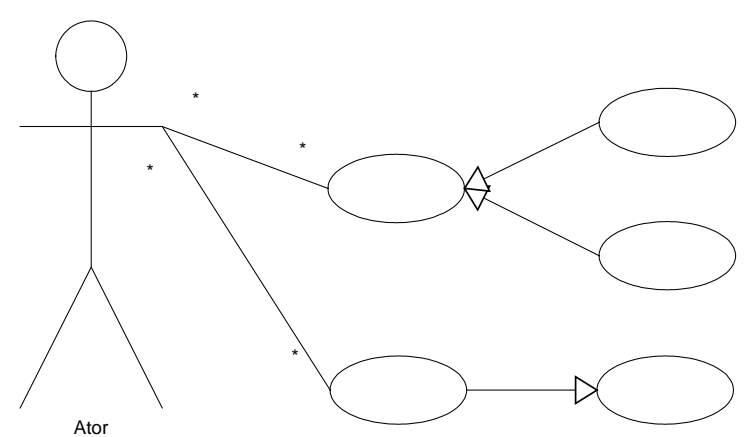

Figura C.6 - Um exemplo de um diagrama de caso de uso (COSTA et al., 2001).

\section{C.6. Diagrama de gráfico de estados}

O diagrama de estados (Figura C.7) representa o comportamento interno de uma classe durante seu tempo de vida, mostrando as fases pelas quais passa o objeto derivado desta classe ao longo de seu ciclo de vida (da sua criação até sua destruição), e os eventos que causam a mudança de um estado para outro. Estados são definidos como situações durante a vida de um objeto onde este satisfaz algumas condições, desempenha algumas atividades, ou aguarda por algum evento. Uma transição é uma relação entre dois estados de um objeto indicando que baseando-se em certas ações e satisfazendo-se condições específicas, o estado de um objeto é alterado. 


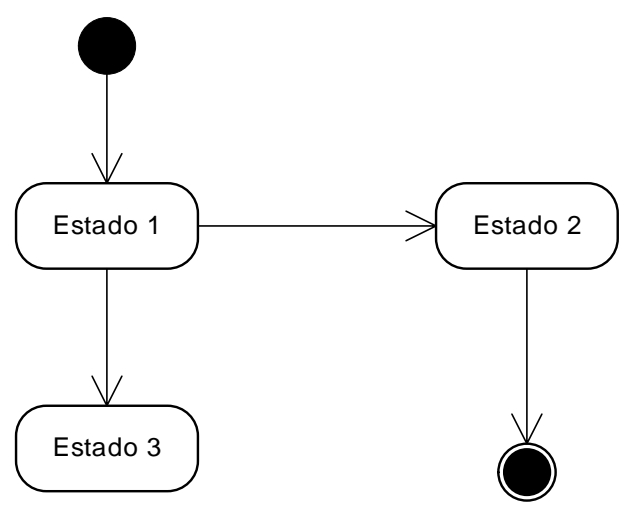

Figura C.7 - Um exemplo de diagrama de estados (COSTA et al., 2001).

\section{C.7. Diagrama de seqüência}

Uma diagrama de sequiência (um tipo de diagrama de interação ${ }^{24}$ ) é geralmente usando para definir rigorosamente a lógica para um cenário de caso de uso. Tradicionalmente os diagramas de sequiência (Figura C.8) mostram os tipos de objetos envolvidos no caso de uso, as mensagens (ordenadas no tempo) que trocam entre si, e qualquer valor retornado associado com a mensagem. Os diagramas de seqüência são uma forma de revisar o trabalho uma vez que ele força o projetista a revisar os passos através da lógica para preencher os cenários de caso de uso.

Estes diagramas representam principalmente os aspectos comportamentais dos objetos, mostrando que métodos (funções) são necessários para satisfazer um caso de uso específico (COSTA et al., 2001).

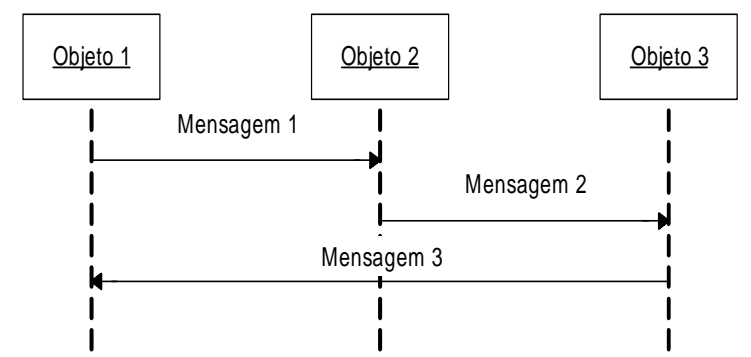

Figura C.8 - Um exemplo de diagrama de seqüência (COSTA et al., 2001).

\footnotetext{
24 Um diagrama de interação mostra uma interação, consistindo de um conjunto de objetos e seus relacionamentos, incluindo as mensagens trocadas entre eles. Diagramas de interação abordam a visão dinâmica do sistema.
} 


\section{C.8. Diagrama de colaboração}

É um diagrama de interação que enfatiza a organização estrutural dos objetos que enviam e recebem mensagens. Da mesma forma que o diagrama de estados é utilizado para documentar a complexidade interna de uma classe, os diagramas de colaboração são usados para documentar as interações externas entre objetos (Figura C.9).

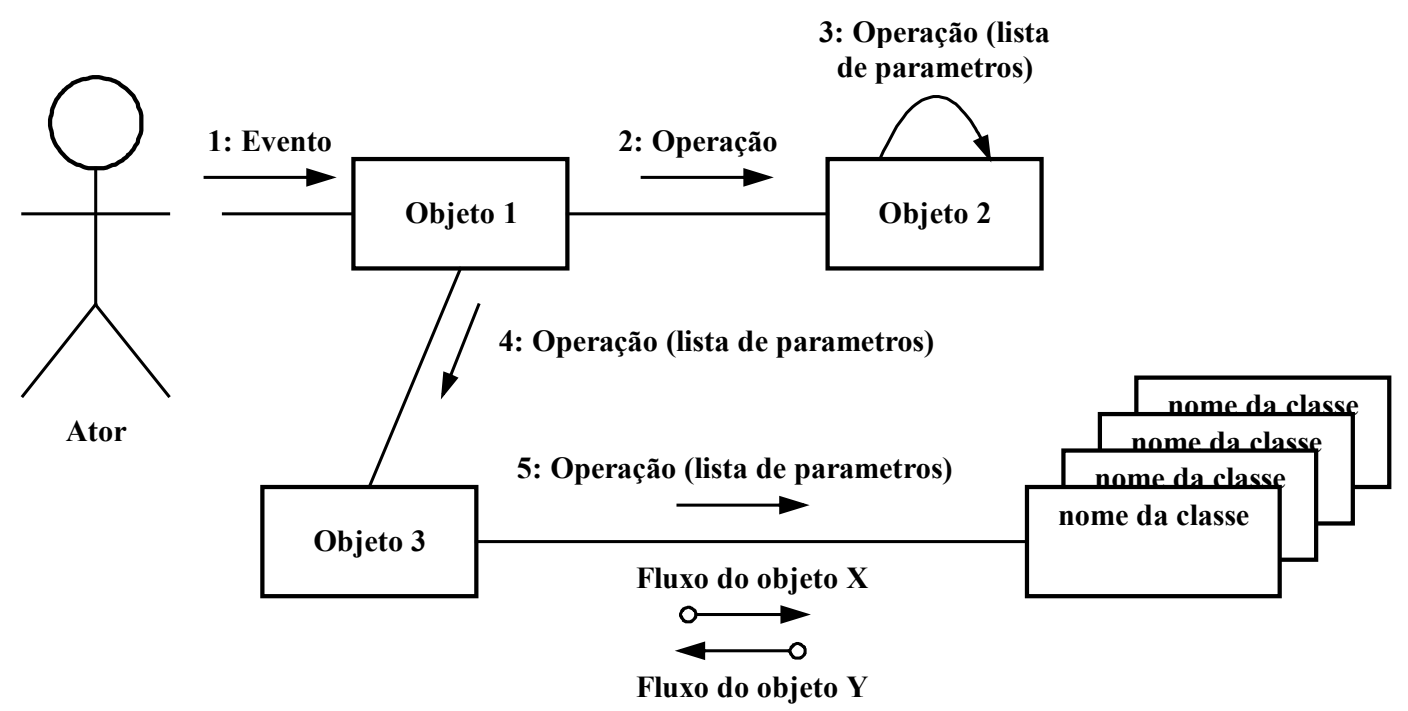

Figura C.9 - Um exemplo de diagrama de colaboração (DOUGLASS, 1998).

\section{C.9. Diagrama de atividades}

O diagrama de atividades (Figura C.10) modela a seqüência de atividades (passos) em um processo, bem como seus elementos ativos e passivos. Eles são tipicamente aplicados na modelagem tanto do fluxo de trabalho do sistema (entre objetos) quanto de uma operação.

Os diagramas de atividades são geralmente documentados com uma breve descrição da atividade e uma indicação da (s) ação (ões) que ocorre (m) durante um processo. 


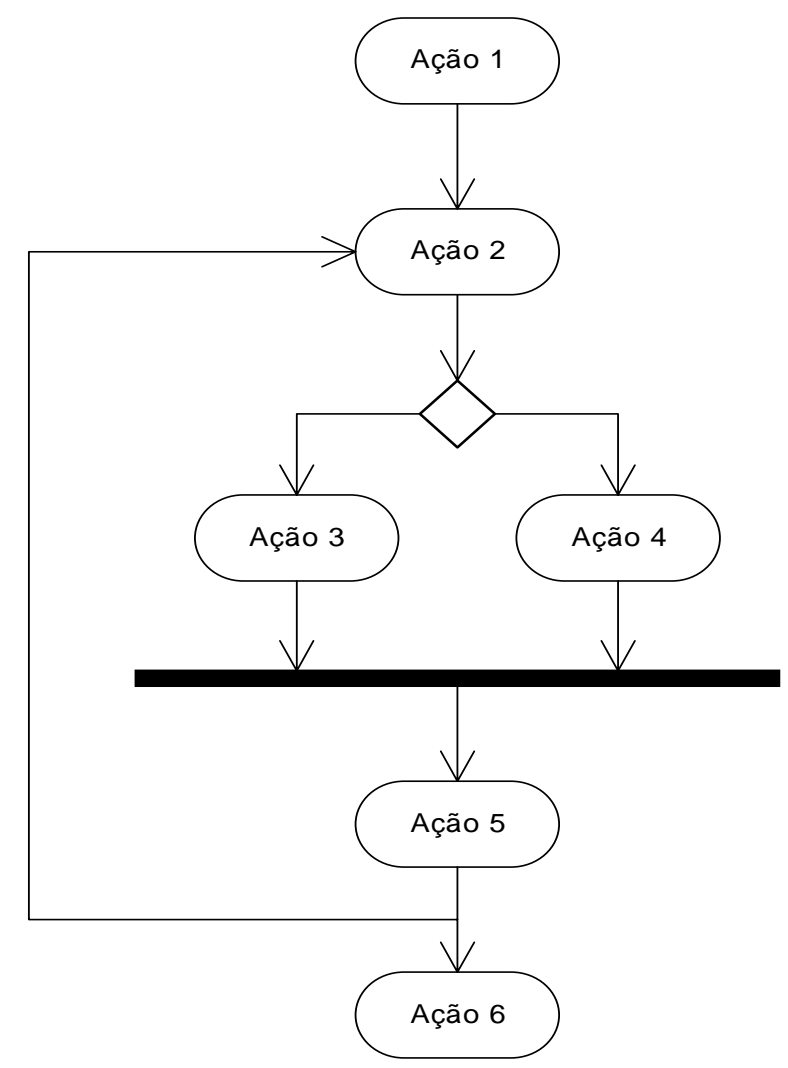

Figura C.10 - Um exemplo de diagrama de atividades (COSTA et al., 2001). 


\section{ANEXO D - UTILIZAÇÃO DE XML PARA ARMAZENAMENTO E COMPARTILHAMENTO DE MODELOS}

Este anexo se relaciona à seção 2.4, apresentando uma forma de descrever, armazenar e compartilhar os modelos propostos (classes, componentes e aplicativos).

Uma possibilidade é o uso de tabelas de banco de dados. Neste caso, um modelo seria subdivido em um conjunto de tabelas, cada uma contendo um tipo específico de elemento e seus respectivos atributos, isto é, uma tabela para armazenamento de lugares, outra de transições, outra de arcos, etc. (Figura D.1).

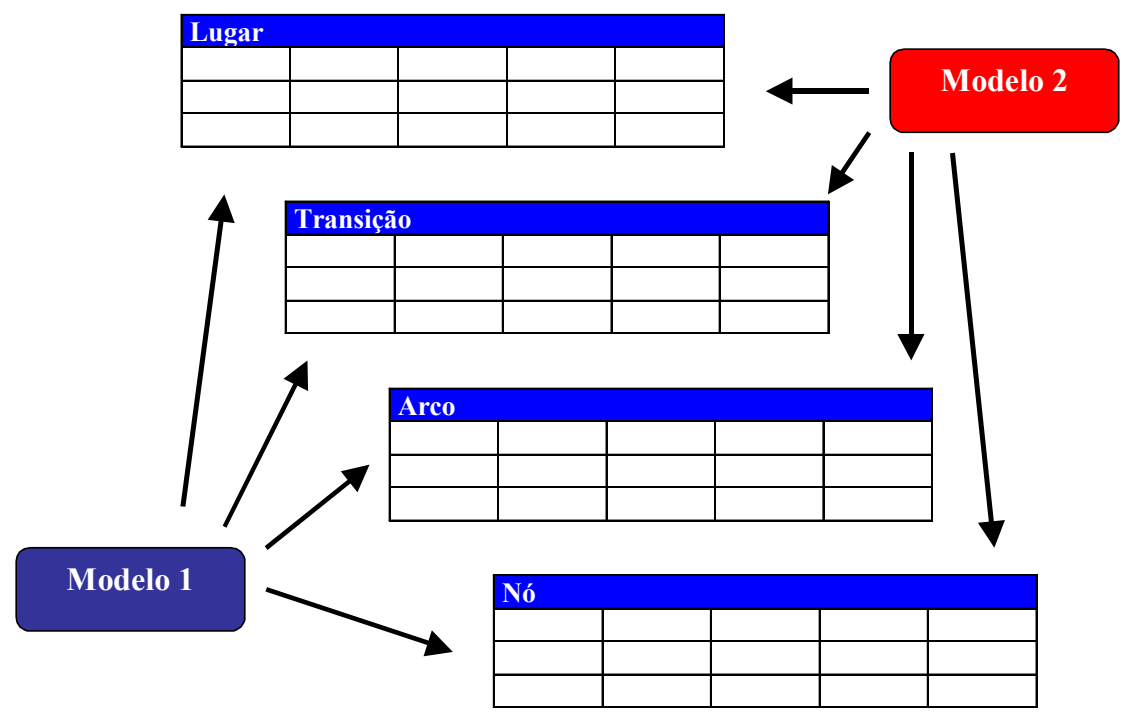

Figura D.1 - Uso de tabelas para o armazenamento de modelos em Rede de Petri.

Uma outra possibilidade vem sendo adotada pela comunidade de Rede de Petri (RdP), o Extensible Markup Language (XML) (W3C, 2005a). Originalmente o XML foi concebido para atender os desafios das publicações eletrônicas em larga escala, porém, este padrão vem desempenhando importante papel na troca de uma grande variedade de dados via internet. Com relação à RdP, o XML tem sido utilizado em muitas ferramentas de modelagem e simulação como formato para armazenamento de modelos. Mais do que pelo apelo comercial, tem sido adotada como uma forma de se propor uma notação única que possa ser utilizada nestas diferentes ferramentas de modelagem e simulação, permitindo assim o intercâmbio de modelos (JÜNGEL et al., 2000). Neste caso, todos os elementos que compõem um modelo estão presentes em um mesmo documento, delimitados por tags (Figura D.2). Esta notação apresenta-se como 
mais simples de se utilizar quando comparado ao uso de tabelas: alterações na estrutura da RdP implicam em mudanças no código que interpreta a RdP no simulador; porém, com o uso de XML, não há a necessidade de alterações nas colunas das tabelas e nem nas queries utilizadas na sua leitura e/ou escrita. Outro ponto positivo da XML para aplicação em RdP é a facilidade de compartilhamento de modelos que esta apresenta uma vez que todos os seus elementos estão contidos em um mesmo documento.

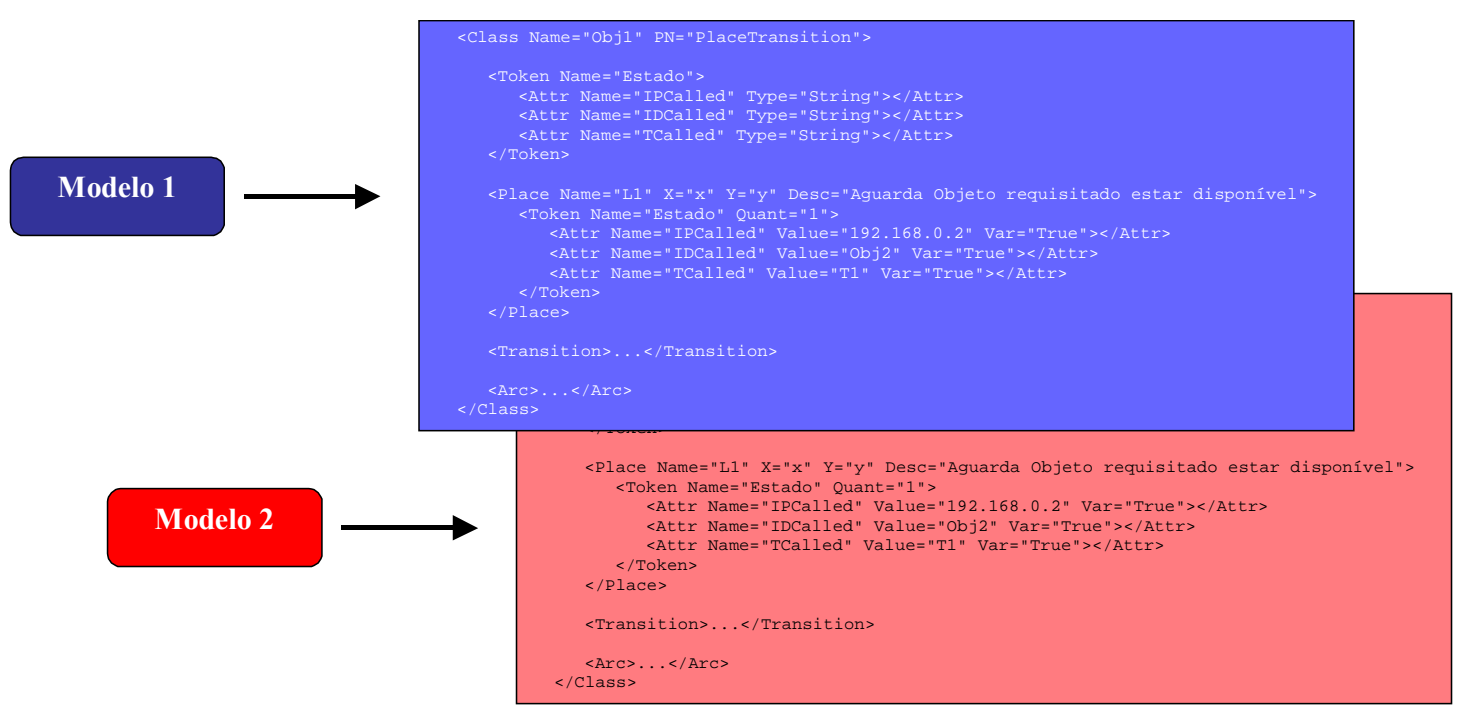

Figura D.2 - Uso de XML para o armazenamento de modelos em Rede de Petri.

Alguns membros da comunidade de RdP vem trabalhando em uma notação baseada em XML para o intercâmbio de modelos, chamada de PNML (Petri Net Markup Language) (JUNGLE; KINDLER; WEBER, 2000). A Figura D.3 apresenta um exemplo de RdP e a sua descrição em PNML é apresentada na Figura D.4.

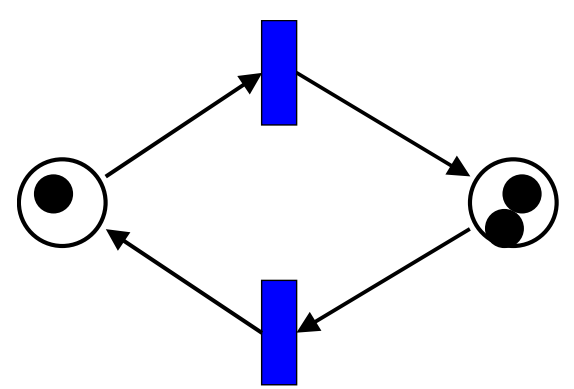

Figura D.3 - Uso de XML para o armazenamento de modelos em Rede de Petri ${ }^{25}$.

${ }^{25}$ <http://www.informatik.hu-berlin.de/top/pnml/download/nets/sample_ptNet.pnml>. Acesso em 10 de fevereiro de 2006. 


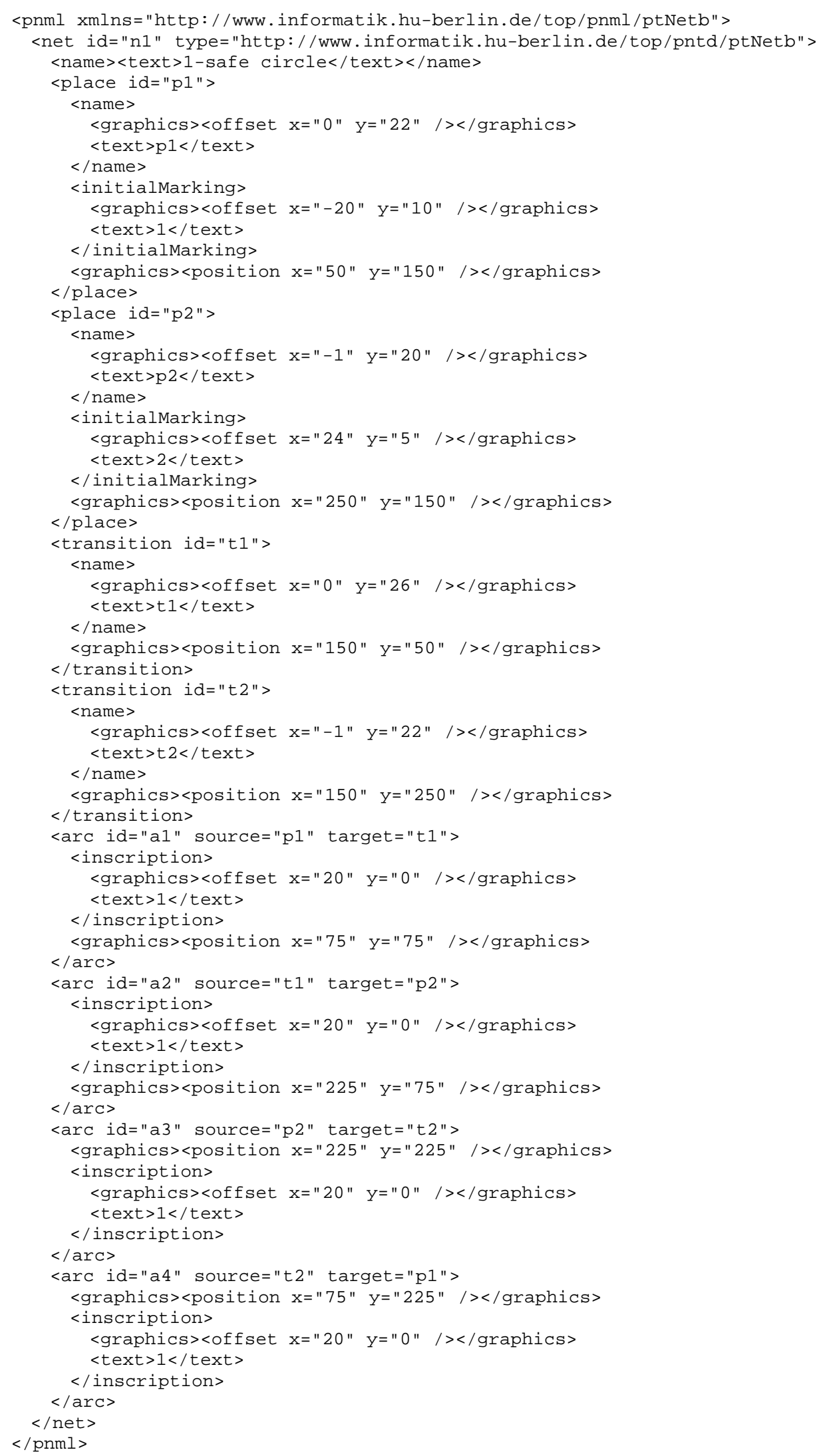

Figura D.4 - Exemplo de Rede de Petri descrita utilizando-se a notação PNML. 
A PNML não se trata de um trabalho fechado, permitindo assim novas contribuições. Neste sentido, visando-se descrever os modelos utilizando os conceitos de classes, componentes e aplicativos apresentados na seção 2.4, propôs-se o uso de uma notação, também baseado em XML, porém difererente do PNML, uma vez que o PNML não prevê até o momento o mesmo conceito de modelagem hierárquica proposto neste trabalho.

Para definir os tags que serão utilizados na aplicação bem como estes devem ser utilizados, a W3C adota como uma de suas linguagens de descrição o XML Schema (W3C, 2005b). O propósito de um XML Schema é definir e descrever classes de documentos XML através do uso de componentes de Schema a fim de conter e documentar a definição, o uso e o relacionamento de suas partes constituintes: tipos de dados, elementos e seu conteúdo, como atributos e seus valores. Tendo como exemplo a linha <place id="p1"> da Figura D.4, <place> é um elemento; id é um atributo; e p1 é um valor. O Schema também pode ser utilizado para prover informações adicionais como normalizações e valores "padrão” para atributos e elementos.

A Figura D.5 apresenta o XML Schema utilizado para descrever modelos do tipo classe (Figura 2.11), e a Tabela D.1 apresenta uma breve descrição de seus elementos e atributos.

A Figura D.6 apresenta o XML Schema utilizado para descrever modelos do tipo componente (Figura 2.12), e a Tabela D.2 apresenta uma breve descrição de seus elementos e atributos. Como apresentado na seção 2.4 um componente é composto por uma ou mais objetos baseados em classes. Desta forma, para a descrição de um componente é importante definir os objetos que o compõem, as classes em que cada objeto está baseado e a relação entre os objetos, sem no entanto detalhar seu conteúdo.

A Figura D.7 apresenta o XML Schema utilizado como base para descrever modelos do tipo aplicativo (Figura 2.15), e a Tabela D.3 apresenta uma breve descrição de seus elementos e atributos. Cada aplicativo é composto por um ou mais componentes. Faz-se necessário também definir os relacionamentos entre os componentes. 
$<$ ?xml version="1.๑" encoding="ISO-8859-1" ?>

<xsd: schema xmlns: xsd="http://WWW.w3.org/2001/XMLSchema">

// Definição dos tipos de atributos que as marcas podem comportar: inteiro ou string

<xsd:element name="At trType">

$<x$ sd: simpletype>

$<x s d$ :restriction base="xsd:string">

$<x s d$ :enumeration value="Integer">

$<x$ sd: enumeration value="String" >

$</ x s d$ :restriction $>$

$</ x s d$ : simpleType $>$

$</ x s d$ : element $>$

// Definição dos tipos de transições que podem ser definidas em um modelo: normal, temporizada,

// de entrada, ou de saída

$<$ xsd:element name="TransitionType">

<xsd: simpletype>

$<x s d$ :restriction base="xsd:string">

<xsd: enumeration value="Normal">

$<x s d$ : enumeration value="Timed">

$<x s d$ : enumeration value="Input">

$<x s d$ : enumeration value="Output">

$</ x s d$ :restriction $>$

$</ x s d$ : simpleType

$</ x$ sd:element $>$

// Definição dos tipos de arco que podem ser definidos em um modelo: padrão, habilitador, ou

// inibidor

$<x s d:$ element name="ArcType">

$<x$ sd: simpletype >

<xsd:restriction base="xsd:string">

$<x$ sd: enumeration value="Standard">

$<x s d$ : enumeration value="Enabling">

$<x s d$ : enumeration value="Inhibitor">

$</ x s d$ :restriction $>$

$</ x$ sd: simpleType $>$

$</ x$ sd:element $>$

// Definição do elemento “Class” que possui definições de marcas (elemento “Token”), lugares

// (elemento “Place”), transições (elemento “Transition”), arcos (elemento “Arc”), bem como os

// atribuntos "Name” (nome da classe) e "PN" (o tipo de RdP utilizada)

$<x s d$ :element name="Class">

$<x$ sd:complextype $>$

$<x s d$ : sequence $>$

// O elemento “Token” contém elementos do tipo atributo (“Attr”) e atributos: “Name” (nome // da marca) e "Desc" (descrição da marca)

$<x s d$ :element name="Token" maxOccurs="unbounded">

$<x$ sd:complextype >

$<x s d$ : sequence $>$

$<x s d$ :element name="Attr" maxoccurs="unbounded"> <xsd: complexType>

// Um elemento “Attr” possui dois tipos de atributos: "Name” (nome do atributo)

// e “Type" (tipo do atributo (inteiro ou string))

<xsd:attribute name="Name" type="xsd:string" use="required"/>

$<x s d: a t t r i b u t e$ name="Type" type="AttrType" use="required"/>

$</$ xsd:complexType $>$

$</ x$ sd:element $>$

$</ x s d$ : sequence $>$

<xsd:attribute name="Name" type="xsd:string" use="required"/>

$<x s d: a t t r i b u t e$ name="Desc" type="xsd:string" use="optional"/>

$</ x$ sd: complexType $>$

$</ x s d:$ element $>$

Figura D.5 - Descrição da estrutura de uma classe (em Rede de Petri) utilizando XML Schema. 


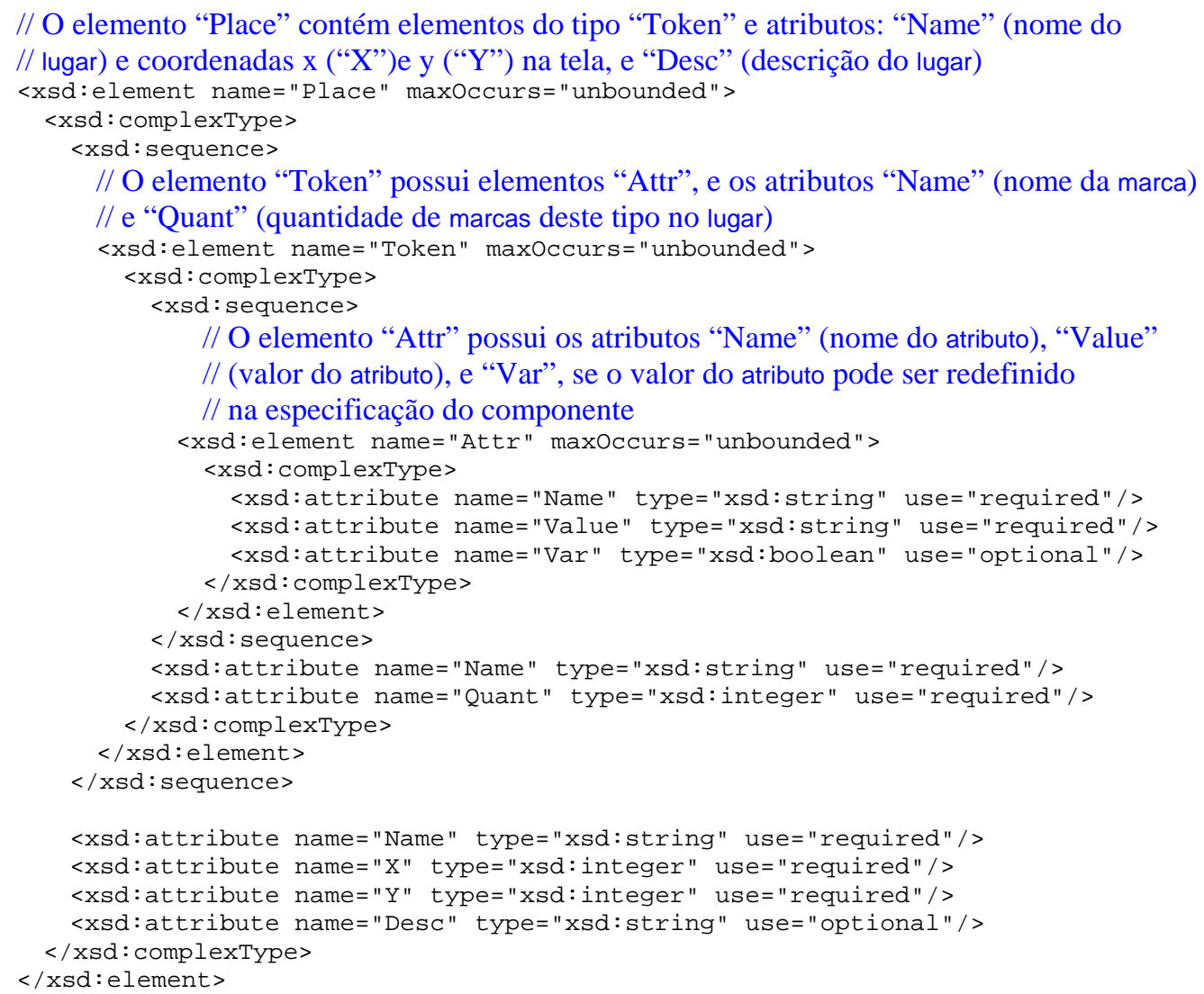

// O elemento “Transition” contém elementos do tipo "Rule”, que são regras associadas à // transição. Além disso, possui osatributos “Name” (nome da transição), "Desc” (descrição // da transição), coordenadas x ("X”) e y ("Y”) do elemento na tela, “Ang” (a orientação da // transição na tela - horizontal ou vertical), “Type” (o tipo de transição), “Time” (o tempo de // disparo no caso da transição ser temporizada) e "Var" (para o tempo poder ser redefinido // na especificação do componente

<xsd:element name="Transition" maxoccurs="unbounded">

$<x s d$ : complextype>

$<x s d$ : sequence $>$

$<x$ sd:element name="Rule" type="xsd:integer" maxoccurs="unbounded"/>

$</ x s d$ : sequence $>$

$<x s d$ :attribute name="Name" type="xsd:string" use="required"/>

$<x s d: a t t r i b u t e$ name="Desc" type="xsd:string" use="optional"/>

$<x s$ :attribute name="X" type="xsd:integer" use="required"/>

$<x s d: a t t r i b u t e$ name="Y" type="xsd:integer" use="required"/>

$<x s d$ :attribute name="Ang" type="xsd:boolean" use="optional"/>

<xsd:attribute name="Type" type="TransitionType" use="required"/>

<xsd:attribute name="Time" type="xsd:decimal" use="optional"/>

<xsd:attribute name="Var" type="xsd:boolean" use="optional"/>

$</ x$ sd: complexType $>$

$</ x s d$ : element $>$

Figura D.5 - Descrição da estrutura de uma classe (em Rede de Petri) utilizando XML Schema. (continuação). 


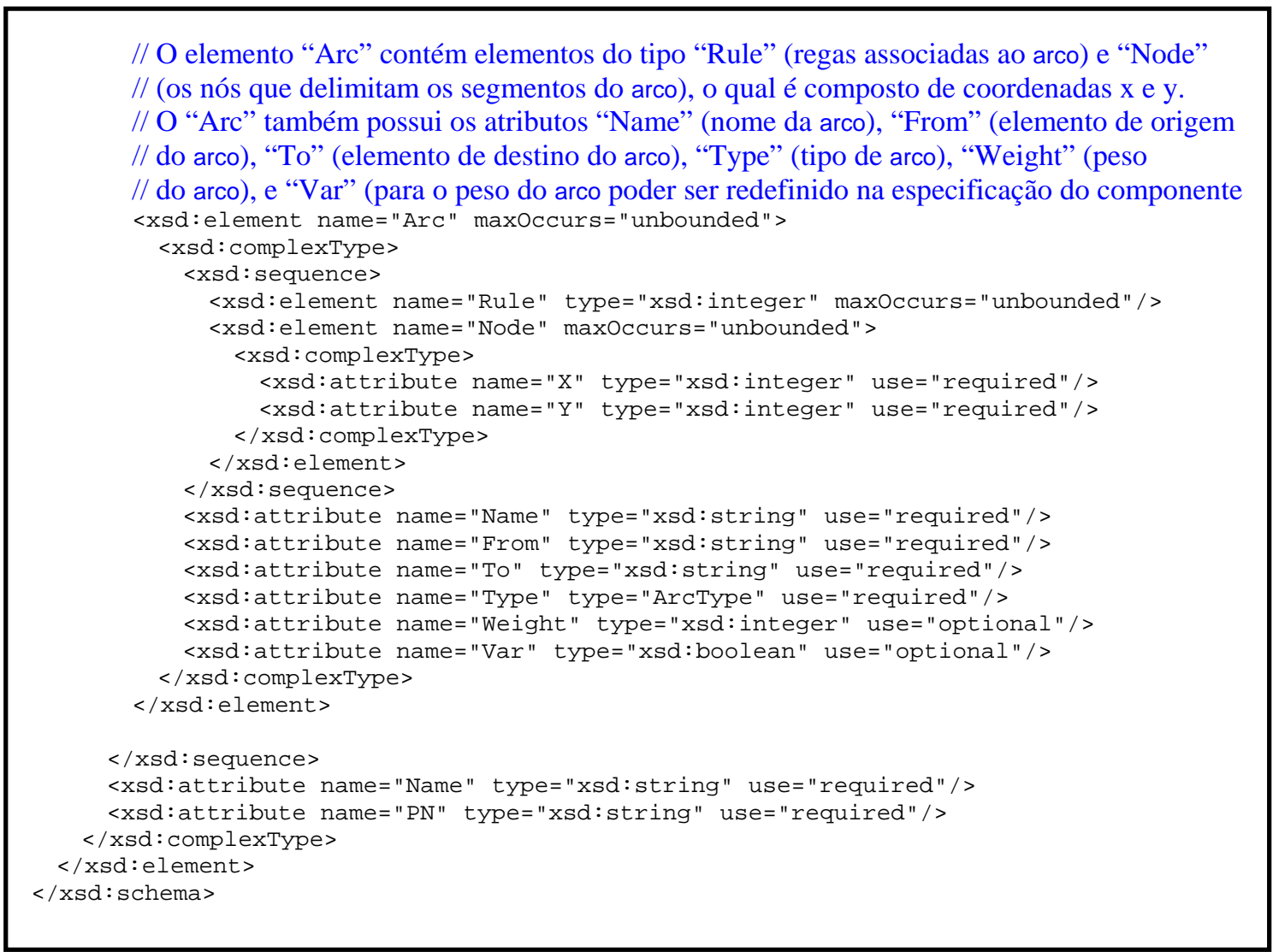

Figura D.5 - Descrição da estrutura de uma classe (em Rede de Petri) utilizando XML Schema. (continuação).

Tabela D.1 - Descrição dos tags utilizados na Figura D.5.

\begin{tabular}{|l|l|}
\hline Marcador & Descrição \\
\hline Class & Elemento que indica o início da declaração de uma classe \\
\hline Name & Atributo que indica o nome da classe \\
\hline PN & Atributo que indica o tipo de Rede de Petri utilizada \\
\hline Token & Elemento que indica a declaração de marca usada na Rede de Petri \\
\hline Name & Atributo que indica nome da marca \\
\hline Desc & Atributo que indica a descrição \\
\hline Attr & Elemento que indica a existência de atributo na marca \\
\hline Name & Atributo que indica o nome do atributo da marca \\
\hline Type & Atributo que indica o tipo de atributo da marca \\
\hline Place & Elemento que indica a declaração de lugar usado na Rede de Petri \\
\hline Name & Atributo que indica o nome do lugar \\
\hline X & Atribunto que indica a coordenada x do lugar \\
\hline Y & Atribunto que indica a coordenada y do lugar \\
\hline Desc & Atributo que indica a descrição \\
\hline Token & Elemento que indica a presença de marca no lugar \\
\hline Name & Atributo que indica o nome da marca \\
\hline Quant & Atributo que indica a quantidade de marcas presente no lugar \\
\hline Attr & Elemento que indica a presença de atributo no lugar \\
\hline Name & Atribunto que indica o nome do atributo da marca \\
\hline Value & Atributo que indica o valor do atributo da marca \\
\hline Var & $\begin{array}{l}\text { Atributo que indica se o valor do atributo pode ser alterado no nível superior, o de } \\
\text { componente }\end{array}$ \\
\hline
\end{tabular}


Tabela D.1 - Descrição dos tags utilizados na Figura D.5 (continuação).

\begin{tabular}{|l|l|}
\hline Marcador & Descrição \\
\hline Transition & Elemento que indica a declaração de transição usada na Rede de Petri \\
\hline Name & Atributo que indica o nome da transição \\
\hline Desc & Atributo que indica a descrição \\
\hline X & Atribunto que indica a coordenada x da transição \\
\hline Y & Atribunto que indica a coordenada y da transição \\
\hline Ang & Atributo que indica se a transição está rotacionada de 90 graus \\
\hline Type & Atributo que indica o tipo de transição (normal, temporizada, de entrada ou saída) \\
\hline Time & Atributo que indica o tempo de disparo no caso de transição temporizada \\
\hline Var & $\begin{array}{l}\text { Atributo que indica se o valor do atributo pode ser alterado no nível superior, o de } \\
\text { componente }\end{array}$ \\
\hline Rule & Elemento que indica a declaração de uma regra associada à transição \\
\hline Arc & Elemento que indica a declaração de arco usado na Rede de Petri \\
\hline Name & Atributo que indica o nome do arco \\
\hline From & Atributo que indica a origem (lugar ou transição) do arco \\
\hline To & Atributo que indica o destino (lugar ou transição) do arco \\
\hline Type & Atributo que indica o tipo do arco (normal, habilitador ou inibidor) \\
\hline Weigh & Atributo que indica o peso do arco \\
\hline Var & $\begin{array}{l}\text { Atributo que indica se o valor do atributo pode ser alterado no nível superior, o de } \\
\text { componente }\end{array}$ \\
\hline Rule & Elemento que indica a declaração de regra atrelada ao arco \\
\hline Node & Elemento que indica a declaração de nós que compõem o arco \\
\hline X & Atributo que indica a coordenada x do arco \\
\hline Y & Atributo que indica a coordenada y do arco \\
\hline
\end{tabular}

<?xml version="1.๑" encoding="IS0-8859-1" ?>

<xsd: schema xmlns: xsd="http://WWW.w3.org/2001/XMLSchema">

// O elemento “Component” contém elementos do tipo "Object” (objetos baseados nas classes),

// "CompInterface” (as interfaces externas do componente), e "Arc” (os arcos que conectam as

// transições de interface dos objetos; e o atributo "Name" (o nome do componente)

$<x$ sd:element name="Component">

$<$ xsd: complexType>

$<x$ sd: sequence $>$

// O elemento “Object” possui quatro atributos: “Name” (nome do objeto), “Class” (classe em

// que o objeto se baseia), e suas coordenadas x e y na tela

<xsd:element name="Object" maxoccurs="unbounded">

<xsd:complexType>

$<x s d$ :attribute name="Name" type="xsd:string" use="required"/>

$<x s d$ :attribute name="Class" type="xsd:string" use="required"/>

<xsd:attribute name="X" type="xsd:integer" use="required"/>

$<x$ s:attribute name="Y" type="xsd:integer" use="required"/>

$</ x s d$ : complexType $>$

$</ x s d:$ element $>$

// O elemento "CompInterface” possui os atributos: "Name” (nome da interface), "Object”

// (nome do objeto que está relacionada), “Transition” (transição do objeto que está sendo

// mapeada como interface do componente), e coordenadas x e y na tela

<xsd:element name="CompInterface" maxoccurs="unbounded">

$<x s d$ : complexType $>$

$<x s d$ :attribute name="Name" type="xsd:string" use="required"/>

<xsd:attribute name="Object" type="xsd:string" use="required"/>

$<x$ s:attribute name="Transition" type="xsd:string" use="required"/>

$<x s d$ :attribute name="X" type="xsd:integer" use="required"/>

$<x$ s:attribute name="Y" type="xsd:integer" use="required"/>

$</ x$ sd: complexType $>$

$</ x s d$ : element $>$

Figura D.6 - Descrição da estrutura de um componente utilizando XML Schema. 
// O elemento “Arc” possui elemetos do tipo "Node” e os atributos: "Name” (nome do

// arco), "Caller” (objeto de onde parte o arco), "From” (transição do objeto "Caller” que o

// arco se relaciona), “Called” (objeto para onde vai o arco), e “To” (transição do objeto

// "Called” que o arco se relaciona)

<xsd:element name="Arc" maxOccurs="unbounded">

<xsd:complexType>

$<x$ sd: sequence $>$

$<$ <sd:element name="Node" maxoccurs="unbounded">

<xsd:complexType>

$<x s d: a t t r i b u t e$ name="X" type="xsd:integer" use="required"/>

$<x s d:$ attribute name="Y" type="xsd:integer" use="required"/>

$</ x$ sd: complexType $>$

$</ x$ sd:element $>$

$</$ xsd: sequence $>$

$<x s d: a t$ tribute name="Name" type="xsd:string" use="required" $/>$

$<x s d$ :attribute name="Caller" type="xsd:string" use="required"/>

<xsd:attribute name="From" type="xsd:string" use="required"/>

$<x$ s:attribute name="Called" type="xsd:string" use="required"/>

<xsd:attribute name="To" type="xsd:string" use="required"/>

$</ x s d$ : complexType $>$

</xsd:element $>$

$</ x s d$ : sequence $>$

$<x s d$ :attribute name="Name" type="xsd:string" use="required"/>

$</ x$ sd: complexType $>$

$</ x s d$ :element $>$

$</ x s d$ : schema

Figura D.6 - Descrição da estrutura de um componente utilizando XML Schema (continuação).

Tabela D.2 - Descrição dos tags utilizados na Figura D.6.

\begin{tabular}{|l|l|}
\hline Marcador & Descrição \\
\hline Component & Elemento que indica o início da declaração de um componente \\
\hline Name & Atributo que indica o nome do componente \\
\hline Object & Elemento que indica a declaração de um objeto baseado em uma classe pré-definida \\
\hline Name & Atributo que indica o nome do objeto \\
\hline Class & Atributo que indica a classe na qual o objeto se baseia \\
\hline $\mathrm{X}$ & Atribunto que indica a coordenada x do objeto \\
\hline Y & Atribunto que indica a coordenada y do objeto \\
\hline CompInterface & Elemento que indica a declaração de interfaces externas do objeto \\
\hline Name & Atributo que indica o nome da interface do objeto \\
\hline Object & Atributo que indica o nome do objeto que será mapeado externamente \\
\hline Transition & Atributo que indica o nome da transição do objeto que será mapeada externamente \\
\hline $\mathrm{X}$ & Atributo que indica a coordenada x da interface do objeto \\
\hline Y & Atributo que indica a coordenada y da interface do objeto \\
\hline Arc & $\begin{array}{l}\text { Elemento que indica a declaração de arco usado para interligar objetos e estes com as } \\
\text { interfaces }\end{array}$ \\
\hline Name & Atributo que indica o nome do arco \\
\hline Caller & Atributo que indica o objeto que realiza a chamada \\
\hline From & $\begin{array}{l}\text { Atributo que indica a transição do objeto de chamada utilizada para fazer a interface } \\
\text { entre os objetos }\end{array}$ \\
\hline Called & Atributo que indica o objeto que será chamado \\
\hline To & $\begin{array}{l}\text { Atributo que indica a transição do objeto chamado utilizada para fazer a interface } \\
\text { entre os objetos }\end{array}$ \\
\hline Node & Elemento que indica a declaração de nós que compõem o arco \\
\hline Y & Atributo que indica a coordenada x do arco \\
\hline Atributo que indica a coordenada y do arco \\
\hline
\end{tabular}




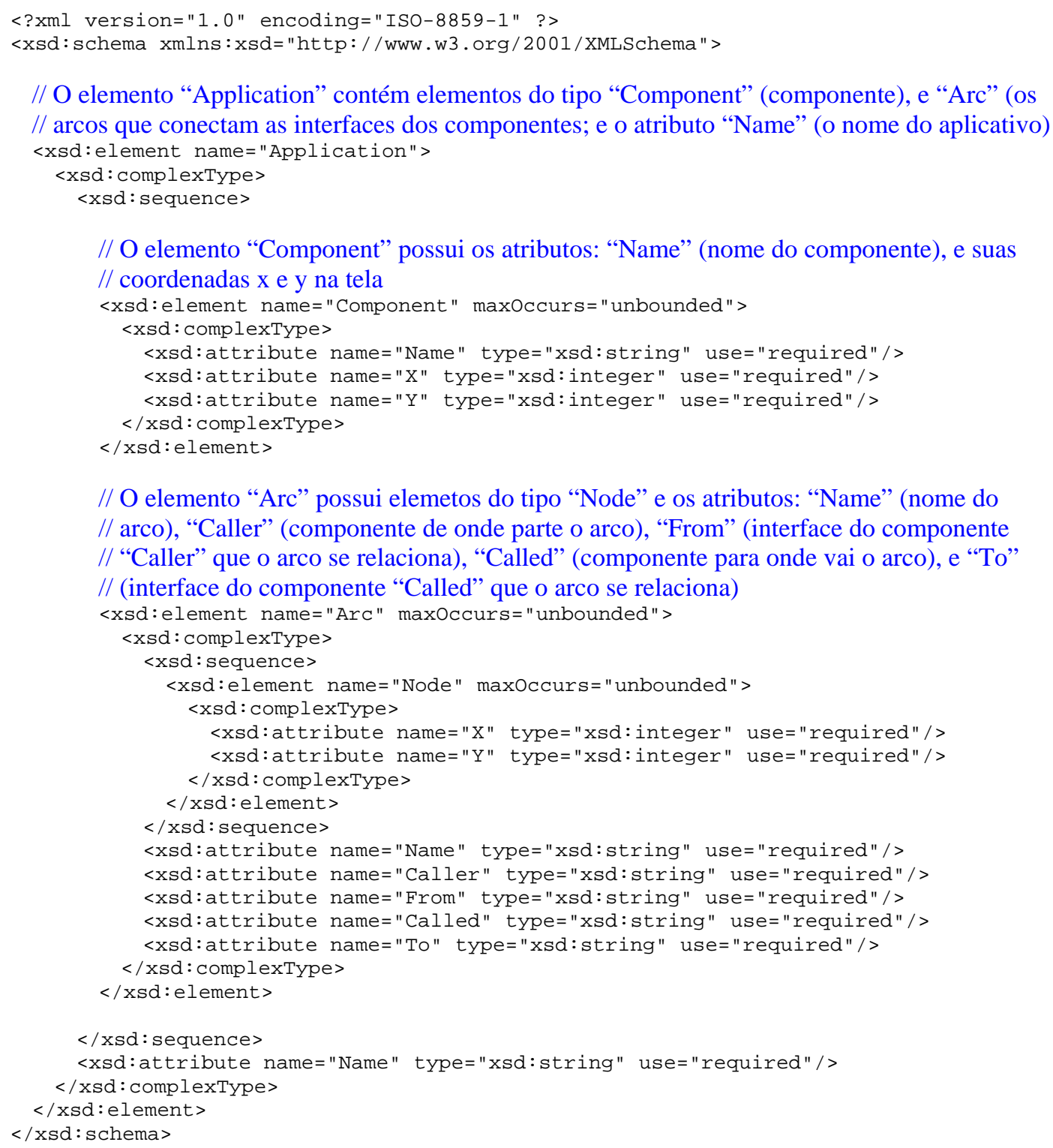

Figura D.7 - Descrição, baseada na notação XML, da estrutura do aplicativo.

Apresentados os Schemas utilizados para definir os modelos propostos na seção 2.4, pode-se reescrever o modelo apresentado nas Figuras D.3 e D.4 utilizando-se o XML Schema da Figura D.5 (Figura D.8). 
Tabela D.3 - Descrição dos tags utilizados na Figura D.7.

\begin{tabular}{|l|l|}
\hline Marcador & Descrição \\
\hline Application & Elemento que indica o início da declaração de um aplicativo \\
\hline Name & Atributo que indica o nome do aplicativo \\
\hline Component & Elemento que indica a declaração de um componente \\
\hline Name & Atributo que indica o nome do componente \\
\hline $\mathrm{X}$ & Atribunto que indica a coordenada x do componente \\
\hline Y & Atribunto que indica a coordenada y do componente \\
\hline Arc & Elemento que indica a declaração de arco usado para interligar componentes \\
\hline Name & Atributo que indica o nome do arco \\
\hline Caller & Atributo que indica o componente que realiza a chamada \\
\hline From & $\begin{array}{l}\text { Atributo que indica a interface do componente de chamada utilizada para fazer a } \\
\text { interface entre os componentes }\end{array}$ \\
\hline Called & Atributo que indica o componente que será chamado \\
\hline To & $\begin{array}{l}\text { Atributo que indica a interface do componente chamado utilizada para fazer a interface } \\
\text { entre os componente }\end{array}$ \\
\hline Node & Elemento que indica a declaração de nós que compõem o arco \\
\hline $\mathrm{X}$ & Atributo que indica a coordenada x do arco \\
\hline $\mathrm{Y}$ & Atributo que indica a coordenada y do arco \\
\hline
\end{tabular}

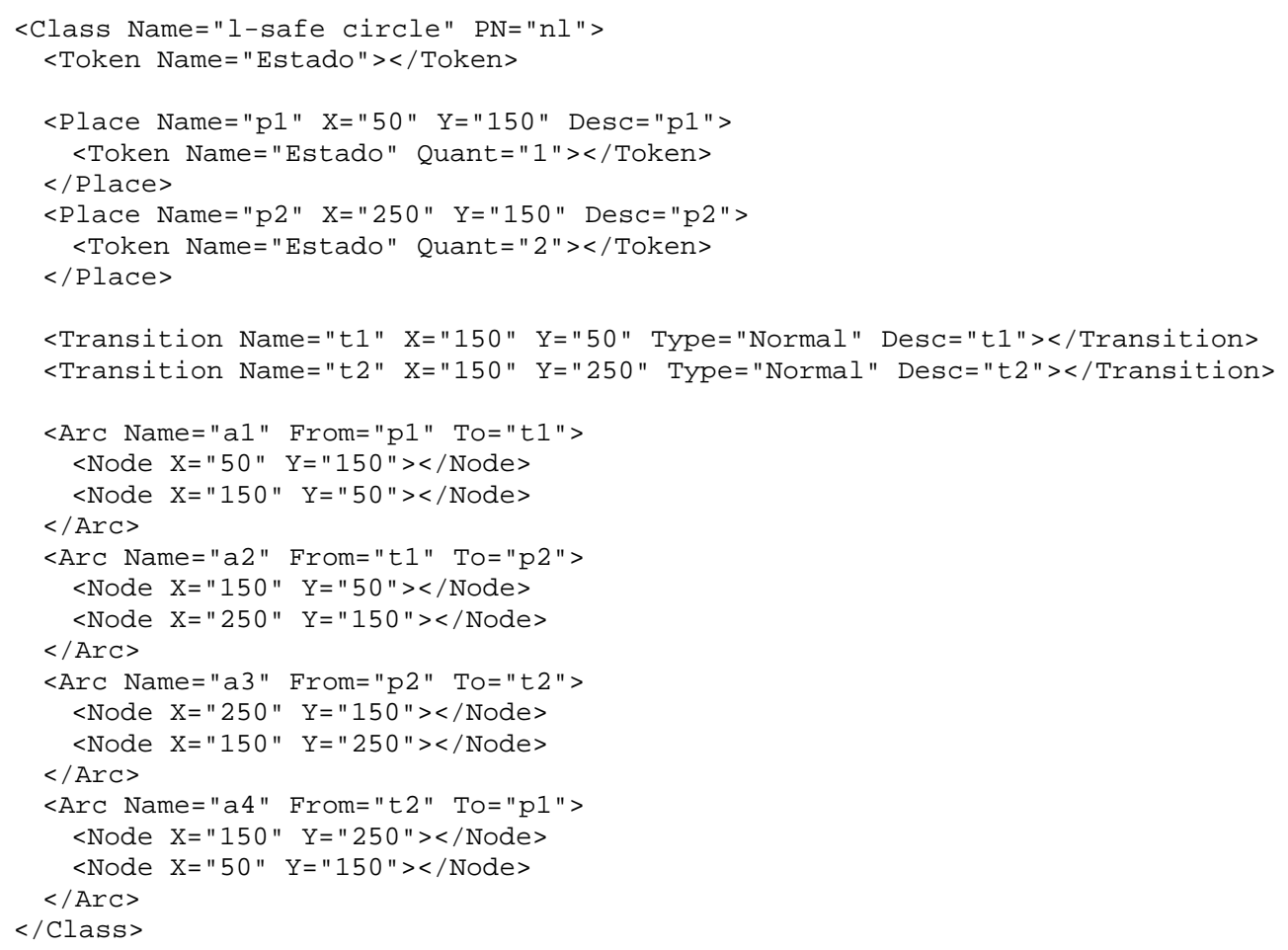

Figura D.8 - Exemplo de Rede de Petri descrita utilizando-se a notação proposta para modelagem de classes.

O modelo da Figura D.8 apresenta-se de forma mais simplificada com relação ao apresentado na Figura D.4. Em parte, isso se deve ao fato de muitas das informações modeladas em PNML com o uso de elementos, passarem a ser modeladas como atributos na Figura D.8, como as coordenadas dos elementos na tela. Em parte se deve 
ao fato de não terem sido considerados alguns elementos do PNML na notação proposta, como o "offset” e o “inscription”.

\section{D.1. Descrição em XML dos modelos da seção 2.5}

As Figuras D.9, D.10 e D.11 apresentam, respectivamente, os modelo da [Estação], [Transportador] e [Transporte entre estações] (A, B, C e D) e a [Parada na estação] (A, B, C e D) em XML. Por se tratar de um exemplo, as coordenadas foram mantidas como "x" e “ $y$ ”.

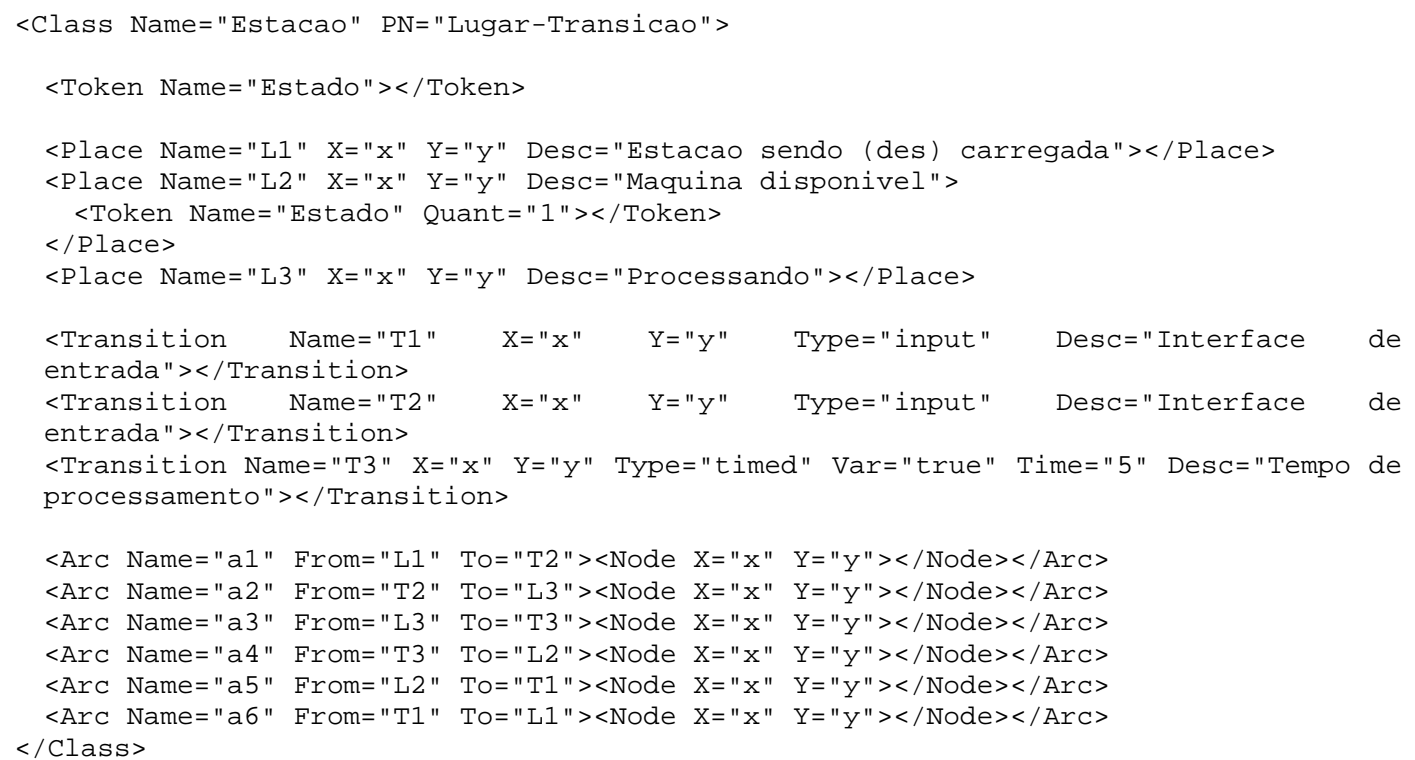

Figura D.9 - Modelo em XML da classe [Estação] (Figura 2.21). 


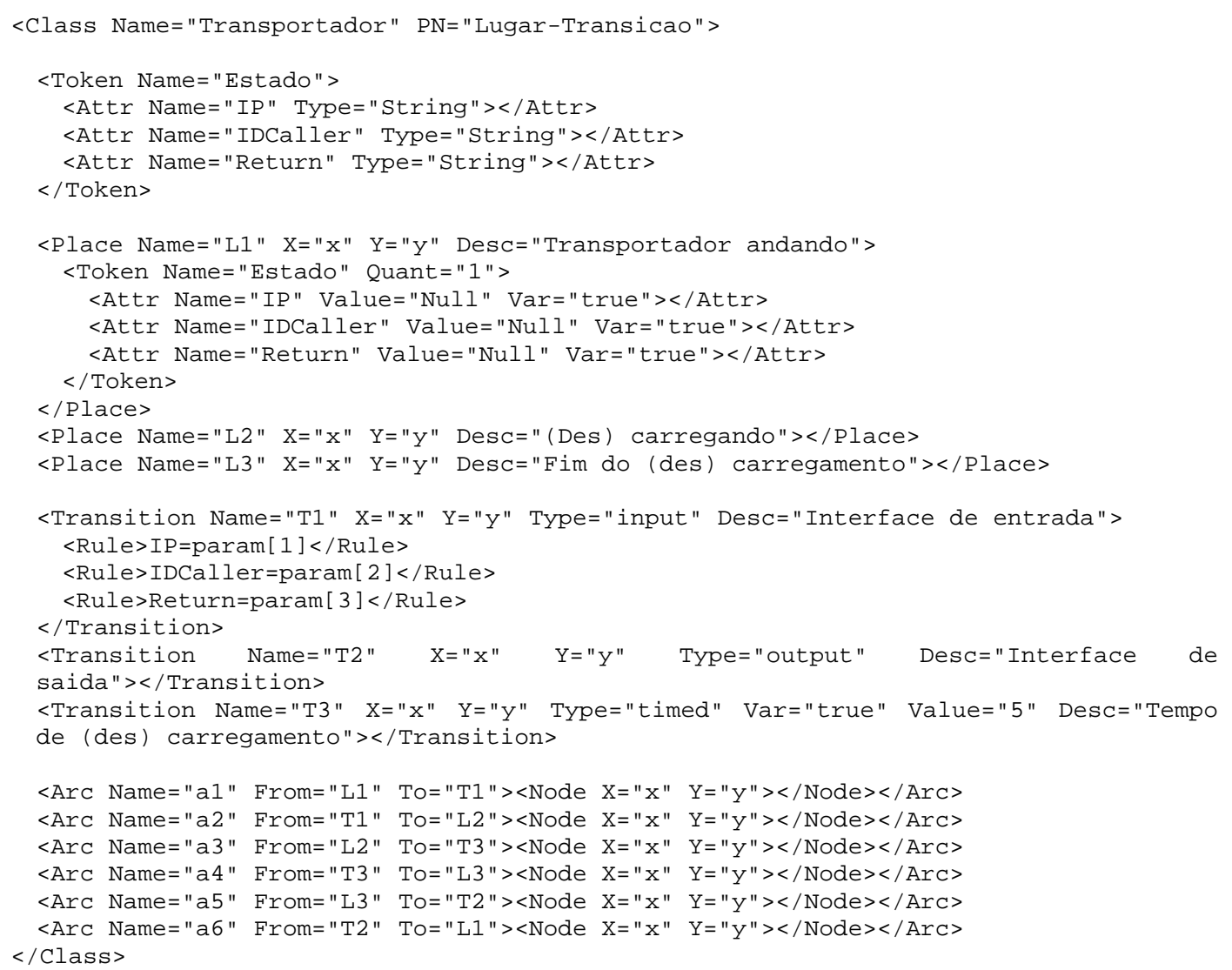

Figura D.10 - Modelo em XML da classe [Transportador] (Figura 2.22).

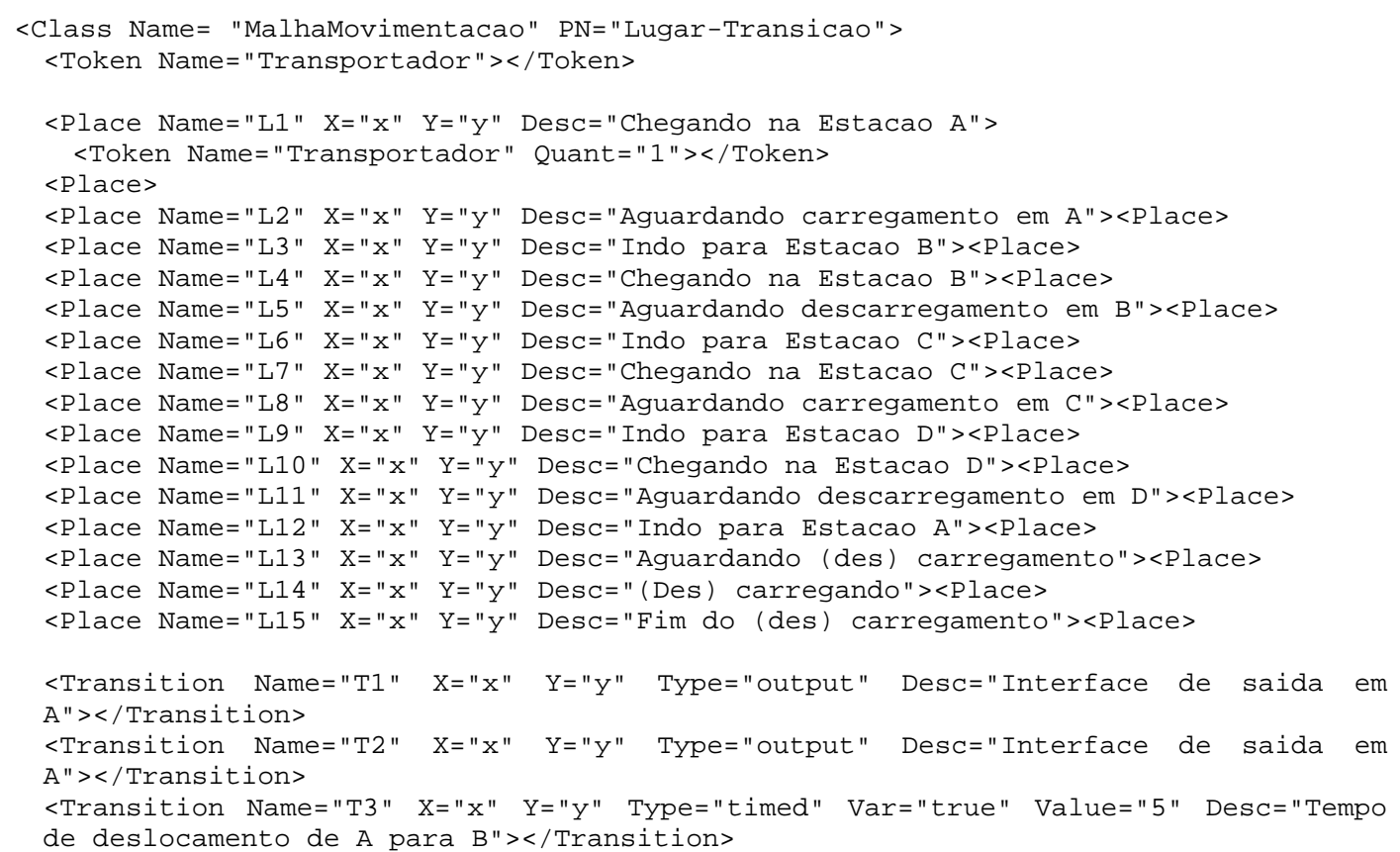

Figura D.11 - Modelo em XML da classe da Malha de movimentação (Figura 2.26). 
<Transition Name="T4" X="X" Y="y" Type="output" Desc="Interface de saida em B" $></$ Transition $>$

<Transition Name="T5" $X=" X " \quad Y=" y "$ Type="output" Desc="Interface de saida em $\mathrm{B} "></$ Transition $>$

$<$ Transition Name="T6" $X=" x " Y=" y "$ Type="timed" Var="true" Value="5" Desc="Tempo de deslocamento de $B$ para $C "></$ Transition $>$

$<$ Transition Name="T7" $X=" X " \quad Y=" y "$ Type="output" Desc="Interface de saida em C" $></$ Transition $>$

$<$ Transition Name="T8" $X=" X " \quad Y=" y "$ Type="output" Desc="Interface de saida em C" $></$ Transition $>$

$<$ Transition Name="T9" $X=" x " Y=" y "$ Type="timed" Var="true" Value="5" Desc="Tempo de deslocamento de $C$ para $D "></$ Transition $>$

$<$ Transition Name="T10" X="X" Y="y" Type="output" Desc="Interface de saida em D" $></$ Transition $>$

$<$ Transition Name="T11" $X=" x " \quad Y=" y "$ Type="output" Desc="Interface de saida em D" $></$ Transition $>$

<Transition Name="T12" $X=" X " Y=" y "$ Type="timed" Var="true" Value="5" Desc="Tempo de deslocamento de $D$ para $A^{\prime \prime}></$ Transition $>$

$<$ Transition Name="T13" $X=" X " \quad Y=" y " \quad$ Type="output" Desc="Chamada para 0 transportador">

$<$ Rule $>$ param [1] = ObjIP $</$ Rule $>$

$<$ Rule $>$ param[2] $=$ objID $</$ Rule $>$

$<$ Rule $>$ param $[3]=$ T14</Rule $>$

$</$ Transition $>$

$<$ Transition Name="T14" X=" $x " \quad Y=" y " \quad$ Type="input" Desc="Resposta do transportador" $></$ Transition $>$

$<$ Arc Name="a1" From="L1" To="T1" $><$ Node $X=" X " Y=" y "></$ Node $></$ ArC $>$

$<$ Arc Name="a2" From="T1" To="L2" $><$ Node $X=" X " Y=" y "></$ Node $></$ Arc $>$

$<$ Arc Name="a3" From="L2" To="T2" $><$ Node $X=" X " Y=" y "></$ Node $></$ ArC $>$

$<$ Arc Name="a4" From="T2" To="L3" $><$ Node $X=" X " Y=" y "></$ Node $></$ ArC $>$

$<$ Arc Name="a5" From="L3" To="T3" $<<$ Node $X=" x " Y=" y "></$ Node $></$ ArC $>$

$<$ Arc Name="a6" From="T3" To="L4" $><$ Node $X=" X " Y=" y "></$ Node $></$ ArC $>$

$<$ Arc Name="a7" From="L4" To="T4" $><$ Node $X=" X " Y=" y "></$ Node $></$ ArC $>$

$<$ Arc Name="a8" From="T4" To="L5" $><$ Node $X=" x " Y=" y "></$ Node $></$ ArC $>$

$<$ Arc Name="a9" From="L5" To="T5" $><$ Node $X=" x " Y=" y "></$ Node $></$ Arc $>$

$<$ Arc Name="a10" From="T5" To="L6" $><$ Node $X=" x " Y=" y "><$ Node $></$ Arc $>$

$<$ Arc Name="a11" From="L6" To="T6" $><$ Node $X=" x " Y=" y "></$ Node $></$ ArC $>$

$<$ Arc Name="a12" From="T6" To="L7" $<<$ Node $X=" x " Y=" y "></$ Node $></$ Arc $>$

$<$ Arc Name="a13" From="L7" To="T7" $><$ Node $X=" x " Y=" y "></$ Node $></$ ArC $>$

$<$ Arc Name="a14" From="T7" To="L8" $<<$ Node $X=" X " Y=" y "></$ Node $></$ Arc $>$

$<$ Arc Name="a15" From="L8" To="T8" $><$ Node $X=" x " Y=" y "></$ Node $></$ ArC $>$

$<$ Arc Name="a16" From="T8" To="L9" $><$ Node $X=" x " Y=" y "></$ Node $></$ ArC $>$

$<$ Arc Name="a17" From="L9" To="T9" $><$ Node $X=" x " Y=" y "></$ Node $></$ Arc $>$

$<$ Arc Name="a18" From="T9" To="L10" $><$ Node $X=" X " Y=" y "></$ Node $></$ ArC $>$

$<$ Arc Name="a19" From="L10" To="T10" $><$ Node $X=" x " Y=" y "></$ Node $></$ ArC $>$

$<$ Arc Name="a20" From="T10" To="L11" $<<$ Node $X=" x " Y=" y "></$ Node $></$ ArC $>$

$<$ Arc Name="a21" From="L11" To="T11" $><$ Node $X=" x " Y=" y "></$ Node $></ \operatorname{ArC}>$

$<$ Arc Name $=" a 22 "$ From="T11" To="L12" $><$ Node $X=" X " Y=" y "></$ Node $></$ ArC $>$

$<$ Arc Name="a23" From="L12" To="T12" $><$ Node $X=" x " Y=" y "></$ Node $></ \operatorname{Arc}>$

$<$ Arc Name="a24" From="L1" To="T12" $><$ Node $X=" x " Y=" y "></$ Node $></$ ArC $>$

$<$ Arc Name $="$ a25" From="L13" To $=" T 13 "><$ Node $X=" x " Y=" y "></$ Node $></$ ArC $>$

$<$ Arc Name="a26" From="T13" To="L14" $><$ Node $X=" x " Y=" y "></$ Node $></ \operatorname{ArC}>$

$<$ Arc Name="a27" From="L14" To="T14" $><$ Node $X=" x " Y=" y "></$ Node $></$ ArC $>$

$<$ Arc Name="a28" From="T14" To="L15" $><$ Node $X=" x " Y=" y "></$ Node $></$ ArC $>$

$<$ Arc Name="a29" From="L13" To="T1" $><$ Node $X=" x " Y=" y "></$ Node $></$ ArC $>$

$<$ Arc Name="a30" From="T4" To="L13" $><$ Node $X=" x " \quad Y=" y "></$ Node $></$ Arc $>$

$<$ Arc Name="a31" From="T7" To="L13" $><$ Node $X=" x " Y=" y "></$ Node $></$ ArC $>$

$<$ Arc Name="a32" From="T10" To="L13" $><$ Node $X=" X " Y=" y "></$ Node $></ \operatorname{ArC}>$

$<$ Arc Name $="$ a33" From="L15" To $=" T 2 "><$ Node $X=" x " \mathrm{Y}=" \mathrm{y} "></$ Node $></$ Arc $>$

$<$ Arc Name="a34" From="L15" To="T5" $><$ Node $X=" x " Y=" y "></$ Node $></$ ArC $>$

$<$ Arc Name="a35" From="L15" To="T8" $><$ Node $X=" x " Y=" y "></$ Node $></$ ArC $>$

$<$ Arc Name="a36" From="L15" To="T11" $><$ Node $X=" x " Y=" y "></$ Node $></ \operatorname{Arc}>$ $</$ Class $>$

Figura D.11 Modelo em XML da classe Malha de movimentação (Figura 2.26) (continuação). 
O modelo da Figura 2.28 é apresentado em XML na Figura D.12.

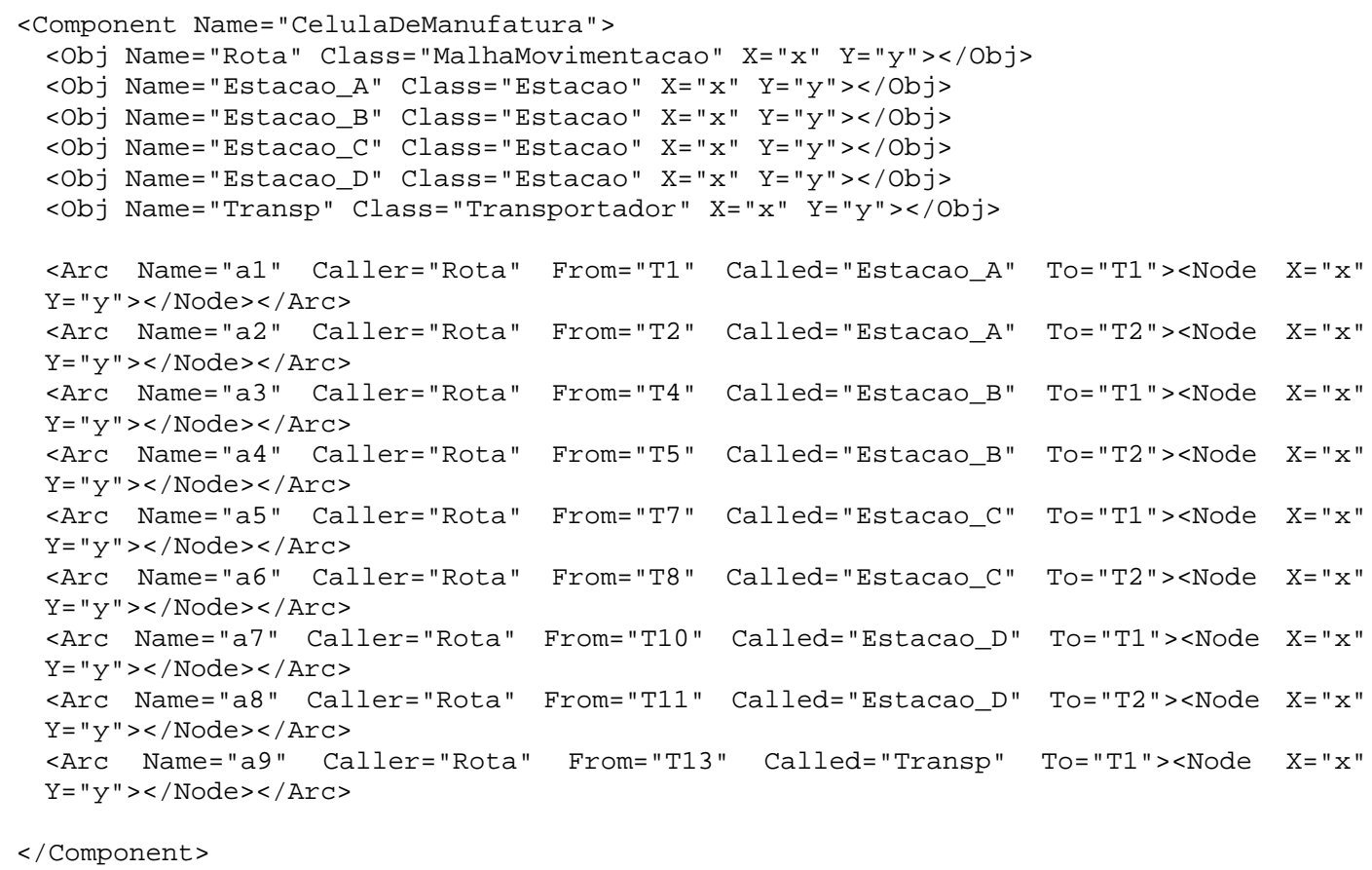

Figura D.12 - Modelo em XML do componente CelulaDeManufatura (Figura 2.28). 


\section{ANEXO E - ESTUDO DE CASO (OUTROS MODELOS DO CAPÍTULO 3)}

Neste anexo, dá-se continuidade ao processo de modelagem da célula de manufatura FESTO iniciado no capítulo 3. Assim, apresenta-se a modelagem das demais atividades da Figura 3.4, os quais estão em destaque na Figura E.1.

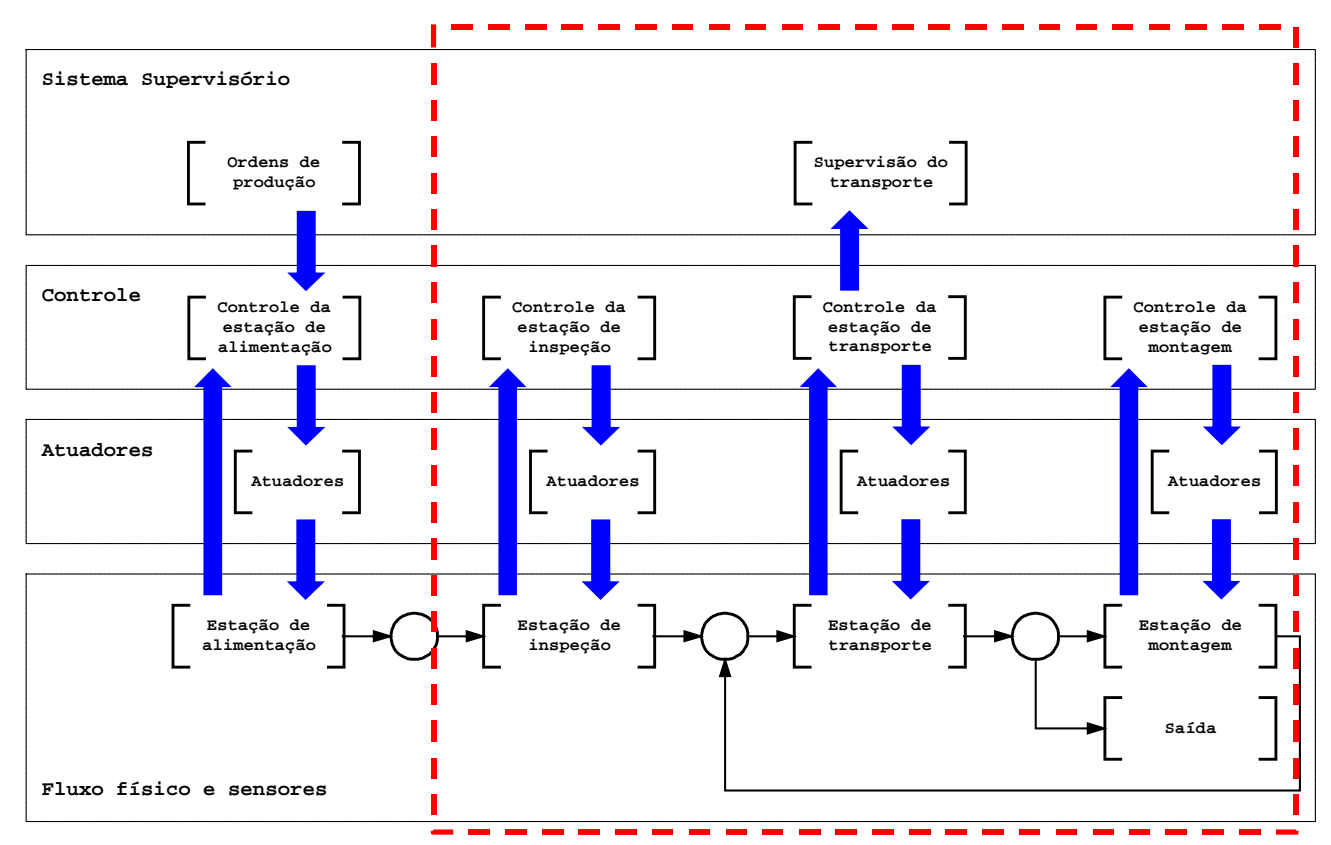

Figura E.1 - Segundo nível de detalhamento: PFS da Célula de Manufatura.

No terceiro nível de detalhamento são refinadas as atividades de controle das outras três estações. As demais atividades em PFS apresentada na Figura E.1 não são detalhadas em PFS por serem relativamente simples e, desta forma, já poderem ser modeladas em RdP na Etapa 3.

A Figura E.2 apresenta o detalhamento da atividade [Controle da estação de inspeção]. Quando o cilindro base chega à estação, há uma [Inspeção dimensional do cilindro base]. Se recusado, tem-se a sub-atividade [Descarta o cilindro base], do contrário tem-se as sub-atividades [Detecta a cor do cilindro base] e [Envia o cilindro base para a estação de transporte]. 


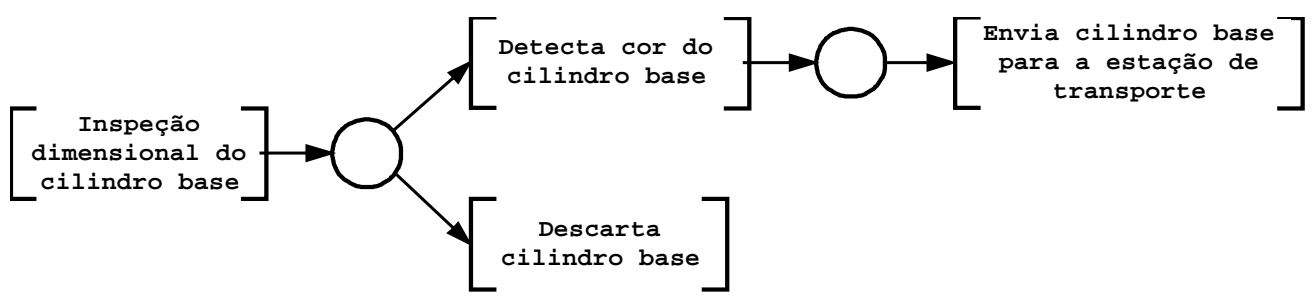

Figura E.2 - Terceiro nível de detalhamento: PFS da atividade [Controle da estação de inspeção].

O detalhamento da atividade [Controle da estação de transporte] é apresentado na Figura E.3. Nela pode-se destacar a existência de sub-atividades relacionadas ao controle das paradas dos paletes junto às estações de inspeção ([Parada na estação de inspeção]) e montagem ([Parada na estação de montagem]), bem como outras duas posições de parada dos paletes não utilizadas ([Parada]) previstas para futura expansão da célula. Entre as paradas, existem trechos de esteira responsáveis pela atividade de [Movimentação] dos paletes (com ou sem cilindros base).

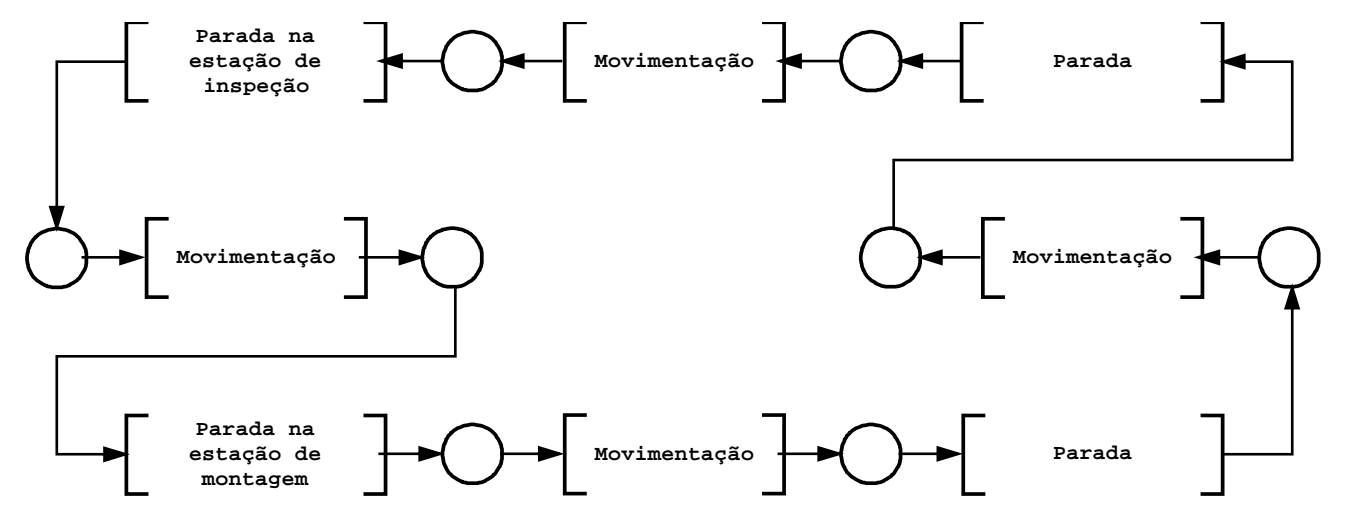

Figura E.3 - Terceiro nível de detalhamento: PFS da atividade [Controle da estação de transporte].

Na Figura E.4 é apresentado o detalhamento da atividade [Controle da estação de montagem]. Nela pode-se acompanhar todo o processo de montagem da peça final, desde a retirada do palete (contendo a peça base) da [Estação de transporte], o posicionamento do cilindro base, agregação da mola, pino e tampa, e o retorno do palete com o cilindro montado para a [Estação de transporte]. 

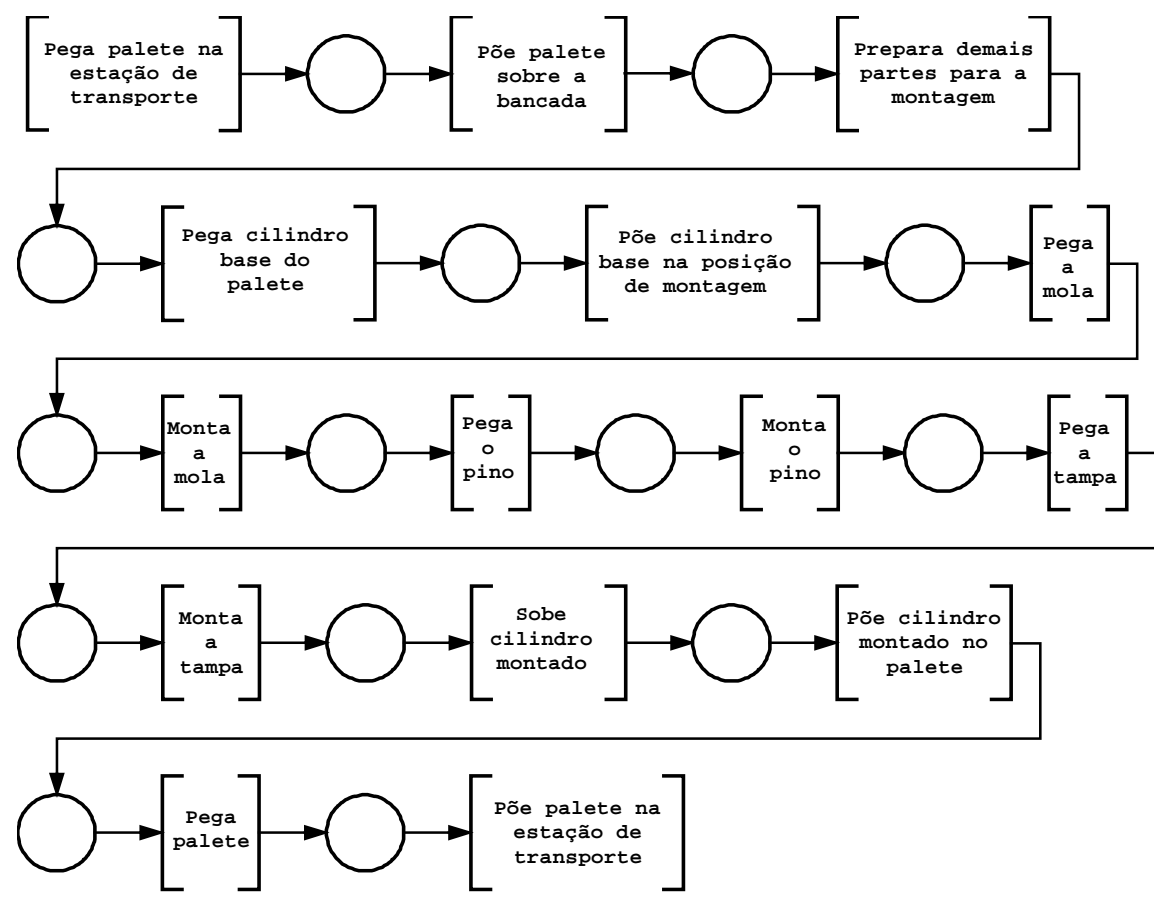

Figura E.4 - Terceiro nível de detalhamento: PFS da atividade [Controle da estação de montagem].

No quarto e último nível de detalhamento em PFS considerado neste estudo de caso, detalha-se na Figura E.5 a atividade [Prepara as demais partes para a montagem], apresentada na Figura E.4. Nela observa-se que é necessário alimentar com as devidas partes a [Estação de montagem] que faz a montagem da peça final com três outras partes (mola, êmbolo e tampa), além do cilindro base que [Estação de montagem] recebe através da [Estação de transporte].

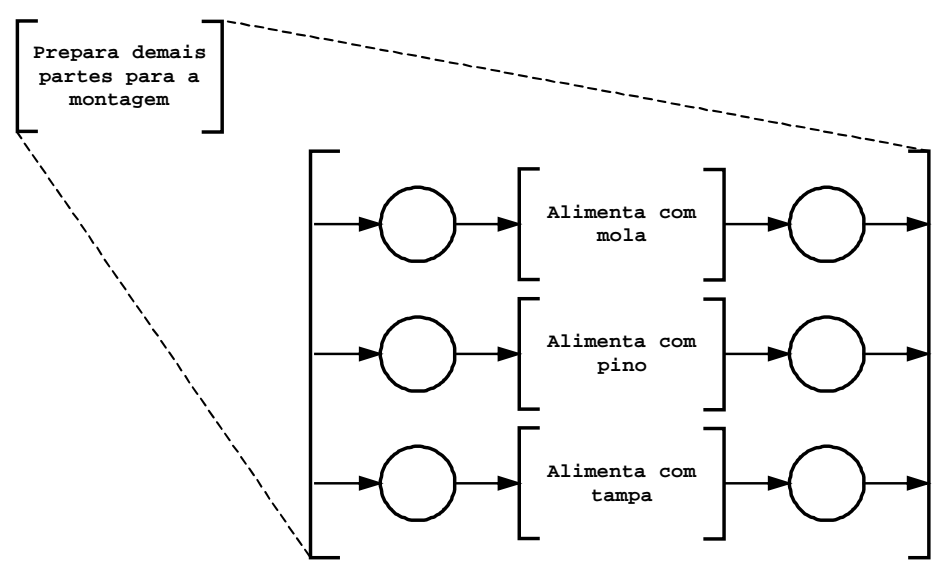

Figura E.5 - Quarto nível de detalhamento - detalhamento em PFS da atividade [Prepara demais partes para a montagem]. 


\section{Etapa 3 - Modelagem dos elementos básicos em Redes de Petri (RdP)}

Nesta etapa, os modelos já detalhados com o PFS são refinados utilizando a RdP. Procurando facilitar o acompanhamento o refinamento dos modelos, estes foram agrupados conforme o nível a que pertencem no sistema, ou seja: (1) sistema supervisório; (2) controle; (3) atuadores; e (4) fluxo físico e sensores.

\section{i) Elementos do sistema supervisório}

O detalhamento em RdP colorida da atividade [Supervisão do transporte] (Figura E.1) é apresentado na Figura E.6. Nela pode-se observar que todas as transições são do tipo requisitada (vermelha, conforme nomenclatura adotada na seção 2.3), sendo habilitadas pelo [Controle da estação de transporte] de forma a atualizar a posição dos paletes. Os lugares L1, L3, L5 e L7 correspondem às esteiras, com capacidade para até quatro paletes. Os lugares L2, L4, L6 e L8 correspondem às paradas, sendo que o lugar L8 corresponde à parada na estação de inspeção e L6 à parada junto à estação de montagem.

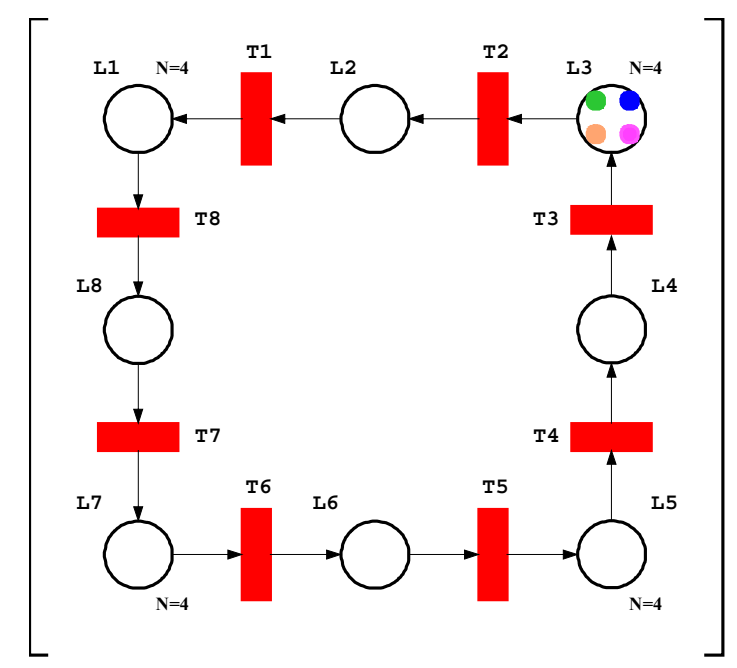

Figura E.6 - Modelo em RdP colorida da atividade [Supervisão do transporte].

\section{ii) Elementos do sistema de controle}

A Figura E.7 apresenta o modelo em RdP colorida da atividade [Controle da estação de inspeção] (Figura E.2) e a Tabela E.1 contém a descrição dos seus elementos. Neste modelo utiliza-se RdP colorida pois são coletadas, através de sensores, informações (cor e dimensões) sobre os cilindros base quando inspecionados. 


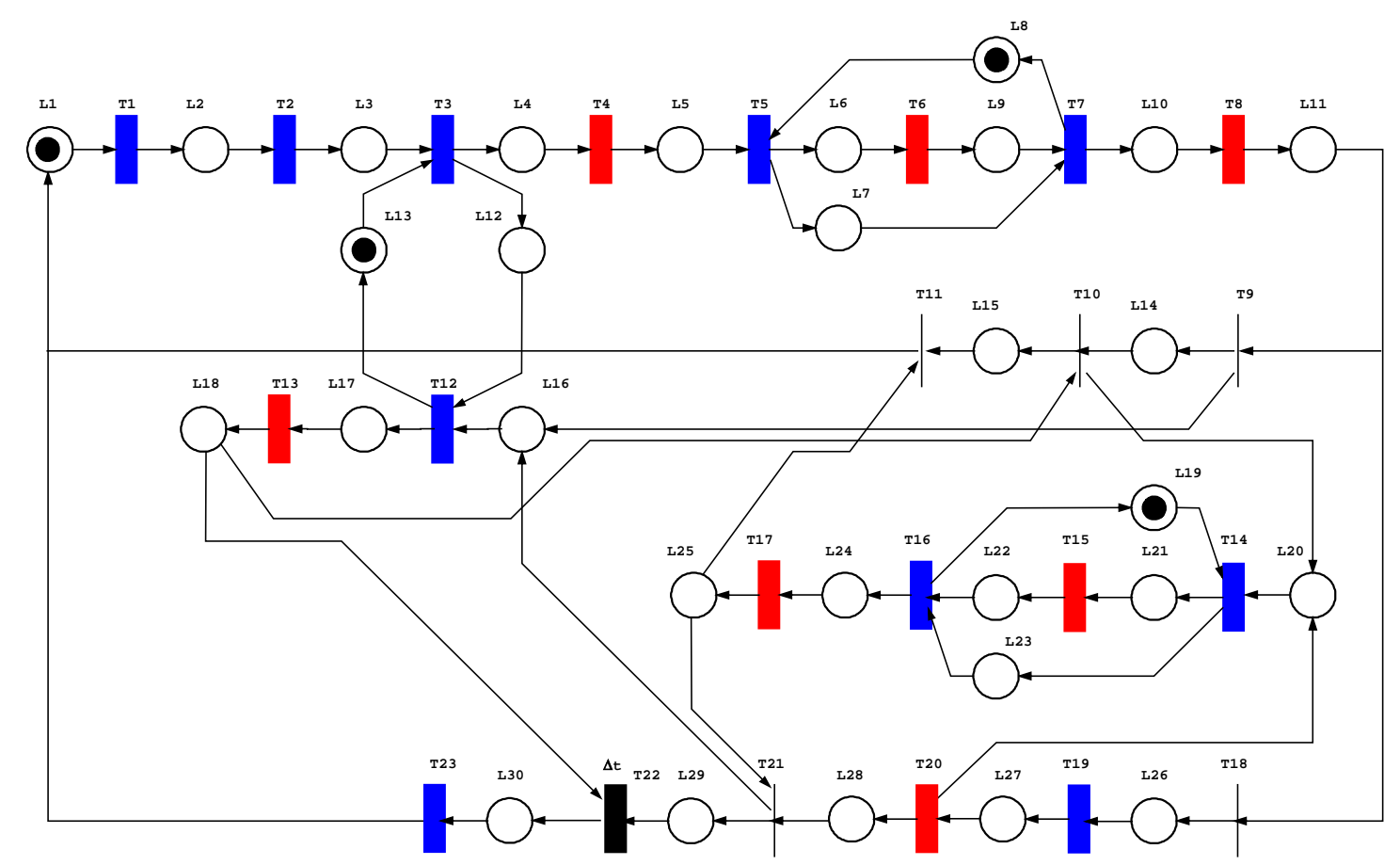

Figura E.7 - Modelo em RdP colorida da atividade [Controle da estação de inspeção].

Ainda com relação ao modelo da Figura E.7, observa-se que a partir do lugar L11 as operações podem evoluir de duas formas distintas: (1) se o cilindro base é rejeitado; ou (2) se o cilindro base é aprovado. Entretanto, observa-se que o conflito existente para acionar os atuadores é explicitado no próprio modelo. Um exemplo é a operação de recolher o atuador que controla a movimentação da plataforma (fazendo-a descer), entre os lugares L16 e L18. Assim, bastam as transições T12 e T13 para interagir como elementos externos ao modelo. Se não fosse assim, seria necessário mais um par de transições para interagir com os mesmos elementos externos. Como conseqüências: (1) o conflito existente para descer a plataforma não seria claramente evidenciado; e (2) ao se gerar um componente, seria necessário fazer um segundo par de ligações, podendo resultar em erros no modelo do componente. 
Tabela E.1 - Descrição dos elementos do modelo em RdP da atividade [Controle da estação de inspeção].

\begin{tabular}{|c|c|}
\hline Lugar & Descrição \\
\hline L1 & A estação está livre e pronta para produzir \\
\hline L2 & $\begin{array}{l}\text { O controle aguardando que a estação de alimentação esteja com o atuador de transporte } \\
\text { sobre ela }\end{array}$ \\
\hline L3 & Representa o início do processo de inspeção \\
\hline L4 & O atuador que eleva a plataforma de medição está sendo distendido \\
\hline L5 & O atuador que eleva a plataforma de medição foi totalmente distendido \\
\hline L6 & O atuador responsável por aproximar o medidor do cilindro base está sendo distendido \\
\hline L7 & Válvula está energizada para distender o atuador, aproximando o medidor do cilindro base \\
\hline L8 & Válvula está energizada para recolher o atuador, afastando o medidor do cilindro base \\
\hline L9 & O atuador responsável por aproximar o medidor do cilindro base foi distendido \\
\hline L10 & O atuador responsável por aproximar o medidor do cilindro base está sendo recolhido \\
\hline L11 & O atuador do medidor foi recolhido e a peça foi inspecionada \\
\hline L12 & Válvula está energizada para distender o atuador que eleva a plataforma \\
\hline L13 & Válvula está energizada para recolher o atuador que eleva a plataforma \\
\hline L14 & Indica que o atuador que desloca a plataforma está sendo recolhido \\
\hline L15 & Indica que o cilindro base está sendo descartado pela estação de inspeção \\
\hline L16 & Recebimento de uma ordem para recolher o atuador que eleva a plataforma \\
\hline L17 & O atuador que eleva a plataforma de medição está sendo recolhido \\
\hline L18 & O atuador que eleva a plataforma de medição foi totalmente recolhido \\
\hline L19 & Válvula está energizada para recolher o atuador que expulsa o cilindro base da inspeção \\
\hline $\mathrm{L} 20$ & Recebimento de uma ordem para expulsa o cilindro base da inspeção \\
\hline $\mathrm{L} 21$ & O atuador que expulsa o cilindro base da inspeção está sendo distendido \\
\hline L22 & O atuador que expulsa o cilindro base da inspeção foi distendido \\
\hline L23 & Válvula está energizada para distender o atuador que expulsa o cilindro base da inspeção \\
\hline $\mathrm{L} 24$ & O atuador que expulsa o cilindro base da inspeção está sendo recolhido \\
\hline L25 & O atuador que expulsa o cilindro base da inspeção foi recolhido \\
\hline L26 & $\begin{array}{l}\text { Dados sobre cor da peça e pedido de palete prontos para serem enviados à estação de } \\
\text { transporte }\end{array}$ \\
\hline L27 & Aguarda chegada de um palete \\
\hline L28 & Indica que o cilindro base está sendo enviado para a estação de transporte \\
\hline L29 & $\begin{array}{l}\text { Indica que o atuador que desloca a plataforma está sendo recolhido, enquanto o cilindro } \\
\text { base desce até o palete }\end{array}$ \\
\hline L30 & Indica que o cilindro base já está no palete e a estação pode ser liberada \\
\hline Transição & Descrição \\
\hline T1 & Transição requisitante que informa a estação de alimentação que esta está livre \\
\hline $\mathrm{T} 2$ & $\begin{array}{l}\text { Transição requisitante que verifica se o atuador de transporte está sobre a estação de } \\
\text { alimentação }\end{array}$ \\
\hline T3 & $\begin{array}{l}\text { Transição requisitante que representa a ordem para distender o atuador que movimenta a } \\
\text { plataforma }\end{array}$ \\
\hline T4 & $\begin{array}{l}\text { Transição requisitada que representa a confirmação, através de sensor, que a plataforma foi } \\
\text { elevada }\end{array}$ \\
\hline T5 & $\begin{array}{l}\text { Transição requisitante que representa a ordem para distender o atuador que abaixa o medidor } \\
\text { sobre o cilindro base }\end{array}$ \\
\hline T6 & $\begin{array}{l}\text { Transição requisitada que representa a confirmação, através de sensor, que medidor foi } \\
\text { abaixado }\end{array}$ \\
\hline T7 & $\begin{array}{l}\text { Transição requisitante que representa a ordem para recolher o atuador que movimenta o } \\
\text { medidor }\end{array}$ \\
\hline T8 & $\begin{array}{l}\text { Transição requisitada que representa a confirmação, através de sensor, que medidor foi } \\
\text { recolhido }\end{array}$ \\
\hline T9 & $\begin{array}{l}\text { Transição representa a rejeição do cilindro base, mandando recolher o atuador da plataforma, } \\
\text { fazendo-a descer }\end{array}$ \\
\hline $\mathrm{T} 10$ & Transição representa o pedido para descartar a peça rejeitada \\
\hline T11 & Transição que representa a liberação da estação no caso do cilindro base ter sido rejeitado \\
\hline
\end{tabular}


Tabela E.1 - Descrição dos elementos do modelo em RdP da atividade [Controle da estação de inspeção].

\begin{tabular}{|l|l|}
\hline Transição & Descrição \\
\hline T12 & $\begin{array}{l}\text { Transição requisitante que representa a ordem para recolher o atuador que movimenta a } \\
\text { plataforma }\end{array}$ \\
\hline T13 & $\begin{array}{l}\text { Transição requisitada que representa a confirmação, através de sensor, que a plataforma foi } \\
\text { abaixada }\end{array}$ \\
\hline T14 & $\begin{array}{l}\text { Transição requisitante que representa a ordem para distender o atuador que empurra o } \\
\text { cilindro base para fora da estação de inspeção }\end{array}$ \\
\hline T15 & $\begin{array}{l}\text { Transição requisitada que representa a confirmação, através de sensor, que o atuador está } \\
\text { distendido }\end{array}$ \\
\hline T16 & $\begin{array}{l}\text { Transição requisitante que representa a ordem para recolher o atuador que empurra o cilindro } \\
\text { base }\end{array}$ \\
\hline T17 & $\begin{array}{l}\text { Transição requisitada que representa a confirmação, através de sensor, que o atuador está } \\
\text { recolhido }\end{array}$ \\
\hline T18 & Transição indica que o cilindro base foi aprovado na inspeção \\
\hline T19 & $\begin{array}{l}\text { Transição requisitante que representa o envio das característica do cilindro base para a } \\
\text { estação de transporte bem como a requisição de um palete }\end{array}$ \\
\hline T20 & $\begin{array}{l}\text { Transição requisitada que solicita a expulsão do cilindro base logo após ter sido confirmado } \\
\text { que o palete está pronto para receber o cilindro aprovado }\end{array}$ \\
\hline T21 & $\begin{array}{l}\text { Transição manda recolher o atuador da plataforma, fazendo-a descer } \\
\text { Transição temporizada que representa o tempo necessário para que o cilindro base desça até } \\
\text { o palete da estação de transporte }\end{array}$ \\
\hline T23 & $\begin{array}{l}\text { Transição que representa a liberação da estação no caso do cilindro base ter sido aprovado e } \\
\text { informar a estação de transporte que o palete pode ser liberado }\end{array}$ \\
\hline
\end{tabular}

A Figura E.8 apresenta o modelo em RdP colorida da atividade [Controle da estação de transporte] (Figura E.3). Como no caso de [Controle da estação de inspeção], neste modelo utiliza-se de RdP colorida pois as informações sobre a cor do cilindro base, passadas pelo [Controle da estação de inspeção], são associadas à informação que identifica univocamente cada palete.

Ainda com relação ao modelo do [Controle da estação de transporte], destacase que preferiu-se utilizar duas transições (T11 e T12) para informar a cor do cilindro base para o [Controle da estação de montagem] pois, desta forma, pode-se utilizar uma RdP lugar-transição, mais simples, ao invés de uma RdP colorida no modelo do [Controle da estação de montagem].

A Tabela E.2 contém a descrição dos elementos da RdP da Figura E.8. 


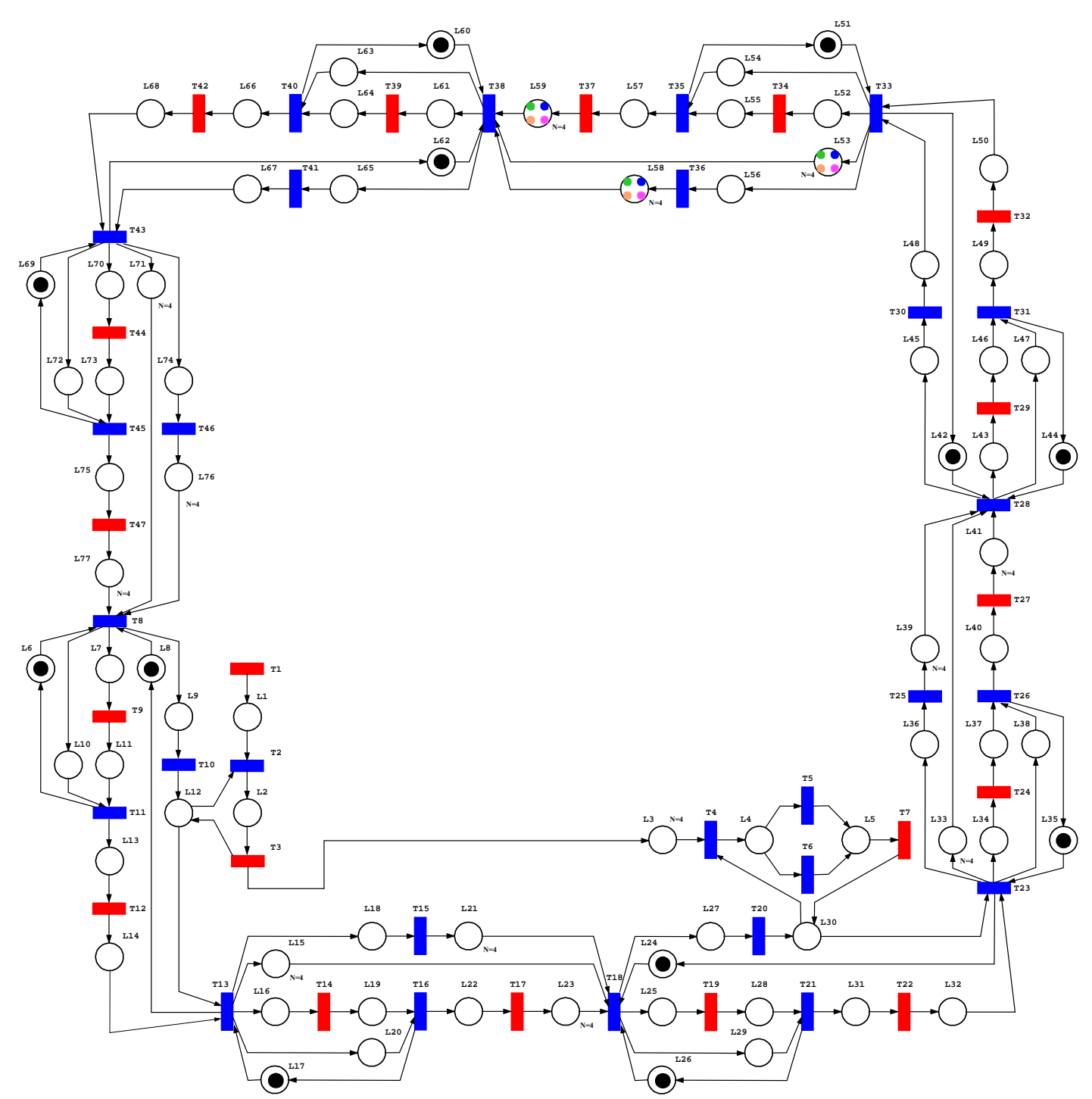

Figura E.8 - Modelo em RdP colorida da atividade [Controle da estação de transporte].

Tabela E.2 - Descrição dos elementos do modelo em RdP da atividade [Controle da estação de transporte].

\begin{tabular}{|l|l|}
\hline Lugar & Descrição \\
\hline L1 & Representa a existência de um pedido de palete proveniente da estação de inspeção \\
\hline L2 & Representa o palete aguardando o cilindro base proveniente da estação de inspeção \\
\hline L3 & $\begin{array}{l}\text { Representa a informação de um palete transportando um cilindro base para ser montado } \\
\text { bem como a correlação entre a identificação do palete e a cor do cilindro base }\end{array}$ \\
\hline L4 & $\begin{array}{l}\text { Representa a memória do controle com informação da cor do cilindro base que está sendo } \\
\text { usado na montagem }\end{array}$ \\
\hline L5 & Representa o retorno do palete com o cilindro montado para a estação de transporte \\
\hline L6 & Válvula está energizada para distender o atuador e parar o palete \\
\hline L7 & Recolhendo cilindro de trava \\
\hline L8 & Parada na estação de inspeção está livre \\
\hline L9 & Lugar auxiliar \\
\hline L10 & Válvula está energizada para recolher o atuador e deixar o palete passar \\
\hline L11 & Cilindro pneumático de trava recolhido e palete se deslocando \\
\hline L12 & Representa o palete parado na estação de inspeção \\
\hline L13 & Distendendo cilindro de trava \\
\hline
\end{tabular}


Tabela E.2 - Descrição dos elementos do modelo em RdP da atividade [Controle da estação de transporte] (continuação).

\begin{tabular}{|c|c|}
\hline Lugar & Descrição \\
\hline L14 & Lugar auxiliar \\
\hline L15 & $\begin{array}{l}\text { Representa a existência de palete na esteira entre as paradas da estação de inspeção e } \\
\text { montagem }\end{array}$ \\
\hline L16 & Recolhendo cilindro de trava \\
\hline L17 & Válvula está energizada para distender o atuador e parar o palete \\
\hline L18 & Lugar auxiliar \\
\hline L19 & Cilindro pneumático de trava recolhido e palete se deslocando \\
\hline L20 & Válvula está energizada para recolher o atuador e deixar o palete passar \\
\hline L21 & Lugar auxiliar \\
\hline $\mathrm{L} 22$ & Distendendo cilindro de trava \\
\hline L23 & Lugar auxiliar \\
\hline L24 & Parada na estação de montagem está livre \\
\hline L25 & Recolhendo cilindro de trava \\
\hline L26 & Válvula está energizada para distender o atuador e parar o palete \\
\hline L27 & Lugar auxiliar \\
\hline L28 & Cilindro pneumático de trava recolhido e palete se deslocando \\
\hline L29 & Válvula está energizada para recolher o atuador e deixar o palete passar \\
\hline L30 & Representa o palete parado na estação de montagem \\
\hline L31 & Distendendo cilindro de trava \\
\hline L32 & Lugar auxiliar \\
\hline L33 & $\begin{array}{l}\text { Representa a existência de palete na esteira entre as paradas da estação de montagem e uma } \\
\text { das paradas sem uso }\end{array}$ \\
\hline L34 & Recolhendo cilindro de trava \\
\hline L35 & Válvula está energizada para distender o atuador e parar o palete \\
\hline L36 & Lugar auxiliar \\
\hline L37 & Cilindro pneumático de trava recolhido e palete se deslocando \\
\hline L38 & Válvula está energizada para recolher o atuador e deixar o palete passar \\
\hline L39 & Lugar auxiliar \\
\hline L40 & Distendendo cilindro de trava \\
\hline L41 & Lugar auxiliar \\
\hline L42 & Parada está livre \\
\hline L43 & Recolhendo cilindro de trava \\
\hline L44 & Válvula está energizada para distender o atuador e parar o palete \\
\hline L45 & Lugar auxiliar \\
\hline L46 & Cilindro pneumático de trava recolhido e palete se deslocando \\
\hline L47 & Válvula está energizada para recolher o atuador e deixar o palete passar \\
\hline L48 & Representa o palete parado \\
\hline L49 & Distendendo cilindro de trava \\
\hline L50 & Lugar auxiliar \\
\hline L51 & Válvula está energizada para distender o atuador e parar o palete \\
\hline L52 & Recolhendo cilindro de trava \\
\hline L53 & Representa a existência de palete na esteira entre as paradas sem uso \\
\hline L54 & Válvula está energizada para recolher o atuador e deixar o palete passar \\
\hline L55 & Cilindro pneumático de trava recolhido e palete se deslocando \\
\hline L56 & Lugar auxiliar \\
\hline L57 & Distendendo cilindro de trava \\
\hline L58 & Lugar auxiliar \\
\hline L59 & Lugar auxiliar \\
\hline L60 & Válvula está energizada para distender o atuador e parar o palete \\
\hline L61 & Recolhendo cilindro de trava \\
\hline L62 & Parada está livre \\
\hline L63 & Válvula está energizada para recolher o atuador e deixar o palete passar \\
\hline L64 & Cilindro pneumático de trava recolhido e palete se deslocando \\
\hline
\end{tabular}


Tabela E.2 - Descrição dos elementos do modelo em RdP da atividade [Controle da estação de transporte] (continuação).

\begin{tabular}{|c|c|}
\hline Lugar & Descrição \\
\hline L65 & Lugar auxiliar \\
\hline L66 & Distendendo cilindro de trava \\
\hline L67 & Representa o palete parado \\
\hline L68 & Lugar auxiliar \\
\hline L69 & Válvula está energizada para distender o atuador e parar o palete \\
\hline L70 & Recolhendo cilindro de trava \\
\hline L71 & $\begin{array}{l}\text { Representa a existência de palete na esteira entre uma das paradas sem uso e a da estação de } \\
\text { inspeção }\end{array}$ \\
\hline L72 & Válvula está energizada para recolher o atuador e deixar o palete passar \\
\hline L73 & Cilindro pneumático de trava recolhido e palete se deslocando \\
\hline L74 & Lugar auxiliar \\
\hline L75 & Distendendo cilindro de trava \\
\hline L76 & Lugar auxiliar \\
\hline L77 & Lugar auxiliar \\
\hline Transição & Descrição \\
\hline T1 & $\begin{array}{l}\text { Transição requisitada que representa o pedido de palete proveniente da estação de inspeção, } \\
\text { bem como o recebimento da informação quanto à cor do cilindro base }\end{array}$ \\
\hline $\mathrm{T} 2$ & Transição requisitante que informa à estação de inspeção que o palete foi reservado \\
\hline T3 & $\begin{array}{l}\text { Transição requisitada que representa o recebimento da informação de que o cilindro base foi } \\
\text { enviado }\end{array}$ \\
\hline $\mathrm{T} 4$ & $\begin{array}{l}\text { Transição requisitante que informa à estação de montagem que há um palete com cilindro } \\
\text { base para ser montado }\end{array}$ \\
\hline T5 & $\begin{array}{l}\text { Transição requisitante que representa o envio, para a estação de montagem, da informação de } \\
\text { que a cor do cilindro base é não preto }\end{array}$ \\
\hline T6 & $\begin{array}{l}\text { Transição requisitante que representa o envio, para a estação de montagem, da informação de } \\
\text { que a cor do cilindro base é preto }\end{array}$ \\
\hline T7 & $\begin{array}{l}\text { Transição requisitada que representa a notificação de que o palete retornou para a estação de } \\
\text { transporte }\end{array}$ \\
\hline T8 & $\begin{array}{l}\text { Transição requisitante que representa a ordem para recolher o atuador e permitir a passagem } \\
\text { do palete }\end{array}$ \\
\hline T9 & $\begin{array}{l}\text { Transição requisitada que representa a confirmação, através de sensor, que o palete passou } \\
\text { pelo atuador }\end{array}$ \\
\hline $\mathrm{T} 10$ & $\begin{array}{l}\text { Transição requisitante que representa o envio da informação ao sistema supervisório de que } \\
\text { o palete está na parada da estação de inspeção }\end{array}$ \\
\hline T11 & $\begin{array}{l}\text { Transição requisitante que representa a ordem para recolher o atuador e permitir a passagem } \\
\text { do palete }\end{array}$ \\
\hline T12 & $\begin{array}{l}\text { Transição requisitada que representa a confirmação, através de sensor, que o palete passou } \\
\text { pelo atuador }\end{array}$ \\
\hline T13 & $\begin{array}{l}\text { Transição requisitante que representa a ordem para recolher o atuador e permitir a passagem } \\
\text { do palete }\end{array}$ \\
\hline T14 & $\begin{array}{l}\text { Transição requisitada que representa a confirmação, através de sensor, que o palete passou } \\
\text { pelo atuador }\end{array}$ \\
\hline T15 & $\begin{array}{l}\text { Transição requisitante que representa o envio da informação ao sistema supervisório de que } \\
\text { o palete está na esteira chegando à estação de montagem }\end{array}$ \\
\hline T16 & $\begin{array}{l}\text { Transição requisitante que representa a ordem para recolher o atuador e permitir a passagem } \\
\text { do palete }\end{array}$ \\
\hline $\mathrm{T} 17$ & $\begin{array}{l}\text { Transição requisitada que representa a confirmação, através de sensor, que o palete passou } \\
\text { pelo atuador }\end{array}$ \\
\hline T18 & $\begin{array}{l}\text { Transição requisitante que representa a ordem para recolher o atuador e permitir a passagem } \\
\text { do palete }\end{array}$ \\
\hline T19 & $\begin{array}{l}\text { Transição requisitada que representa a confirmação, através de sensor, que o palete passou } \\
\text { pelo atuador }\end{array}$ \\
\hline T20 & $\begin{array}{l}\text { Transição requisitante que representa o envio da informação ao sistema supervisório de que } \\
\text { o palete está na parada da estação de montagem }\end{array}$ \\
\hline
\end{tabular}


Tabela E.2 - Descrição dos elementos do modelo em RdP da atividade [Controle da estação de transporte] (continuação).

\begin{tabular}{|c|c|}
\hline Transição & Descrição \\
\hline T21 & $\begin{array}{l}\text { Transição requisitante que representa a ordem para recolher o atuador e permitir a passagem } \\
\text { do palete }\end{array}$ \\
\hline T22 & $\begin{array}{l}\text { Transição requisitada que representa a confirmação, através de sensor, que o palete passou } \\
\text { pelo atuador }\end{array}$ \\
\hline $\mathrm{T} 23$ & $\begin{array}{l}\text { Transição requisitante que representa a ordem para recolher o atuador e permitir a passagem } \\
\text { do palete }\end{array}$ \\
\hline T24 & $\begin{array}{l}\text { Transição requisitada que representa a confirmação, através de sensor, que o palete passou } \\
\text { pelo atuador }\end{array}$ \\
\hline T25 & $\begin{array}{l}\text { Transição requisitante que representa o envio da informação ao sistema supervisório de que } \\
\text { o palete está na esteira chegando a uma estação sem uso }\end{array}$ \\
\hline T26 & $\begin{array}{l}\text { Transição requisitante que representa a ordem para recolher o atuador e permitir a passagem } \\
\text { do palete }\end{array}$ \\
\hline T27 & $\begin{array}{l}\text { Transição requisitada que representa a confirmação, através de sensor, que o palete passou } \\
\text { pelo atuador }\end{array}$ \\
\hline T28 & $\begin{array}{l}\text { Transição requisitante que representa a ordem para recolher o atuador e permitir a passagem } \\
\text { do palete }\end{array}$ \\
\hline T29 & $\begin{array}{l}\text { Transição requisitada que representa a confirmação, através de sensor, que o palete passou } \\
\text { pelo atuador }\end{array}$ \\
\hline T30 & $\begin{array}{l}\text { Transição requisitante que representa o envio da informação ao sistema supervisório de que } \\
\text { o palete está na parada sem uso }\end{array}$ \\
\hline T31 & $\begin{array}{l}\text { Transição requisitante que representa a ordem para recolher o atuador e permitir a passagem } \\
\text { do palete }\end{array}$ \\
\hline T32 & $\begin{array}{l}\text { Transição requisitada que representa a confirmação, através de sensor, que o palete passou } \\
\text { pelo atuador }\end{array}$ \\
\hline T33 & $\begin{array}{l}\text { Transição requisitante que representa a ordem para recolher o atuador e permitir a passagem } \\
\text { do palete }\end{array}$ \\
\hline T34 & $\begin{array}{l}\text { Transição requisitada que representa a confirmação, através de sensor, que o palete passou } \\
\text { pelo atuador }\end{array}$ \\
\hline T35 & $\begin{array}{l}\text { Transição requisitante que representa a ordem para recolher o atuador e permitir a passagem } \\
\text { do palete }\end{array}$ \\
\hline T36 & $\begin{array}{l}\text { Transição requisitante que representa o envio da informação ao sistema supervisório de que } \\
\text { o palete está na esteira chegando à estação sem uso }\end{array}$ \\
\hline T37 & $\begin{array}{l}\text { Transição requisitada que representa a confirmação, através de sensor, que o palete passou } \\
\text { pelo atuador }\end{array}$ \\
\hline T38 & $\begin{array}{l}\text { Transição requisitante que representa a ordem para recolher o atuador e permitir a passagem } \\
\text { do palete }\end{array}$ \\
\hline T39 & $\begin{array}{l}\text { Transição requisitada que representa a confirmação, através de sensor, que o palete passou } \\
\text { pelo atuador }\end{array}$ \\
\hline $\mathrm{T} 40$ & $\begin{array}{l}\text { Transição requisitante que representa a ordem para recolher o atuador e permitir a passagem } \\
\text { do palete }\end{array}$ \\
\hline T41 & $\begin{array}{l}\text { Transição requisitante que representa o envio da informação ao sistema supervisório de que } \\
\text { o palete está na parada sem uso }\end{array}$ \\
\hline T42 & $\begin{array}{l}\text { Transição requisitada que representa a confirmação, através de sensor, que o palete passou } \\
\text { pelo atuador }\end{array}$ \\
\hline T43 & $\begin{array}{l}\text { Transição requisitante que representa a ordem para recolher o atuador e permitir a passagem } \\
\text { do palete }\end{array}$ \\
\hline T44 & $\begin{array}{l}\text { Transição requisitada que representa a confirmação, através de sensor, que o palete passou } \\
\text { pelo atuador }\end{array}$ \\
\hline T45 & $\begin{array}{l}\text { Transição requisitante que representa a ordem para recolher o atuador e permitir a passagem } \\
\text { do palete }\end{array}$ \\
\hline T46 & $\begin{array}{l}\text { Transição requisitante que representa o envio da informação ao sistema supervisório de que } \\
\text { o palete está na esteira chegando à estação de inspeção }\end{array}$ \\
\hline T47 & $\begin{array}{l}\text { Transição requisitada que representa a confirmação, através de sensor, que o palete passou } \\
\text { pelo atuador }\end{array}$ \\
\hline
\end{tabular}


Os modelos em RdP lugar-transição das Figuras E.9 a E.26 estão relacionados ao detalhamento das atividades do [Controle da estação de montagem], o qual foi modelado em partes devido a sua complexidade (função do número de elementos que compõem o modelo). Pode-se observar que em alguns destes modelos existe uma parte ainda em PFS. Estas partes correspondem aos conflitos internos, modelados como no caso do [Controle da estação de inspeção] (Figura E.7). Como se tratam de partes de um mesmo modelo, a numeração dos lugares e transições é contínua.

A Figura E.9 apresenta o modelo em RdP da atividade [Pega palete na estação de transporte] do [Controle da estação de montagem] (Figura E.4) e a Tabela E.3 contém a descrição dos seus elementos. O detalhamento das atividades [Abaixa o braço], [Fecha a garra], [Sobe o braço], entre outras presentes até a Figura E.24, são apresentados nas Figuras E.25 e E.26.

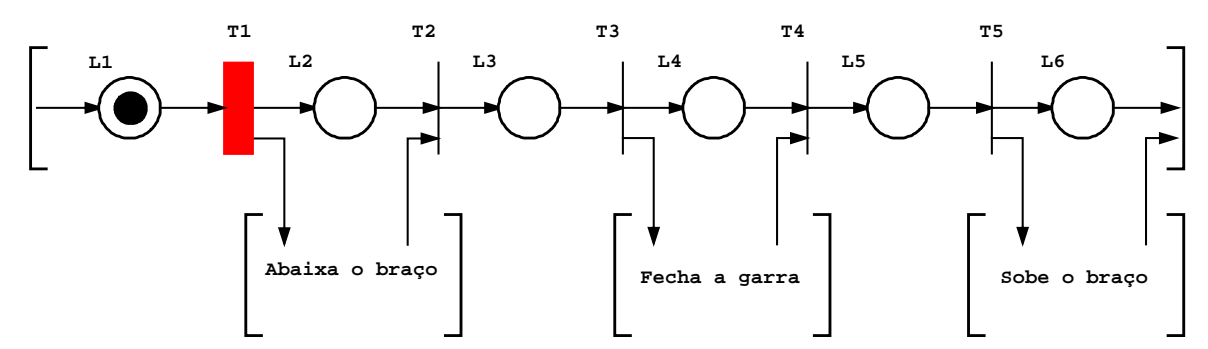

Figura E.9 - Modelo em RdP lugar-transição da atividade [Pega palete na estação de transporte] do [Controle da estação de montagem].

Tabela E.3 - Descrição dos elementos do modelo em RdP da atividade [Pega palete na estação de transporte].

\begin{tabular}{|l|l|}
\hline Lugar & Descrição \\
\hline L1 & Representa a estação de montagem disponível \\
\hline L2 & Representa o pedido para que o robô abaixe o braço \\
\hline L3 & Representa o estado “robô com o braço abaixado” \\
\hline L4 & Representa o pedido para que o robô feche a garra \\
\hline L5 & Representa o estado “robô com a garra fechada” \\
\hline L6 & Representa o pedido para que o robô suba o braço \\
\hline Transição & Descrição \\
\hline T1 & $\begin{array}{l}\text { Transição requisitada que representa a chegada de um palete com cilindro base para ser } \\
\text { montado e o início da operação "abaixa o braço” }\end{array}$ \\
\hline T2 & Transição que representa o fim da operação “abaixa o braço” \\
\hline T3 & Transição que representa o início da operação “fecha a garra” \\
\hline T4 & Transição que representa o fim da operação “fecha a garra” \\
\hline T5 & Transição que representa o início da operação “sobe o braço” \\
\hline
\end{tabular}

A Figura E.10 apresenta o modelo em RdP da atividade [Põe palete sobre a bancada] do [Controle da estação de montagem] (Figura E.4) e a Tabela E.4 contém a descrição dos seus elementos. 


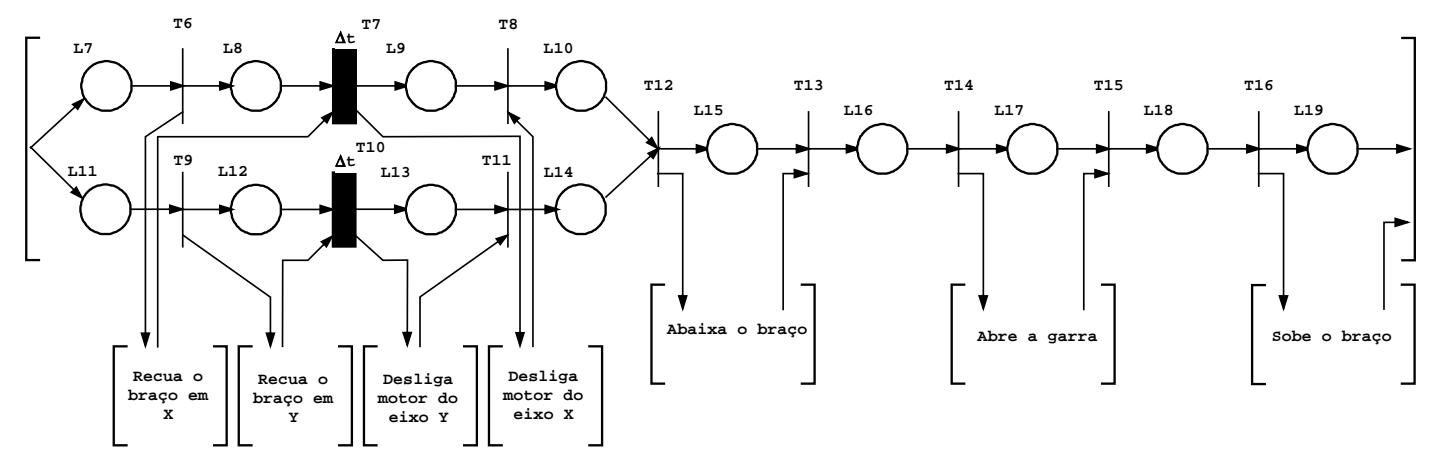

Figura E.10 - Modelo em RdP lugar-transição da atividade [Põe palete sobre a bancada] do [Controle da estação de montagem].

Tabela E.4 - Descrição dos elementos do modelo em RdP da atividade [Põe palete sobre a bancada].

\begin{tabular}{|c|c|}
\hline Lugar & Descrição \\
\hline L7 & Representa o comando para recuar o braço do robô no eixo X \\
\hline L8 & Braço do robô recuando em $\mathrm{X}$ \\
\hline L9 & Desligando acionamento do braço no eixo X \\
\hline L10 & Acionamento do braço no eixo $\mathrm{X}$ desligado \\
\hline L11 & Representa o comando para recuar o braço do robô no eixo Y \\
\hline L12 & Braço do robô recuando em Y \\
\hline L13 & Desligando acionamento do braço no eixo Y \\
\hline L14 & Acionamento do braço no eixo Y desligado \\
\hline L15 & Representa o comando para que o robô abaixe o braço \\
\hline L16 & Representa a detecção de que o robô se encontra com o braço abaixado \\
\hline L17 & Representa o comando para que o robô abra a garra \\
\hline L18 & Representa a detecção de que o robô se encontra com a garra aberta \\
\hline L19 & Representa o comando para que o robô suba o braço \\
\hline Transição & Descrição \\
\hline T6 & Representa o início da operação “recua braço do robô no eixo X” \\
\hline $\mathrm{T} 7$ & $\begin{array}{l}\text { Representa o tempo necessário para que o braço do robô se desloque no eixo X até a } \\
\text { posição desejada }\end{array}$ \\
\hline T8 & Representa o fim da operação de deslocamento do braço do robô em X \\
\hline T9 & Representa o início da operação “recua braço do robô no eixo Y” \\
\hline $\mathrm{T} 10$ & $\begin{array}{l}\text { Representa o tempo necessário para que o braço do robô se desloque no eixo Y até a } \\
\text { posição desejada }\end{array}$ \\
\hline T11 & Representa o fim da operação de deslocamento do braço do robô em Y \\
\hline T12 & Transição que representa o inicío da operação “abaixa o braço” \\
\hline T13 & Transição que representa o fim da operação “abaixa o braço” \\
\hline T14 & Transição que representa o início da operação “abre a garra” \\
\hline T15 & Transição que representa o fim da operação “abre a garra” \\
\hline T16 & Transição que representa o início da operação "sobe o braço" \\
\hline
\end{tabular}

Na Figura E.11 são apresentados o modelo em RdP que representa as atividades [Alimenta com mola] e [Alimenta com tampa] do [Controle da estação de montagem] (Figura E.5) e a Tabela E.5 contém a descrição dos seus elementos. Na tabela, os número em parênteses representam os nomes dos lugares e transições referentes à atividade [Alimenta com tampa]. 


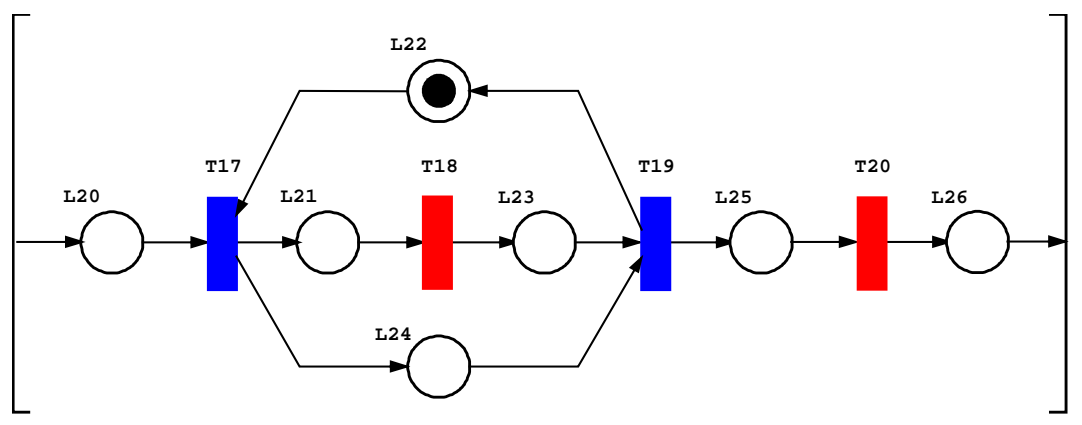

Figura E.11 - Modelo em RdP lugar-transição tanto para a atividade [Alimenta com mola] como para a atividade [Alimenta com tampa] do [Prepara demais partes para a montagem] do [Controle da estação de montagem].

Tabela E.5 - Descrição dos elementos do modelo em RdP da atividade [Alimenta com mola] e [Alimenta com tampa].

\begin{tabular}{|l|l|}
\hline Lugar & Descrição \\
\hline L20 (27) & Uma mola (tampa) foi requisitada \\
\hline L21 (28) & O atuador está sendo distendido \\
\hline L22 (29) & Válvula está energizada na posição “recolher atuador” \\
\hline L23 (30) & O atuador foi distendido \\
\hline L24 (31) & Válvula está energizada na posição “distender atuador” \\
\hline L25 (32) & O atuador está sendo recolhido \\
\hline L26 (33) & O atuador foi recolhido \\
\hline Transição & Descrição \\
\hline T17 (21) & $\begin{array}{l}\text { Transição requisitante que representa a ordem para distender o atuador e posicionar uma } \\
\text { mola (tampa) }\end{array}$ \\
\hline T18 (22) & $\begin{array}{l}\text { Transição requisitada que representa a confirmação, através de sensor, que o atuador foi } \\
\text { distendido }\end{array}$ \\
\hline T19 (23) & Transição requisitante que representa a ordem para recolher o atuador \\
\hline T20 (24) & $\begin{array}{l}\text { Transição requisitada que representa a confirmação, através de sensor, que o atuador foi } \\
\text { recolhido }\end{array}$ \\
\hline
\end{tabular}

A Figura E.12 apresenta o modelo em RdP da atividade [Alimenta com pino] do [Controle da estação de montagem] (Figura E.5) e a Tabela E.6 contém a descrição dos seus elementos.

Na Figura E.13 é apresentado o modelo, em RdP, da atividade [Pega cilindro base do palete] do [Controle da estação de montagem] (Figura E.4) e a descrição de seus elementos é apresentada na Tabela E.7. 


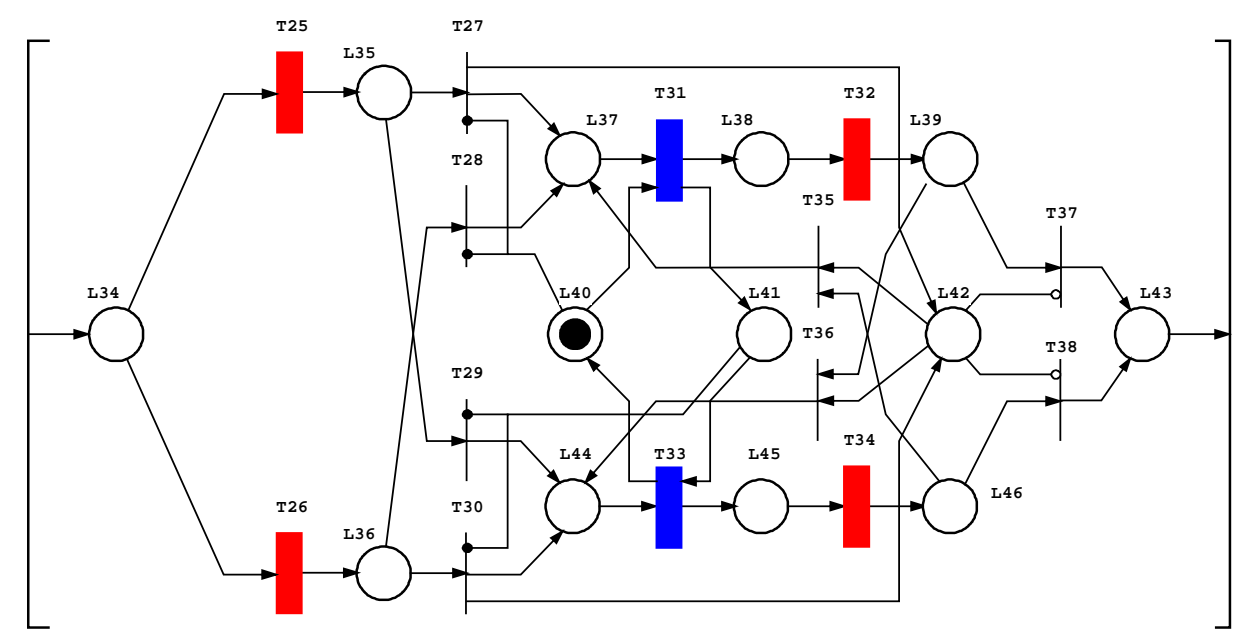

Figura E.12 - Modelo em RdP lugar-transição da atividade [Alimenta com pino] do [Prepara demais partes para a montagem] do [Controle da estação de montagem].

Tabela E.6 - Descrição dos elementos do modelo em RdP da atividade [Alimenta com pino].

\begin{tabular}{|c|c|}
\hline Lugar & Descrição \\
\hline L34 & Um pino foi requisitado \\
\hline L35 & Representa que o pino requisitado é preto \\
\hline L36 & Representa que o pino requisitado é prata \\
\hline L37 & Ordem para girar atuador no sentido anti-horário \\
\hline L38 & Atuador girando no sentido anti-horário \\
\hline L39 & Atuador atingiu o fim de curso do sentido anti-horário \\
\hline L40 & $\begin{array}{l}\text { Válvula está energizada para manter atuador no fim de curso da poisção horária (pino prata } \\
\text { selecionado) }\end{array}$ \\
\hline L41 & $\begin{array}{l}\text { Válvula está energizada para manter atuador no fim de curso da poisção anti-horária (pino } \\
\text { preto selecionado) }\end{array}$ \\
\hline L42 & $\begin{array}{l}\text { Representa a necessidade de girar o atuador no senti oposto do que foi girado para } \\
\text { posicionar o pino correto para ser montado }\end{array}$ \\
\hline L43 & Pino pronto para ser montado \\
\hline L44 & Ordem para girar atuador no sentido horário \\
\hline L45 & Atuador girando no sentido horário \\
\hline L46 & Atuador atingiu o fim de curso do sentido horário \\
\hline Transição & Descriçãa \\
\hline $\mathrm{T} 25$ & $\begin{array}{l}\text { Transição requisitada que representa o recebimento, da estação de transporte, da informação } \\
\text { que a cor do cilindro base não é preto, ou seja, monta-se com pino preto }\end{array}$ \\
\hline T26 & $\begin{array}{l}\text { Transição requisitada que representa o recebimento, da estação de transporte, da informação } \\
\text { que a cor do cilindro base é preto, ou seja, monta-se com pino prata }\end{array}$ \\
\hline $\mathrm{T} 27$ & Transição que representa "pino preto a ser selecionado e posicionado" \\
\hline T28 & Transição que representa “posicionar pino prata já selecionado” \\
\hline T29 & Transição que representa “posicionar pino preto já selecionado" \\
\hline T30 & Transição que representa “pino prata a ser selecionado e posicionado" \\
\hline T31 & Transição requisitante que representa a ordem para girar o atuador no sentido anti-horário \\
\hline T32 & $\begin{array}{l}\text { Transição requisitada que representa a confirmação, através de sensor, que o atuador chegou } \\
\text { no fim de curso do sntido anti-horário }\end{array}$ \\
\hline T33 & Transição requisitante que representa a ordem para girar o atuador no sentido horário \\
\hline T34 & $\begin{array}{l}\text { Transição requisitada que representa a confirmação, através de sensor, que o atuador chegou } \\
\text { no fim de curso do sntido horário }\end{array}$ \\
\hline T35 & Transição que representa “posicionar pino prata que acabou de ser pego” \\
\hline T36 & Transição que representa "posicionar pino preto que acabou de ser pego" \\
\hline T37 & Transição que representa que há um pino prata pronto para ser montado \\
\hline T38 & Transição que representa que há um pino preto pronto para ser montado \\
\hline
\end{tabular}




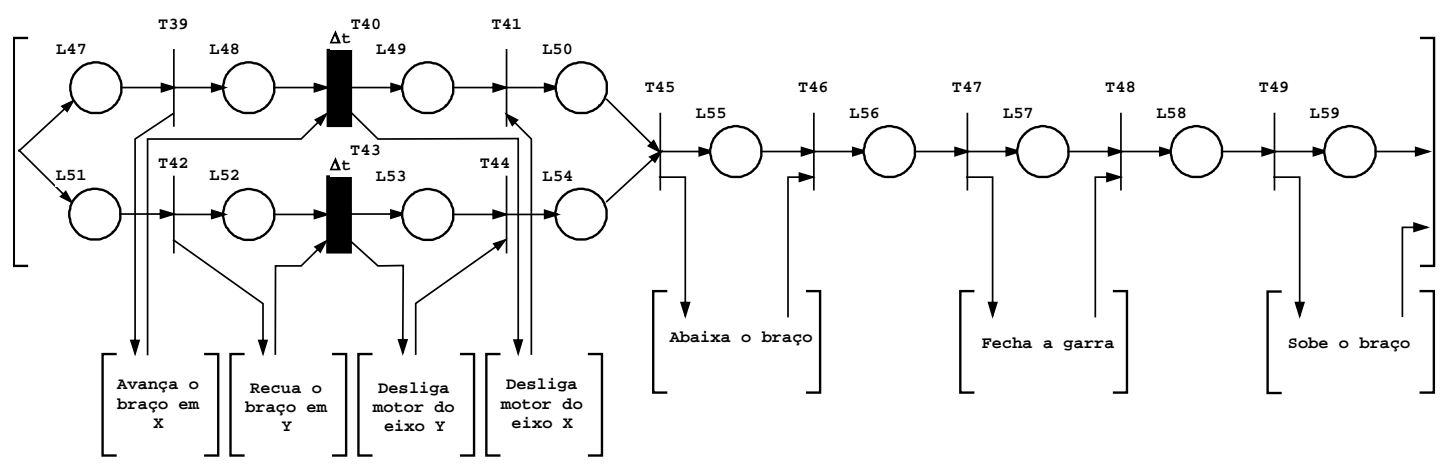

Figura E.13 - Modelo em RdP lugar-transição da atividade [Pega cilindro base do palete] do [Controle da estação de montagem].

Tabela E.7 - Descrição dos elementos do modelo em RdP da atividade [Pega cilindro base do palete].

\begin{tabular}{|c|c|}
\hline Lugar & Descrição \\
\hline L47 & Representa o comando para avançar o braço do robô no eixo X \\
\hline L48 & Braço do robô avançando em X \\
\hline L49 & Desligando acionamento do braço no eixo X \\
\hline L50 & Acionamento do braço no eixo $\mathrm{X}$ desligado \\
\hline L51 & Representa o comando para recuar o braço do robô no eixo Y \\
\hline L52 & Braço do robô recuando em Y \\
\hline L53 & Desligando acionamento do braço no eixo Y \\
\hline L54 & Acionamento do braço no eixo Y desligado \\
\hline L55 & Representa o comando para que o robô abaixe o braço \\
\hline L56 & Representa a detecção de que o robô se encontra com o braço abaixado \\
\hline L57 & Representa o comando para que o robô feche a garra \\
\hline L58 & Representa a detecção de que o robô se encontra com a garra fechada \\
\hline L59 & Representa o comando para que o robô suba o braço \\
\hline Transição & Descrição \\
\hline T39 & Representa o início da operação “avança braço do robô no eixo X” \\
\hline $\mathrm{T} 40$ & $\begin{array}{l}\text { Representa o tempo necessário para que o braço do robô se desloque no eixo X até a } \\
\text { posição desejada }\end{array}$ \\
\hline T41 & Representa o fim da operação de deslocamento do braço do robô em X \\
\hline T42 & Representa o início da operação “recua braço do robô no eixo Y” \\
\hline T43 & $\begin{array}{l}\text { Representa o tempo necessário para que o braço do robô se desloque no eixo Y até a } \\
\text { posição desejada }\end{array}$ \\
\hline T44 & Representa o fim da operação de deslocamento do braço do robô em Y \\
\hline T45 & Transição que representa o inicío da operação “abaixa o braço” \\
\hline T46 & Transição que representa o fim da operação “abaixa o braço” \\
\hline T47 & Transição que representa o início da operação “fecha a garra” \\
\hline T48 & Transição que representa o fim da operação “fecha a garra” \\
\hline T49 & Transição que representa o início da operação "sobe o braço" \\
\hline
\end{tabular}

A Figura E.14 apresenta o modelo em RdP da atividade [Põe cilindro base na posição de montagem] do [Controle da estação de montagem] (Figura E.4) e a

Tabela E.8 contém a descrição dos seus elementos. 


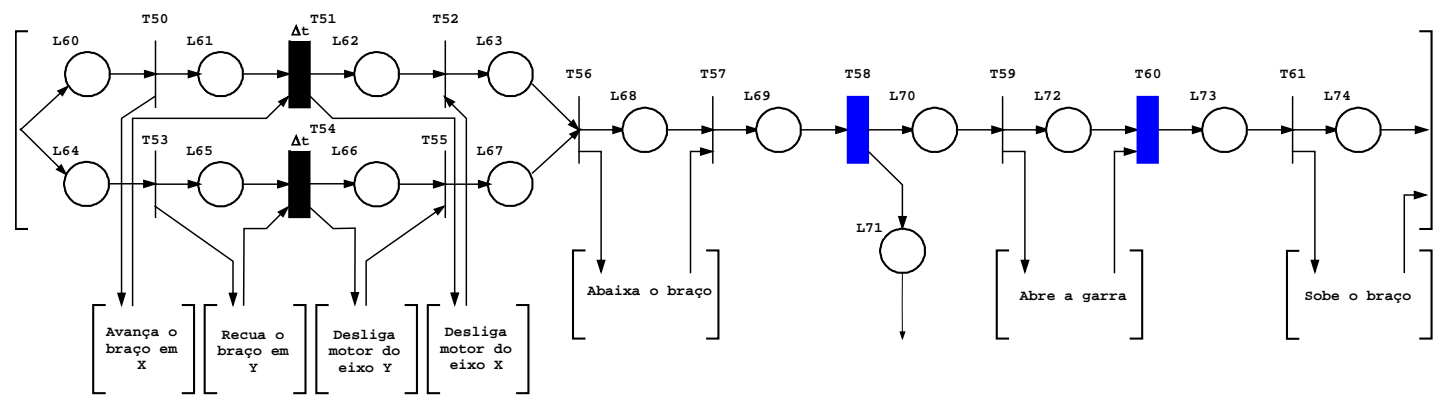

Figura E. 14 - Modelo em RdP lugar-transição da atividade [Põe cilindro base na posição de montagem] do [Controle da estação de montagem].

Tabela E.8 - Descrição dos elementos do modelo em RdP da atividade [Põe cilindro base na posição de montagem].

\begin{tabular}{|c|c|}
\hline Lugar & Descrição \\
\hline L60 & Representa o comando para avançar o braço do robô no eixo X \\
\hline L61 & Braço do robô avançando em $\mathrm{X}$ \\
\hline L62 & Desligando acionamento do braço no eixo X \\
\hline L63 & Acionamento do braço no eixo X desligado \\
\hline L64 & Representa o comando para recuar o braço do robô no eixo Y \\
\hline L65 & Braço do robô recuando em Y \\
\hline L66 & Desligando acionamento do braço no eixo Y \\
\hline L67 & Acionamento do braço no eixo Y desligado \\
\hline L68 & Representa o comando para que o robô abaixe o braço \\
\hline L69 & Representa a detecção de que o robô se encontra com o braço abaixado \\
\hline L70 & Cilindro base preso na bancada de montagem \\
\hline L71 & $\begin{array}{l}\text { Válvula que faz com que o cilindro base fique preso na bancada de montagem está } \\
\text { energizada }\end{array}$ \\
\hline L72 & Representa o comando para que o robô abra a garra \\
\hline L73 & Representa a detecção de que o robô se encontra com a garra aberta \\
\hline L74 & Representa o comando para que o robô suba o braço \\
\hline Transição & Descrição \\
\hline T50 & Representa o início da operação “avança braço do robô no eixo X” \\
\hline T51 & $\begin{array}{l}\text { Representa o tempo necessário para que o braço do robô se desloque no eixo X até a } \\
\text { posição desejada }\end{array}$ \\
\hline T52 & Representa o fim da operação de deslocamento do braço do robô em X \\
\hline T53 & Representa o início da operação “recua braço do robô no eixo Y” \\
\hline T54 & $\begin{array}{l}\text { Representa o tempo necessário para que o braço do robô se desloque no eixo Y até a } \\
\text { posição desejada }\end{array}$ \\
\hline T55 & Representa o fim da operação de deslocamento do braço do robô em Y \\
\hline T56 & Transição que representa o inicío da operação “abaixa o braço” \\
\hline T57 & Transição que representa o fim da operação “abaixa o braço” \\
\hline T58 & $\begin{array}{l}\text { Transição que representa o acionamento da válvula que prende o cilindro base na bancada de } \\
\text { montagem }\end{array}$ \\
\hline T59 & Transição que representa o início da operação “abre a garra” \\
\hline T60 & $\begin{array}{l}\text { Transição que representa o fim da operação “abre a garra” bem como um artifício para } \\
\text { sinalizar à planta que o cilindro base se encontra na posição de montagem já que a planta } \\
\text { não possui sensores para isso }\end{array}$ \\
\hline T61 & Transição que representa o início da operação “sobe o braço” \\
\hline
\end{tabular}

A Figura E.15 apresenta o modelo em RdP da atividade [Pega mola] do [Controle da estação de montagem] (Figura E.4) e a Tabela E.9 contém a descrição dos seus elementos. 


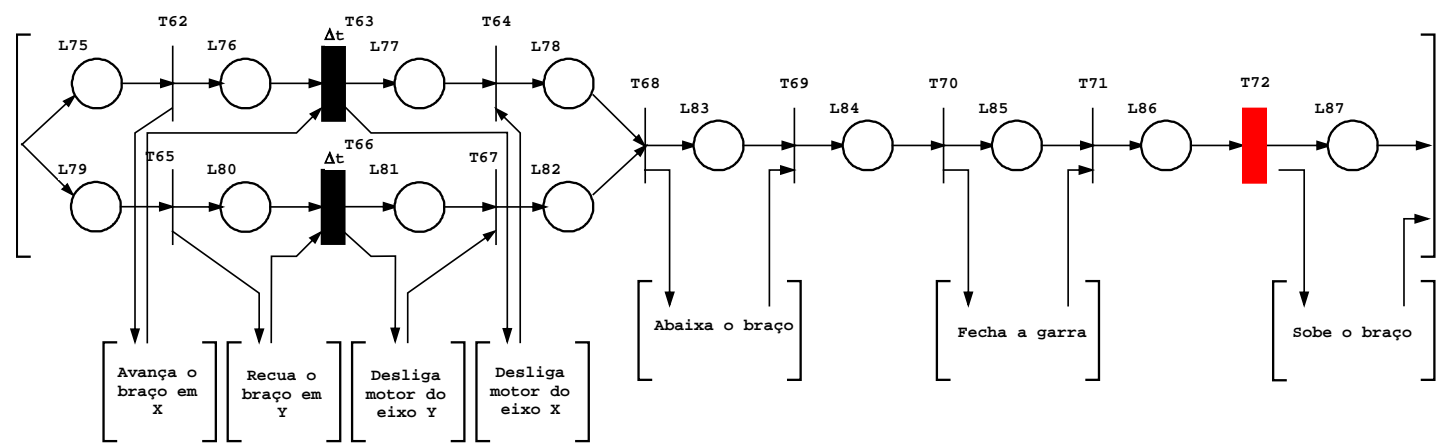

Figura E.15 - Modelo em RdP lugar-transição da atividade [Pega a mola] do [Controle da estação de montagem].

Tabela E.9 - Descrição dos elementos do modelo em RdP da atividade [Pega a mola].

\begin{tabular}{|c|c|}
\hline Lugar & Descrição \\
\hline L75 & Representa o comando para avançar o braço do robô no eixo X \\
\hline L76 & Braço do robô avançando em X \\
\hline L77 & Desligando acionamento do braço no eixo X \\
\hline L78 & Acionamento do braço no eixo X desligado \\
\hline L79 & Representa o comando para recuar o braço do robô no eixo Y \\
\hline L80 & Braço do robô recuando em Y \\
\hline L81 & Desligando acionamento do braço no eixo Y \\
\hline L82 & Acionamento do braço no eixo Y desligado \\
\hline L83 & Representa o comando para que o robô abaixe o braço \\
\hline L84 & Representa a detecção de que o robô se encontra com o braço abaixado \\
\hline L85 & Representa o comando para que o robô feche a garra \\
\hline L86 & Representa a detecção de que o robô se encontra com a garra fechada \\
\hline L87 & Representa o comando para que o robô suba o braço \\
\hline Transição & Descrição \\
\hline T62 & Representa o início da operação “avança braço do robô no eixo X” \\
\hline T63 & $\begin{array}{l}\text { Representa o tempo necessário para que o braço do robô se desloque no eixo X até a } \\
\text { posição desejada }\end{array}$ \\
\hline T64 & Representa o fim da operação de deslocamento do braço do robô em X \\
\hline T65 & Representa o início da operação “recua braço do robô no eixo Y” \\
\hline T66 & $\begin{array}{l}\text { Representa o tempo necessário para que o braço do robô se desloque no eixo Y até a } \\
\text { posição desejada }\end{array}$ \\
\hline T67 & Representa o fim da operação de deslocamento do braço do robô em Y \\
\hline T68 & Transição que representa o inicío da operação “abaixa o braço” \\
\hline T69 & Transição que representa o fim da operação "abaixa o braço" \\
\hline T70 & Transição que representa o início da operação “fecha a garra” \\
\hline T71 & Transição que representa o fim da operação “fecha a garra” \\
\hline T72 & $\begin{array}{l}\text { Transição que representa o início da operação “sobe o braço” e o sinal do sensor na planta } \\
\text { indicando que a mola foi retirada do alimentador de molas }\end{array}$ \\
\hline
\end{tabular}

Na Figura E.16 é apresentado o modelo, em RdP, da atividade [Monta a mola] do [Controle da estação de montagem] (Figura E.4) e a descrição de seus elementos é apresentada na Tabela E.10. 


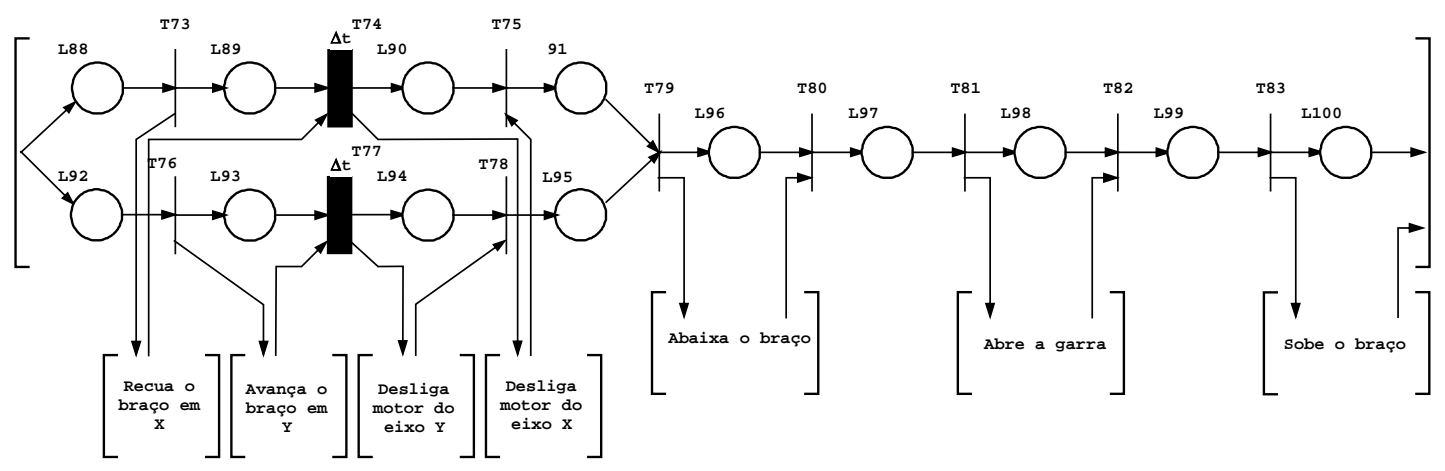

Figura E.16 - Modelo em RdP lugar-transição da atividade [Monta a mola] do [Controle da estação de montagem].

Tabela E.10 - Descrição dos elementos do modelo em RdP da atividade [Monta a mola].

\begin{tabular}{|c|c|}
\hline Lugar & Descrição \\
\hline L88 & Representa o comando para recuar o braço do robô no eixo X \\
\hline L89 & Braço do robô recuando em $\mathrm{X}$ \\
\hline L90 & Desligando acionamento do braço no eixo X \\
\hline L91 & Acionamento do braço no eixo X desligado \\
\hline L92 & Representa o comando para avançar o braço do robô no eixo Y \\
\hline L93 & Braço do robô avançando em Y \\
\hline L94 & Desligando acionamento do braço no eixo Y \\
\hline L95 & Acionamento do braço no eixo Y desligado \\
\hline L96 & Representa o comando para que o robô abaixe o braço \\
\hline L97 & Representa a detecção de que o robô se encontra com o braço abaixado \\
\hline L98 & Representa o comando para que o robô abra a garra \\
\hline L99 & Representa a detecção de que o robô se encontra com a garra aberta \\
\hline L100 & Representa o comando para que o robô suba o braço \\
\hline Transição & Descrição \\
\hline T73 & Representa o início da operação “recua braço do robô no eixo X” \\
\hline T74 & $\begin{array}{l}\text { Representa o tempo necessário para que o braço do robô se desloque no eixo X até a } \\
\text { posição desejada }\end{array}$ \\
\hline T75 & Representa o fim da operação de deslocamento do braço do robô em X \\
\hline T76 & Representa o início da operação “avança braço do robô no eixo Y” \\
\hline T77 & $\begin{array}{l}\text { Representa o tempo necessário para que o braço do robô se desloque no eixo Y até a } \\
\text { posição desejada }\end{array}$ \\
\hline T78 & Representa o fim da operação de deslocamento do braço do robô em Y \\
\hline T79 & Transição que representa o inicío da operação “abaixa o braço” \\
\hline T80 & Transição que representa o fim da operação “abaixa o braço” \\
\hline T81 & Transição que representa o início da operação “abre a garra” \\
\hline T82 & Transição que representa o fim da operação “abre a garra” \\
\hline T83 & Transição que representa o início da operação “sobe o braço” \\
\hline
\end{tabular}

A Figura E.17 apresenta o modelo em RdP da atividade [Pega o pino] do [Controle da estação de montagem] (Figura E.4) e a Tabela E.11 contém a descrição dos seus elementos. 


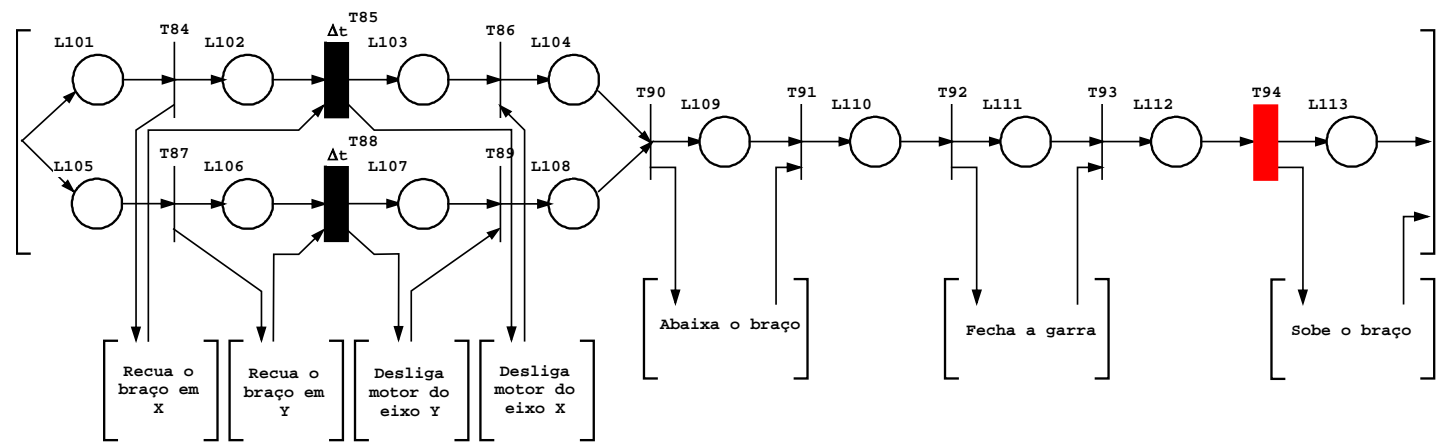

Figura E.17 - Modelo em RdP lugar-transição da atividade [Pega o pino] do [Controle da estação de montagem].

Tabela E.11 - Descrição dos elementos do modelo em RdP da atividade [Pega o pino].

\begin{tabular}{|c|c|}
\hline Lugar & Descrição \\
\hline L101 & Representa o comando para recuar o braço do robô no eixo X \\
\hline L102 & Braço do robô recuando em $\mathrm{X}$ \\
\hline L103 & Desligando acionamento do braço no eixo X \\
\hline L104 & Acionamento do braço no eixo X desligado \\
\hline L105 & Representa o comando para recuar o braço do robô no eixo Y \\
\hline L106 & Braço do robô recuando em Y \\
\hline L107 & Desligando acionamento do braço no eixo Y \\
\hline L108 & Acionamento do braço no eixo Y desligado \\
\hline L109 & Representa o comando para que o robô abaixe o braço \\
\hline L110 & Representa a detecção de que o robô se encontra com o braço abaixado \\
\hline L111 & Representa o comando para que o robô feche a garra \\
\hline L112 & Representa a detecção de que o robô se encontra com a garra fecahda \\
\hline L113 & Representa o comando para que o robô suba o braço \\
\hline Transição & Descrição \\
\hline T84 & Representa o início da operação “recua braço do robô no eixo X” \\
\hline T85 & $\begin{array}{l}\text { Representa o tempo necessário para que o braço do robô se desloque no eixo X até a } \\
\text { posição desejada }\end{array}$ \\
\hline T86 & Representa o fim da operação de deslocamento do braço do robô em X \\
\hline T87 & Representa o início da operação “recua braço do robô no eixo Y” \\
\hline T88 & $\begin{array}{l}\text { Representa o tempo necessário para que o braço do robô se desloque no eixo Y até a } \\
\text { posição desejada }\end{array}$ \\
\hline T89 & Representa o fim da operação de deslocamento do braço do robô em Y \\
\hline T90 & Transição que representa o inicío da operação “abaixa o braço” \\
\hline T91 & Transição que representa o fim da operação “abaixa o braço” \\
\hline T92 & Transição que representa o início da operação “fecha a garra” \\
\hline T93 & Transição que representa o fim da operação “fecha a garra” \\
\hline T94 & $\begin{array}{l}\text { Transição que representa o início da operação "sobe o braço" e o sinal do sensor na planta } \\
\text { indicando que o pino foi retirado do alimentador de pinos }\end{array}$ \\
\hline
\end{tabular}

A Figura E.18 apresenta o modelo em RdP da atividade [Monta pino] do [Controle da estação de montagem] (Figura E.4) e a Tabela E.12 contém a descrição dos seus elementos. 


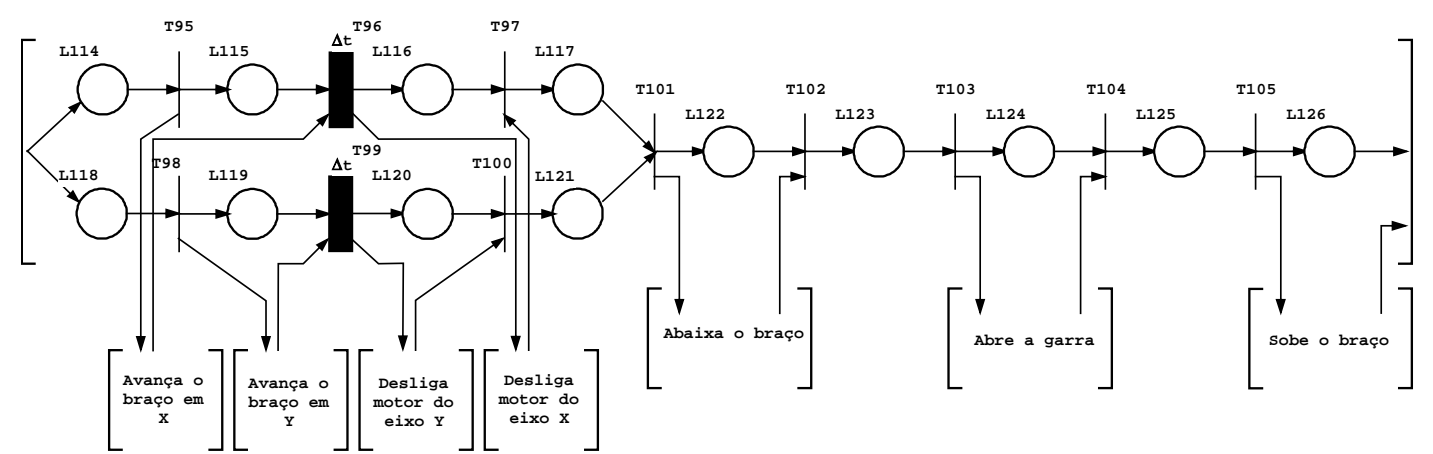

Figura E.18 - Modelo em RdP lugar-transição da atividade [Monta Pino] do [Controle da estação de montagem].

Tabela E.12 - Descrição dos elementos do modelo em RdP da atividade [Monta pino].

\begin{tabular}{|c|c|}
\hline Lugar & Descrição \\
\hline L114 & Representa o comando para avançar o braço do robô no eixo X \\
\hline L115 & Braço do robô avançando em X \\
\hline L116 & Desligando acionamento do braço no eixo X \\
\hline L117 & Acionamento do braço no eixo X desligado \\
\hline L118 & Representa o comando para avançar o braço do robô no eixo Y \\
\hline L119 & Braço do robô avançando em Y \\
\hline L120 & Desligando acionamento do braço no eixo Y \\
\hline L121 & Acionamento do braço no eixo Y desligado \\
\hline L122 & Representa o comando para que o robô abaixe o braço \\
\hline L123 & Representa a detecção de que o robô se encontra com o braço abaixado \\
\hline L124 & Representa o comando para que o robô abra a garra \\
\hline L125 & Representa a detecção de que o robô se encontra com a garra aberta \\
\hline L126 & Representa o comando para que o robô suba o braço \\
\hline Transição & Descrição \\
\hline T95 & Representa o início da operação “avança braço do robô no eixo X” \\
\hline T96 & $\begin{array}{l}\text { Representa o tempo necessário para que o braço do robô se desloque no eixo X até a } \\
\text { posição desejada }\end{array}$ \\
\hline T97 & Representa o fim da operação de deslocamento do braço do robô em X \\
\hline T98 & Representa o início da operação “avança braço do robô no eixo Y” \\
\hline T99 & $\begin{array}{l}\text { Representa o tempo necessário para que o braço do robô se desloque no eixo Y até a } \\
\text { posição desejada }\end{array}$ \\
\hline T100 & Representa o fim da operação de deslocamento do braço do robô em Y \\
\hline T101 & Transição que representa o inicío da operação “abaixa o braço” \\
\hline T102 & Transição que representa o fim da operação "abaixa o braço” \\
\hline T103 & Transição que representa o início da operação “abre a garra” \\
\hline T104 & Transição que representa o fim da operação “abre a garra” \\
\hline T105 & Transição que representa o início da operação “sobe o braço” \\
\hline
\end{tabular}

Na Figura E.19 é apresentado o modelo, em RdP, da atividade [Pega a tampa] do [Controle da estação de montagem] (Figura E.4) e a descrição de seus elementos é apresentada na Tabela E.13. 


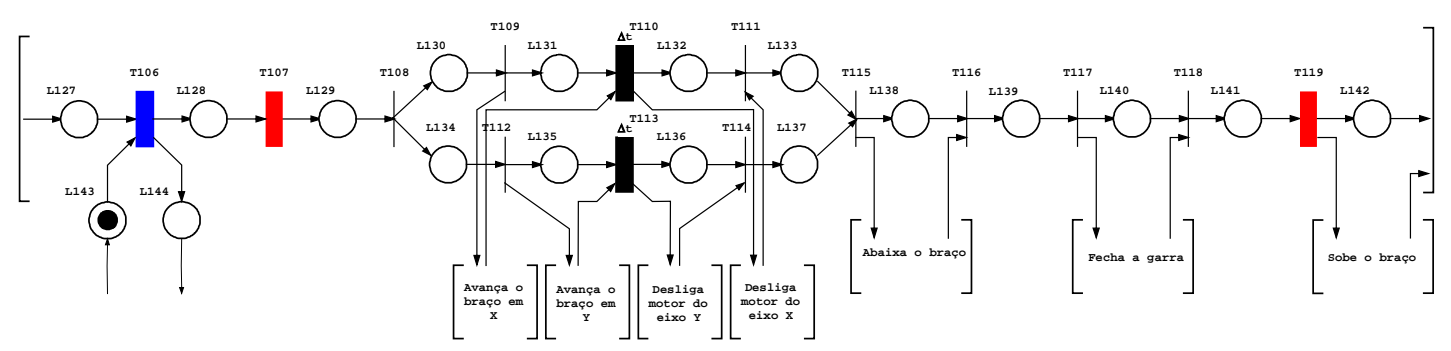

Figura E.19 - Modelo em RdP lugar-transição da atividade [Pega a tampa] do [Controle da estação de montagem].

Tabela E.13 - Descrição dos elementos do modelo em RdP da atividade [Pega a tampa].

\begin{tabular}{|c|c|}
\hline Lugar & Descrição \\
\hline L127 & Representa o braço do robô no alto \\
\hline L128 & A garra está sendo girada no sentido anti-horário \\
\hline L129 & A garra está totalmente girada no sentido anti-horário \\
\hline L130 & Representa o comando para avançar o braço do robô no eixo X \\
\hline L131 & Braço do robô avançando em X \\
\hline L132 & Desligando acionamento do braço no eixo X \\
\hline L133 & Acionamento do braço no eixo X desligado \\
\hline L134 & Representa o comando para avançar o braço do robô no eixo Y \\
\hline L135 & Braço do robô avançando em Y \\
\hline L136 & Desligando acionamento do braço no eixo Y \\
\hline L137 & Acionamento do braço no eixo Y desligado \\
\hline L138 & Representa o comando para que o robô abaixe o braço \\
\hline L139 & Representa a detecção de que o robô se encontra com o braço abaixado \\
\hline L140 & Representa o comando para que o robô feche a garra \\
\hline L141 & Representa a detecção de que o robô se encontra com a garra fechada \\
\hline L142 & Representa o comando para que o robô suba o braço \\
\hline L143 & Válvula está energizada para manter a garra girada no sentido horário \\
\hline L144 & Válvula está energizada para manter a garra girada no sentido anti-horário \\
\hline Transição & Descrição \\
\hline T106 & Transição requisitante que representa a ordem para girar a garra no sentido anti-horário \\
\hline T107 & $\begin{array}{l}\text { Transição requisitada que representa a confirmação, através de sensor, que a garra foi } \\
\text { completamente girada no sentido anti-horário }\end{array}$ \\
\hline T108 & $\begin{array}{l}\text { Transição auxiliar que paraleliza as operações de deslocamento do braço do robô nos eixos } \\
\text { X e Y }\end{array}$ \\
\hline T109 & Representa o início da operação “avança braço do robô no eixo X” \\
\hline T110 & $\begin{array}{l}\text { Representa o tempo necessário para que o braço do robô se desloque no eixo X até a } \\
\text { posição desejada }\end{array}$ \\
\hline $\mathrm{T} 111$ & Representa o fim da operação de deslocamento do braço do robô em X \\
\hline T112 & Representa o início da operação “avança braço do robô no eixo Y” \\
\hline T113 & $\begin{array}{l}\text { Representa o tempo necessário para que o braço do robô se desloque no eixo Y até a } \\
\text { posição desejada }\end{array}$ \\
\hline $\mathrm{T} 114$ & Representa o fim da operação de deslocamento do braço do robô em Y \\
\hline T115 & Transição que representa o inicío da operação “abaixa o braço” \\
\hline T116 & Transição que representa o fim da operação "abaixa o braço” \\
\hline T117 & Transição que representa o início da operação “fecha a garra” \\
\hline T118 & Transição que representa o fim da operação “fecha a garra” \\
\hline T119 & $\begin{array}{l}\text { Transição que representa o início da operação “sobe o braço” e o sinal do sensor na planta } \\
\text { indicando que a tampa foi retirada do alimentador de tampas }\end{array}$ \\
\hline
\end{tabular}


Na Figura E.20 é apresentado o modelo, em RdP, da atividade [Monta a tampa] do [Controle da estação de montagem] (Figura E.4) e a descrição de seus elementos é apresentada na Tabela E.14.

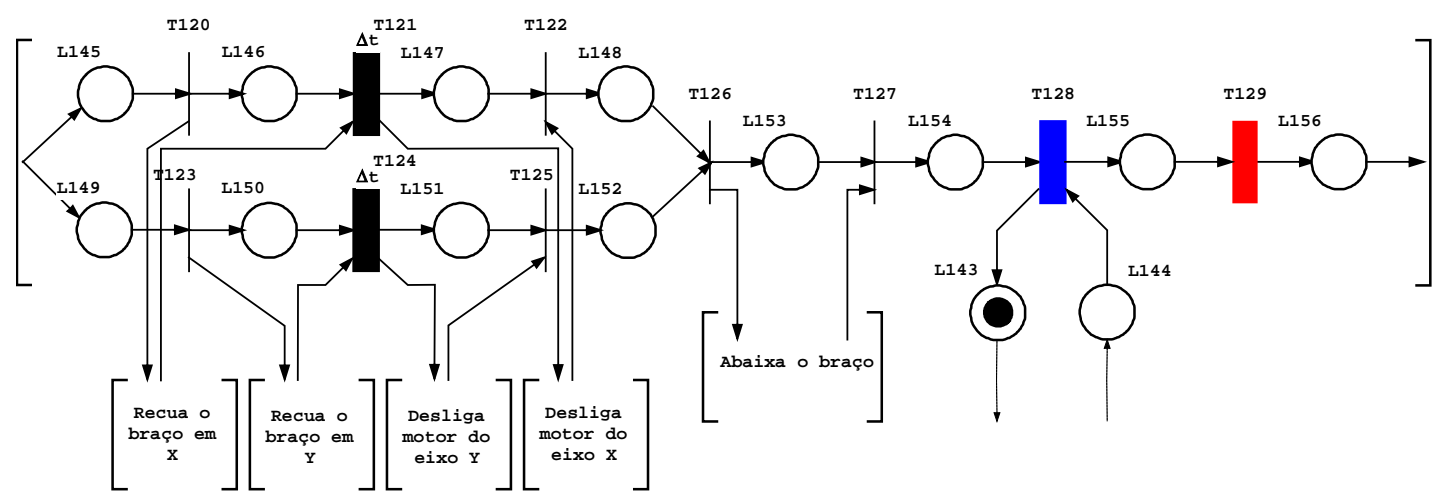

Figura E.20 - Modelo em RdP lugar-transição da atividade [Monta a tampa] do [Controle da estação de montagem].

Tabela E.14 - Descrição dos elementos do modelo em RdP da atividade [Monta a tampa].

\begin{tabular}{|l|l|}
\hline Lugar & Descrição \\
\hline L145 & Representa o comando para recuar o braço do robô no eixo X \\
\hline L146 & Braço do robô recuando em X \\
\hline L147 & Desligando acionamento do braço no eixo X \\
\hline L148 & Acionamento do braço no eixo X desligado \\
\hline L149 & Representa o comando para recuar o braço do robô no eixo Y \\
\hline L150 & Braço do robô recuando em Y \\
\hline L151 & Desligando acionamento do braço no eixo Y \\
\hline L152 & Acionamento do braço no eixo Y desligado \\
\hline L153 & Representa o comando para que o robô abaixe o braço \\
\hline L154 & Representa a detecção de que o robô se encontra com o braço abaixado \\
\hline L155 & A garra está sendo girada no sentido horário \\
\hline L156 & A garra está totalmente girada no sentido horário \\
\hline Transição & Descrição \\
\hline T120 & Representa o início da operação “recua braço do robô no eixo X” \\
\hline T121 & $\begin{array}{l}\text { Representa o tempo necessário para que o braço do robô se desloque no eixo X até a } \\
\text { posição desejada }\end{array}$ \\
\hline T122 & Representa o fim da operação de deslocamento do braço do robô em X \\
\hline T123 & Representa o início da operação “recua braço do robô no eixo Y” \\
\hline T124 & $\begin{array}{l}\text { Representa o tempo necessário para que o braço do robô se desloque no eixo Y até a } \\
\text { posição desejada }\end{array}$ \\
\hline T125 & Representa o fim da operação de deslocamento do braço do robô em Y \\
\hline T126 & Transição que representa o inicío da operação “abaixa o braço” \\
\hline T127 & Transição que representa o fim da operação “abaixa o braço” \\
\hline T128 & Transição requisitante que representa a ordem para girar a garra no sentido horário \\
\hline T129 & completamente girada no sentido horário \\
\hline
\end{tabular}


A Figura E.21 apresenta o modelo em RdP da atividade [Sobe cilindro montado] do [Controle da estação de montagem] (Figura E.4) e a Tabela E.15 contém a descrição dos seus elementos.

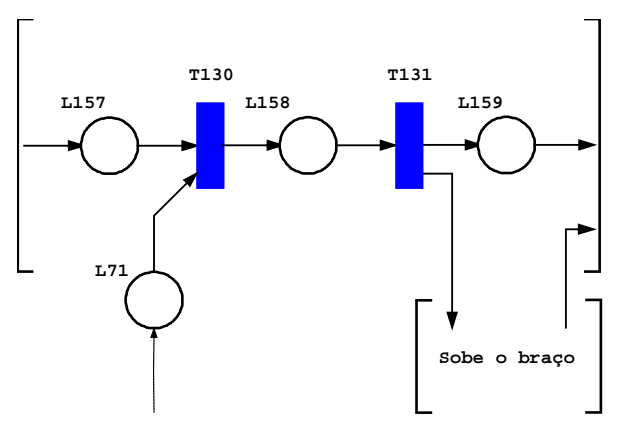

Figura E.21 - Modelo em RdP lugar-transição da atividade [Sobe cilindro montado] do [Controle da estação de montagem].

Tabela E.15 - Descrição dos elementos do modelo em RdP da atividade [Sobe cilindro montado].

\begin{tabular}{|l|l|}
\hline Lugar & Descrição \\
\hline L157 & Cilindro base montado \\
\hline L158 & Cilindro base solto na bancada de montagem \\
\hline L159 & Representa o comando para que o robô suba o braço \\
\hline Transição & Descrição \\
\hline T130 & $\begin{array}{l}\text { Transição que representa o desligamento da válvula que prende o cilindro base na bancada } \\
\text { de montagem }\end{array}$ \\
\hline T131 & $\begin{array}{l}\text { Transição que representa o início da operação “sobe o braço” bem como um artifício para } \\
\text { sinalizar à planta que o cilindro base foi retirado da posição de montagem já que a planta } \\
\text { não possui sensores para isso }\end{array}$ \\
\hline
\end{tabular}

A Figura E.22 apresenta o modelo em RdP da atividade [Põe cilindro montado no palete] do [Controle da estação de montagem] (Figura E.4) e a Tabela E.16 contém a descrição dos seus elementos.

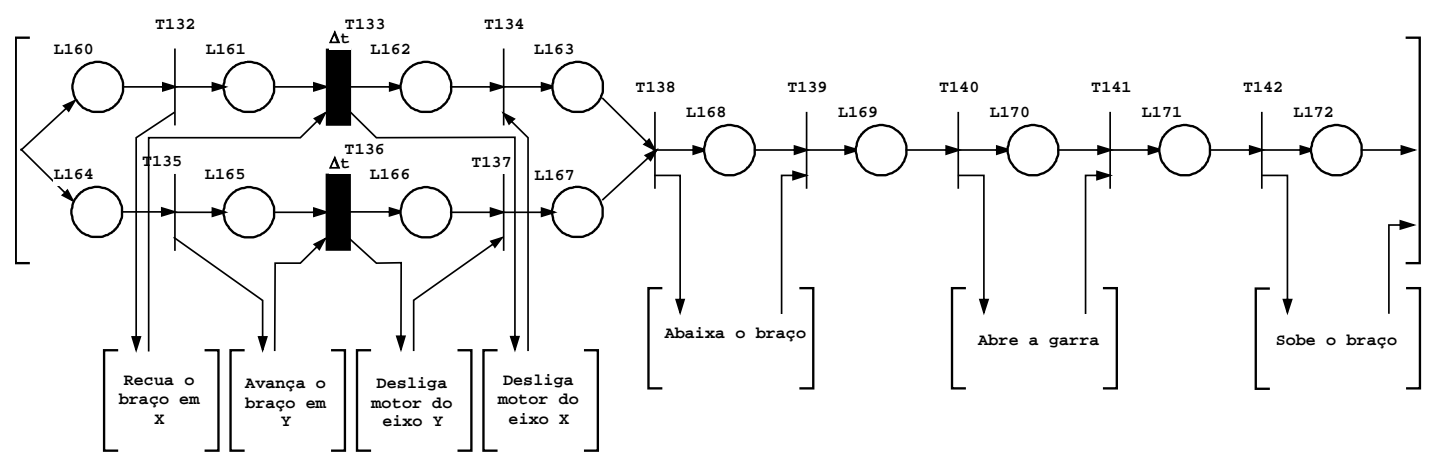

Figura E.22 - Modelo em RdP lugar-transição da atividade [Põe cilindro montado no palete] do [Controle da estação de montagem]. 
Tabela E.16 - Descrição dos elementos do modelo em RdP da atividade [Põe cilindro montado no palete].

\begin{tabular}{|c|c|}
\hline Lugar & Descrição \\
\hline L160 & Representa o comando para recuar o braço do robô no eixo X \\
\hline L161 & Braço do robô recuando em $\mathrm{X}$ \\
\hline L162 & Desligando acionamento do braço no eixo X \\
\hline L163 & Acionamento do braço no eixo X desligado \\
\hline L164 & Representa o comando para avançar o braço do robô no eixo Y \\
\hline L165 & Braço do robô avançando em Y \\
\hline L166 & Desligando acionamento do braço no eixo Y \\
\hline L167 & Acionamento do braço no eixo Y desligado \\
\hline L168 & Representa o comando para que o robô abaixe o braço \\
\hline L169 & Representa a detecção de que o robô se encontra com o braço abaixado \\
\hline L170 & Representa o comando para que o robô abra a garra \\
\hline L171 & Representa a detecção de que o robô se encontra com a garra aberta \\
\hline L172 & Representa o comando para que o robô suba o braço \\
\hline Transição & Descrição \\
\hline T132 & Representa o início da operação “recua braço do robô no eixo X” \\
\hline T133 & $\begin{array}{l}\text { Representa o tempo necessário para que o braço do robô se desloque no eixo X até a } \\
\text { posição desejada }\end{array}$ \\
\hline T134 & Representa o fim da operação de deslocamento do braço do robô em X \\
\hline T135 & Representa o início da operação “avança braço do robô no eixo Y” \\
\hline T136 & $\begin{array}{l}\text { Representa o tempo necessário para que o braço do robô se desloque no eixo Y até a } \\
\text { posição desejada }\end{array}$ \\
\hline T137 & Representa o fim da operação de deslocamento do braço do robô em Y \\
\hline T138 & Transição que representa o inicío da operação “abaixa o braço” \\
\hline T139 & Transição que representa o fim da operação “abaixa o braço” \\
\hline $\mathrm{T} 140$ & Transição que representa o início da operação “abre a garra” \\
\hline T141 & Transição que representa o fim da operação “abre a garra” \\
\hline T142 & Transição que representa o início da operação “sobe o braço” \\
\hline
\end{tabular}

Na Figura E.23 é apresentado o modelo, em RdP, da atividade [Pega palete] do [Controle da estação de montagem] (Figura E.4) e a descrição de seus elementos é apresentada na Tabela E.17.

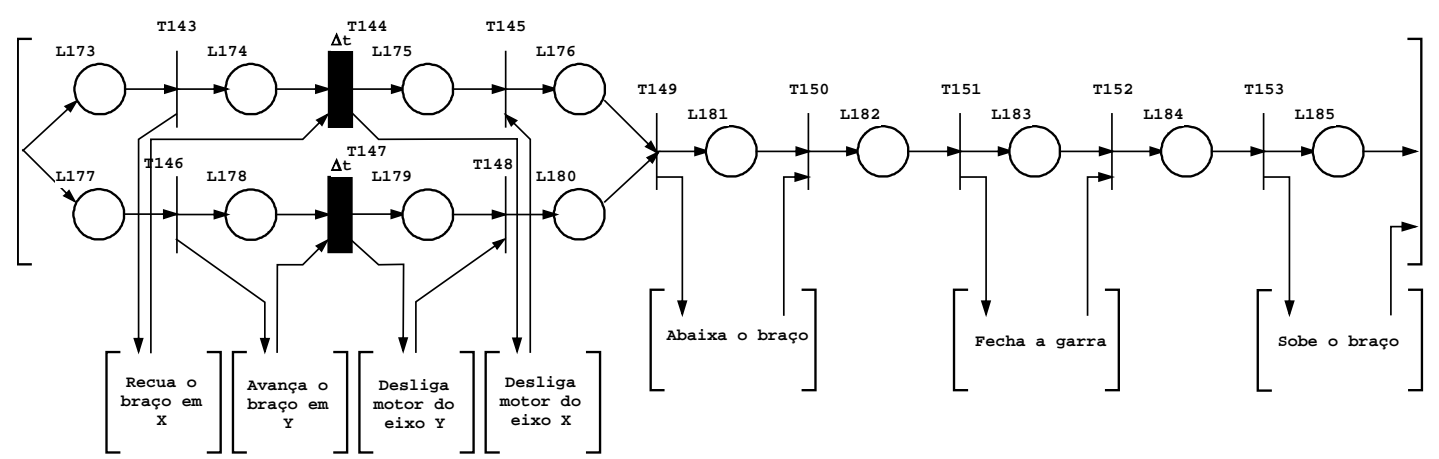

Figura E.23 - Modelo em RdP lugar-transição da atividade [Pega palete] do [Controle da estação de montagem]. 
Tabela E.17 - Descrição dos elementos do modelo em RdP da atividade [Pega palete].

\begin{tabular}{|c|c|}
\hline Lugar & Descrição \\
\hline L173 & Representa o comando para recuar o braço do robô no eixo X \\
\hline L174 & Braço do robô recuando em $\mathrm{X}$ \\
\hline L175 & Desligando acionamento do braço no eixo X \\
\hline L176 & Acionamento do braço no eixo X desligado \\
\hline L177 & Representa o comando para avançar o braço do robô no eixo Y \\
\hline L178 & Braço do robô avançando em Y \\
\hline L179 & Desligando acionamento do braço no eixo Y \\
\hline L180 & Acionamento do braço no eixo Y desligado \\
\hline L181 & Representa o comando para que o robô abaixe o braço \\
\hline L182 & Representa a detecção de que o robô se encontra com o braço abaixado \\
\hline L183 & Representa o comando para que o robô feche a garra \\
\hline L184 & Representa a detecção de que o robô se encontra com a garra fechada \\
\hline L185 & Representa o comando para que o robô suba o braço \\
\hline Transição & Descrição \\
\hline T143 & Representa o início da operação “recua braço do robô no eixo X” \\
\hline T144 & $\begin{array}{l}\text { Representa o tempo necessário para que o braço do robô se desloque no eixo X até a } \\
\text { posição desejada }\end{array}$ \\
\hline T145 & Representa o fim da operação de deslocamento do braço do robô em X \\
\hline T146 & Representa o início da operação “avança braço do robô no eixo Y” \\
\hline T147 & $\begin{array}{l}\text { Representa o tempo necessário para que o braço do robô se desloque no eixo Y até a } \\
\text { posição desejada }\end{array}$ \\
\hline T148 & Representa o fim da operação de deslocamento do braço do robô em Y \\
\hline T149 & Transição que representa o inicío da operação “abaixa o braço” \\
\hline T150 & Transição que representa o fim da operação “abaixa o braço” \\
\hline $\mathrm{T} 151$ & Transição que representa o início da operação “fecha a garra” \\
\hline T152 & Transição que representa o fim da operação “fecha a garra” \\
\hline T153 & Transição que representa o início da operação “sobe o braço” \\
\hline
\end{tabular}

Na Figura E.24 é apresentado o modelo, em RdP, da atividade [Põe palete na estação de transporte] do [Controle da estação de montagem] (Figura E.4) e a descrição de seus elementos é apresentada na Tabela E.18.

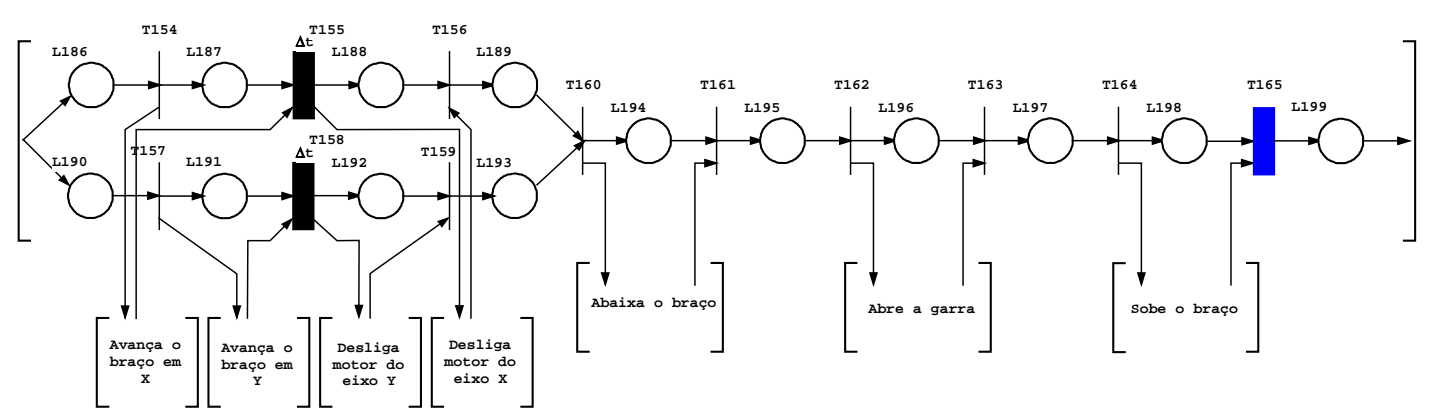

Figura E.24 - Modelo em RdP lugar-transição da atividade [Põe palete na estação de transporte] do [Controle da estação de montagem]. 
Tabela E.18 - Descrição dos elementos do modelo em RdP da atividade [Põe palete na estação de transporte].

\begin{tabular}{|c|c|}
\hline Lugar & Descrição \\
\hline L186 & Representa o comando para avançar o braço do robô no eixo X \\
\hline L187 & Braço do robô avançando em X \\
\hline L188 & Desligando acionamento do braço no eixo X \\
\hline L189 & Acionamento do braço no eixo X desligado \\
\hline L190 & Representa o comando para avançar o braço do robô no eixo Y \\
\hline L191 & Braço do robô avançando em Y \\
\hline L192 & Desligando acionamento do braço no eixo Y \\
\hline L193 & Acionamento do braço no eixo Y desligado \\
\hline L194 & Representa o comando para que o robô abaixe o braço \\
\hline L195 & Representa a detecção de que o robô se encontra com o braço abaixado \\
\hline L196 & Representa o comando para que o robô abra a garra \\
\hline L197 & Representa a detecção de que o robô se encontra com a garra aberta \\
\hline L198 & Representa o comando para que o robô suba o braço \\
\hline L199 & Represnta a liberação do palete \\
\hline Transição & Descrição \\
\hline T154 & Representa o início da operação “avança braço do robô no eixo X” \\
\hline T155 & $\begin{array}{l}\text { Representa o tempo necessário para que o braço do robô se desloque no eixo X até a } \\
\text { posição desejada }\end{array}$ \\
\hline T156 & Representa o fim da operação de deslocamento do braço do robô em X \\
\hline T157 & Representa o início da operação “avança braço do robô no eixo Y” \\
\hline T158 & $\begin{array}{l}\text { Representa o tempo necessário para que o braço do robô se desloque no eixo Y até a } \\
\text { posição desejada }\end{array}$ \\
\hline T159 & Representa o fim da operação de deslocamento do braço do robô em Y \\
\hline $\mathrm{T} 160$ & Transição que representa o inicío da operação “abaixa o braço” \\
\hline $\mathrm{T} 161$ & Transição que representa o fim da operação “abaixa o braço” \\
\hline T162 & Transição que representa o início da operação “abre a garra” \\
\hline T163 & Transição que representa o fim da operação “abre a garra” \\
\hline T164 & Transição que representa o início da operação “sobe o braço” \\
\hline T165 & $\begin{array}{l}\text { Transição requisitante que representa o comando de liberação do palete na estação de } \\
\text { transporte }\end{array}$ \\
\hline
\end{tabular}

Apresenta-se na Figura E.25 o detalhamento das atividades relacionadas ao avanço e recuo do braço do robô, além da operação “desliga motor”, tanto para o eixo X quanto para o eixo Y. Estas três atividades, juntas, caracterizam as operações relacionadas aos movimentos do braço do robô que são realizadas utilizando-se motores de passo.

A Tabela E.19 apresenta o detalhamento de cada elemento da RdP presente nas atividades da Figura E.25 para a movimentação do braço no eixo X e, entre parênteses, para o eixo $Y$. 


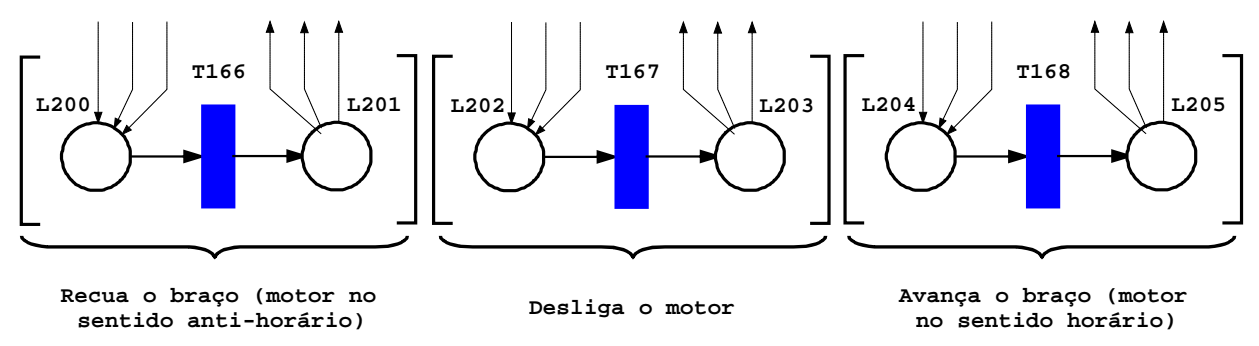

Figura E.25 - Modelo em RdP lugar-transição para as atividades [Avança o braço], [Recua o braço] e [Desliga motor].

Tabela E.19 - Descrição dos elementos do modelo em RdP das atividades [Avança o braço], [Recua o braço] e [Desliga motor].

\begin{tabular}{|l|l|}
\hline Lugar & Descrição \\
\hline L200 (206) & $\begin{array}{l}\text { Existe um comando para ligar o motor que aciona o eixo X (Y) no sentido anti-horário a } \\
\text { fim de recuar o braço }\end{array}$ \\
\hline L201 (207) & Motor acionado no sentido anti-horário \\
\hline L202 (208) & Existe um comando para desligar o motor que aciona o eixo X (Y) \\
\hline L203 (209) & Motor desligado \\
\hline L204 (210) & $\begin{array}{l}\text { Existe um comando para ligar o motor que aciona o eixo X (Y) no sentido horário a fim de } \\
\text { avançar o braço }\end{array}$ \\
\hline L205 (211) & Motor acionado no sentido horário \\
\hline Transição & Descrição \\
\hline T166 (169) & $\begin{array}{l}\text { Transição requisitante que representa o acionamento do motor do eixo X (Y) no sentido anti- } \\
\text { horário }\end{array}$ \\
\hline T167 (170) & Transição requisitante que representa o desligamento do motor do eixo X (Y) \\
\hline T168 (171) & $\begin{array}{l}\text { Transição requisitante que representa o acionamento do motor do eixo X (Y) no sentido } \\
\text { horário }\end{array}$ \\
\hline
\end{tabular}

A Figura E.26 apresenta o modelo em RdP das atividades [Abre a garra] (ou [Desce o braço]) e [Fecha a garra] ([Sobe o braço]). A Tabela E.20 contém a descrição dos elementos das atividades [Abre a garra] e [Fecha a garra] e, entre parênteses, de [Desce o braço] e [Sobe o braço].

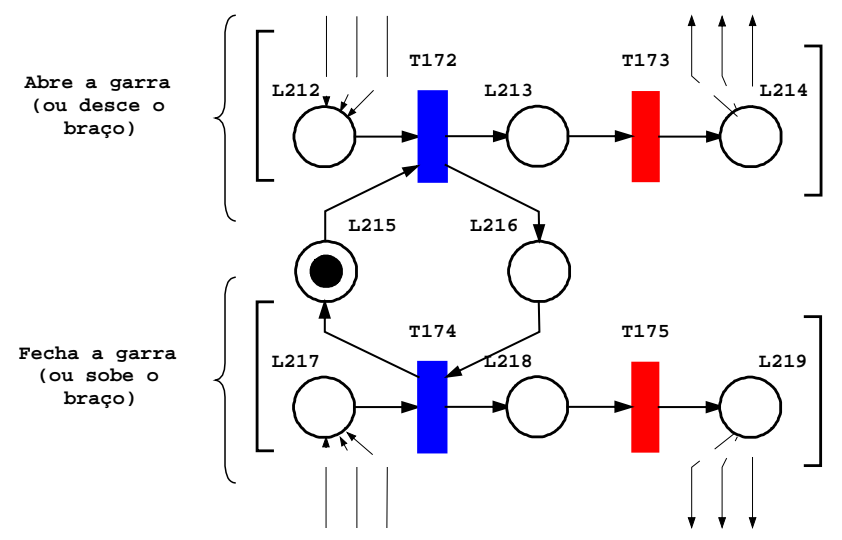

Figura E.26 - Modelo em RdP lugar-transição para as atividades [Abre a garra], [Fecha a garra], [Desce o braço] e [Sobe o braço]. 
Tabela E.20 - Descrição dos elementos do modelo em RdP das atividades [Abre a garra], [Fecha a garra], [Desce o braço] e [Sobe o braço].

\begin{tabular}{|l|l|}
\hline Lugar & Descrição \\
\hline L212 (220) & Comando para abrir garra (descer braço) recebido \\
\hline L213 (221) & Abrindo garra (descendo braço) \\
\hline L214 (222) & Garra aberta (braço embaixo) \\
\hline L215 (223) & Válvula está energizada para distender o atuador que abre a garra (desce o braço) \\
\hline L216 (224) & Válvula está energizada para recolher o atuador que abre a garra (sobe o braço) \\
\hline L217 (225) & Comando para fechar garra (subir braço) recebido \\
\hline L218 (226) & Fechando garra (subindo braço) \\
\hline L219 (227) & Garra fechada (braço no alto) \\
\hline Transição & Descrição \\
\hline T172 (176) & $\begin{array}{l}\text { Transição requisitante que representa a ordem para recolher o atuador que movimenta a garra } \\
\text { (abre) (o braço (desce)) }\end{array}$ \\
\hline T173 (177) & $\begin{array}{l}\text { Transição requisitada que representa a confirmação, através de sensor, que a garra foi aberta } \\
\text { (o braço desceu) }\end{array}$ \\
\hline T174 (178) & $\begin{array}{l}\text { Transição requisitante que representa a ordem para recolher o atuador que movimenta a garra } \\
\text { (fecha) (o braço (sobe)) }\end{array}$ \\
\hline T175 (179) & $\begin{array}{l}\text { Transição requisitada que representa a confirmação, através de sensor, que a garra foi } \\
\text { fechada (o braço subiu) }\end{array}$ \\
\hline
\end{tabular}

\section{iii) Elementos dos atuadores}

Todos os modelos relacionados a este item foram apresentados no capítulo 3 .

Este item foi mantido visando-se manter a relação com o capítulo 3.

\section{iv) Elementos do fluxo físico e sensores}

Outra atividade pertencente a este nível é a [Estação de inspeção] que é apresnetada na Figura E.27. O detalhamento dos elementos da [Estação de inspeção] é apresentado na Tabela E.21.

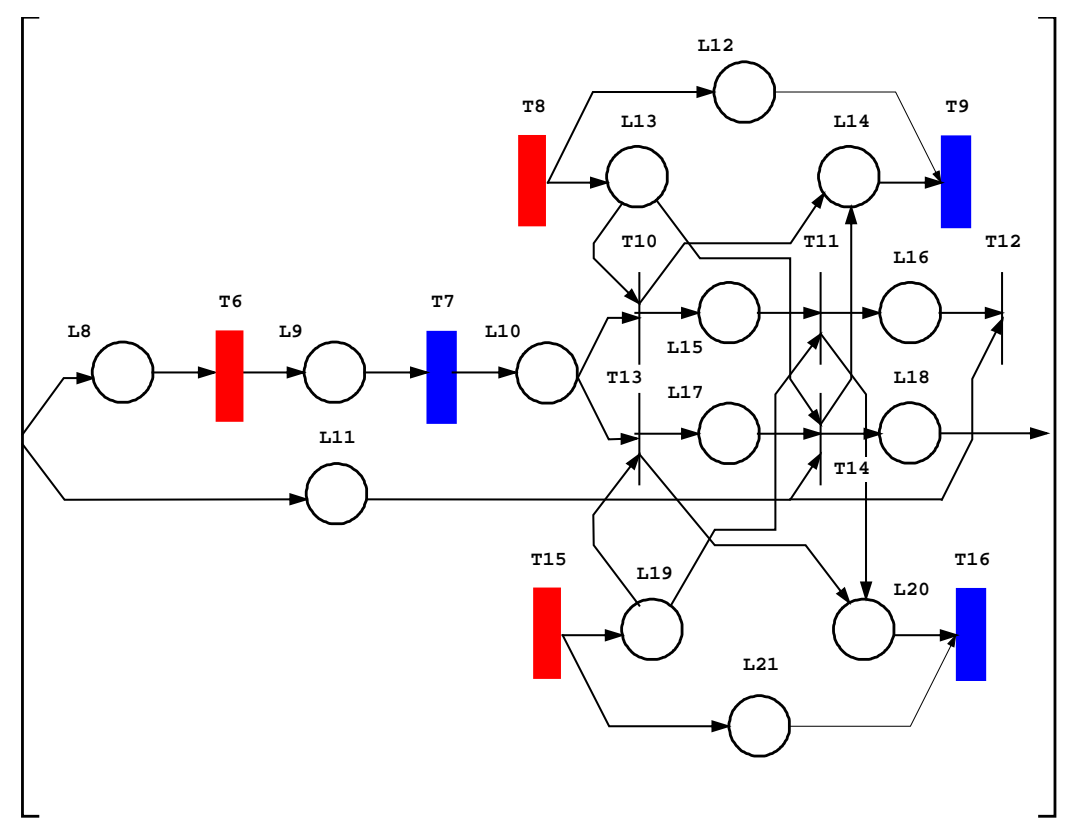

Figura E.27 - Modelo em RdP colorida da atividade [Estação de inspeção]. 
Tabela E.21 - Descrição dos elementos do modelo em RdP da atividade [Estação de inspeção].

\begin{tabular}{|c|c|}
\hline Lugar & Descrição \\
\hline L8 & Representa o cilindro base aguardando a analise dimensional \\
\hline L9 & Representa que o cilindro base acabou de ser medido \\
\hline L10 & $\begin{array}{l}\text { Representa que os sinais quanto às dimensões do cilindro base foram enviadas via sensor ao } \\
\text { controle da estação de inspeção }\end{array}$ \\
\hline L11 & Representa fisicamente o cilindro base na estação de inspeção \\
\hline L12 & Lugar auxiliar \\
\hline L13 & Representa a ação do atuador que faz a plataforma descer \\
\hline L14 & Representa a detecção o sinal do sensor de final de curso indicando que a plataforma desceu \\
\hline L15 & $\begin{array}{l}\text { Representa o cilindro base descendo junto com a plataforma pois este não passou no teste } \\
\text { dimensional }\end{array}$ \\
\hline L16 & Representa o cilindro base sendo descartado \\
\hline L17 & $\begin{array}{l}\text { Representa o cilindro base sendo empurrado (via rampa) para a estação de transporte após } \\
\text { ter sido aprovado no teste dimensional }\end{array}$ \\
\hline L18 & Representa o cilindro base descendo a rampa \\
\hline L19 & Representa a ação do atuador sobre o cilindro base, empurrando-o \\
\hline L20 & Representa a detecção o sinal do sensor de final de curso do atuador \\
\hline L21 & Lugar auxiliar \\
\hline Transição & Descrição \\
\hline T6 & Transição requistada que representa a avaliação dimensional \\
\hline T7 & $\begin{array}{l}\text { Transição requisitante que representa o envio das dimensões do cilindro base para o controle } \\
\text { da estação de inspeção }\end{array}$ \\
\hline T8 & Transição requisitada que representa a ação do atuador que desce a plataforma \\
\hline T9 & $\begin{array}{l}\text { Transição requisitante que representa o envio do sinal de fim de curso indicando que a } \\
\text { plataforma desceu }\end{array}$ \\
\hline T10 & $\begin{array}{l}\text { Transição que representa o comando para a plataforma descer pelo fato do cilindro base ter } \\
\text { sido rejeitado }\end{array}$ \\
\hline T11 & Transição que representa o cilindro base sendo empurrado para fora da estação \\
\hline T12 & Transição que representa a saída do cilindro base do sistema \\
\hline T13 & Transição que representa o cilindro base sendo empurrado para a estação de transporte \\
\hline T14 & Transição que representa a saída do cilindro base da estação de inspeção \\
\hline T15 & Transição requisitada que representa a ação do atuador que empurra o cilindro base \\
\hline T16 & $\begin{array}{l}\text { Transição requisitante que representa o envio do sinal de fim de curso indicando que o } \\
\text { atuador foi distendido }\end{array}$ \\
\hline
\end{tabular}

Passando pelas atividades [Estação de alimentação] e [Estação de inspeção], os cilindros base seguem para a [Estação de transporte], que é apresentada na Figura E.28. Pode-se notar que este modelo é dividido em duas partes: (1) uma referente à existência de cilindros base na estação de transporte (L22); e (2) outra relacionada à posição de cada palete na estação (demais elementos da RdP). A Tabela E.22 contém a descrição dos elementos da atividade [Estação de transporte]. 


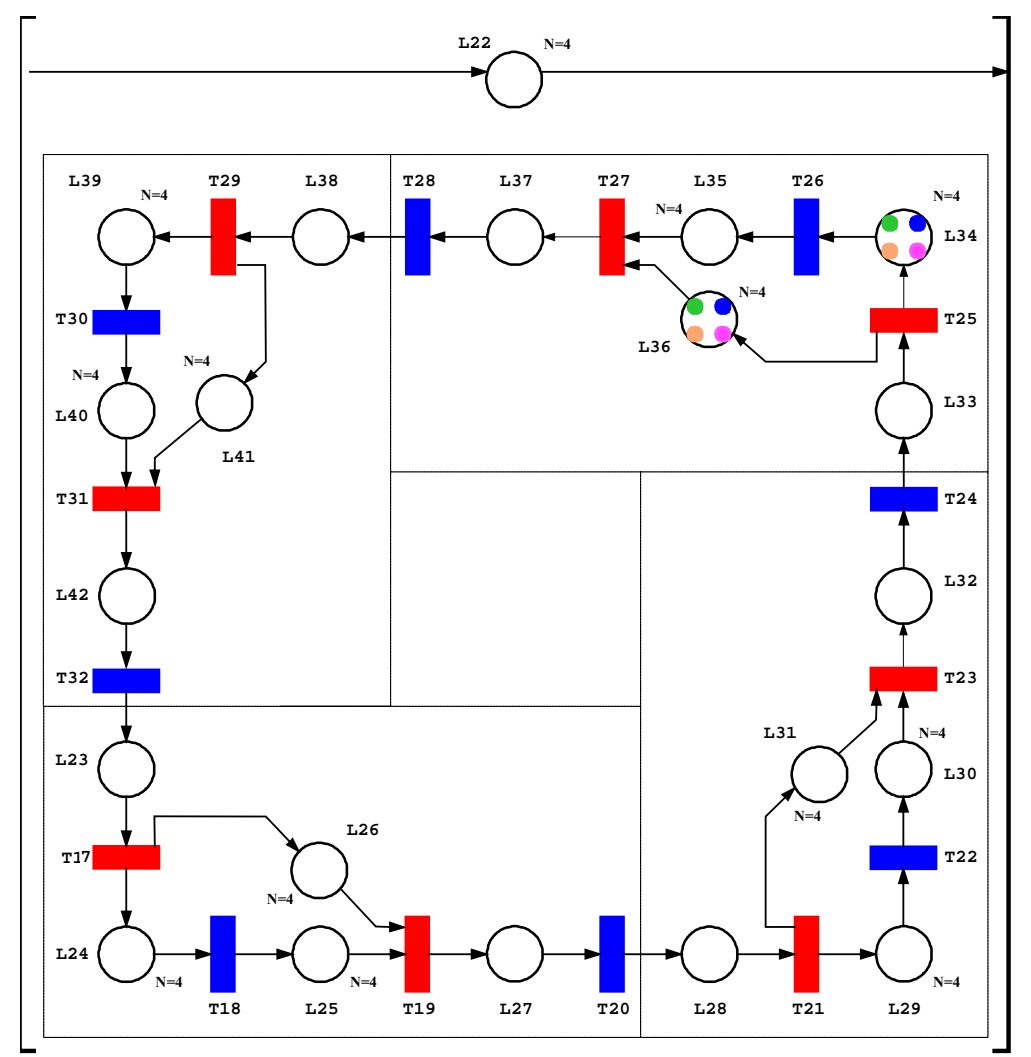

Figura E.28 - Modelo em RdP colorida da atividade [Estação de transporte].

Tabela E.22 - Descrição dos elementos do modelo em RdP da [Estação de transporte].

\begin{tabular}{|l|l|}
\hline Lugar & Descrição \\
\hline L22 & Presença de cilindros base e/ou cilindros montados na estação de transporte \\
\hline L23 & Patete na parada junto à estação de inspeção \\
\hline L24 & Palete entrando na esteira entre as estaços de inspeção e montagem \\
\hline L25 & Lugar auxiliar \\
\hline L26 & Palete na esteira entre as paradas da estação de inspeção e de montagem \\
\hline L27 & Palete entrando na parada junto à estação de montagem \\
\hline L28 & Patete na parada junto à estação de montagem \\
\hline L29 & $\begin{array}{l}\text { Palete entrando na esteira entre as estações de montagem e a destinada à futuras expansões } \\
\text { da célula de manufatura }\end{array}$ \\
\hline L30 & Lugar auxiliar \\
\hline L31 & $\begin{array}{l}\text { Palete na esteira entre as paradas da estação de montagem e outra destinada à futuras } \\
\text { expansões da célula de manufatura }\end{array}$ \\
\hline L32 & Palete entrando na parada destinada à futuras expansão da célula de manufatura \\
\hline L33 & Patete está em uma parada reservada à futuras expansões da célula de manufatura \\
\hline L34 & $\begin{array}{l}\text { Palete entrando na esteira entre as estações destinadas à futuras expansões da célula de } \\
\text { manufatura }\end{array}$ \\
\hline L35 & Lugar auxiliar \\
\hline L36 & Palete na esteira entre as paradas destinadas à futuras expansões da célula de manufatura \\
\hline L37 & Palete entrando na parada destinada à futuras expansões da célula de manufatura \\
\hline L38 & Patete está em uma parada reservada à futuras expansões da célula de manufatura \\
\hline L39 & $\begin{array}{l}\text { Palete entrando na esteira entre a estação destinada à futuras expansões da célula de } \\
\text { manufatura e a estação de inspeção }\end{array}$ \\
\hline L40 & Lugar auxiliar \\
\hline L41 & $\begin{array}{l}\text { Palete na esteira entre a parada destina à futuras expansões da célula de manufatura e a da } \\
\text { estação de inspeção } \\
\text { Palete entrando na parada junto à estação de inspeção }\end{array}$ \\
\hline L42 &
\end{tabular}


Tabela E.22 - Descrição dos elementos do modelo em RdP da [Estação de transporte] (continuação).

\begin{tabular}{|l|l|}
\hline Transição & Descrição \\
\hline T17 & Transição requisitada que representa o atuador sendo recolhido para que o palete passe \\
\hline T18 & $\begin{array}{l}\text { Transição requisitante que representa o sensor informando ao controle a posição e a } \\
\text { identificação do palete que passa por ele }\end{array}$ \\
\hline T19 & Transição requisitada que representa o atuador sendo recolhido para que o palete passe \\
\hline T20 & $\begin{array}{l}\text { Transição requisitante que representa o sensor informando ao controle a posição e a } \\
\text { identificação do palete que passa por ele }\end{array}$ \\
\hline T21 & Transição requisitada que representa o atuador sendo recolhido para que o palete passe \\
\hline T22 & $\begin{array}{l}\text { Transição requisitante que representa o sensor informando ao controle a posição e a } \\
\text { identificação do palete que passa por ele }\end{array}$ \\
\hline T23 & Transição requisitada que representa o atuador sendo recolhido para que o palete passe \\
\hline T24 & $\begin{array}{l}\text { Transição requisitante que representa o sensor informando ao controle a posição e a } \\
\text { identificação do palete que passa por ele }\end{array}$ \\
\hline T25 & Transição requisitada que representa o atuador sendo recolhido para que o palete passe \\
\hline T26 & $\begin{array}{l}\text { Transição requisitante que representa o sensor informando ao controle a posição e a } \\
\text { identificação do palete que passa por ele }\end{array}$ \\
\hline T27 & Transição requisitada que representa o atuador sendo recolhido para que o palete passe \\
\hline T28 & $\begin{array}{l}\text { Transição requisitante que representa o sensor informando ao controle a posição e a } \\
\text { identificação do palete que passa por ele }\end{array}$ \\
\hline T29 & Transição requisitada que representa o atuador sendo recolhido para que o palete passe \\
\hline T30 & $\begin{array}{l}\text { Transição requisitante que representa o sensor informando ao controle a posição e a } \\
\text { identificação do palete que passa por ele }\end{array}$ \\
\hline T31 & $\begin{array}{l}\text { Transição requisitada que representa o atuador sendo recolhido para que o palete passe } \\
\text { identificação do palete que passa por ele }\end{array}$ \\
\hline T32 & \begin{tabular}{l} 
Transica requisitante que representa o sensor informando ao controle a posição e a \\
\hline
\end{tabular} \\
\hline
\end{tabular}

A última atividade relacionada ao fluxo de materiais e sensores refere-se à [Estação de montagem], que é apresentada na Figura E.29. Nesta estação, são acrescidos molas, pinos e tampas aos cilindros base, montando o produto final que em seguida retorna para a estação de transporte. O detalhamento dos elementos que compõem esta estação é apresentado na Tabela E.23. 


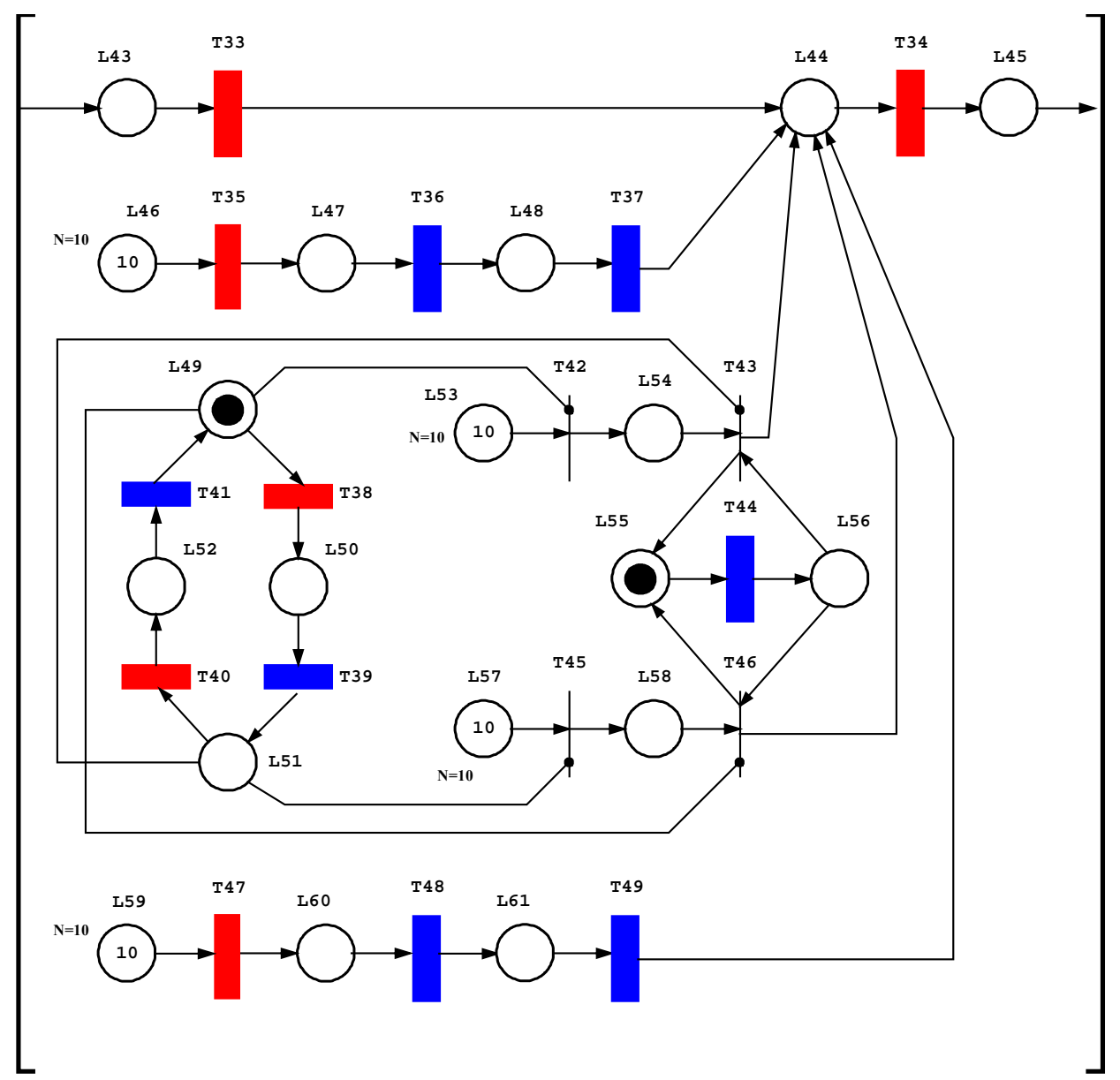

Figura E.29 - Modelo em RdP colorida da atividade [Estação de montagem].

Tabela E.23 - Descrição dos elementos do modelo em RdP da [Estação de montagem].

\begin{tabular}{|l|l|}
\hline Lugar & Descrição \\
\hline L43 & Cilindro base sendo transportado para o dispositivo de retenção \\
\hline L44 & Cilindro base no dispositivo de retenção e recebendo demais partes a serem montadas \\
\hline L45 & Cilindro montado sendo transportado para a estação de transporte \\
\hline L46 & Buffer de molas contendo inicialmente 10 molas \\
\hline L48 & Mola sendo retirada do buffer e disponibilizada para o robô \\
\hline L49 & Coletor de pinos pretos sob o buffer de pinos pretos \\
\hline L50 & $\begin{array}{l}\text { Coletor de pinos prata sendo posicionado sob o buffer de pinos prata e o coletor de pinos } \\
\text { pretos disponibilizando pino preto para o robô }\end{array}$ \\
\hline L51 & Coletor de pinos prata sob o buffer de pinos prata \\
\hline L52 & $\begin{array}{l}\text { Coletor de pinos pretos sendo posicionado sob o buffer de pinos pretos e o coletor de pinos } \\
\text { prata disponibilizando pino prata para o robô }\end{array}$ \\
\hline L53 & Buffer de pinos pretos contendo inicialmente 10 pinos \\
\hline L54 & Coletor de pinos pretos com um pino alojado \\
\hline L55 & Pino (preto ou prata) pronto para ser montada \\
\hline L56 & Pino pego pelo robô e coletor livre \\
\hline L57 & Buffer de pinos prata contendo inicialmente 10 pinos \\
\hline L58 & Coletor de pinos prata com um pino alojado \\
\hline L59 & Buffer de tampas contendo inicialmente 10 tampas \\
\hline L60 & Tampa sendo retirada do buffer e disponibilizada para o robô \\
\hline L61 & Tampa pronta para ser montada \\
\hline
\end{tabular}


Tabela E.23 - Descrição dos elementos do modelo em RdP da [Estação de montagem] (continuação)

\begin{tabular}{|c|c|}
\hline Transição & Descrição \\
\hline T33 & $\begin{array}{l}\text { Transição requisitada que representa o posicionamento, pelo robô, do cilindro base no } \\
\text { dispositivo de retenção }\end{array}$ \\
\hline T34 & $\begin{array}{l}\text { Transição requisitada que representa o cilindro base sendo retirado do dispositivo de } \\
\text { retenção pelo robô }\end{array}$ \\
\hline T35 & $\begin{array}{l}\text { Transição requisitada que representa a ação do atuador sobre o buffer de molas, } \\
\text { disponibilizando-as para o robô }\end{array}$ \\
\hline T36 & $\begin{array}{l}\text { Transição requisitante que representa o sensor de fim de curso do atuador que retira molas do } \\
\text { buffer }\end{array}$ \\
\hline T37 & $\begin{array}{l}\text { Transição requisitante que representa o sensor óptico informando o controle da estação que a } \\
\text { mola foi retirada pelo robô }\end{array}$ \\
\hline T38 & $\begin{array}{l}\text { Transição requisitada que representa a ação do atuador sobre os buffers de pinos, } \\
\text { disponibilizando um pino preto para o robô }\end{array}$ \\
\hline T39 & $\begin{array}{l}\text { Transição requisitante que representa o sensor de fim de curso do atuador que posiciona um } \\
\text { pino preto para o robô }\end{array}$ \\
\hline $\mathrm{T} 40$ & $\begin{array}{l}\text { Transição requisitada que representa a ação do atuador sobre os buffers de pinos, } \\
\text { disponibilizando um pino prata para o robô }\end{array}$ \\
\hline T41 & $\begin{array}{l}\text { Transição requisitante que representa o sensor de fim de curso do atuador que posiciona um } \\
\text { pino prata para o robô }\end{array}$ \\
\hline T42 & Transição que representa a retirada de pino preto do buffer \\
\hline T43 & Transição que representa o robô pegando um pino preto \\
\hline T44 & $\begin{array}{l}\text { Transição requisitante que representa o sensor óptico informando o controle da estação que o } \\
\text { pino foi retirado pelo robô }\end{array}$ \\
\hline T45 & Transição que representa a retirada de pino prata do buffer \\
\hline T46 & Transição que representa o robô pegando um pino prata \\
\hline T47 & $\begin{array}{l}\text { Transição requisitada que representa a ação do atuador sobre o buffer de tampas, } \\
\text { disponibilizando-as para o robô }\end{array}$ \\
\hline T48 & $\begin{array}{l}\text { Transição requisitante que representa o sensor de fim de curso do atuador que retira tampas } \\
\text { do buffer }\end{array}$ \\
\hline T49 & $\begin{array}{l}\text { Transição requisitante que representa o sensor óptico informando o controle da estação que a } \\
\text { tampa foi retirada pelo robô }\end{array}$ \\
\hline
\end{tabular}

\section{Etapa 4 - Criação de objetos}

Nesta etapa as classes definidas na etapa 3 servem de referência para a criação de objetos. A Figura E.30 ilustra o objeto Supervisão_Transporte (baseado na classe [Supervisão do Transporte]). A classe [Motor de passo] (Figura 3.11) serve de base para os objetos Motor_Passo_X e Motor_Passo_Y (Figura E.31).

A classe [Cilindro Pneumático] (Figura 3.8) serve de base para os objetos Atuador_Avaliador_Dimensional, Atuador_Elevador, Atuador_Empurra_Cilindro, Atuador_Bloqueia_Palete (do 1 ao 8), Atuador_Pinos, Atuador_Molas, Atuador_Tampas, Atuador_Braço, Atuador_Garra, Atuador_Retenção e Atuador_Giro_Garra (vide Figura 3.15), enquanto a classe [Eletro-válvula] (Figura 3.9) serve de base para os objetos Válvula_Avaliador_Dimensional, Válvula_Elevador, Válvula_Empurra_Cilindro, Válvula_Bloqueia_Palete (da 1 à 8), Válvula_Pinos, Válvula_Molas, Válvula_Tampas, Válvula_Braço, Válvula_Garra, Válvula_Retenção e Válvula_Giro_Garra (vide Figura 3.16). 


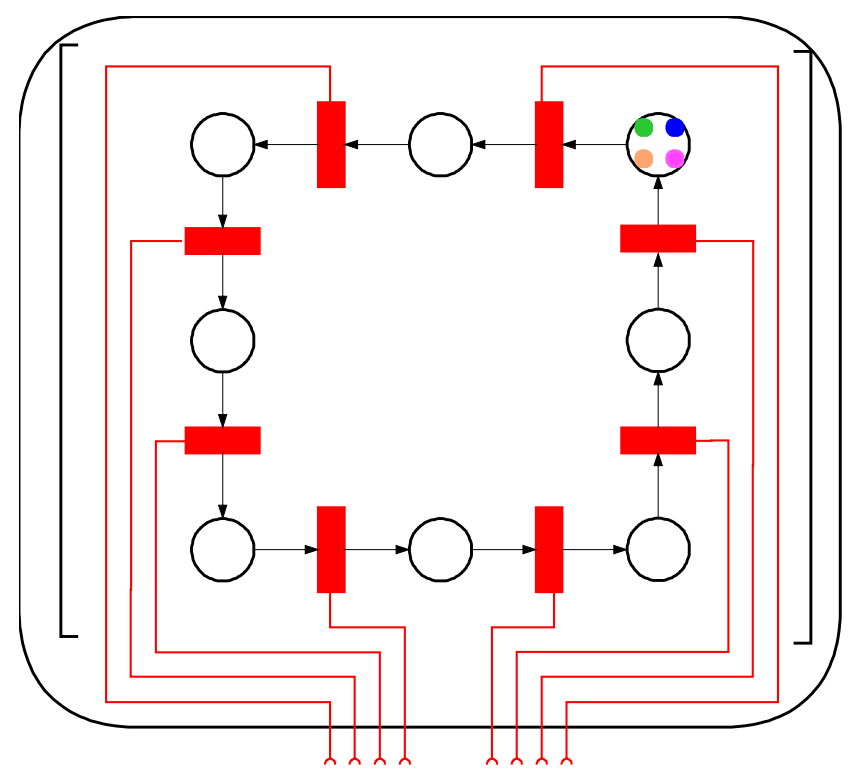

Figura E.30 - Objeto Supervisão_Transporte.

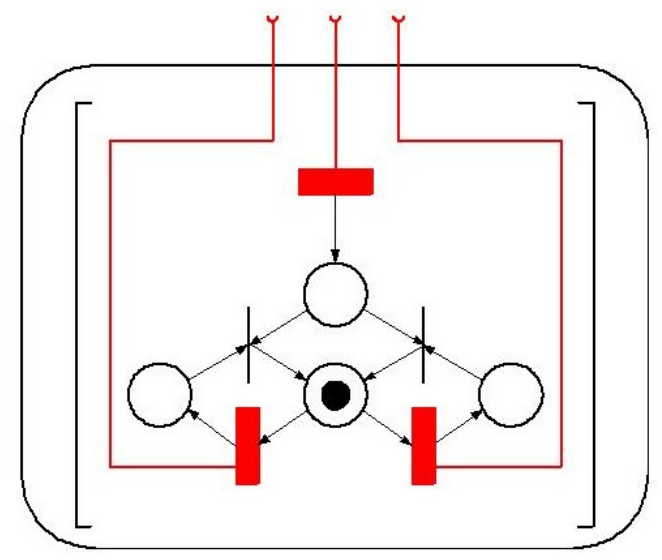

Figura E.31 - Objeto Motor_Passo.

Os objetos Controle_Inspeção (Figura E.32), Controle_Montagem (Figura E.33) e Controle_Transporte (Figura E.34) baseiam-se, respectivamente, nas classes [Controle da estação de inspeção], [Controle da estação de montagem] e [Controle da estação de transporte]. De forma a facilitar a visualização do objeto Controle_Montagem, ao invés de apresentá-lo descrito em RdP, preferiu-se apresentá-lo em PFS, ou seja, em um nível de abstração superior ao de RdP. Os objetos Planta_Inspeção (Figura E.35), Planta_Transporte (Figura E.36) e Planta_Montagem (Figura E.37) baseiam-se, respectivamente, nas classes [Estação de inspeção], [Estação de transporte] e [Estação de montagem]. 


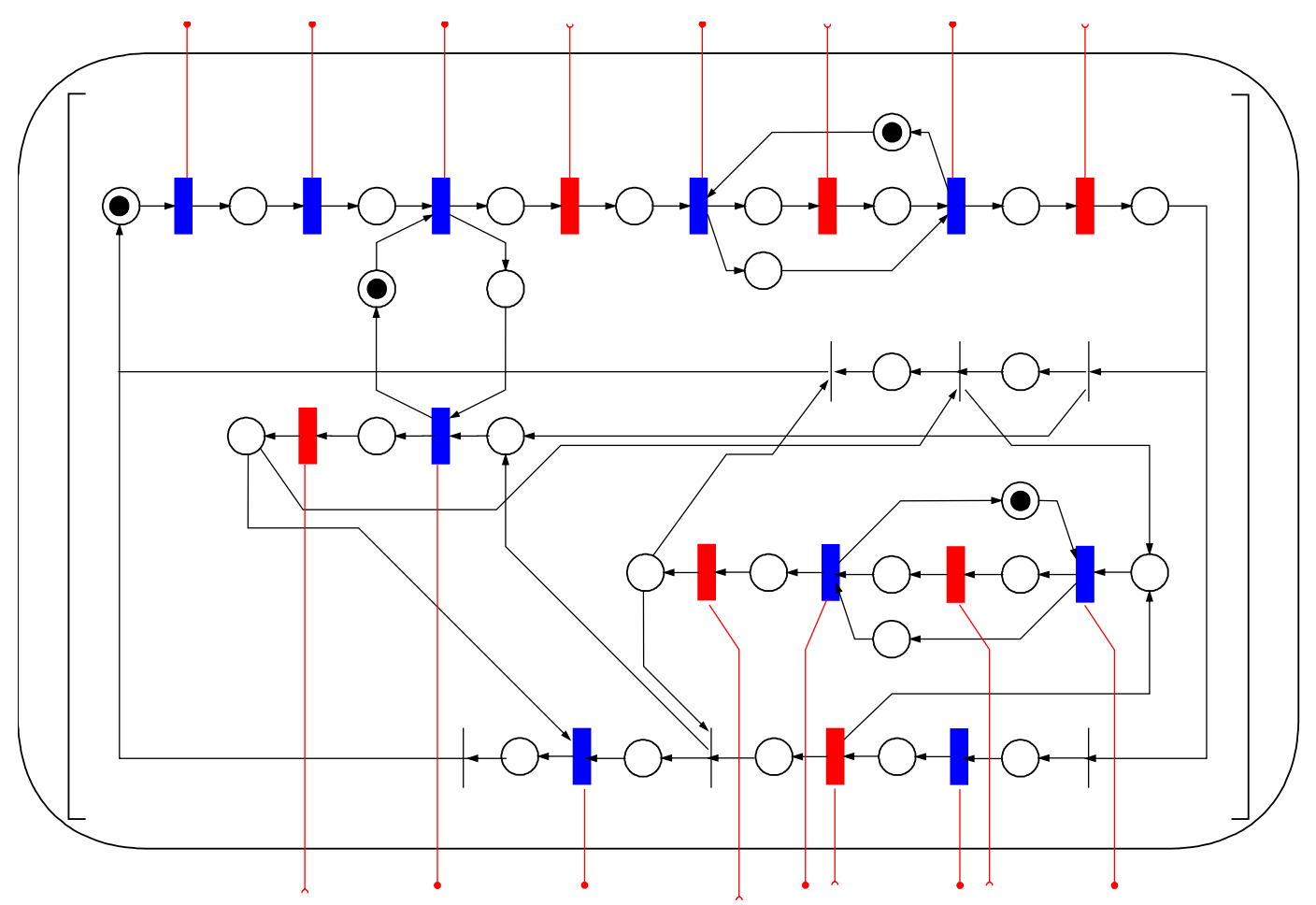

Figura E.32 - Objeto Controle_Inspeção.

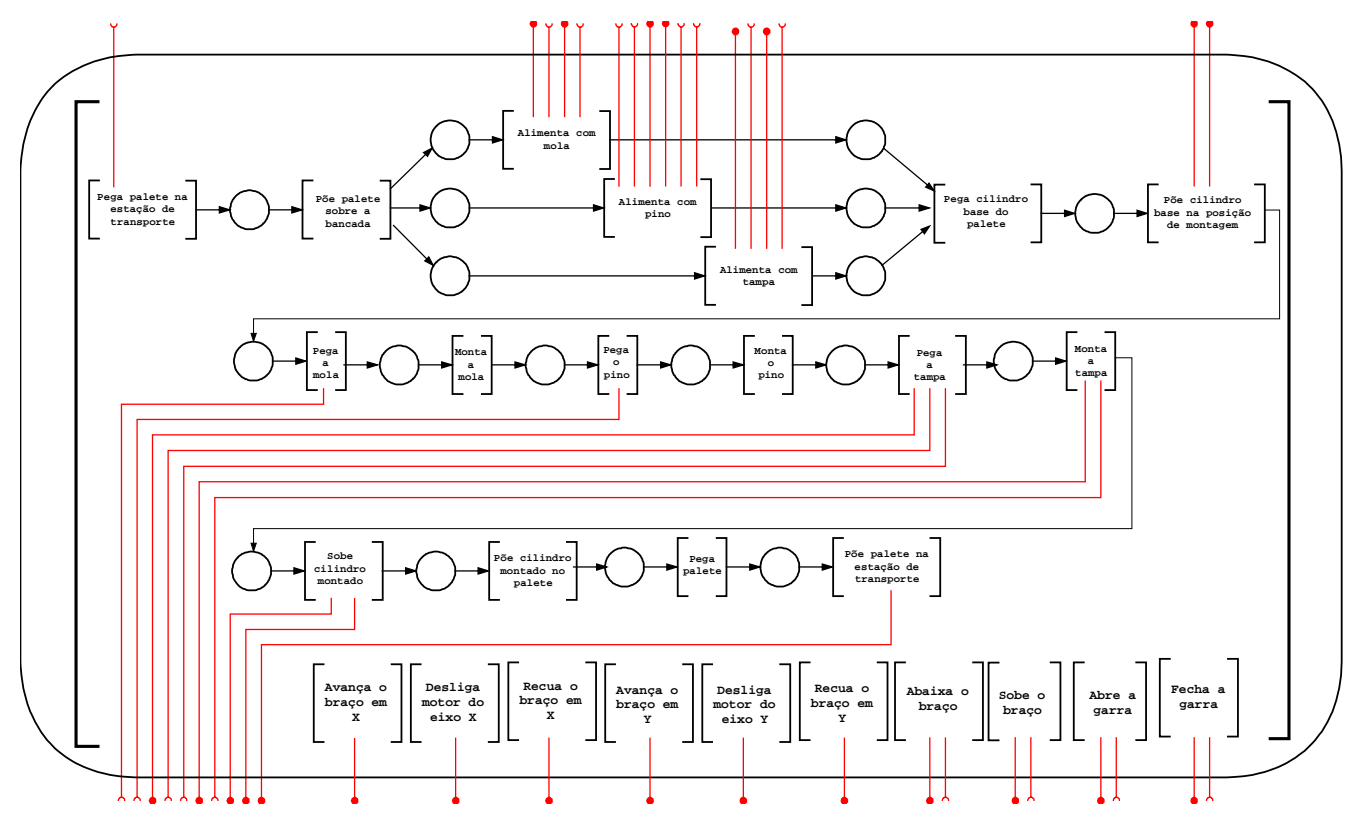

Figura E.33 - Objeto Controle_Montagem. 


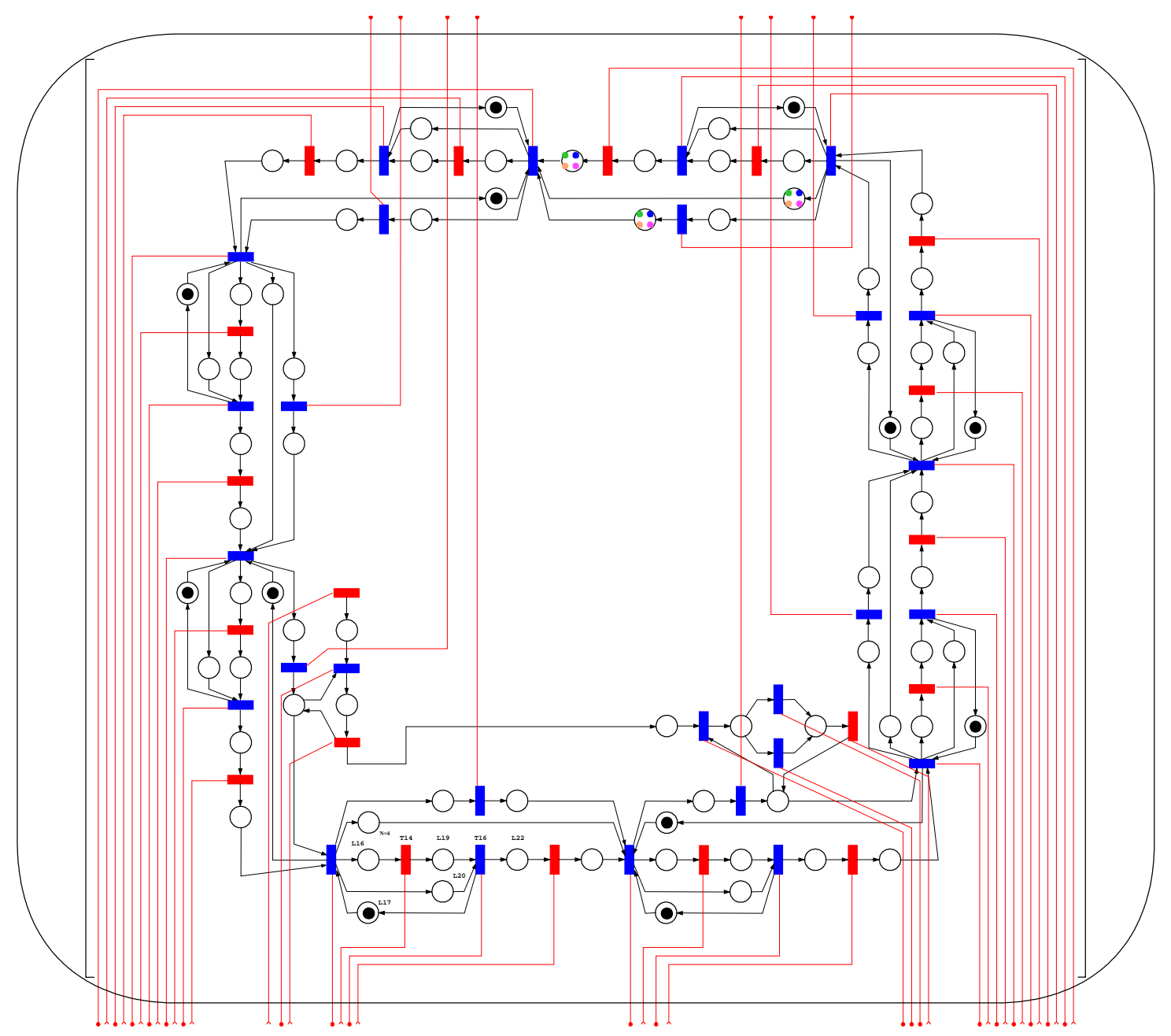

Figura E.34 - Objeto Controle_Transporte.

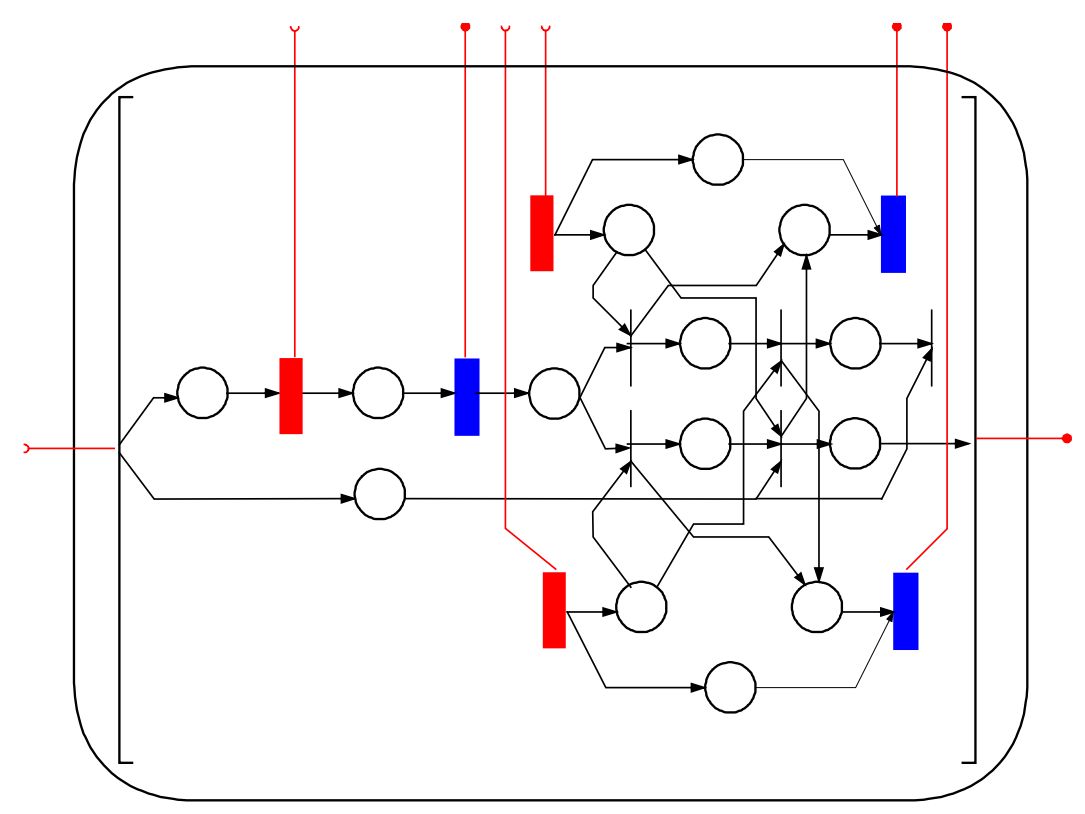

Figura E.35 - Objeto Planta_Inspeção. 


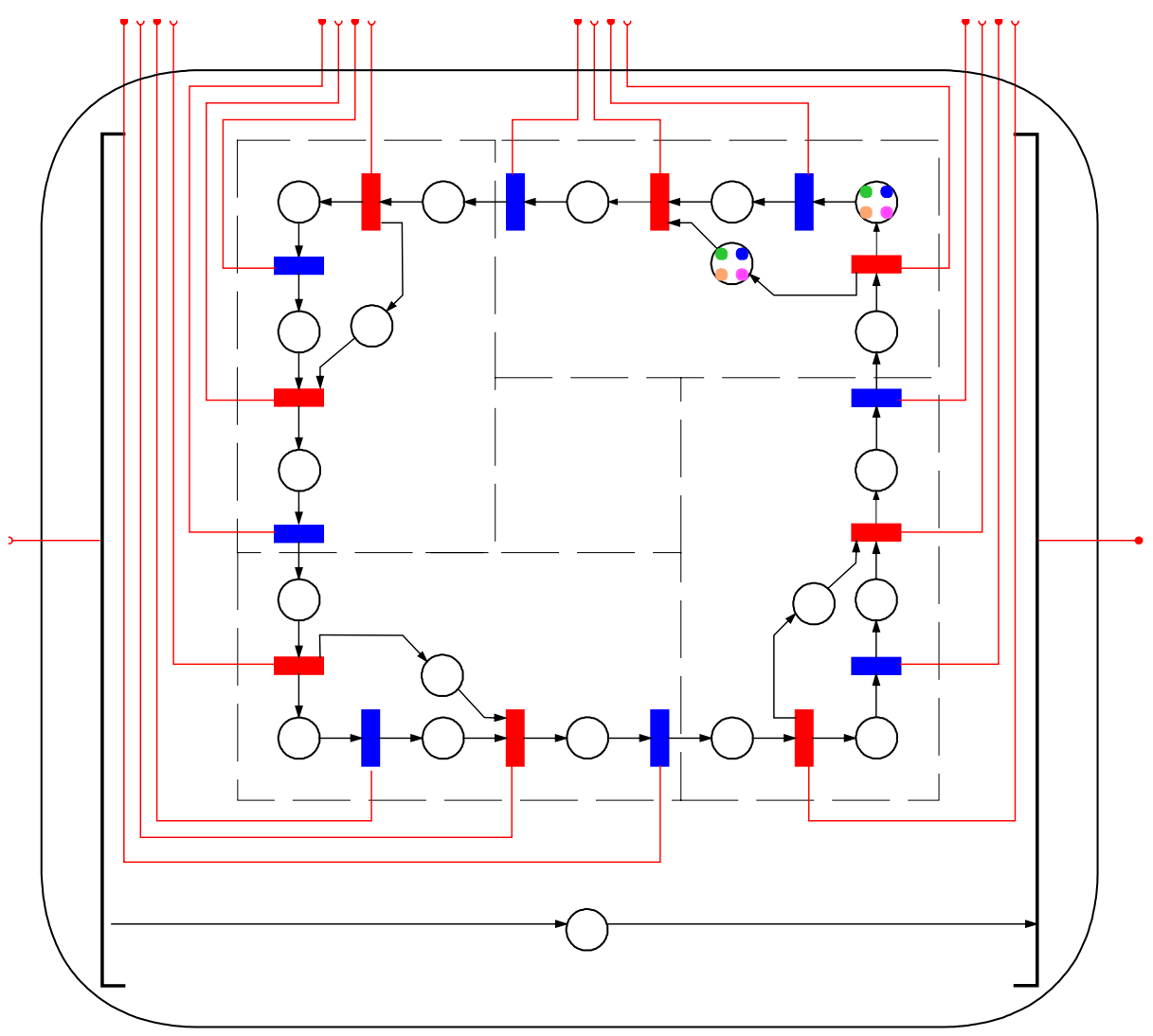

Figura E.36 - Objeto Planta_Transporte.

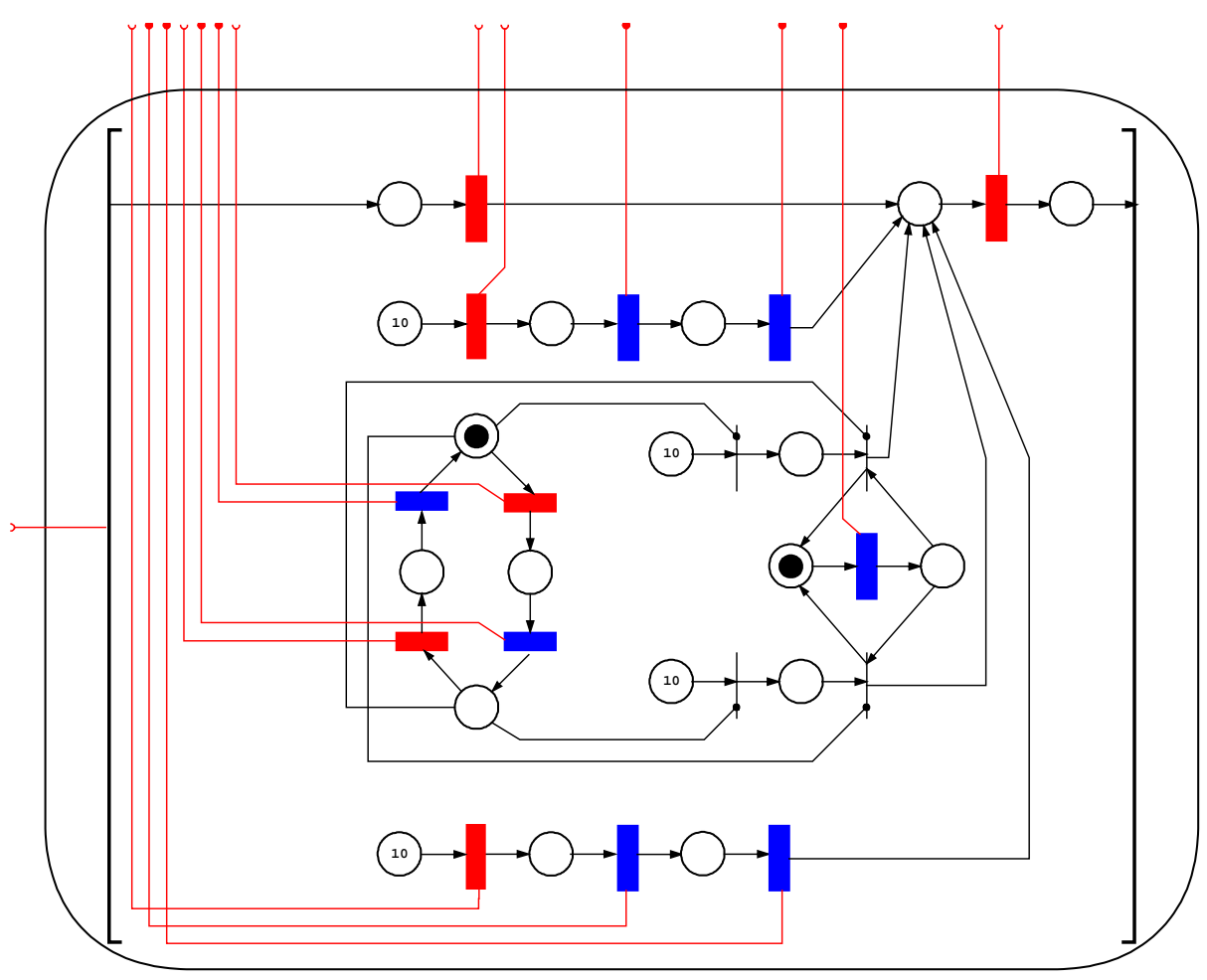

Figura E.37 - Objeto Planta_Montagem. 


\section{Etapa 5 - Geração de componentes}

Os objetos obtidos na etapa 4 são usados para compor os componentes. Neste estudo de caso, como parte dos modelos estão no capítulo 3, serão considerados apenas os modelos deste anexo para a composição dos componentes e do aplicativo. Assim, sendo, a Figura E.38 apresenta o componente "Sistema Supervisório Transporte", composto pelo objeto Supervisão_Transporte. Por se tratar de um software de acompanhamento das operações da Célula de Manufatura, constituindo-se numa interface entre esta e o usuário, este foi componentizado isoladamente. Ainda, devido à evolução dos protocolos de comunicação, o “Sistema Supervisório Transporte” pode ser localmente ou remotamente conectado à Célula de Manufatura, corroborando a componentização adotada.

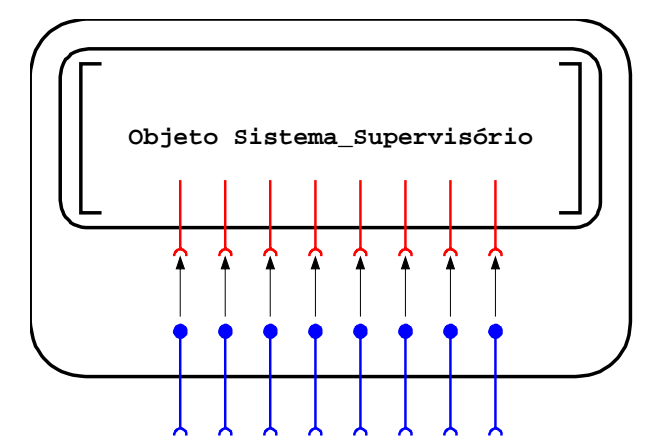

Figura E.38 - Componente Sistema Supervisório Transporte.

Nas Figuras E.39, E.40 e E.41 são apresentados, respectivamente, os componentes: “Inspeção”, composto pelo objeto Controle_Inpeção; “Transporte”, composto pelo objeto Controle_Transporte; e "Montagem" composto pelo objeto Controle_Montagem. Como critério de componentização, levou-se em consideração que estes modelos dêem origem a programas em linguagem de CLP (Controlador Lógico Programável), a ser alocado ao CLP que controla cada uma das respectivas estações. Assim, com a modelagem do aplicativo, será possível evidenciar o fluxo de sinais entre a planta e cada CLP, bem como entre os CLPs. 


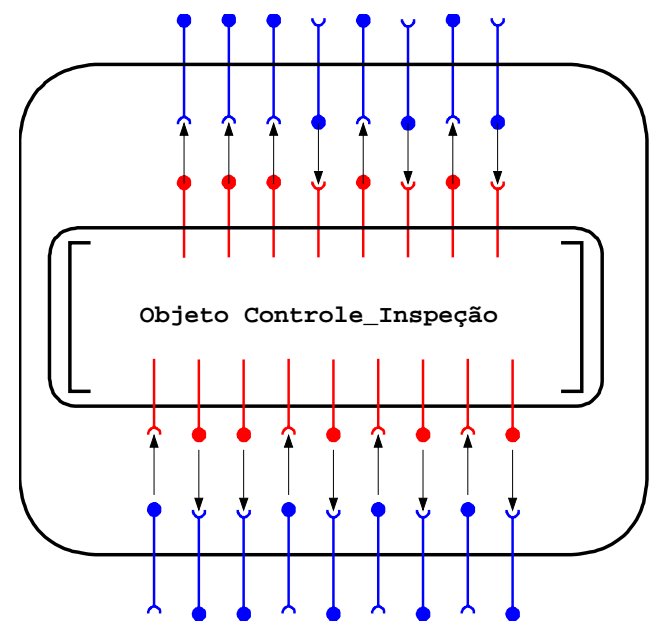

Figura E.39 - Componente Inspeção.

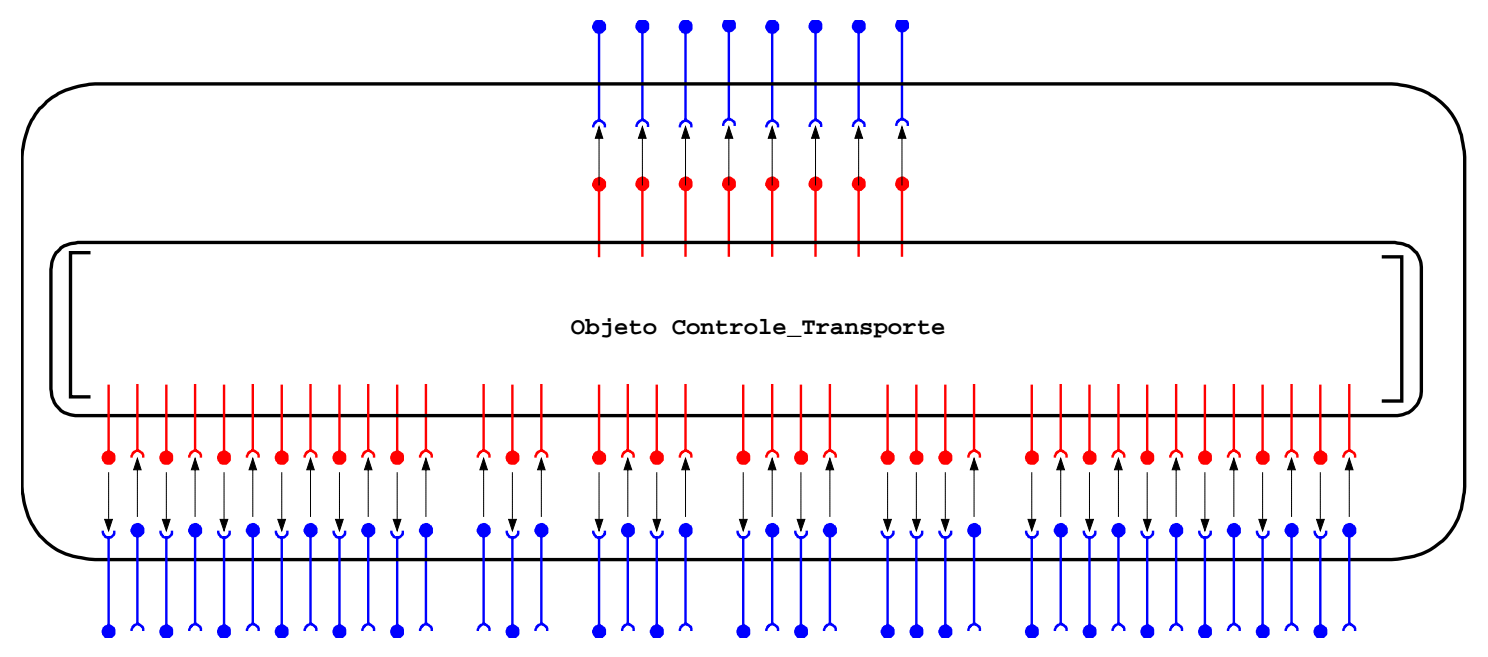

Figura E.40 - Componente Transporte.

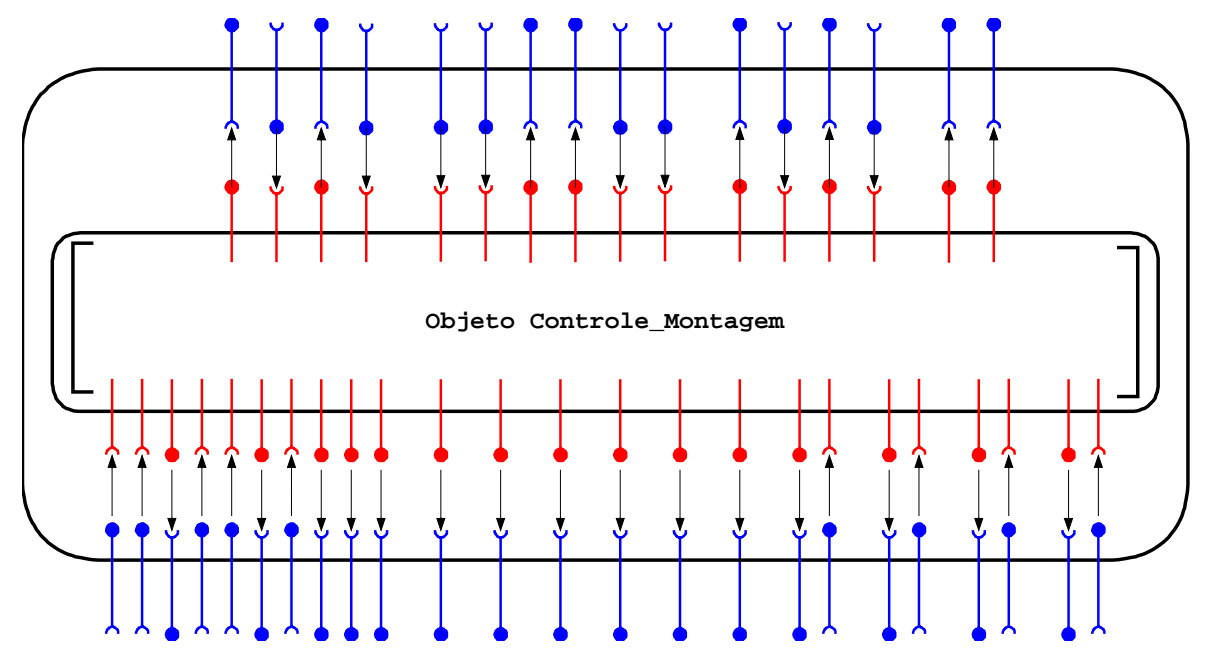

Figura E.41 - Componente da Montagem. 
Assim como na Figura 3.22 onde procurou-se modelar o objeto de controle, ou seja, a planta, apenas do ponto de vista da estação de alimentação, neste anexo as demais partes que compõem a planta serão modeladas como base na estação a que se referem, facilitando, assim, a apresentação e compreensão dos modelos. Desta forma, foram gerados três componentes referentes à "Planta”: "Planta Inspeção” (Figura E.42), “Planta Transporte” (Figura E.43) e “Planta Montagem” (Figura E.44).

O componente "Planta Inspeção" é composto pelos objetos Atuador_Avaliador_Dimensional, Atuador_Elevador, Atuador_Empurra_Cilindro, Válvula_Avaliador_Dimensional, Válvula_Elevador, Válvula_Empurra_Cilindro e Planta_Inspeção.

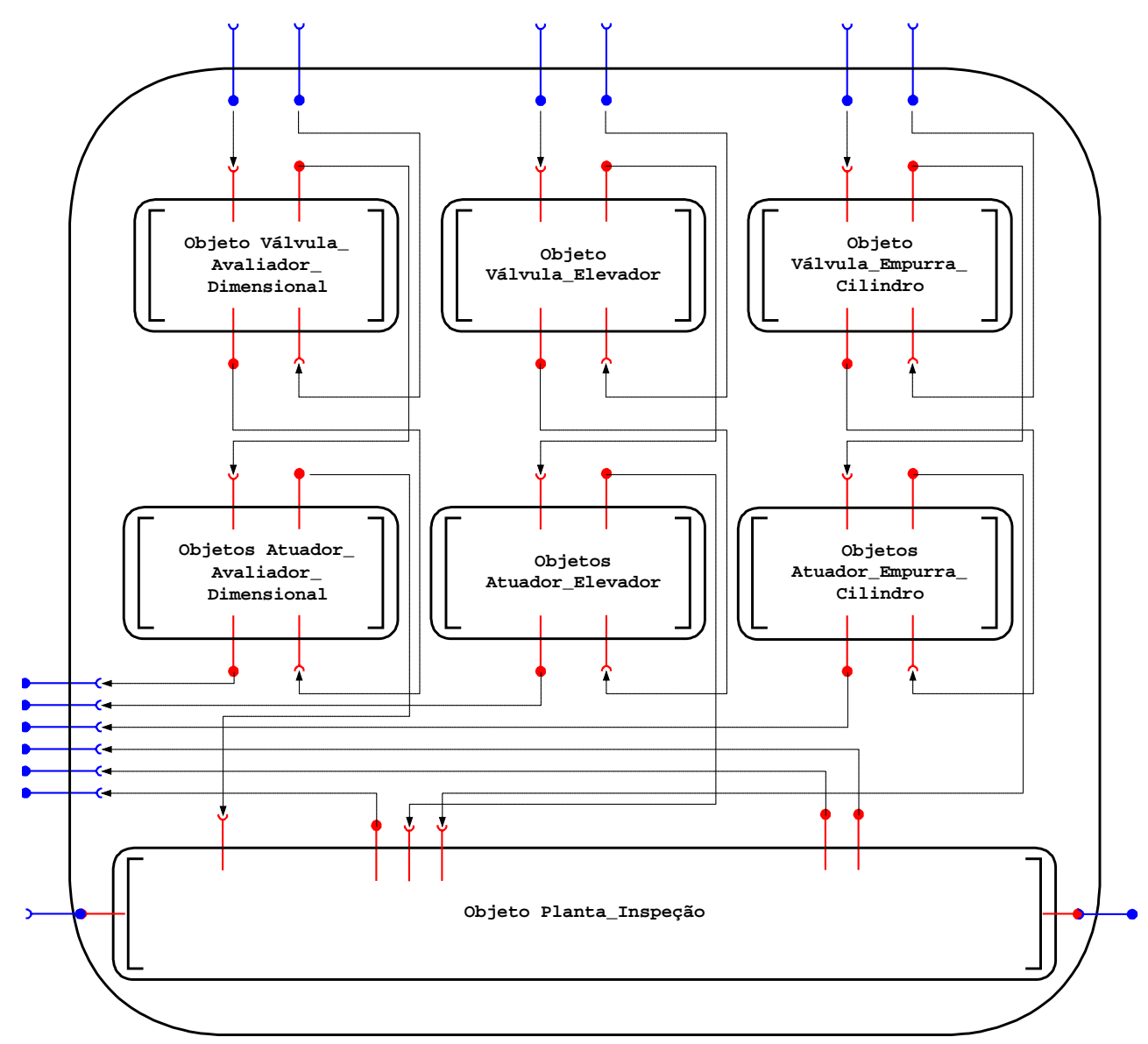

Figura E.42 - Componente Planta Inspeção.

O componente "Planta Transporte" é composto pelos objetos Atuador_Bloqueia_Palete (do 1 ao 8), Válvula_Bloqueia_Palete (da 1 à 8) e Planta_Transporte. 


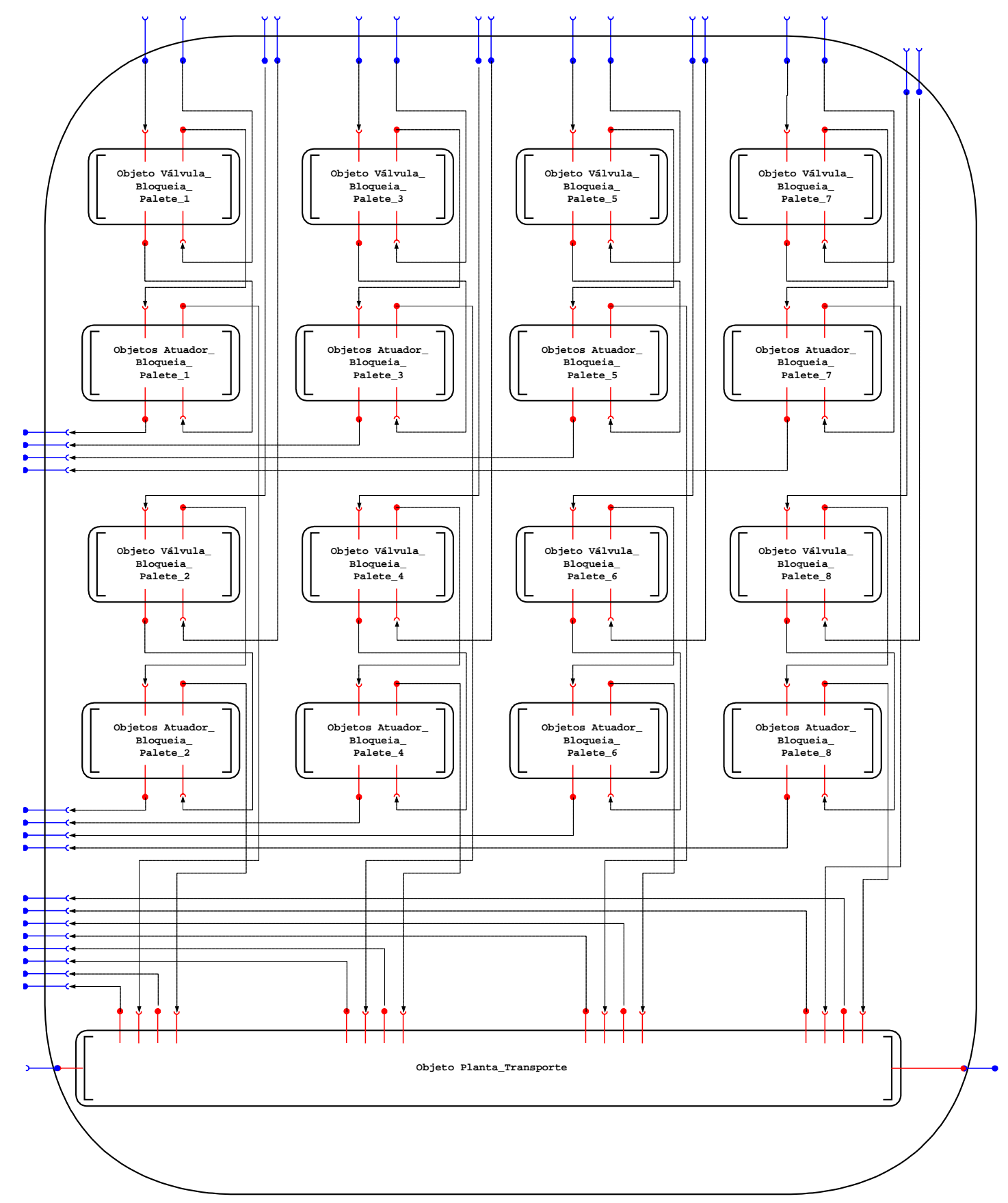

Figura E.43 - Componente Planta Transporte.

O componente "Planta Montagem” é composto pelos objetos Atuador_Pinos, Atuador_Molas, Atuador_Tampas, Atuador_Braço, Atuador_Garra, Atuador_Giro_Garra, Atuador_Retenção, Válvula_Pinos, Válvula_Molas, Válvula_Tampas, Válvula_Braço, Válvula_Garra, Válvula_Giro_Garra, Válvula_Retenção, Motor_Passo_X, Motor_Passo_Y e Planta_Montagem. 


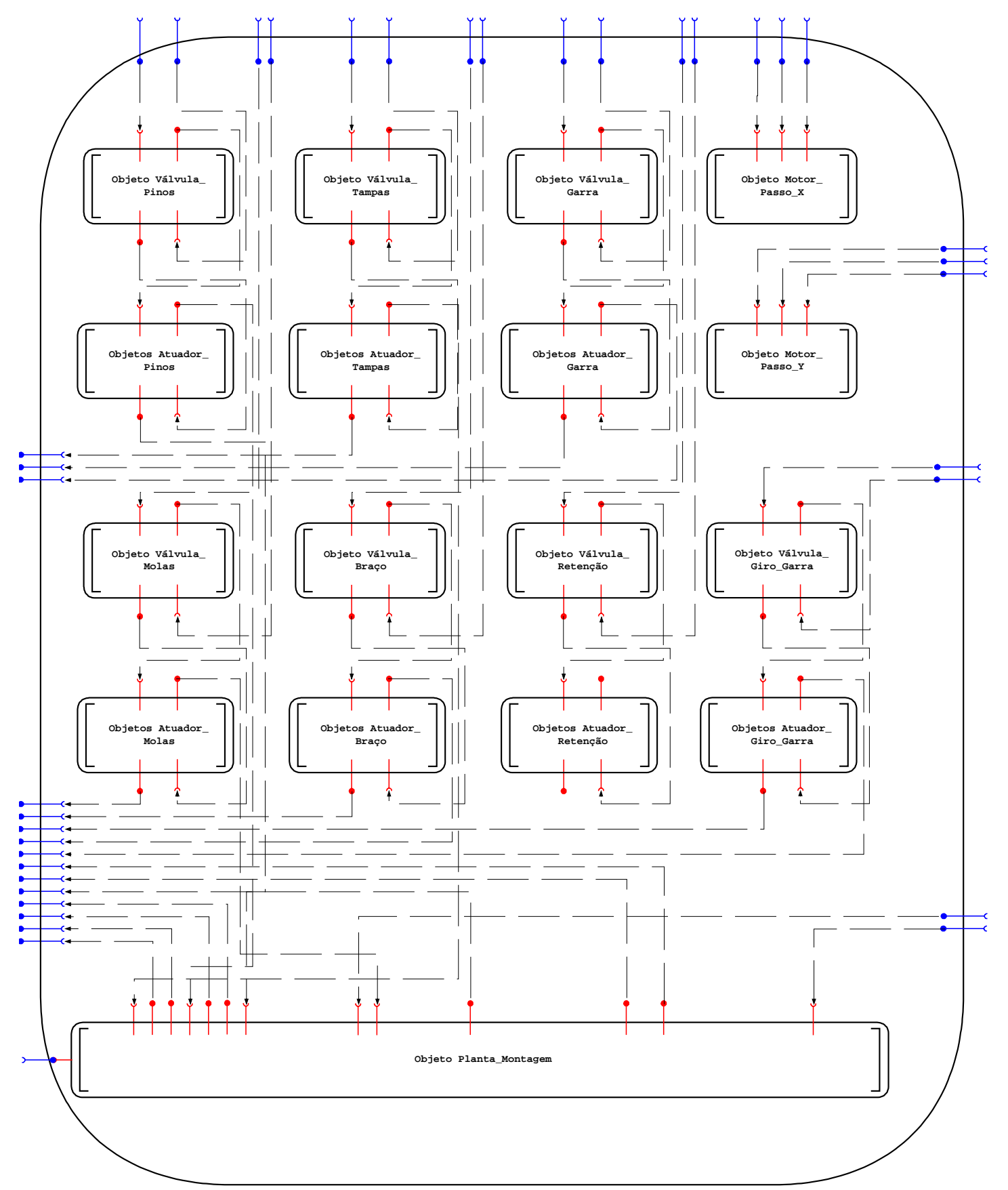

Figura E.44 - Componente Planta Montagem.

\section{Etapa 6 - Geração do aplicativo}

Os componentes da etapa 5 são então agrupados de forma a compor o aplicativo “Célula de Manufatura”. Assim, a Figura E.45 ilustra o aplicativo "Célula de Manufatura”, seus componentes "Planta Alimentação”, “Planta Inspeção”, "Planta Transporte”, “Planta Montagem”, “Alimentação”, “Inspeção”, “Transporte”, “Montagem”, “Sistema Supervisório Ordem” e “Sistema Supervisório Transporte”. 


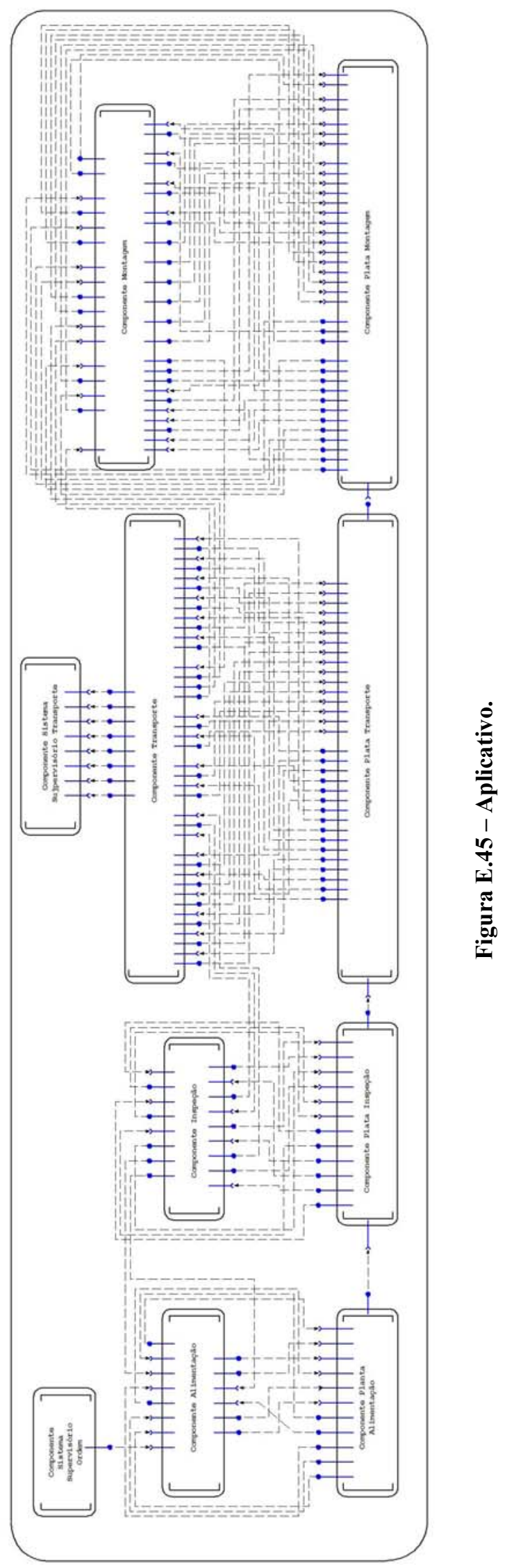




\section{ANEXO F - OPEN AND DISTRIBUTED PROCESSING (ODP)}

Nesta secção é apresentado o Open and Distributed Processing (ODP), um padrão para a modelagem de sistemas distribuídos de informação. Este, em conjunto com os conceitos de UML (Unified Modeling Language) apresentado no Anexo C, fornecem subsídios para a proposta de um possível sistema para modelagem e simulação distribuidos (Anexo G). Na seção F.6 é apresentada uma associação sinergética entre estas duas ferramentas.

A evolução das redes de comunicação bem como dos sistemas computacionais aliados à redução dos custos destes equipamentos têm possibilitado o aumento da utilização de aplicações distribuídas em grande número de áreas (NANKMAN; NIEUWENHUIS, 1996; SINNOTT; TURNER, 1997).

Porém, uma característica inerente aos sistemas distribuídos é o aumento da sua complexidade de especificação bem como de modificação. Desta forma, ter uma "boa” arquitetura de especificação é muito útil para auxiliar na definição de problemas que não estão bem definidos (SINNOTT; TURNER, 1997).

Neste sentido, através do esforço conjunto entre a ISO (International Organization for Standardization) e a ITU (International Telecommunications Union), foi proposto o padrão ODP (Open Distributed Processing) para a solução de problemas em sistemas distribuídos de informação. Dentre estes problemas, pode-se citar os de integração entre elementos heterogêneos (de natureza/funções distintas ou mesmo de diferentes fabricantes, por exemplo) (SINNOTT; TURNER, 1997; BECERRA, 1998; BOITEN et al., 2000).

Como resultado deste trabalho foi proposto o modelo de referência ODP (RMODP) que define uma arquitetura através da qual conceitos como distribuição, trabalho cooperativo e portabilidade possam ser atingidos (SINNOTT; TURNER, 1997; BOITEN et al., 2000).

Esta arquitetura baseia-se em pontos de vista (empresa, informação, computação, engenharia e tecnologia) uma vez que se reconhece que não é possível capturar de forma efetiva todos os aspectos de um sistema aberto e distribuído em uma descrição simples. Cada ponto de vista captura certas facetas do sistema. Desta forma, a complexidade envolvida em se considerar o sistema como um todo é reduzida (GASPOZ, 1996; SINNOTT; TURNER, 1997). 
Cada ponto de vista inclui um conjunto de conceitos (nem todos necessitam ser utilizados), regras e estruturas que formulam uma linguagem específica para cada ponto de vista, e estas usam conceitos que são consistentes entre si através de regras de consistência. Isto é importante pois o que é especificado em um ponto de vista apresenta um correspondente em outros pontos de vista (KANDÉ et al., 1998; BOITEN et al., 2000; PUTMAN, 2001).

Para cada um dos pontos de vista, o modelo de referência apresenta um conjunto de definições e regras que restringem as formas como as definições podem ser relacionadas (SINNOTT; TURNER, 1997; KANDÉ et al., 1998; BOITEN et al., 2000; COSTA et al., 2001):

$>$ ponto de vista da empresa está focado nas políticas do negócio, políticas de gerenciamento e as funções das pessoas no sistema e no ambiente $^{26}$ onde estão inseridas. O uso da palavra empresa não significa que este ponto de vista se limite a apenas uma organização. O modelo construído pode bem descrever as restrições existentes entre várias organizações distintas;

ponto de vista da informação concentra-se na modelagem da informação. Construindose um modelo de informação independente de seus componentes individuais, provêse uma visão simples das origens e destinos das informações bem como o fluxo entre eles. O ponto de vista da informação define conceitos para a definição de esquemas de informação. O ponto de vista faz distinção entre uma visão instantânea da informação (esquema estático), da informação que não pode ser alterada (esquema invariante) e uma descrição da informação refletindo o comportamento e evolução do sistema (esquema dinâmico);

ponto de vista da computação concentra-se nos algoritmos e fluxos de dados que provêm as funções do sistema distribuído. Este ponto de vista representa os componentes individuais que são as fontes e destinos dos fluxos de informação. Ele representa o sistema e seu ambiente em termos de objetos que interagem através da troca de informações por interfaces. Isso não implica necessariamente que os objetos computacionais irão concretizar em um eventual sistema por componentes separados; ponto de vista da engenharia foca no mecanismo de distribuição e a infraestrutura para prover e dar suporte à distribuição. O ponto de vista da engenharia define um número

\footnotetext{
${ }^{26}$ Tudo o que não pertence ao sistema, porém interage com ele.
} 
de blocos funcionais que podem ser combinados para prover as funções necessárias/requisitadas (isto é, função de distribuição, de falha ou de migração). Este ponto de vista lista um grande número de funções de suporte que são candidatas para a padronização;

Ponto de vista da tecnologia concentra-se no detalhe dos componentes e ligações (links) físicas a partir dos quais o sistema distribuído é construído.

\section{F.1. Ponto de vista da empresa}

No RM-ODP, a especificação dos sistemas abertos e distribuídos segundo o ponto de vista da empresa possibilita identificar o propósito, escopo e políticas do sistemas através da organização de conceitos, requisitos, regras, estruturas e restrições do sistema (e sub sistemas) sem, no entanto, se restringir à aspectos de implementação e distribuição, por exemplo (ITU, 1995; PUTMAN, 2001).

Segundo Putman (2001), a especificação do sistema segundo o ponto de vista da empresa pode conter:

$>$ definição das comunidades ${ }^{27}$, que são constituídas de objetos empresa ou de funções empresariais necessárias para satisfazer algum propósito da empresa, como por exemplo departamentos ou grupos de trabalho;

> declaração objetiva para uma comunidade da empresa; qual o seu papel no sistema e a função que deve desempenhar;

identificação dos objetos da empresa que compreendem a comunidade empresarial, incluindo tanto as funções dos participantes (atores) bem como dos artefatos (recursos), ou seja, uma visão abstrata do que é necessário para que o sistema desempenhe sua função;

$>$ função desempenhada pelos objetos da empresa dentro da comunidade, restringidas pelas regras da comunidade;

$>$ regras para os objetos, que podem habilitar ou restringir ações: (1) obrigação - o que deve ser feito; (2) permissão - o que pode ser feito; e (3) proibição - o que não pode ser feito;

atividades desempenhadas pelos objetos da empresa;

\footnotetext{
${ }^{27}$ Cada comunidade, composta por um ou mais objetos empresa, é formada para atingir um objetivo.
} 
configuração dos objetos;

$\operatorname{contratos}^{28}$ com o ambiente definindo as restrições impostas por este à empresa e ao ambiente pela comunidade.

Comunidade é um conceito central no ponto de vista da empresa. Ele consiste de todos os elementos que o projetista do sistema foca ao se especificar a empresa. Uma comunidade pode ser pensada como um conjunto de funções que definem comportamentos, um conjunto de objetos que assumem estas funções, e interações entre os objetos da comunidade e o ambiente. O que a comunidade pode ou não fazer é determinado nos contratos da comunidade o nos contratos com o ambiente.

Além dos conceitos apresentados sobre comunidades, há também outros dois conceitos importantes: domínio e federação:

$>$ domínio - um domínio é um conjunto de objetos, relacionados a um objeto de controle, que pode ou não ser parte do domínio. Um domínio pode ser organizacional como uma unidade de negócios, administrativo como um domínio de nomes, e técnico, onde cada um destes domínios possui sua própria autoridade de controle, provendo gerenciamento de políticas, controle de recursos, controle de acesso e até mesmo qualidade de serviço.

federação - uma federação é uma comunidade ou uma coleção de múltiplos domínios que se unem para compartilhar recursos enquanto retêm sua autonomia sobre seus recursos. Esta permite a colaboração, coordenação, interoperabilidade e compartilhamento entre os diferentes domínios. A habilidade de ingressar ou deixar uma federação bem como a de mudar a natureza do relacionamento são partes da especificação da autonomia de cada domínio, contratado entre este e a federação.

\section{F.2. Ponto de vista da informação}

O ponto de vista da informação envolve um conjunto de modelos que especifica a semântica de um sistema aberto e distribuído e a sua estrutura da informação. O ponto de vista da informação auxilia a responder questões como “o tipo de informação que é

\footnotetext{
${ }^{28}$ Contratos dizem respeito, por exemplo, a restrições, como qualidade de serviço, uso ou gerenciamento.
} 
gerenciada pelo sistema”, “quais restrições e critérios são necessários para acessar a informação” e “quais restrições são aplicadas às interfaces” (PUTMAN, 2001).

Este ponto de vista considera um conjunto de conceitos, regras e estruturas para especificação de sistemas ODP. Os conceitos são independentes de detalhes de distribuição e implementação.

A especificação da informação contém:

> identificação de um conjunto de objetos de informação;

$>$ os atributos estáticos dos objetos de informação;

$>$ as associações entre os objetos de informação;

$>$ uma especificação dos comportamentos dos objetos de informação;

$>$ o relacionamento entre os comportamentos dos objetos de informação;

$>$ contratos do ambiente com os objetos de informação.

A prescrição do ponto de vista da informação é restrita a um pequeno conjunto de conceitos e regras relacionadas ao escopo e natureza das especificações da informação. Os conceitos incluem três esquemas: esquema invariante; esquema estático; e esquema dinâmico, descritos a seguir:

o esquema invariante é um conjunto de predicados que devem ser sempre verdadeiros para um ou mais objetos de informação para algum período ou intervalo de tempo. Ele restringe os estados possíveis e mudanças de estado dos objetos. O esquema invariante também restringe os esquemas dinâmico e estático;

$>$ o esquema estático define o estado e a estrutura de um ou mais objetos de informação em algum ponto no tempo. O esquema estático captura os efeitos sobre o objeto que resultam em uma mudança de estado ou estrutura do objeto, como uma das ações do esquema dinâmico, criação ou destruição de objetos ou alguma propriedade de interesse;

$>$ o esquema dinâmico define todas as ações que permitem a mudança do estado ou estrutura de um objeto de informação. Este esquema foca as possíveis ações que dinamicamente afetam a mudança e ajuda a definir os aspectos computacionais, posteriormente refinados no ponto de vista da computação. A ação que causa mudanças de estado nos objetos de informação são todos capturados no esquema dinâmico daquele objeto, bem como suas pré e pós-condições. 


\section{F.3. Ponto de vista da computação}

O ponto de vista da computação foca na decomposição do sistema aberto e distribuído em estruturas passíveis de distribuição. Estas estruturas são expressas em termos de objetos (chamados objetos computacionais ${ }^{29}$ ), suas ações internas, suas interações (que são realizadas através de interfaces) e as restrições impostas às ações e interações (GASPOZ, 1996; NANKMAN; NIEUWENHUIS et al., 1996; BECERRA, 1998; PUTMAN, 2001).

Uma especificação computacional permite visualizar o sistema em termos de configurações de objetos computacionais e interações necessárias para atingir a funcionalidade completa do sistema de modo distribuído.

Esta especificação está centrada na estruturação de aplicações independentes de como os objetos computacionais estão distribuídos ou qual o tipo de computador ou rede de comunicação utilizados. A especificação computacional, então, é um modelo lógico, não um modelo físico de topologia de rede de comunicação e módulos. A especificação computacional permite o foco no processamento de componentes de aplicação, como interagem com outros componentes (em paralelo ou em seqüência), como se dá a ligação entre componentes, e como as restrições entre as ligações são alcançadas (PUTMAN, 2001).

A visão computação do RM-ODP descreve também como as aplicações e os componentes distribuídos do sistema interagem de forma cooperativa e transparente. A linguagem computacional do RM-ODP define as ações que um objeto pode executar, propiciando que novos objetos e interfaces possam ser criados e as ligações estabelecidas. Assim, esta linguagem computacional provê as bases para permitir uma interoperabilidade aberta e uma portabilidade dos componentes do sistema (BECERRA, 1998).

Neste ponto de vista, além de se identificar os objetos computacionais e seu comportamento, deve-se identificar como estes interagem entre si. O mecanismo de interação é a interface e sua ligação. Uma interface consiste de uma ou mais interações, que podem ser dos seguintes tipos (PUTMAN, 2001):

$>$ sinal - uma interação de via única entre o objeto de chamada e o de resposta;

\footnotetext{
${ }^{29}$ E que são gerados com base nos objetos empresa e informação dos ponto de vista da empresa e ponto de vista da informação, respectivamente.
} 
operação - a interação entre um objeto cliente e um servidor;

fluxo - um conjunto ordenado de interações de via única de um objeto fonte para um consumidor.

A atividade de modelagem do ponto de vista da computação aborda as seguintes questões (FAROOQUI, 2002):

$>$ quais são os objetos computacionais (componentes de aplicativos distribuídos; unidades de estrutura e distribuição) do sistema;

quais atividades (os agentes através dos quais a computação progride) ocorrem em cada objeto computacional do sistema;

$>$ quais as interfaces dos objetos computacionais do sistema;

$>$ quais operações podem ser executadas através da interface computacional;

$>$ qual comportamento é observado na interface computacional;

$>$ qual a função da interface computacional;

$>$ quais restrições ambientais estão associadas com cada objeto computacional e suas interfaces;

$>$ que interações são possíveis entre objetos computacionais (suas interfaces).

Com relação ao objeto de ligação, este é um objeto intermediário entre duas ou mais interfaces de objetos e que gerencia a ligação entre elas. Pode haver mais que dois objetos ligados/conectados pelo objeto de ligação (Figura F.1).

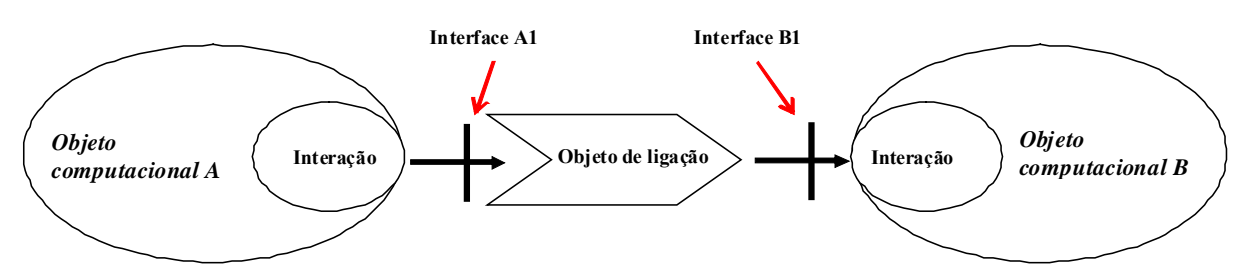

Figura F.1 - Relacionamento entre objetos, interfaces e objetos de ligação (PUTMAN, 2001).

O objeto de ligação deve interagir com o objeto fonte para interceptar a chamada, mapeá-la para a interface de destino, e interagir com o objeto alvo para fornecer a chamada. Da mesma forma, o objeto de ligação deve interagir com o objeto alvo para receber a resposta, mapeá-la na resposta apropriada para o objeto solicitante e entregá-la (PUTMAN, 2001). 


\section{F.4. Ponto de vista da engenharia}

No ponto de vista da computação os objetos computacionais são definidos de forma que estes sejam passíveis de distribuição, porém tratando-a de forma transparente. Já o ponto de vista da engenharia foca na infraestrutura necessária para prover e dar suporte às interações transparentes de forma distribuída entre objetos (GASPOZ, 1996; NANKMAN; NIEUWENHUIS, 1996). Este ponto de vista descreve como as funcionalidades dos objetos computacionais são distribuídas e qual infraestrutura está disponível para suportar esta distribuição (NANKMAN; NIEUWENHUIS, 1996; BECERRA, 1998; MARTE, 2000).

Este ponto de vista envolve um conjunto de diagramas de objetos constituídos de objetos engenharia e suas respectivas associações. A especificação utiliza parte do ponto de vista da computação por existir correspondência direta com este (Marte, 2000). Um objeto computacional é refinado em um ou mais objetos básicos de engenharia (OBEs) acoplados com objetos engenharia (OEs) que não são visíveis na linguagem computacional, mas são visíveis na linguagem de engenharia para dar suporte aos mecanismos de transparência e distribuição, funções ODP, capacidade de ligação, etc. (MARTE, 2000; PUTMAN, 2001).

Além dos objetos básicos, a modelagem apresenta outros objetos engenharia que implementam o sistema distribuído por meio de agrupamentos de clusters em nós e transparências em canais.

No ponto de vista da engenharia o nó representa o computador. Ele é composto por um núcleo (correspondendo ao sistema operacional) que gerencia os recursos, processa a criação, remoção e comunicação para os objetos do nó (MARTE, 2000; PUTMAN, 2001). O nó por si só é configurado em uma coleção de objetos básicos de engenharia e objetos engenharia, chamados grupos e cápsulas. Cada um destes inclui um objeto de gerenciamento para ajudar na criação, remoção, e gerenciamento geral do grupo de objetos. Um nó consiste de um ou mais cápsulas, e uma cápsula consiste de um ou mais grupos (PUTMAN, 2001).

Uma cápsula é uma unidade de processamento e armazenamento e que pode conter tanto objetos básicos de engenharia como objetos engenharia. A cápsula é como o componente ou processo de um software de uma aplicação, encapsulando o processamento e realizando os armazenamentos necessários. O núcleo instancia a cápsula 
e todos os objetos associados com a cápsula, inclusive o grupo. Cada cápsula possui um gerenciador de cápsula que a gerencia e interage com o gerenciador de grupo (PUTMAN, 2001).

Um grupo, contido em uma única cápsula, é a configuração de um objeto básico de engenharia que pode ser considerado uma única unidade para o propósito de ativação, reativação, desativação, verificação, migração e recuperação. A Figura F.2 ilustra o relacionamento entre os objetos de engenharia descritos.

O tratamento do grupo como uma unidade permite um grau de autonomia para este. A separação do grupo em uma única entidade encapsulada quer dizer que se um grupo falhar, os efeitos que a falha podem provocar são minimizados.

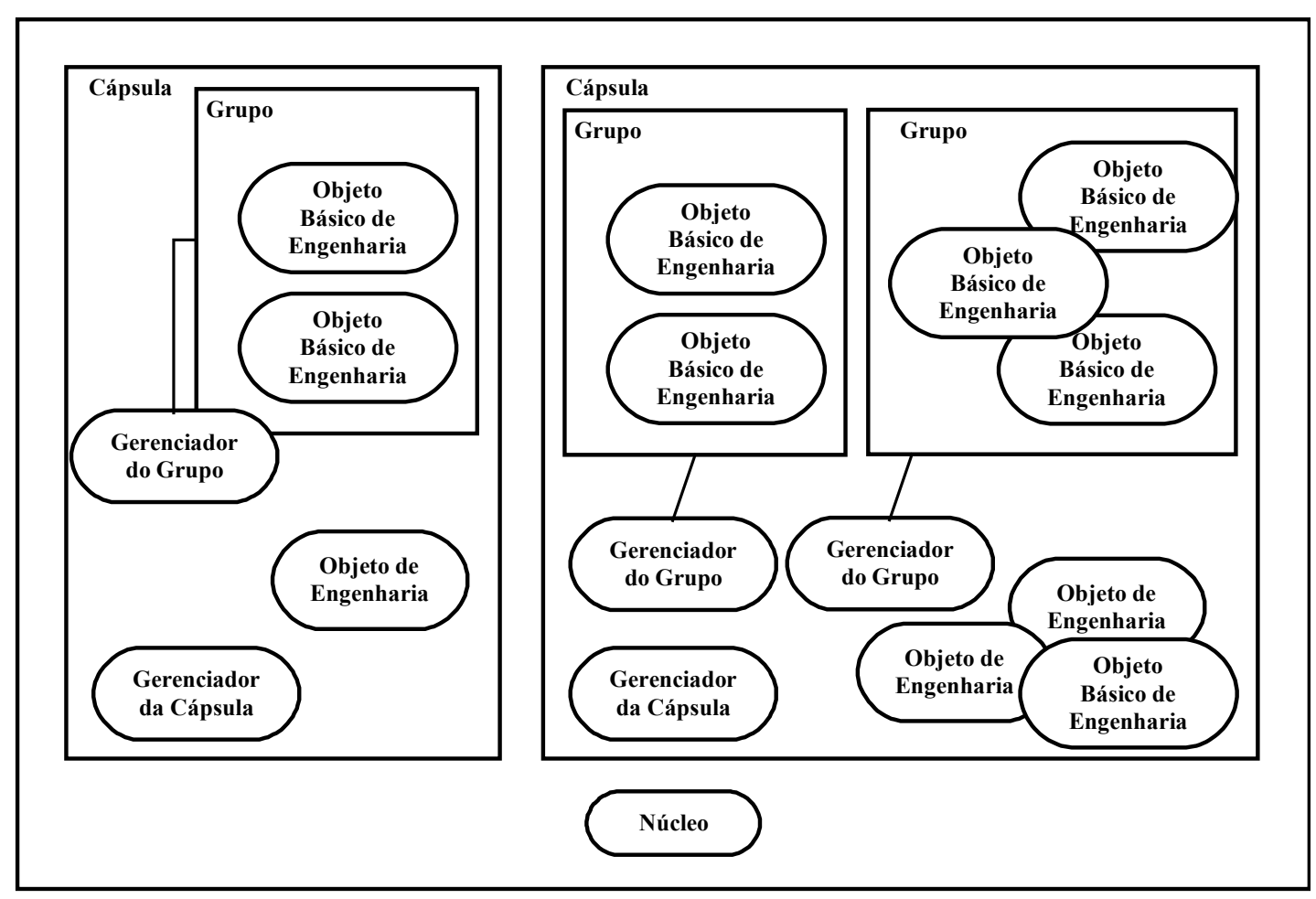

Figura F.2 - Relação entre os elementos do ponto de vista da engenharia (PUTMAN, 2001).

O propósito de um canal é dar suporte às interações distribuídas de forma transparente entre objetos de engenharia. O canal (Figura F.3) consiste de uma configuração de stubs $^{30}$, binders ${ }^{31}$, objetos protocolo ${ }^{32}$ e interceptadores ${ }^{33}$. Os stubs

\footnotetext{
${ }^{30}$ Um objeto de engenharia em um canal que provê interpretação e suporte para a interação no canal para o objeto básico de engenharia, como a organização dos parâmetros.

${ }^{31}$ Um objeto de engenharia em um canal que gerencia a conexão no canal.

32 Um objeto de engenharia em um canal que prevê o mecanismo de comunicação para que haja interação.
} 
realizam as transcrições necessárias entre formatos de dados entre nós distintos e o conector (binder) assegura que o dado apresentado/passado pelo stub seja transportado para os stubs dos nós corretos. Um objeto protocolo se comunica com os outros objetos protocolos para executar as interações entre os objetos de engenharia conectados (NANKMAN; NIEUWENHUIS, 1996; PUTMAN, 2001). O interceptador é utilizado para promover as traduções entre domínios, como por exemplo convenções de nome (PUTMAN, 2001).

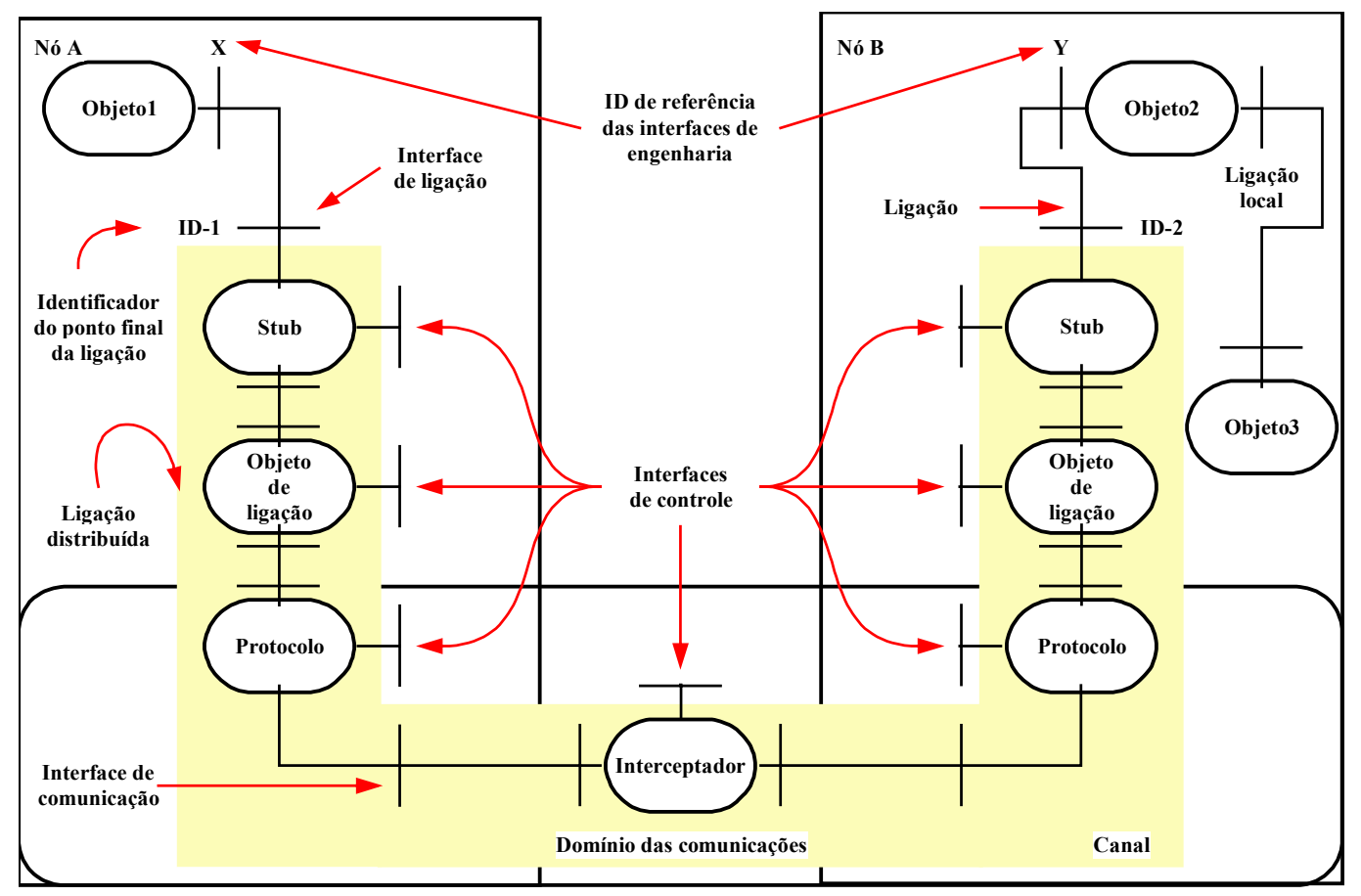

Figura F.3 - Modelo do canal.

\section{F.5. Ponto de vista da tecnologia}

Através dos conceitos presentes em nós e canais, o ponto de vista da engenharia pode prover um modelo de infraestrutura computacional capaz de suportar o sistema aberto e distribuído. Para que este modelo seja implementado, é necessário que sejam identificadas as tecnologias que possam desempenhar as funções requeridas por este e pelos demais pontos de vista (MARTE, 2000).

\footnotetext{
${ }^{33}$ Um objeto de engenharia no canal que gerencia as políticas e as transformações necessárias através de um domínio específico.
} 
A especificação de um sistema segundo o ponto de vista da tecnologia no RMODP, permite descrever a implementação do sistema em termos de hardware e software utilizados (NANKMAN; NIEUWENHUIS, 1996; MARTE, 2000; PUTMAN, 2001). As opções de tecnologia sempre mudam, porém a especificação da arquitetura (como um conjunto de especificações da empresa, de informação, computacional e de engenharia) pode permanecer imutável (PUTMAN, 2001).

Para a implementação e comunicação entre objetos distribuídos, pode-se citar três padrões: um padrão “de jure” denominado CORBA (Common Object Request Broker Architecture) da OMG (Objetc Management Group) e padrões de mercado, como: COM/DCOM (Component Object Model / Distributed Component Object Model) da Microsoft e o Java RMI da Sun Microsystems. Estes três padrões implementam os canais de comunicação entre os diferentes nós da visão engenharia, os quais, por convenção, são chamados ORBs (Objetc Request Brokers) na visão tecnologia (MARTE, 2000; PUTMAN, 2001).

\section{F.6. Uma associação sinergética entre RM-ODP e UML}

Para cada ponto de vista, o RM-ODP define uma linguagem própria, tendo-se em vista um conjunto de conceitos e regras para serem usadas quando se especifica o sistema no ponto de vista correspondente. Porém, deixou-se em aberto a notação a ser usada em cada linguagem dos pontos de vista (KANDÉ et al., 1998).

A escolha das notações para os pontos de vista do RM-ODP deve considerar aspectos tais como:

$>$ sendo o RM-ODP baseado no paradigma de orientação a objetos, a notação para cada ponto de vista deve contemplar este paradigma.

$>$ a notação deve ser capaz de expressar os conceitos definidos em cada ponto de vista.

> deve ser possível verificar a consistência da especificação do sistema em vários pontos de vista. A possibilidade de se localizar uma entidade em mais de um ponto de vista pode ser vista como uma vantagem adicional.

Outra consideração é que a notação deve ser intuitiva, fácil de usar e entender, facilitando a comunicação entre os membros do time de projeto. 
Há muitas linguagens/notações formais e semi-formais que satisfazem este propósito de especificar os pontos de vista do RM-ODP. Entre elas, optou-se pela UML que segundo Costa et al. (2001) melhor preenche as necessidades/requisitos.

Ao contrário do RM-ODP, a UML oferece suporte direto para o projeto e implementação de cada aspecto do sistema de informação e provê uma notação integrada para sua representação. Em adição ao suporte aos principais relacionamentos entre estas representações, a aplicação da UML provê um processo de migração natural, através das diferentes fases e perspectivas do sistema, tal como funcionalidade, análise, projeto, implementação, etc.

A Figura F.4 apresenta como o UML pode ser empregado em cada uma das etapas de modelagem do RM-ODP, ilustrando o relacionamento entre estes pontos de vista e os diagramas UML, bem como entre diagramas UML entre si.

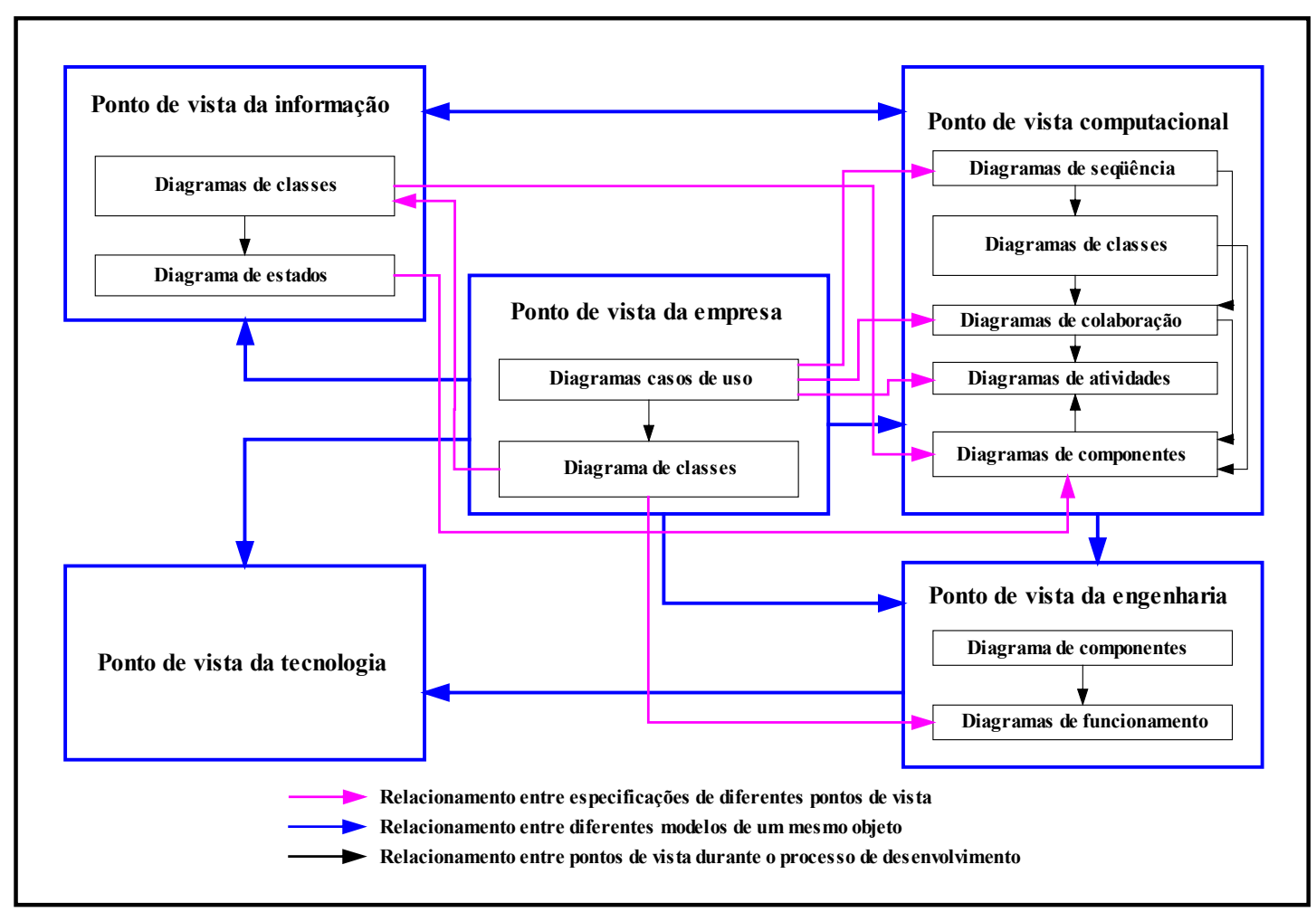

Figura F.4 - Relacionamento entre os diagramas UML e os pontos de vista da ODP (KANDÉ et al., 1998).

\section{F.6.1. Ponto de vista da empresa}

O ponto de vista da empresa captura os principais objetos e políticas de restrição do sistema. Assim, o diagrama de casos de uso lida com as principais funcionalidades do 
sistema, provendo um ponto de partida para o ponto de vista da empresa (COSTA et al., 2001). O resultado obtido com o modelo de casos de uso pode ser usado para gerar diagramas de classes, e que podem ser especificados com mais detalhes no ponto de vista da informação. O passo entre passar dos diagramas de classes para os diagramas de estados permite a especificação do comportamento dinâmico dos objetos mais importantes (KANDÉ et al., 1998; COSTA et al., 2001).

\section{F.6.2. Ponto de vista da informação}

O ponto de vista da informação mapeia principalmente os aspectos relacionados à estrutura da informação do sistema, que pode ser representada através dos atributos dos objetos e relacionamentos. O diagrama de classes aparecem como principal elemento dos pontos de vista da informação e da computação. No ponto de vista da informação eles são representados como diagramas de classes e diagramas de estados (COSTA et al., 2001).

\section{F.6.3. Ponto de vista da computação}

O ponto de vista da computação representa principalmente os aspectos relacionados às operações que realizam mudanças na informação, que pode ser descrita através de relacionamento entre objetos (COSTA et al., 2001).

Como um ponto de partida para o projeto computacional, os componentes identificados no ponto de vista da empresa podem ser mapeados em objetos computacionais que provêem uma visão abstrata do sistema. Neste nível, o diagrama de classes da UML tem sido usado para descrever a estrutura do objeto computacional, suas interfaces, e o relacionamento entre eles. Em um nível abstrato, o diagrama de componentes da UML tem sido usado para descrever os componentes do sistema e suas interfaces externas, mostrando a organização e a dependência entre os componentes (KANDÉ et al., 1998).

Já para descrever as interações entre objetos computacionais, os diagramas de colaboração (mostram as interações entre as instâncias e as relações entre si) e o diagrama de sequiência (descreve as interações entre objetos de forma temporal) da UML tem sido usados. Além destes, o diagrama de atividades permite a especificação das ordens nas quais as atividades (tal como as operações providas pelas interfaces dos objetos computacionais) têm que ser executadas. 


\section{F.6.4. Ponto de vista da engenharia}

O ponto de vista da engenharia foca na realização de interações entre objetos (distribuídos) e nos recursos necessários para efetuar estas interações. Isto abrange conceitos, regras e estruturas para a especificação do sistema pela perspectiva da engenharia (KANDÉ et al., 1998).

Este ponto de vista introduz três conceitos principais, chamados: nó, cluster e cápsula, vistos anteriormente. Os nós do RM-ODP são semelhantes aos nós da UML.

Para se especificar as cápsulas e suas interações, utiliza-se o diagrama de componentes da UML. A visão geral do sistema, isto é, como as cápsulas estão distribuídas entre os nós, é então mais naturalmente modelada pelo diagrama de funcionamento da UML.

Em adição ao diagrama de componentes, o diagrama de funcionamento é mapeado para o ponto de vista da engenharia. Este último diagrama mostra como os componentes e objetos do sistema são distribuídos pelo sistema.

\section{F.6.5. Ponto de vista da tecnologia}

O ponto de vista da tecnologia descreve a escolha de tecnologias de implementação usadas para conceber o projeto completo através dos outros quatro pontos de vista. Este ponto de vista descreve a configuração de softwares e hardwares com os quais o sistema (aberto e distribuído) conta (KANDÉ et al., 1998).

Embora não haja nenhum diagrama UML dedicado a descrever este ponto de vista, os conceitos de orientação a objetos (de encapsulamento e abstração) providos pela UML nos passos anteriores permitem que o sistema seja implementado em um ambiente heterogêneo em termos de arquitetura de computadores, linguagem de programação e sistemas operacionais. Esta é uma das principais vantagens da abordagem orientada a objetos da UML (KANDÉ et al., 1998). 


\section{ANEXO G - PROPOSTA DE UM SISTEMA COMPUTACIONAL PARA MODELAGEM E SIMULAÇÃO DISTRIBUÍDAS DE MODELOS EM REDE DE PETRI}

Neste anexo, pretende-se, através do uso dos conceitos abordados nas seções 2.4 e 4.3, bem como nos anexos C e F, apresentar a especificação das principais partes de um sistema computacional destinado à modelagem e simulação de sistemas produtivos através do uso de Rede de Petri (RdP). Entende-se como principais partes as relativas à diferença que esta proposta tem dos demais sistemas de modelagem e simulação baseados em RdP, ou seja, o seu aspecto distribuído. Utiliza-se a metodologia RMODP/UML na especificação deste sistema computacional enquanto os demais conceitos, como o de RdP, o método apresentado na seção 2.4 e o algoritmo proposto na seção 4.3 são utilizados como premissas e/ou restrições ao sistema computacional especificado.

\section{G.1. Especificação utilizando o ponto de vista da empresa}

O ponto de vista da empresa está direcionado às necessidades dos usuários dos sistema. Este sistema computacional deve ser entendido em termos das funcionalidades requeridas, dos domínios envolvidos, dos atores e seus papéis.

O primeiro passo neste sentido é definir o objetivo do sistema computacional como um todo, que neste caso pode ser entendido como "ser um sistema distribuído para a modelagem e simulação de sistemas produtivos discretos, ou seja, que possam ser modelados como SEDs (sistemas com estados discretos e eventos instantâneos)”.

São identificados dois tipos de atores que interagem com este sistema computacional:

$>$ Usuário;

$>$ Administrador.

Destaca-se também dois objetos empresa, elementos que compõem este sistema computacional:

> Ambiente de Modelagem e Simulação (AMS);

$>$ Servidor, o qual é resoponsável por gerenciar os usuários, gerenciar os modelos e monitorar a comunicação e a simulação. 
Além dos elementos já apresentados, definem-se os domínios e as federações:

Domínio - é o conjunto de um ou mais administradores e zero ou mais usuários; também é composto por um servidor e um ou mais AMS.

Federação -é o resultado de um acordo de cooperação entre domínios, que permite que atores de um domínio utilizem modelos desenvolvidos em outros domínios pertencentes à mesma federação. Como conseqüência direta, uma federação, para existir, deve ser composta por dois ou mais domínios.

Com base nestes atores e objetos empresa, é possível especificar suas funções bem como as regras a que estão submetidos.

\section{Ambiente de Modelagem e Simulação (AMS)}

$>$ Deve possuir recursos gráficos amigáveis para a criação e edição de modelos em RdP;

$>$ Deve possuir ferramenta para análise dos modelos através de simulação de modelos em RdP;

Deve permitir a simulação de modelos em RdP de forma isolada (Figura G.1 (a)) ou em conjunto com outros AMSs, através do uso de servidor (Figura G.1 (b) ${ }^{34}$ ).

\section{Servidor}

Deve verifica o login dos atores;

$>$ Deve registrar quando os AMSs ficam on-line ou off-line de forma a se ter controle da disponibilidade de recursos computacionais;

$>$ Deve armazenar os modelos desenvolvidos e que são de domínio público;

$>$ Deve fornecer para os atores uma lista de modelos disponíveis para edição e desenvolvimento de novos modelos;

> Deve ordenar as estações com os AMS disponíveis em anel, preparando-as para realizar simulações;

> Deve ter a possibilidade de interação (através de uma interface padrão) com diferentes sistemas, permitindo a substituição dos modelos pelas entidades reais. 


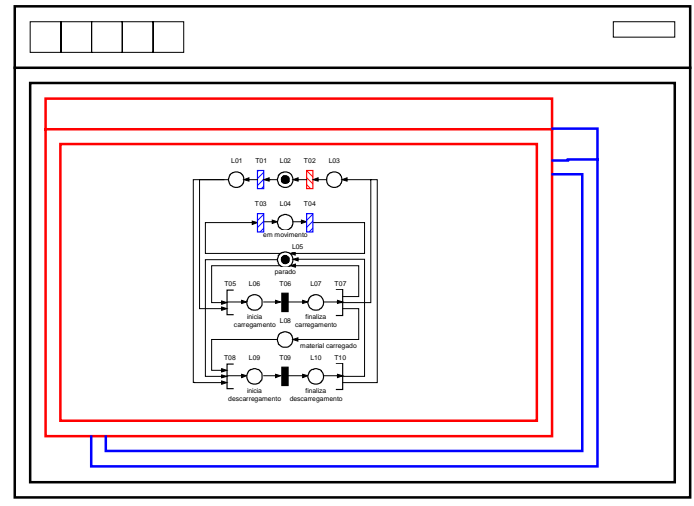

(a)

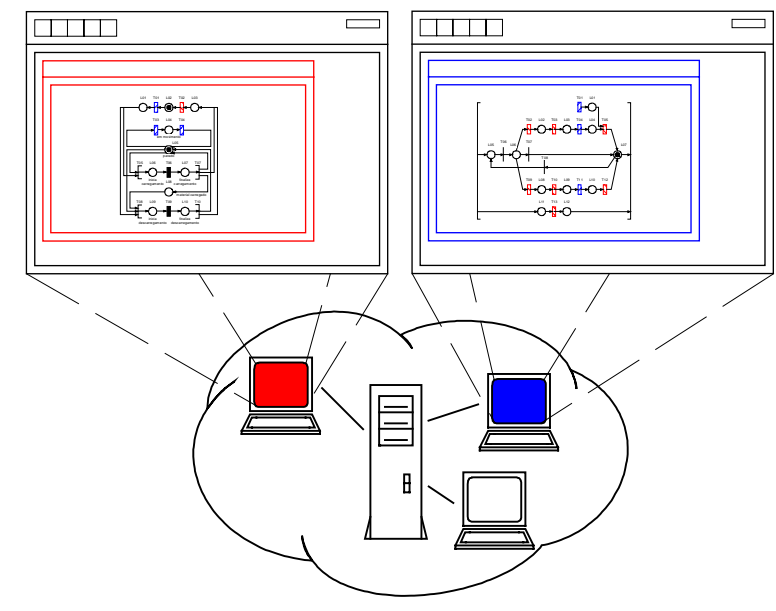

(b)

Figura G.1 - (a) Um exemplo de dois modelos (em Rede de Petri) interagindo entre si no mesmo AMS; (b) - Um exemplo de dois modelos (em Rede de Petri), cada um sendo executado em um AMS, interagindo entre si através do servidor.

\section{Usuário}

$>$ Deve criar ou editar (modificar) modelos ${ }^{35}$;

Deve solicitar a exclusão de modelos;

Deve definir as permissões de acesso aos modelos.

\section{Administrador}

Deve poder realizar todas as funções desempenhadas pelo usuário;

Deve poder alterar as permissão de acesso aos modelos;

> Deve poder apagar os modelos solicitados pelo usuário

Deve poder adicionar e remover usuários;

Deve poder federar seu domínio com outros domínios (Figura G.2);

D Deve poder compartilhar modelos com outros domínios.

\section{Domínio}

Deve assegurar que todos os atores têm livre acesso aos modelos deste domínio bem como sua implementação.

\footnotetext{
${ }^{34}$ No exemplo da Figura G.1 (b) estão sendo simulados menos modelos do que AMSs disponíveis. Neste caso, não há a necessidade de se utilizar todos os AMSs.

${ }^{35}$ Os tipos de modelos são especificados no ponto de vista da informação.
} 


\section{Federação}

Deve controlar o acesso dos atores, isto é, os atores de uma federação, porém de domínios distintos, só possuem acesso aos componentes e aplicativos (seção 2.4) de outros domínios e, ao contrário do que é permitido na regra do domínio, não podem ter acesso às implementações dos modelos (classes), ou seja, estes são tratados como “caixas pretas”.

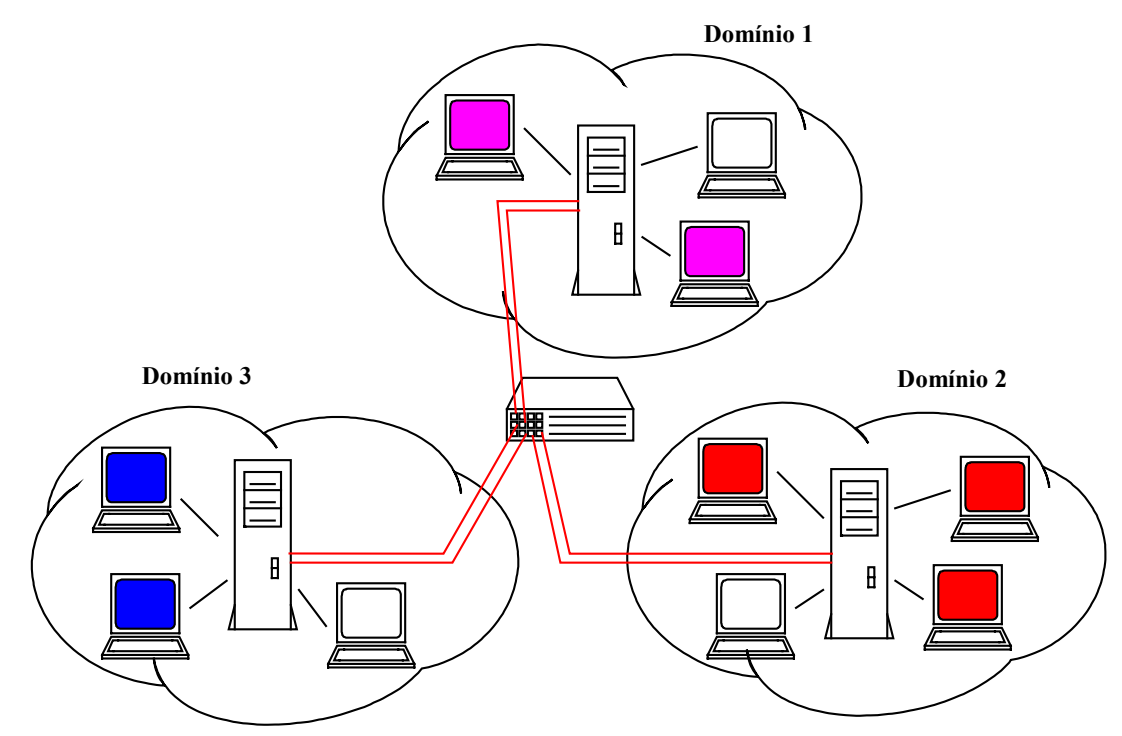

Figura G.2 - Um exemplo de projeto usando modelos de diferentes domínios, todos pertencentes à uma mesma federação.

A Figura G.3 apresenta o diagrama de casos de uso consolidando as funções desempenhadas pelos objetos empresa e pelos atores.

\section{G.2. Especificação utilizando o ponto de vista da informação}

Baseado nas descrições apresentadas no ponto de vista da empresa, procede-se com a especificação do ponto de vista da informação, identificando os objetos informação e seus relacionamentos.

Para tanto, na seção G.2.1 faz-se o detalhamento do Ambiente de Modelagem e Simulação (AMS) e na seção G.2.2, o detalhamento do Servidor. 


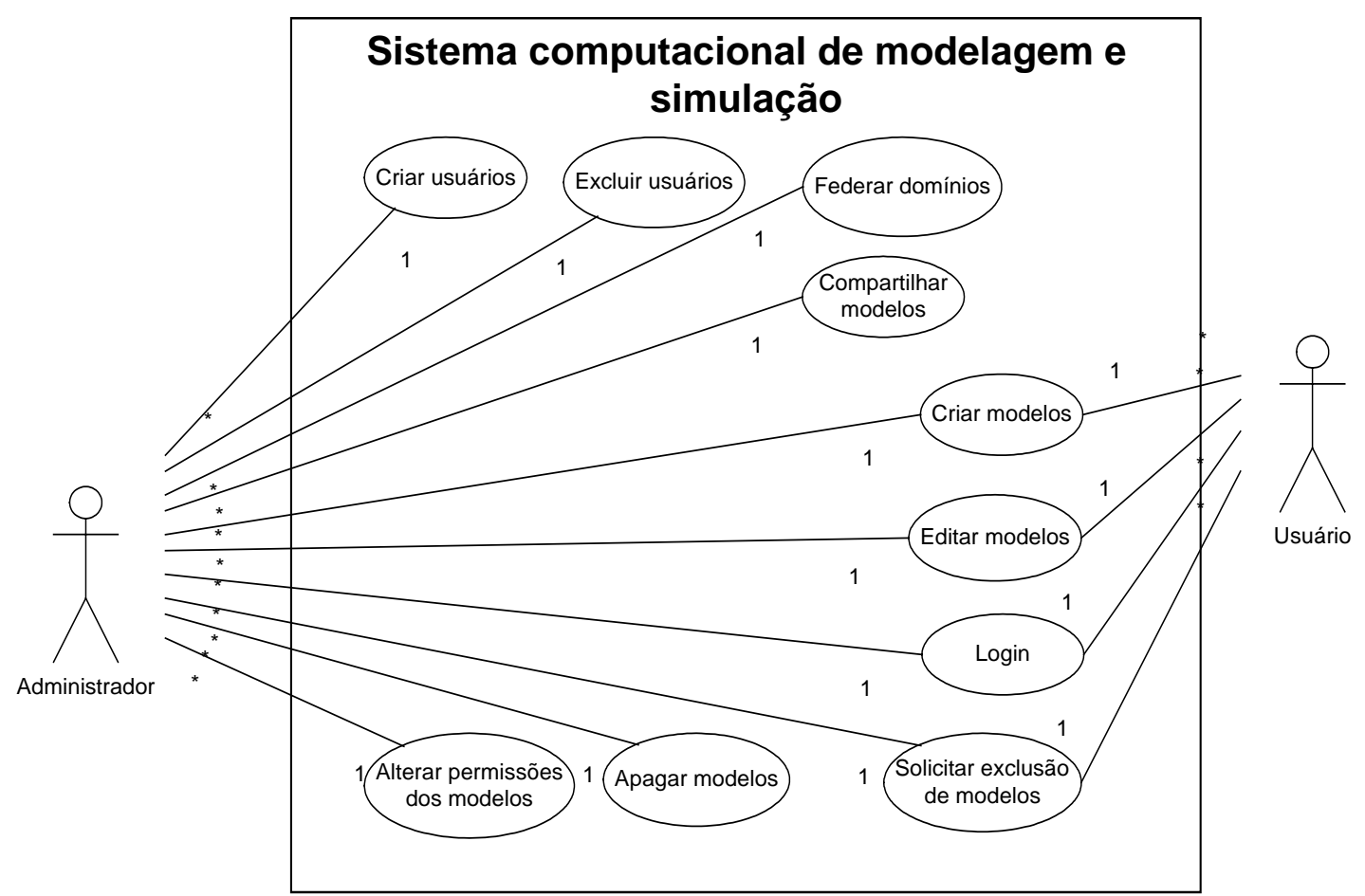

Figura G.3 - Diagrama de casos de uso referente ao sistema computacional proposto.

G.2.1. Identificação dos objetos informação do AMS

Inicia-se a identificação dos objetos informação do AMS pelo seu detalhamento apresentado na Figura G.4.

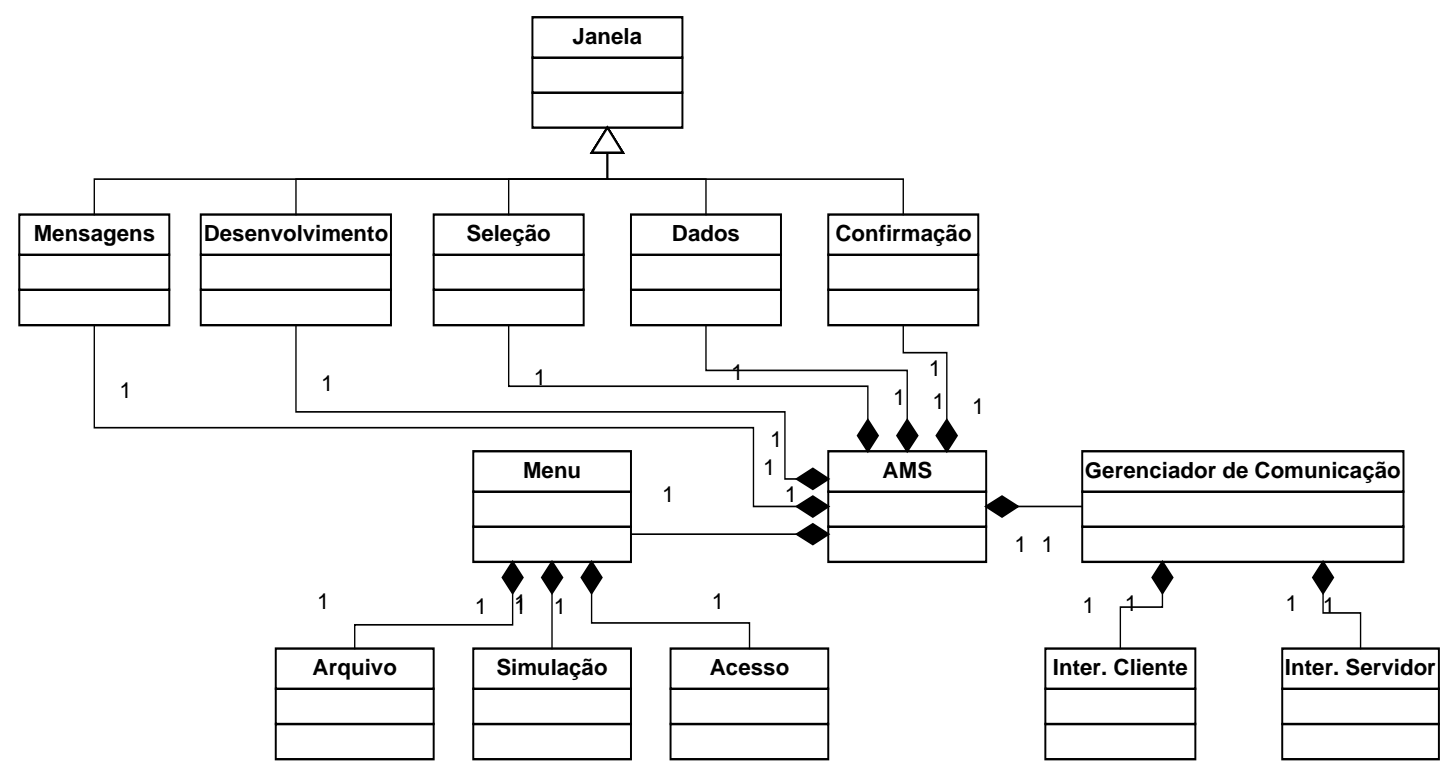

Figura G.4 - Diagrama UML de classe do Ambiente de Modelagem e Simulação (AMS). 
Neste diagrama, observa-se a presença de um MENU contendo comandos referentes: (1) aos ARQUIVOS tra balhados no AMS; (2) à SIMULAÇÃO, ou seja, comandos para controlar a evolução da simulação do modelo em RdP, e (3) comandos de ACESSO, que estão relacionados ao acesso dos atores ao sistema computacional proposto e seus modelos. Além destes, destaca-se também:

> Janela de DESENVOLVIMENTO - onde o modelo é construído;

> Janela de SELEÇÃO (de modelos) - para se listar os modelos disponíveis de forma que o ator possa escolher o que lhe é de interesse trabalhar;

Janela de DADOS - janela onde o ator entra com seus dados para login ou alteração de senha;

> Janela de CONFIRMAÇÃO - janela que é apresentada ao ator a fim de pedir a sua confirmação antes de realizar uma atividade como, por exemplo, fechar um modelo sem tê-lo salvado antes;

$>$ Interface CLIENTE - utilizada para requisitar conexão com outros AMS ou mesmo com o Servidor;

$>$ Interface SERVIDOR - utilizada para se conectar a outros AMS ou mesmo o servidor quando estes requisitam a conexão; e

> GERENCIADOR DE COMUNICAÇÃO - utilizado para coordenar o processo de simulação.

O menu ARQUIVO é composto pelos seguintes submenus:

NOVO - utilizado para criar um novo modelo, que pode ser três tipos: classe, componente ou aplicativo, cujos significados já foram descritos na seção 2.4;

ABRIR - utilizado para abrir um modelo já existente, podendo este ser LOCAL ou publicado no Servidor;

$>$ SALVAR - utilizado para salvar um novo modelo gerado ou mesmo um editado, podendo salvar o modelo localmente, no disco rígido, ou remotamente, no Servidor, de forma que fique acessível a todos os usuários do domínio;

> GERENCIADOR - utilizado para visualizar os modelos disponíveis no Servidor, permitindo alterar seus atributos ou mesmo requisitar a exclusão de um ou mais modelos;

FECHAR - serve para fechar o modelo aberto; 
SAIR - utilizado para sair do programa e desta forma tirar temporariamente o AMS do domínio.

Já o menu SIMULAÇÃO é composto pelos seguintes submenus:

ENTRAR (em modo de simulação) - esta opção prepara o AMS para que entre no modo de simulação do modelo em RdP;

> SAIR (do modo de simulação) - esta opção tira o AMS do modo de simulação, permitindo a edição dos modelos, por exemplo;

INICIAR - comando que inicia a simulação do modelo em RdP;

> PASSO A PASSO - permite que a simulação seja feita passo a passo;

$>$ PAUSAR - comando que interrompe a simulação até que o comando INICIAR ou PASSO A PASSO seja acionado.

O menu de ACESSO é responsável pelo:

LOGIN, ou seja, verificar se o usuário pertence ao domínio e, se positivo, liberar o AMS para que o usuário o possa utilizar;

LOGOFF;

ALTERAR SENHA - permite que o usuário altere sua senha de acesso, em especial a senha inicial que lhe é atribuída quando este é cadastrado.

A Figura G.5 apresenta o detalhamento da JANELA DE DESENVOLVIMENTO, a qual é composta por um MENU próprio e um PAINEL (detalhando na Figura G.6). Também fazem parte da JANELA DE DESENVOLVIMENTO:

JANELA DE MARCAS - onde as marcas são selecionadas e seus atributos (quando utilizados) preenchidos;

$>$ ATUALIZA TELA - uma rotina para atualização da tela durante a simulação do modelo em RdP;

BARRA DE PROPRIEDADES - onde são apresentadas as propriedades dos elementos da RdP inseridos no modelo, quando selecionados. 
E os métodos:

JOGADOR DE MARCAS - rotina que gerencia os disparos das transições durante a simulação do modelo em RdP;

DESENHA ARCO - uma rotina que desenha arcos (direcionais, habilitadores e inibidores) nos modelos, conectando elementos ativos (transições) e passivos (lugares) da RdP.

E a variável FILA DE DISPAROS, que possui a relação das transições habilitadas.

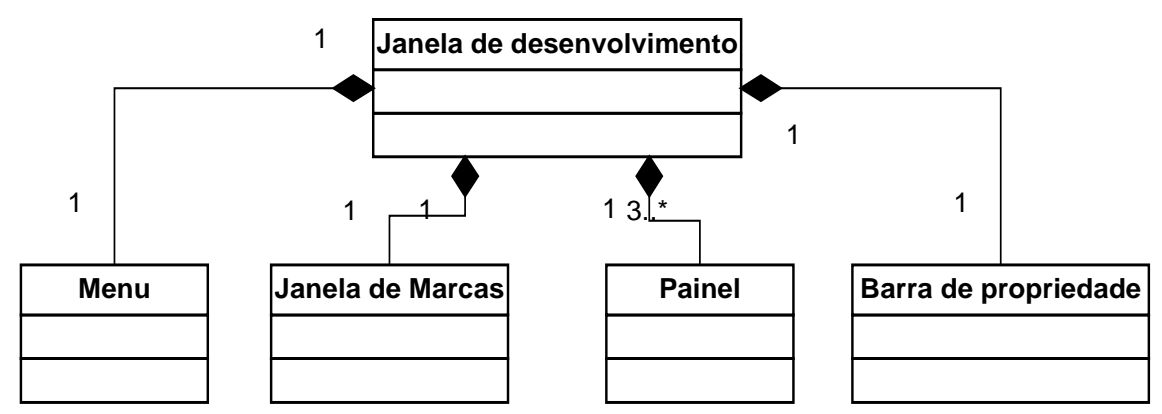

Figura G.5 - Diagrama UML de Classes da Janela de Desenvolvimento.

O MENU é composto de elementos referentes à RdP como lugar, transição, arco e marca. Além destes, conta-se com uma ferramenta de seleção para que elementos já inseridos possam ser selecionados.

O painel (Figura G.6) é onde se dá a modelagem em RdP propriamente dita. Ele, por sua vez, pode ser de três tipos:

DESCRIÇÃO E COMENTÁRIOS - para que o modelista possa descrever o modelo em RdP, destacando prontos importantes ou qualquer característica que auxilie outros usuários a interpretar o modelo;

> DEFINIÇÃO DAS MARCAS - pretende-se ter uma área para definir as marcas e seus atributos;

MODELO - refere-se ao modelo em RdP e que possui alguns objetos informação associados a ele. 


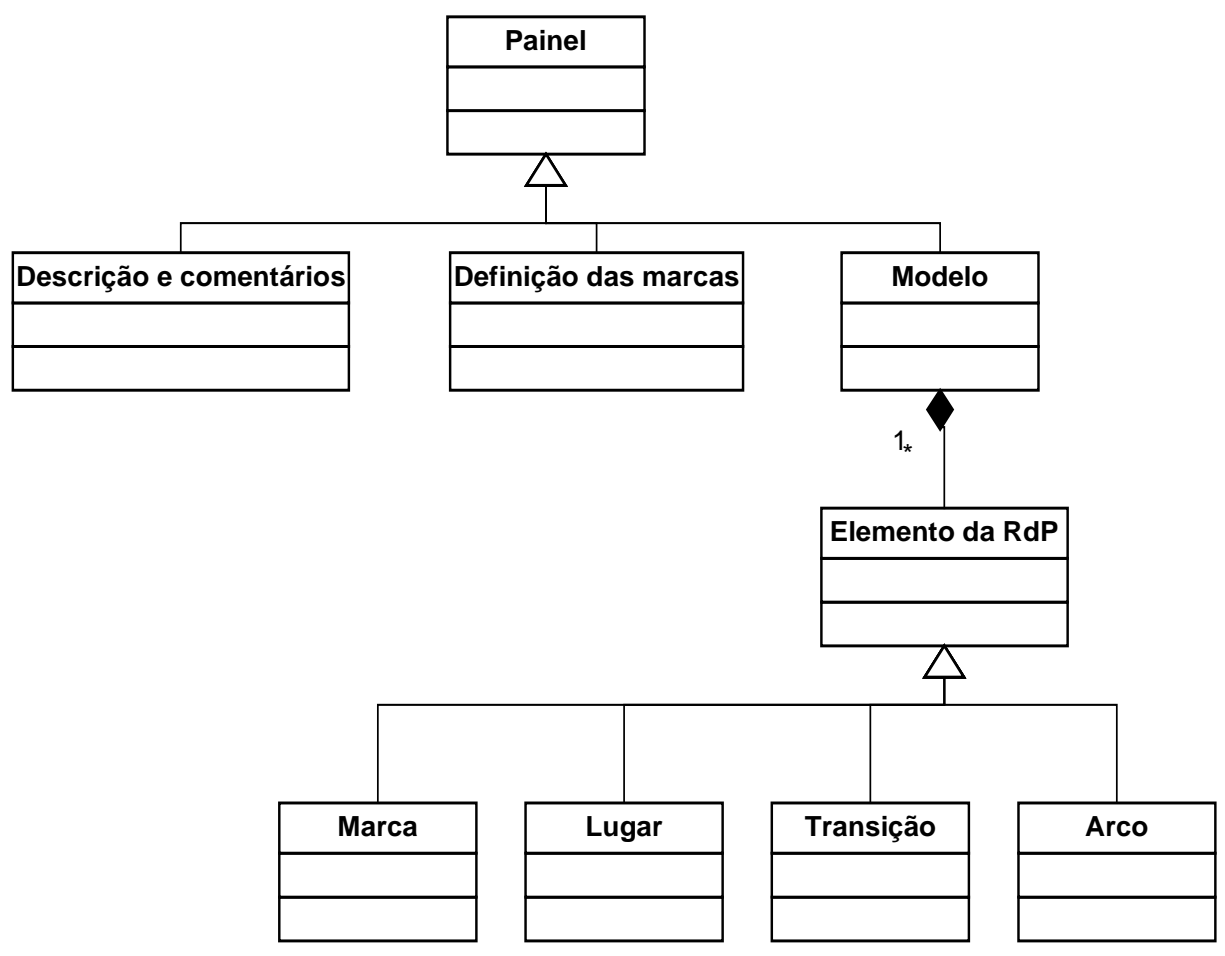

Figura G.6 - Diagrama UML de Classes do Painel da Janela de Desenvolvimento.

As propriedades apresentadas variam de acordo com o elemento da RdP, a saber:

LUGAR - nome, capacidade e marcação inicial (nome da marca, quantidade e valores dos atributos);

TRANSIÇÃO - nome, orientação (horizontal ou vertical), tipo (normal, temporizada, entrada ou saída), regras de disparo, e tempo (no caso das transições temporizadas);

$>$ ARCO - nome, elemento de origem, elemento de destino, peso do arco, filtros, e tipo (direcional, habilitador ou inibidor);

MARCA - nome, atributos e seus valores iniciais.

\section{G.2.2. Identificação dos objetos informação do Servidor}

O Servidor (Figura G.7) possui MENUS relacionados ao gerenciamento e à monitoração da simulação. Através do menu de GERENCIAL, pode-se:

USUÁRIOS - inserir e remover atores (usuários e administradores) ou mesmo alterar informações sobre estes; 
MODELOS - conjunto de rotinas que permitem alterar os atributos dos modelos ou mesmo excluir aqueles solicitados;

AMS ONLINE - permite monitorar os AMS disponíveis para serem usados na simulação distribuída.

Já os MENU de SIMULAÇÃO está, disponível apenas quando se inicia a simulação, onde pode-se:

Monitorar o STATUS DO ANEL, ou seja, como este está configurado;

> Consular a ALOCAÇÃO DE MODELOS em cada AMS.

Além dos menus, possui uma JANELA DE DADOS para a visualização destes, interfaces cliente (INTER. CLIENTE) e servidor (INTER. SERVIDOR) para se comunicar com outros membros do domínio e métodos responsáveis por ALOCAR e DESALOCAR os modelos preparando o domínio para a simulação, ou retirando-o deste estado, respectivamente.

\section{G.3. Especificação utilizando o ponto de vista da computação}

No item anterior, ponto de vista da informação, foram obtidos os principais objetos informação e apresentados os seus relacionamentos estáticos. Dando prosseguimento à especificação do sistema computacional proposto, neste item são apresentados os cenários de utilização, tanto do AMS quanto do Servidor, com seus respectivos diagramas de sequiência, ilustrando o relacionamento dinâmico entre os objetos informação, lembrando-se que neste anexo procura-se destacar as partes relacionadas à simulação distribuída.

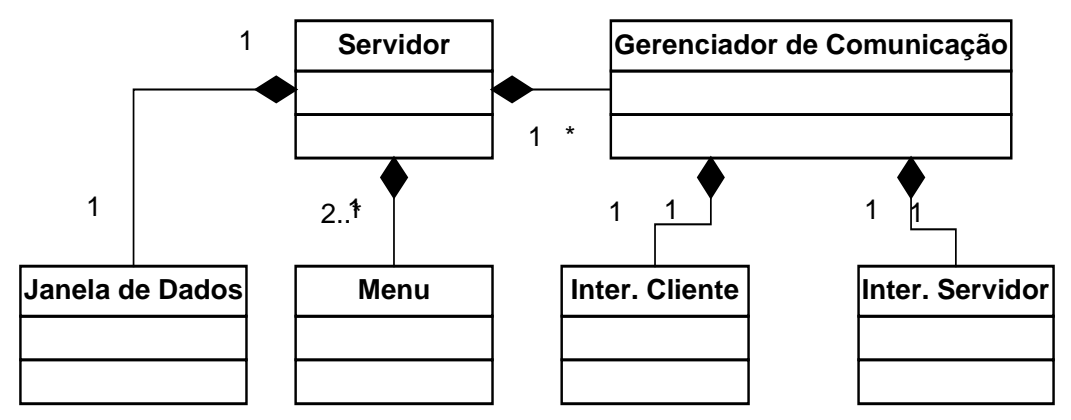

Figura G.7 - Diagrama UML de Classes do Servidor. 
O grupo de cenários a seguir está relacionado com as operações de simulação de uma classe. São estes:

Entrar em modo de simulação (para um modelo do tipo classe) (Figura G.8);

Sair do modo de simulação (para um modelo do tipo classe) (Figura G.9);

Iniciar simulação (para um modelo do tipo classe) (Figura G.10);

> Simulação passo a passo (para um modelo do tipo classe) (Figura G.11);

Pausar simulação (para um modelo do tipo classe) (Figura G.12);

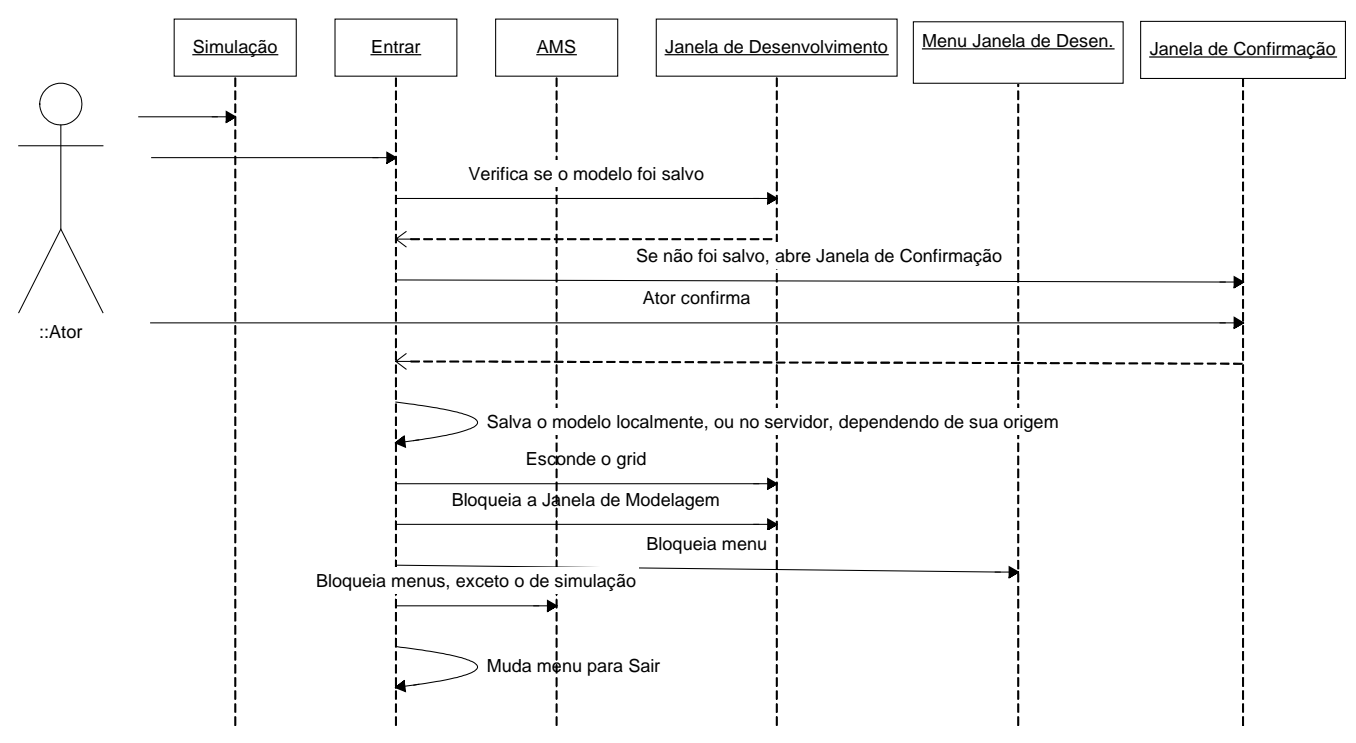

Figura G.8 - Diagrama de seqüência ilustrando a seqüência de atividades necessárias para sair do modo de edição e entrar no modo de simulação para quando se simula um modelo do tipo classe.

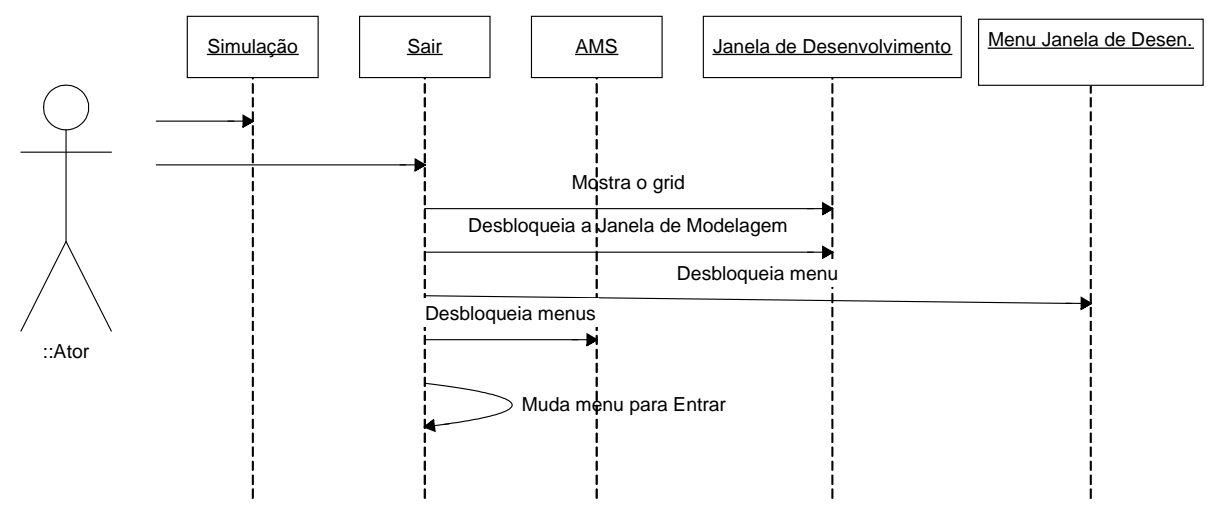

Figura G.9 - Diagrama de seqüência ilustrando a seqüência de atividades necessárias para sair do modo de simulação e voltar para o modo de edição quando se simula um modelo do tipo classe.

Este cenário é válido tanto para quando a simulação está em pausa quanto para quando está em passo a passo. 


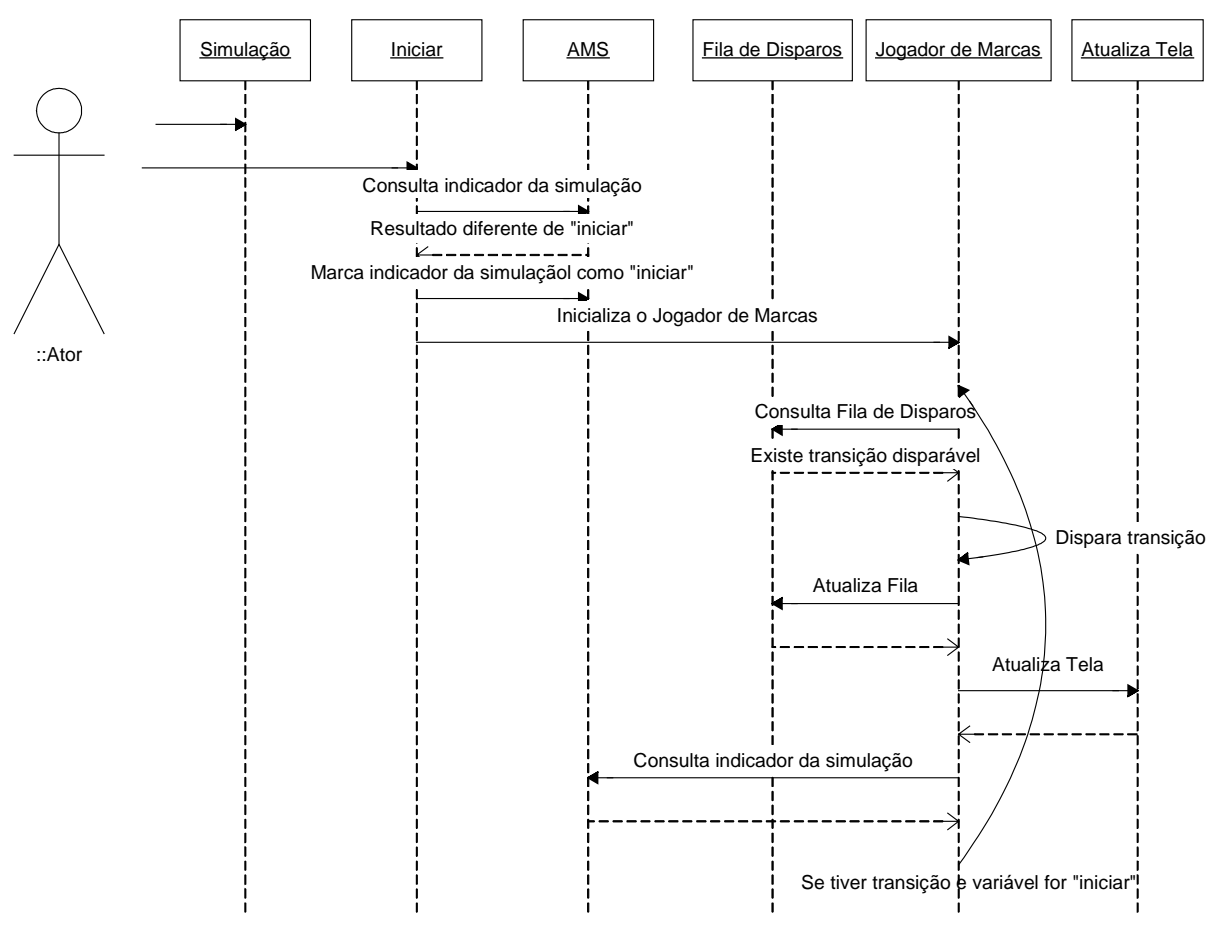

Figura G.10 - Diagrama de seqüência ilustrando a seqüência de atividades necessárias para iniciar a simulação quando se simula um modelo do tipo classe.

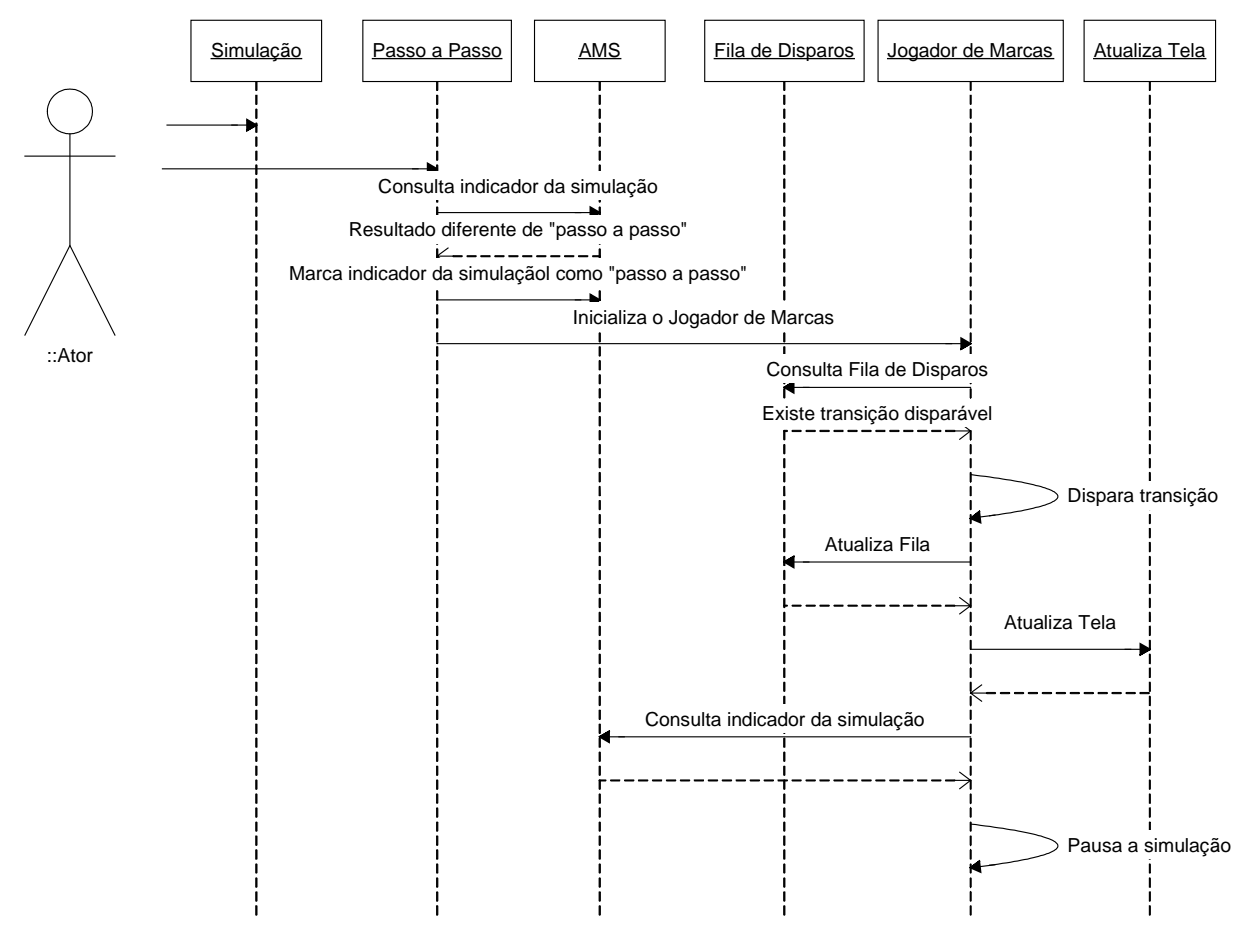

Figura G.11 - Diagrama de seqüência ilustrando a seqüência de atividades necessárias para simular passo a passo quando se simula um modelo do tipo classe. 


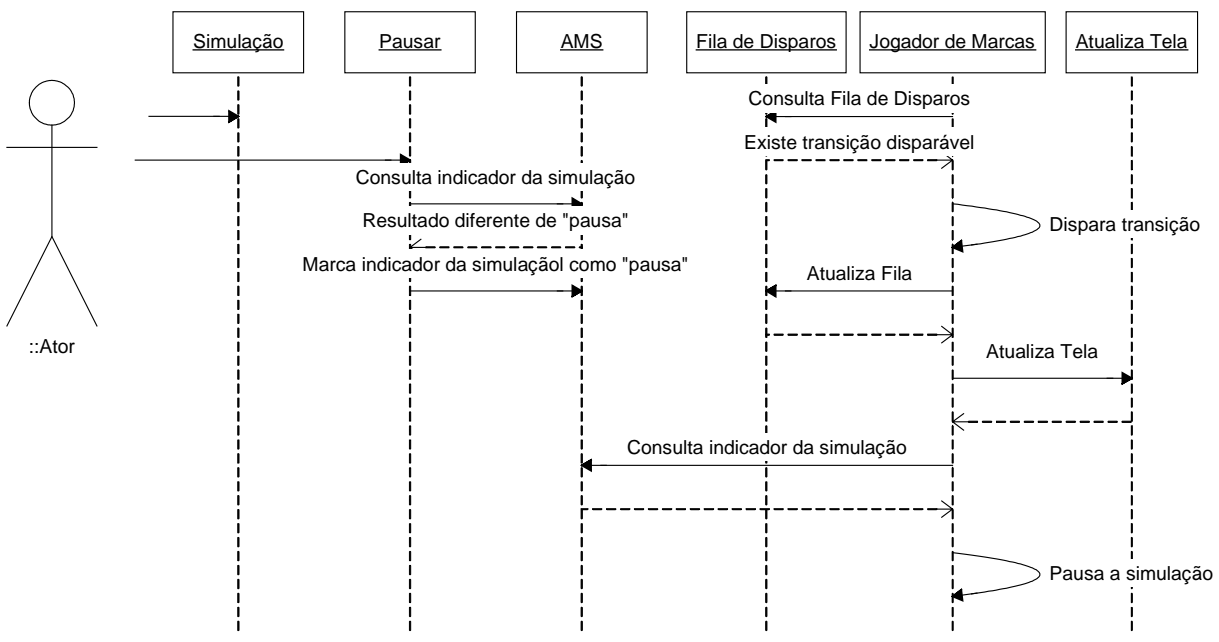

Figura G.12 - Diagrama de seqüência ilustrando a seqüência de atividades necessárias para pausar a simulação quando se simula um modelo do tipo classe.

O próximo grupo de cenários está relacionado com as operações de simulação de elementos diferentes de classes, ou seja, componentes e aplicativos. São estes:

Entrar em modo de simulação (para um modelo diferente de classe) (Figuras G.13, G.14 e G.15);

Sair do modo de simulação (para um modelo diferente de classe) (Figuras G.16 e G.17);

Iniciar simulação (para um modelo diferente de classe) (Figura G.18);

> Pausar simulação (para um modelo diferente de classe) (Figura G.19); 


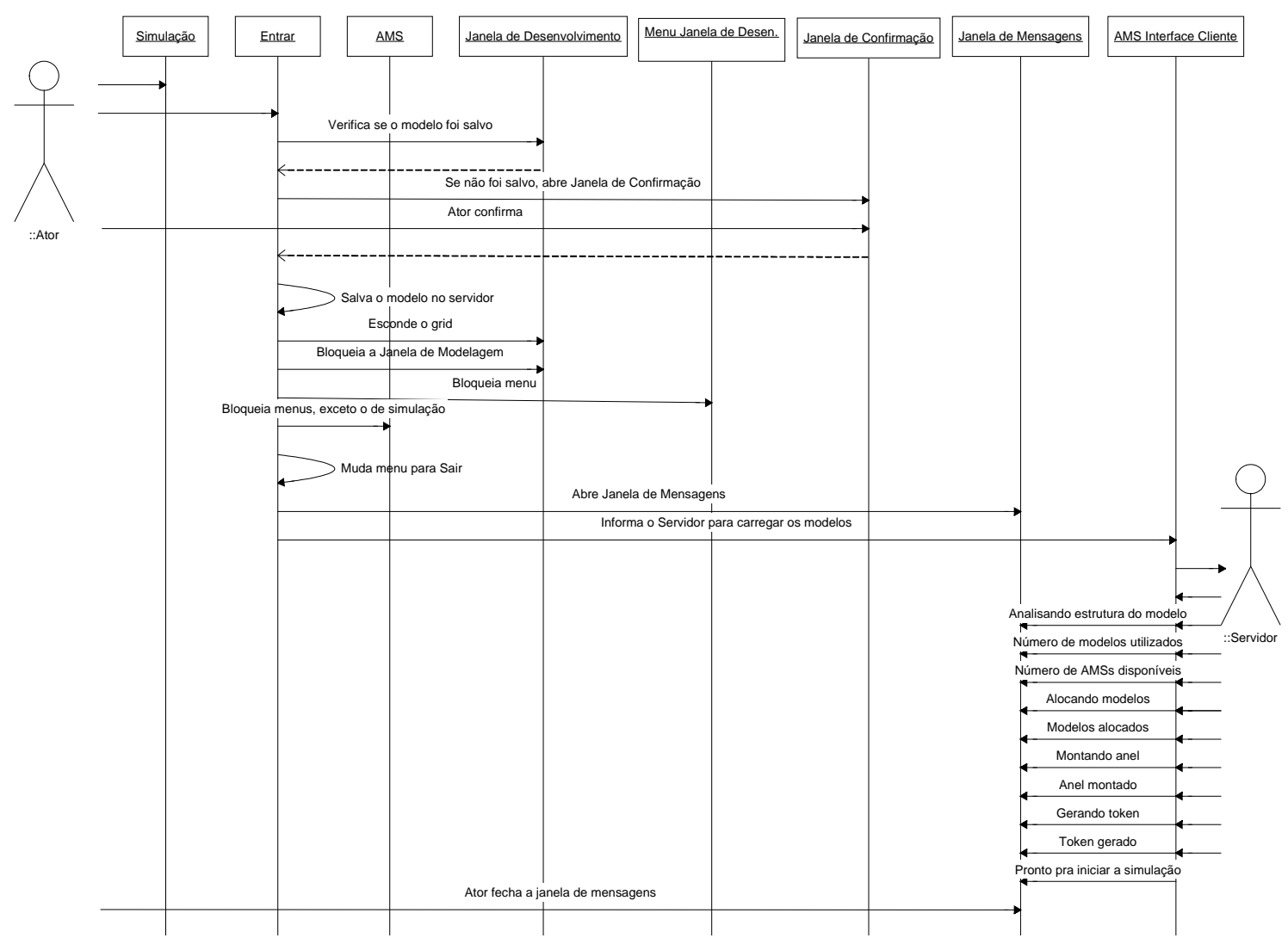

Figura G.13 - Diagrama de seqüência ilustrando a seqüência de atividades necessárias para entrar no modo de simulação e sair do modo de edição quando se simula um modelo diferente de classe Parte I - AMS “mestre". 


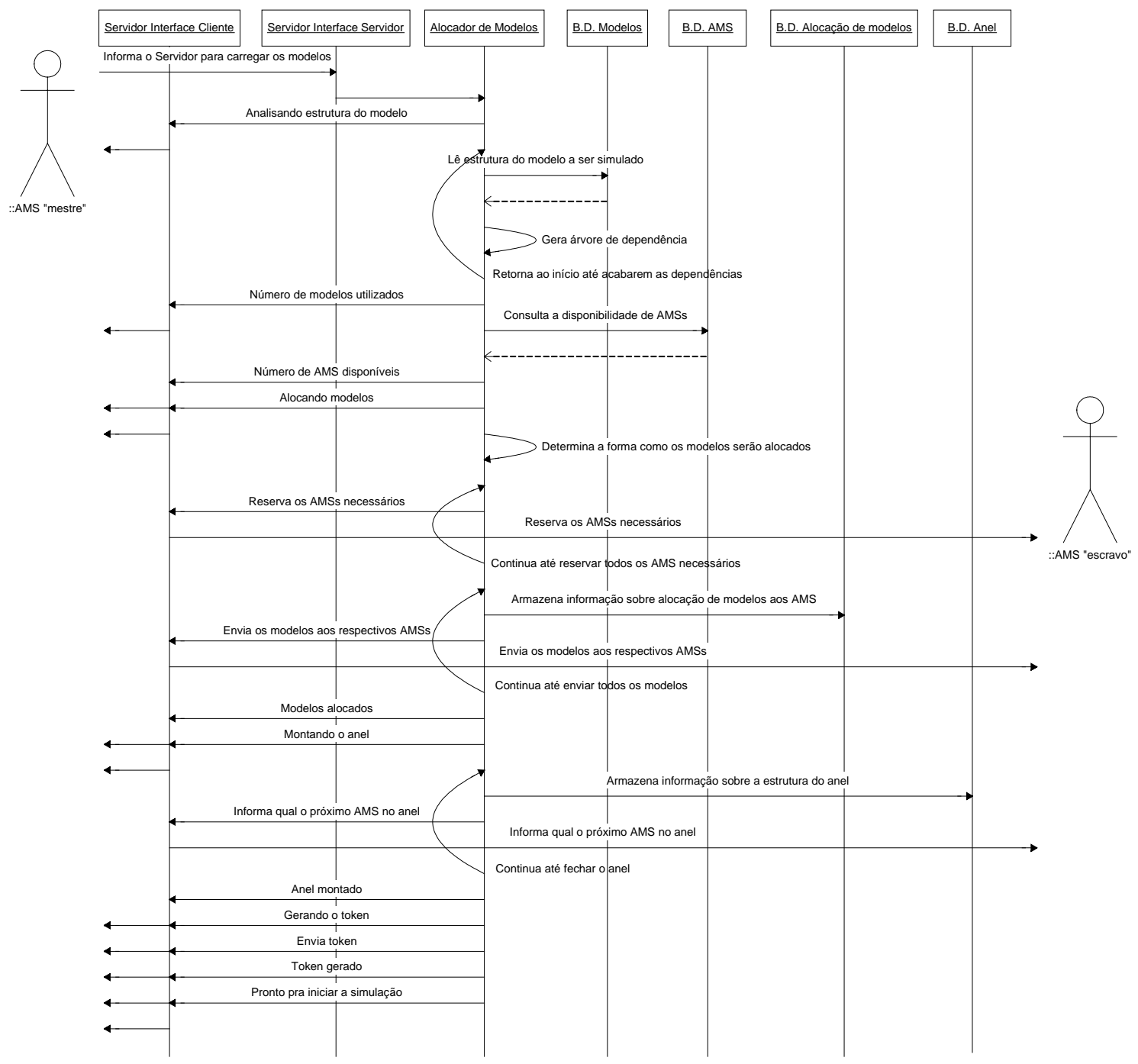

Figura G.14 - Diagrama de seqüência ilustrando a seqüência de atividades necessárias para entrar no modo de simulação e sair do modo de edição quando se simula um modelo diferente de classe Parte II - Servidor. 


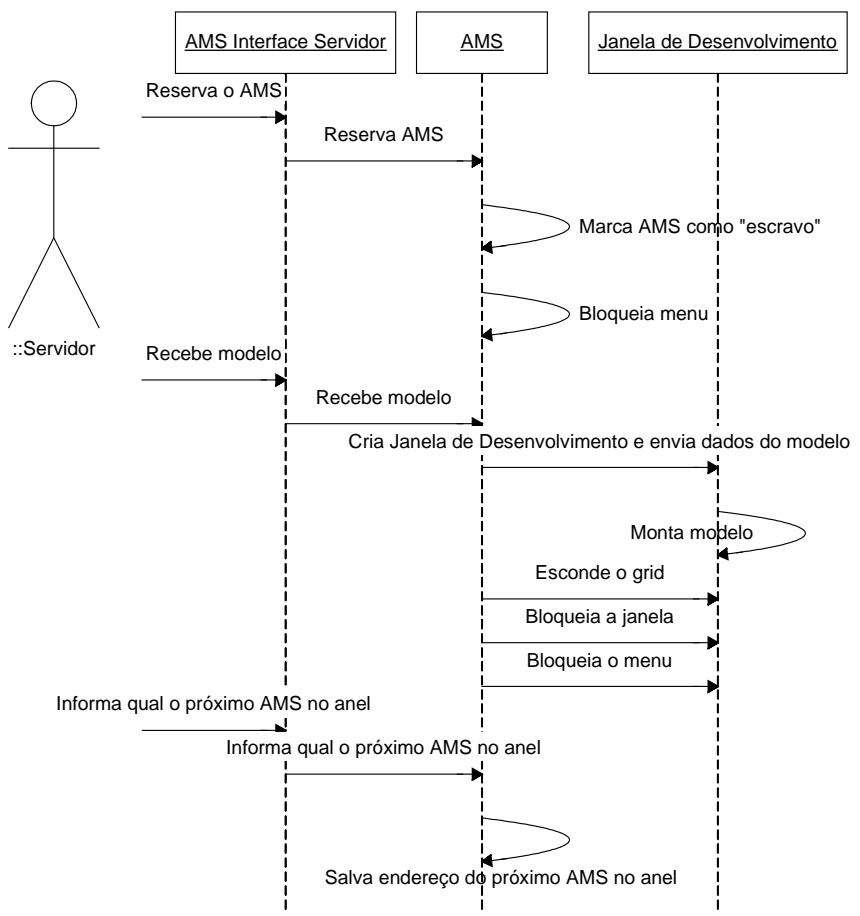

Figura G.15 - Diagrama de seqüência ilustrando a seqüência de atividades necessárias para entrar no modo de simulação e sair do modo de edição quando se simula um modelo diferente de classe Parte III - AMS “escravo".

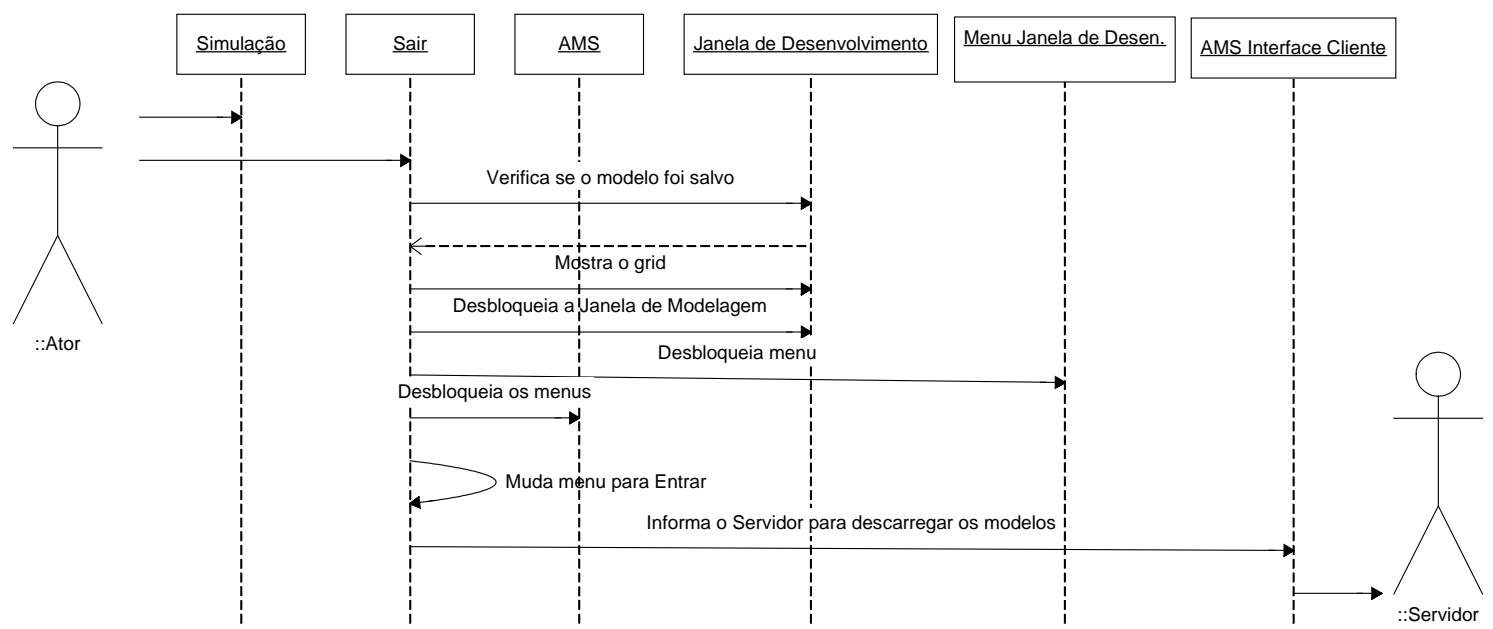

Figura G.16 - Diagrama de seqüência ilustrando a seqüência de atividades necessárias para sair do modo de simulação e voltar para o modo de edição quando se simula um modelo diferente de classe - Parte I - AMS “mestre". 


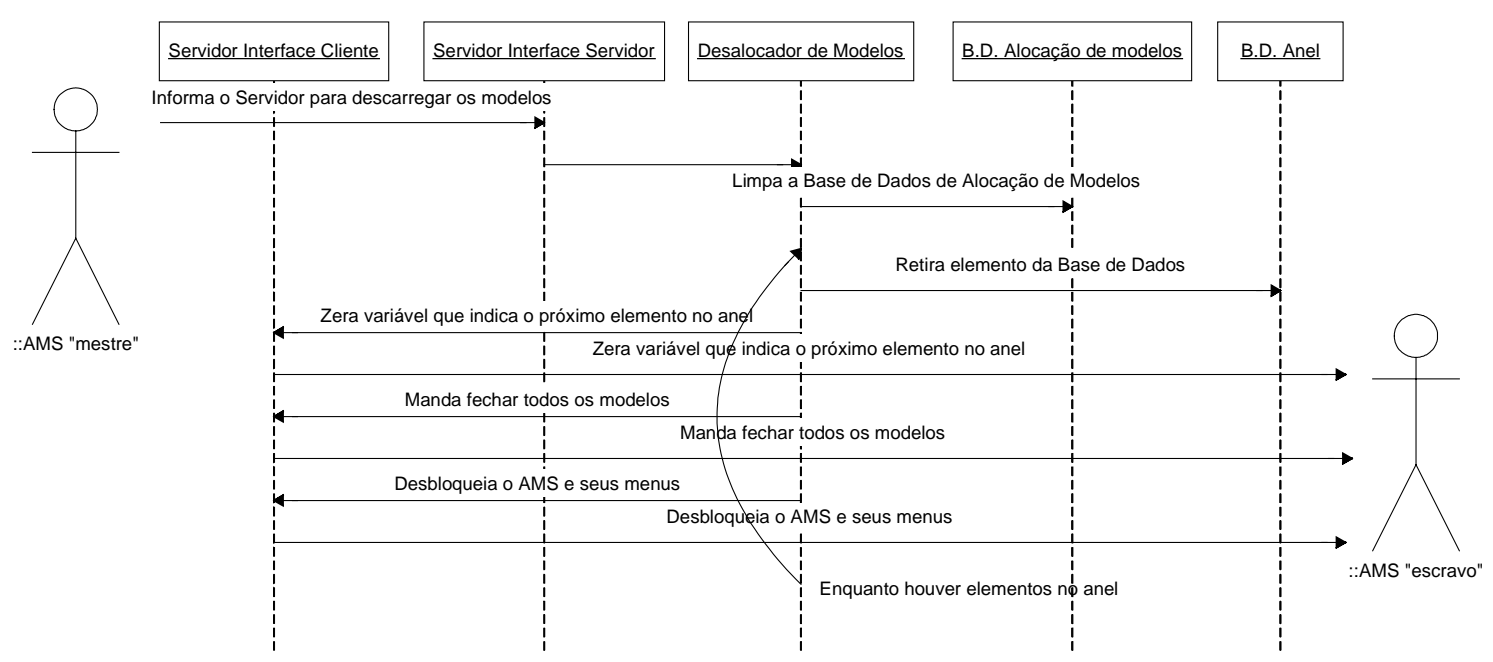

Figura G.17 - Diagrama de seqüência ilustrando a seqüência de atividades necessárias para sair do modo de simulação e voltar para o modo de edição quando se simula um modelo diferente de classe - Parte II - Servidor.

O diagrama de seqüência correspondente ao AMS “escravo”, por se parecer com o do AMS “mestre” não será apresentado.

O diagrama de sequiência para quando se simula modelos diferentes de classe, como componentes e aplicativos é similar ao para classes, no que diz respeito à FILA DE DISPAROS, JOGADOR DE MARCAS e ATUALIZA TELA. As diferenças surgem com relação ao token que circula entre os AMSs, como destacado na Figura G.18, para o caso de INICIAR a simulação, e Figura G.19, para PAUSAR a simulação.

No caso de ser o AMS “mestre”, o GERENCIADOR DE COMUNICAÇÃO apenas pode ler a variável "indicador da simulação”; no caso de ser “escravo”, ele deve escrever nela quando necessário. 


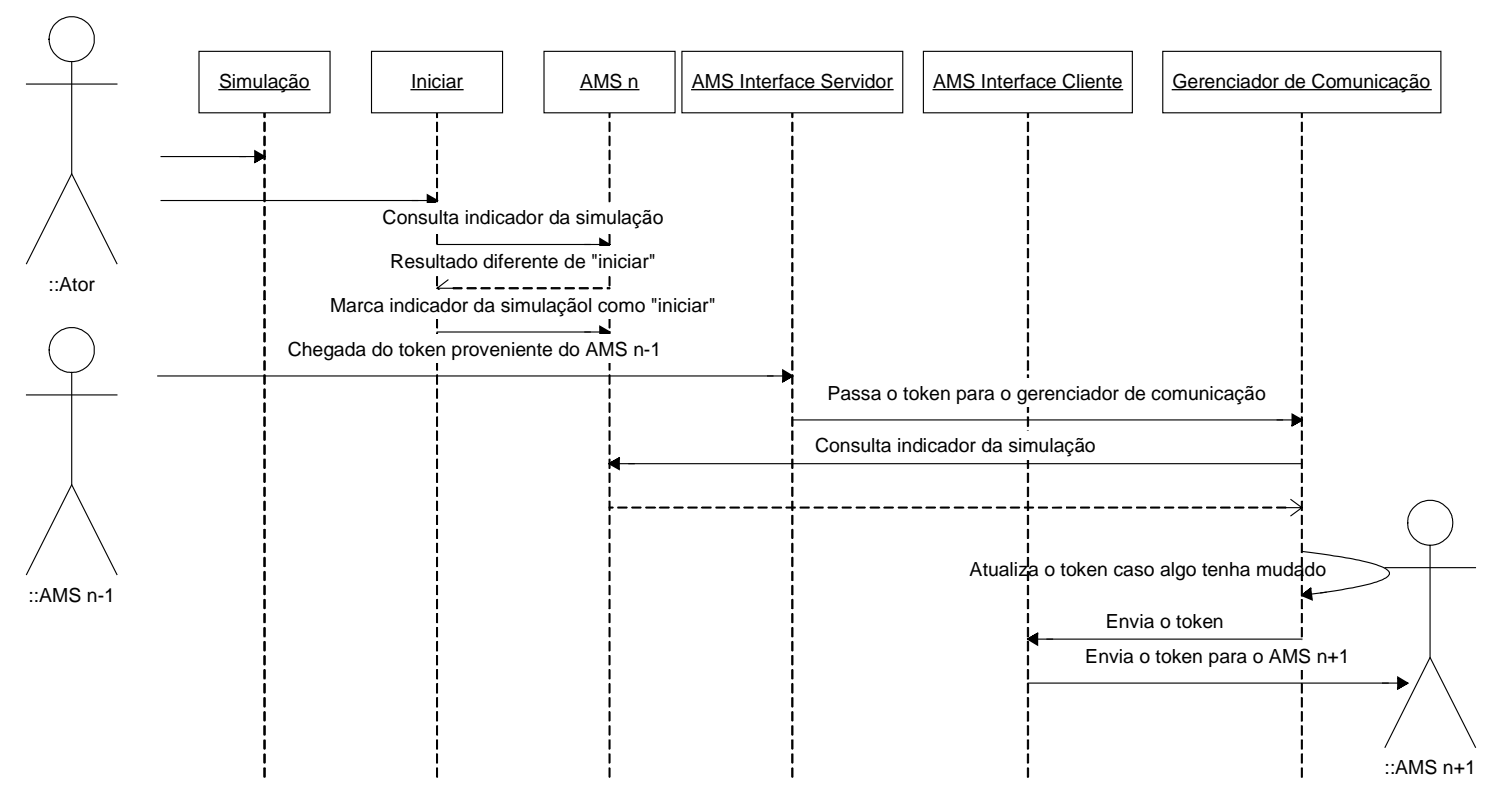

Figura G.18 - Diagrama de seqüência ilustrando a seqüência de atividades necessárias para iniciar a simulação quando se simula um modelo diferente de classe.

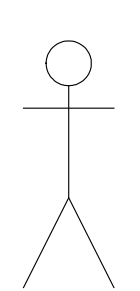

$\because$ Ator

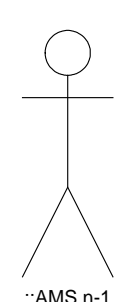

$:$ AMS n-1
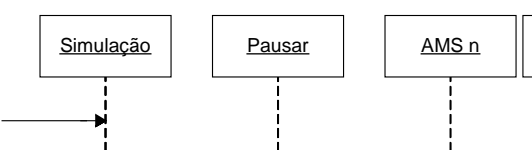

AMS Interface Servidor

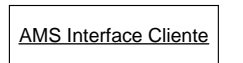

Gerenciador de Comunicação
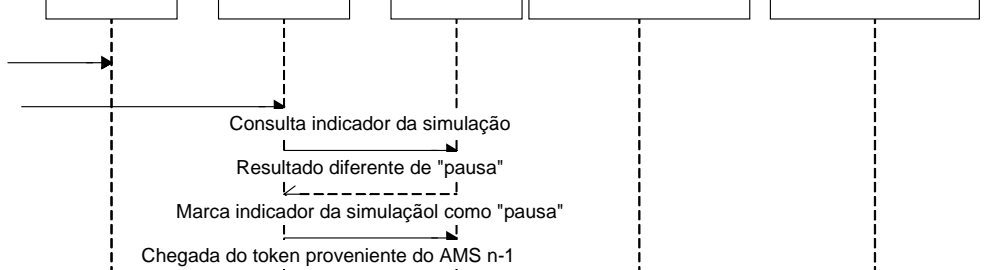

1

Passa o token para o gerenciador de comunicação
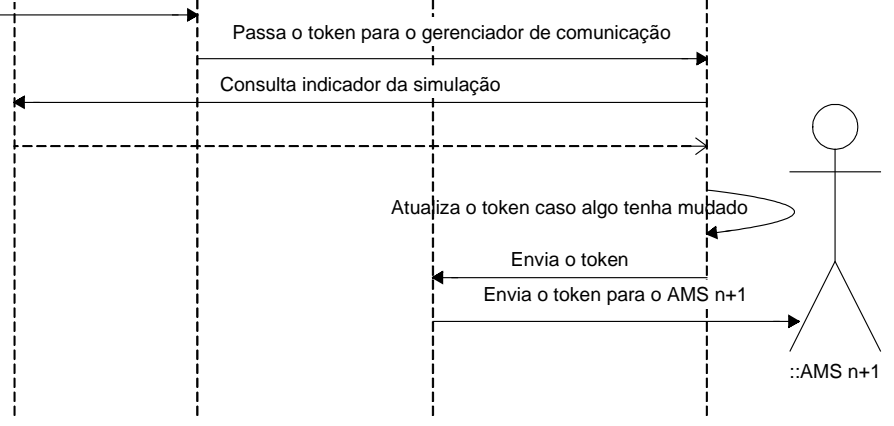

Figura G.19 - Diagrama de seqüência ilustrando a seqüência de atividades necessárias para pausar a simulação quando se simula um modelo diferente de classe.

O próximo cenário (Figura G.20) ilustra a execução de uma chamada de método entre duas classes simuladas em AMS distintos. 


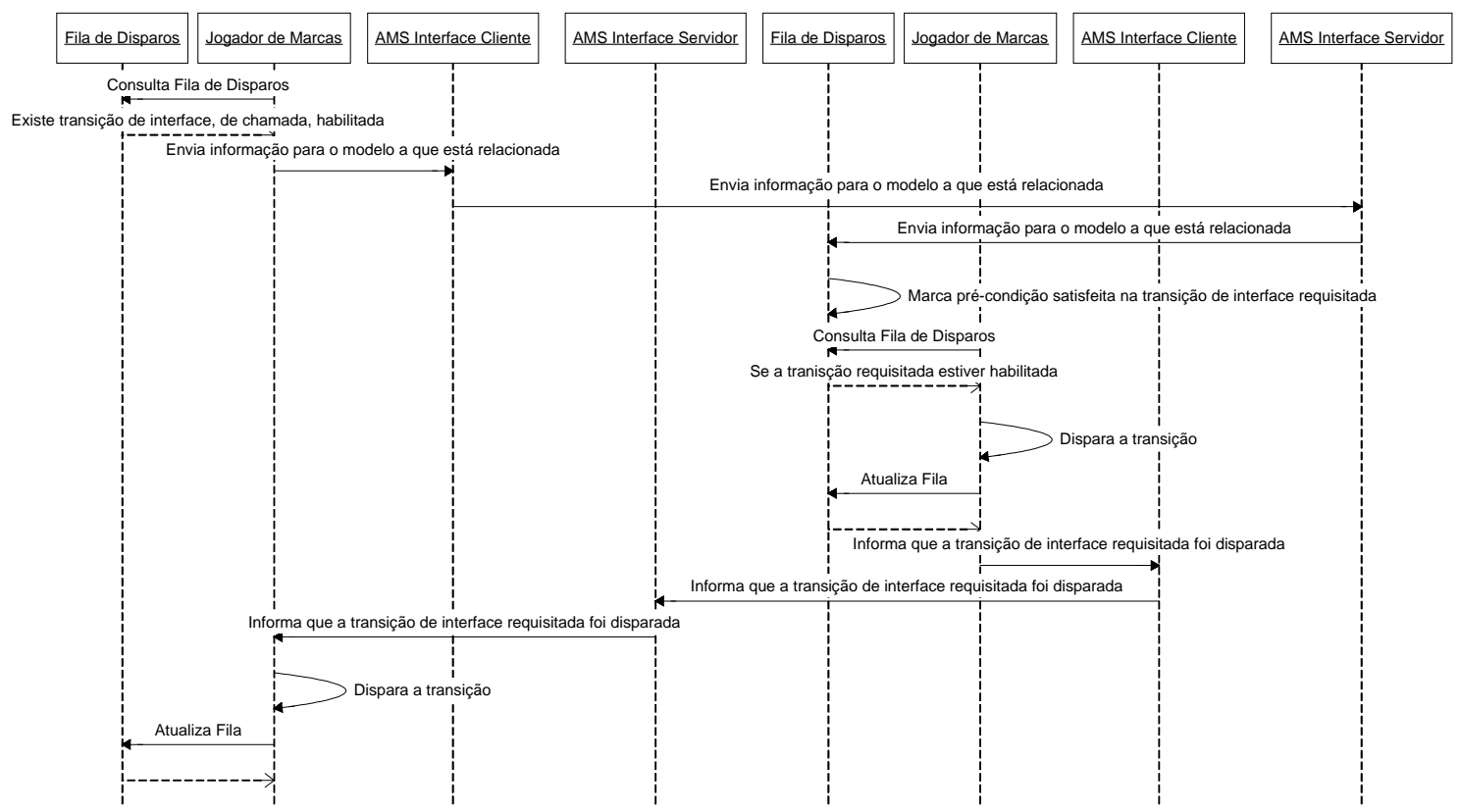

Figura G.20 - Diagrama de seqüência ilustrando a seqüência de atividades que se dá durante a chamada de métodos (através de fusão de transições).

\section{G.4. Especificação utilizando o ponto de vista da engenharia}

Neste ponto de vista são apresentados os diagramas UML dos componentes, ou seja, como as classes (dos diagramas da seção G.2) são agrupadas em macro elementos para a sua implementação e distribuição. A seção G.4.1 apresenta os diagramas de componentes, enquanto a seção G.4.2 apresenta o diagrama de distribuição, ou seja, como estes componentes são associados aos nós ${ }^{36}$.

\section{G.4.1. Diagramas de componentes}

Adotou-se para este projeto a divisão do sistema computacional proposto em três componentes (Figuras G.21 e G.22). O componente MACRO AMS (Figura G.21) reúne as classes apresentadas no diagrama de classes da Figura G.4 com exceção da classe JANELA DE DESENVOLVIMENTO (detalhada nas Figuras G.5 e G.6) que serve de base para o componente MACRO JANELA DE DESENVOLVIMENTO.

\footnotetext{
${ }^{36}$ Cada nó é composto pelo sistema operacional mais a parte do software referente à plataforma.
} 


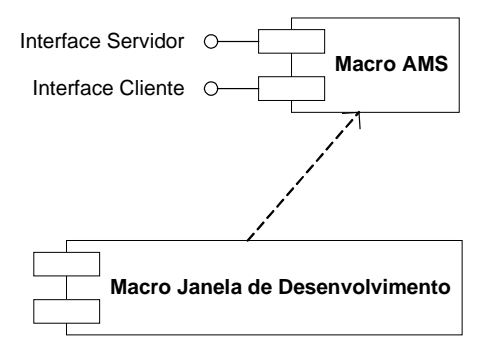

Figura G.21 - Diagrama de componentes ilustrando os componentes (Macro AMS e Macro Janela de Desenvolvimento) utilizados para a geração de modelos em Redes de Petri, bem como sua relação de dependência.

Esta divisão permite que as ferramentas de manipulação de arquivo (abrir, salvar, fechar, etc.), acesso e comunicações, no MACRO AMS, sejam desvinculadas da modelagem propriamente dita (no MACRO JANELA DE DESENVOLVIMENTO), permitindo, por um lado, testar diferentes formas de se implementar as interfaces, ao mesmo tempo que possibilita que outros tipos de RdP sejam implementados e utilizem a infraestrutura já disponível.

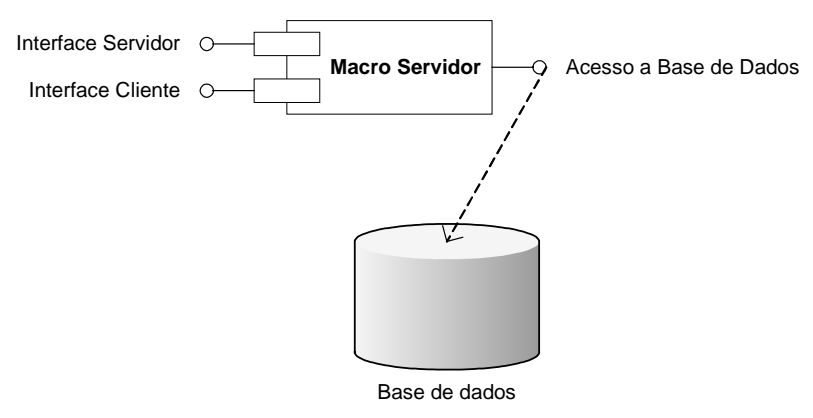

Figura G.22 - Diagrama de componentes ilustrando o componente Macro Servidor responsável pelo gerenciamento do Domínio e a Base de Dados.

A Figura G.22 apresenta o componente MACRO SERVIDOR, que reúne as classes da Figura G.7, e apresenta seu relacionamento com a BASE DE DADOS. Como já apresentado anteriormente nos diagramas de sequiência, as interfaces CLIENTE e SERVIDOR são as mesmas para o MACRO SERVIDOR e MACRO AMS.

\section{G.4.2. Diagramas de distribuição}

Neste caso são considerados dois tipos de nós: nó ESTAÇÃO (Figura G.23) que inclui os componentes MACRO AMS e MACRO JANELA DE DESENVOLVIMENTO e o nó SERVIDOR que é composta pelo componente MACRO SERVIDOR e pela BASE DE DADOS (Figura G.24). 


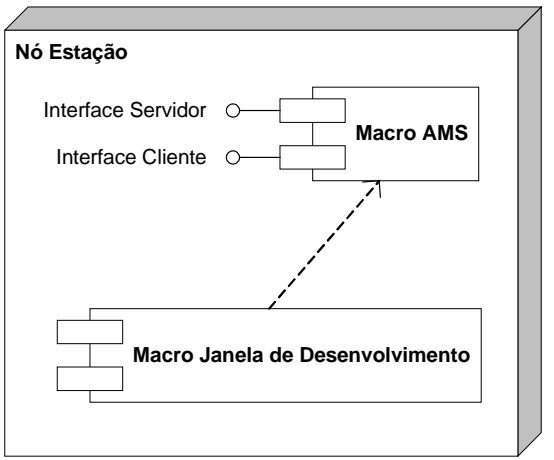

Figura G.23 - Diagrama de distribuição para o Nó Estação.

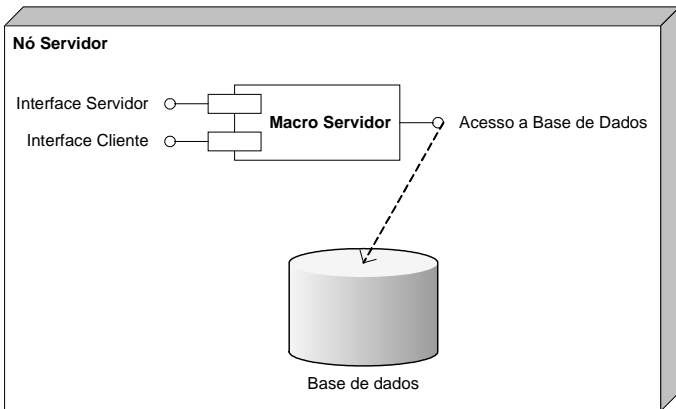

Figura G.24 - Diagrama de distribuição para o Nó Servidor.

A Figura G.25 apresenta um exemplo da relação dinâmica entre os nós ${ }^{37}$ durante a simulação. No exemplo são utilizadas três Estações, que são responsáveis pela simulação dos modelos em RdP, e o Servidor, que monitora o estado do anel virtual.

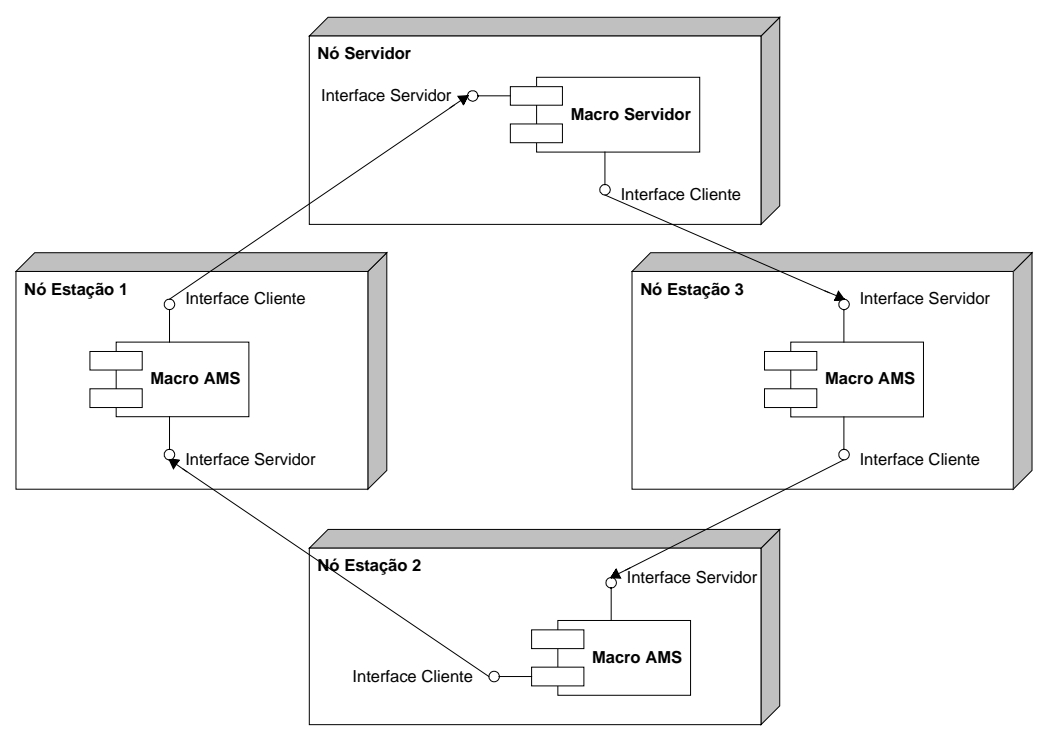

Figura G.25 - Exemplo de relação entre os nós durante a simulação. 


\section{G.5. Especificação utilizando o ponto de vista da tecnologia}

O ponto de vista da tecnologia foca nos detalhes dos componentes (hardware e software) que são usados no sistema computacional para modelagem e simulação proposto.

Para a implementação deste sistema computacional, propõe-se o uso do pacote Borland Delphi ${ }^{38}$, o qual permite que um mesmo programa desenvolvido para Windows $^{39}$ seja portado para outros sistemas operacionais, como Linux ${ }^{40}$, sem a necessidade de nova codificação.

Para a implementação das interfaces, utiliza-se a tecnologia Indy, presente no pacote da Borland, que é composta de serviços baseados em Socket, também portável para outros sistemas operacionais. Outras tecnologias que permitam a interface entre programas, como CORBA (Common Object Request Broker Architecture) (SALEH et al., 1999; SCHMIDT et al., 1998) e DCOM (CHUNG et al., 1997; HOFFMAN, 2003; PAYTON, 2003; RAJ, 2003) também podem ser consideradas como forma de interfaceamento com outros tipos de sistema, em especial sistemas reais aplicados à manufatura automatizada.

\section{G.6. Síntese do anexo}

Neste anexo o RM-ODP foi utilizado em conjunto com os diagramas UML para na proposta de um sistema computacinal para a modelagem e simulação de sistemas produtivos distribuídos. Pôde-se comprovar que a utilização de RM-ODP com UML apresenta-se como mais uma possibilidade na especificação de sistemas computacionais. O RM-ODP guia o projetista (pelos pontos de vista) nas etapas de modelagem enquanto a UML provê subsídios para a descrição dos modelos ao mesmo tempo que garante a consistência entre eles.

\footnotetext{
${ }^{37}$ Alguns detalhes dos nós foram suprimidos para destacar apenas as interações entre as interfaces.

${ }^{38} \mathrm{http}: / / \mathrm{www} \cdot$ borland.com.br/delphi/

${ }^{39} \mathrm{http} / / / \mathrm{www}$.microsoft.com/windows/default.mspx

${ }^{40}$ http://www.linux.org/
} 


\section{REFERÊNCIAS BIBLIOGRÁFICAS}

AMBLER, S. W. The Unified Modeling Language v1.1 and Beyond: The Techniques of Object-Oriented Modeling. Apresenta uma breve revisão sobre os conceitos e diagramas UML. Disponível em: <http://www.aigsi.com/umlandbeyondpdf.pdf $>$. Acesso em: 12 de jul. 2002.

ARAKAKI, J. Técnicas de degeneração no projeto do controle de sistemas produtivos. 2004. 154p. Tese (Doutorado) - Escola Politécnica, Universidade de São Paulo. São Paulo, 2004.

BANKS, J. (Chair) Simulation in the future. In. Proceedings of the 2000 Winter Simulation Conference, p.1568-1576, 2000.

BASTIDAS GUSTIN, G. D. Aplicação de redes de Petri interpretadas na modelagem de sistemas de elevadores em edifícios inteligentes. 2000. 139p. Dissertação (Mestrado) - Escola Politécnica, Universidade de São Paulo. São Paulo, 2000.

BASTIDAS GUSTIN, G. D., VILLANI, E., JUNQUEIRA, F., MIYAGI, P. E. Open Distributed Supervisory System Design using Petri Nets. In: Proceedings of the 2003 IEEE International Symposium on Industrial Electronics (ISIE), Rio de Janeiro, 2003.

BASTIDAS GUSTIN, G. D. Modelagem e análise de sistemas distribuídos e abertos para automação predial. 2005. 196p. Tese (Doutorado) - Escola Politécnica, Universidade de São Paulo. São Paulo, 2005.

BASTIDE, R. Approaches in Unifying Petri Nets and the Object-Oriented Approach. In: 1st Workshop on Object-Oriented Programming and Models of Concurrency, OO-MC'95, 16th international conference on applications and theory of Petri nets, ICATPN'95. Torino, Italy, June 1995.

BECERRA, J. L. R. Aplicabilidade do padrão de processamento distribuído e aberto nos projetos de sistemas abertos de automação. 1998. 162p. Tese (Doutorado) - Escola Politécnica, Universidade de São Paulo. São Paulo, 1998.

BERALDI, R., NIGRO, L. Distributed Simulation of Timed Petri Nets: A Modular Approach Using Actors and Time Warp. IEEE Concurrency, Vol. 7, No. 4, p.52-62, 1999.

BIRD, D. Token Ring Network Design. Addison-Wesley Publishing Co., 1995. 
BLOBEL, B., HOLENA, M. CORBA security services for health information systems. International Journal of Medical Informatics, Vol. 52, No. 1, p.29-37, Oct. 1998. BOITEN, E., BOWMAN, H., DERRICK, J., LININGTON, P., STEEN, M. Viewpoint consistency in ODP. Computer Networks, Vol. 34, No. 3, p.503-537, Sept. 2000.

BOOCH, G., RUMBAUGH, J., JACOBSON, I. The Unified Modeling Language User Guide. Addison Wesley Longman, Inc., 1999.

CALVEZ, J.P. Embedded Real-Time Systems. John Wiley \& Sons, 1993.

CARDOSO, J.; VALETTE, R. Redes de Petri. Florianópolis: Editora da UFSC, 1997.

CASSANDRAS, C. G., STRICKLAND, S. G. Sample Path Properties of timed Discrete Event Systems in Discrete Event Dynamic Systems - Analizing Complexity and Performance in the Modern World. New York: IEEE Press, 1992.

CENTENO, M. A. An Introduction to Simulation Modeling. In: Proceedings of the 1996 Winter Simulation Conference, p.15-22, 1996.

CHANDY, K. M.; MISRA, J. Distributed simulation: A case study in design and verification of distributed programs. In: IEEE Trans. Softw. Eng., Vol 5, No. 5, p.440-452, 1979.

CHEUNG, T., Petri Nets for Protocol Enginnering. In: Computer Communications, Vol. 19, No. 4, p.1250-1257, Dec. 1996.

CHIOLA, G.; FERSCHA, A. A Distributed Discrete Event Simulation Framework for Timed Petri Net Models. In: Technical Report Series of the Austrian Center for Parallel Computation, ACPC/TR 93-21, Dec. 1993.

CHUNG, P. E. et al. DCOM and CORBA Side by Side, Step by Step, and Layer by Layer. 1997. Comparação entre DCOM e CORBA. Disponível em: $<$ http://www.research.microsoft.com/ ymwagn/papers/HTML/DCOMnCORBA/S.ht $\underline{\mathrm{ml}>}$. Acesso em: 05 de fev. 2002.

COSTA, C. A., HARING, J. A., YOUNG, R. I. M. The application of UML and an Open Distributed Process framework to information system design. Computers in Industry, No. 46, p.33-48, 2001.

DAUM, T., SARGENT, R. G. Scaling, hierarchical modeling, and reuse in an objectoriented modeling and simulation system. In. Proceedings of the 1999 Winter Simulation Conference, p.1470-1477, 1999. 
DELL, Dell Global Product Development. Sobre a cadeia produtiva da DELL. Disponível em: <http://www1.la.dell.com/content/topics/global.aspx/innovation/ en/cto_product_development?c=br\&l=pt\&s=corp> . Acesso em 29 de jul. 2005.

DJEMAME, K. et al. Performance comparison of high-level algebraic nets distributed simulation protocols. Journal of Systems Architecture, No. 44, p.457-472, 1998.

DOUGLASS, B. P. Doing Hard Time - Developing Real-Time Systems with UML, Objects, Frameworks, and Patterns. Addison Wesley Longman, Inc., 1999.

DOUGLASS, B. P. Real Time UML: developing efficient objects for embedded systems. Addison Wesley Longman, Inc., 1998.

ELKOUTBI, M., KELLER, R. K. Modeling Interactive Systems with Hierarchical Colored Petri Nets. In: Proceedings of the 1998 Advanced Simulation Technologies Conference, p.432-437, Apr. 1998.

EVANS, J. R., OLSON, D. L. Introduction to simulation and risk analysis. New Jersey: Prentice-Hall Inc, 1998.

EYKHOFF, P. System identification: parameters and state estimation. London: John Wiley, 1974.

FAPESP, TIDIA-KyaTera - Advanced Internet Program, Brasil, 2005. Projeto TIDIA,

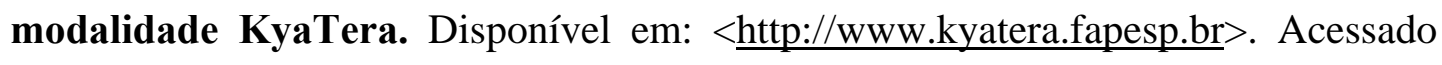
em: abr. 2005.

FAROOQUI, K. Reference Model of Open Distributed Processing (ODP) - A Guide Tour. Ottawa, University of Ottawa. Modelo de referência ODP. Disponível em: $<$ http://lotos.csi.uottawa.ca/ farooqui/> . Acesso em: 12 de jul. 2002.

FESTO, Festo Didactic Products. Produtos didáticos FESTO. Disponível em: $<$ http://www.festo.com/didactic/shop.asp?view=1\&e0=638\&nation=gb\&lang=en $>$. Acesso em: 04 de ago. 2005.

FISHBURN, P. T., GOLKAR, J., TAAFFE, K. M., Simulation of Transportation Systems, In: Proceedings of the 1995 Winter Simulation Conference, p.51-54, 1995.

FUjimoto, R. Parallel Discrete Event Simulation. Communications of the ACM, Vol. 33, No. 10, p.30-53, 1990.

FUJIMOTO, R. M. Parallel and distributed simulation. In. Proceedings of the 1999 Winter Simulation Conference, p.122-131, 1999. 
GARCIA, C. Modelagem e simulação de processos industriais e de sistemas eletromecânicos. São Paulo: Edusp, 1997.

GASPOZ, J-P. Methodology for the Development of Distributed Telecommunications Services. Journal of Systems and Software, New York, No. 33, p.253-271, 1996.

GÖHRING, HANS-GEORG; KAUFFELS, FRANZ-JOACHIM, Token Ring: principles, perspectives and strategies. Addison-Wesley Publishing Co., 1994.

GUSTAVSON, Å., TÖRN, A. Extending Simulation Nets with Sensor Arcs. Proceeding of the 37th SIMS Simulation Conference, Lyngby, Denmark, p.80-84, June 1995.

HO, Y.C.; CAO, X.R., Pertubation Analysis of Discrete Event Dynamic Systems, Kluwer Academic Publishers, 1991.

HOFFMAN, R. Sneaking up on CORBA: the race for the ideal distributed object model. 1999. Sistemas Middleware. Disponível em: <http://www.networkcomputing.com/shared/printArticle.jhtml?article=/1009/1009f2 full.html\&pub=nwc>. Acesso em: 24 de jul. 2003.

INAMASU, R.Y., Modelo de FMS: Uma Plataforma para Simulação e Planejamento, 1995, 134p. Tese (Doutorado) - Escola de Engenharia de São Carlos, Universidade de São Paulo. São Carlos, 1995.

INPRISE CORPORATION. Developer's Guide - Borland Delphi 5 for Windows 98, Windows 95, \& Windows NT. Inprise Corporation, 1999.

ITU. Open Distributed Processing - Reference Model - Part 3: Architecture. ITU Rec. X.903, 1995.

JEFFERSON, D. Virtual Time. In: ACM Transactions on Programming Languages and Systems, Vol. 7, No. 3, p.404-425, 1985.

JENSEN, K. Coloured Petri Nets: Basic Concepts, Analysis Methods and Practical Use. Berlin: Springer-Verlag, Vol. 1., 1992.

JUNGLE, M., KINDLER, E., WEBER, M. Towards a Generic Interchange Format for Petri Nets - Position Paper. In. Bastide, R. et al (eds.): Meeting on XML/SGML based Interchange Formats for Petri Nets. Aarhus, Denmark, 21st ICATPN. (pp. 1-5) Jun. 2000. Disponível em: <http://www.informatik.huberlin.de/top/pnml/download/about/XML-Position00.ps >. Acesso em $10 \mathrm{de}$ fev. 2006. 
JUNQUEIRA, F.; MIYAGI, P. E. Modelagem orientada a processo e a objeto para sistemas autônomos de transporte. In: CBA XIII Congresso Brasileiro de Automática, Florianópolis, p.301-306, 2000.

JUNQUEIRA, F. Modelagem de sistemas flexíveis de movimentação de materiais através de redes de Petri interpretadas. 2001. 128p. Dissertação (Mestrado) Escola Politécnica, Universidade de São Paulo. São Paulo, 2001.

JUNQUEIRA, F.; VILLANI, E. ; MIYAGI, P. E. A Platform for Distributed Modeling and Simulation of Productive Systems based on Petri Nets and Object-Oriented Paradigm. In: ETFA2005 10th IEEE International Conference on Emerging Technologies and Factory Automation, 2005, Catania, 2005.a

JUNQUEIRA, F.; VILlANI, E.; MIYAGI, P. E. A Petri Net Based Platform for Distributed Modeling and Simulation of Productive Systems. In: COBEM2005 18th International Congress of Mechanical Engineering, 2005, Ouro Preto. Proceedings of the COBEM2005 18th International Congress of Mechanical Engineering, 2005b.

JUNQUEIRA, F.; MIYAGI, P. E. A New Method for the Hierarchical Modeling of Productive Systems. In; BASYS'06 7th IFIP International Conference on Information Technology for Balanced Automation Systems in Manufacturing and Services, Niagara Falls, Ontario, Canada, 2006.

KACHITVICHYANUKUL, V. (Chair) Simulation Environment for the new millennium. In. Proceedings of the 2001 Winter Simulation Conference, p.541547, 2001.

KANDÉ, M. et al. Applying UML to Design an Inter-Domani Service Management Application. UML'98: Beyond the Notation - International Workshop, 1998.

KHOSHNEVIS, B. Discrete Systems Simulation. Singapore: McGraw-Hill Inc., 1994. KING, A., HUNT, R. Protocols and architecture for managing TCP/IP network infrastructures. Computer Communications, No. 23, p.1558-1572, 2000.

KRENA, B., VOJNAR, T. Type Analysis in Object-Oriented Petri Nets. In: Proceedings of 4th International Conference on Information System Modelling - ISM'01, Hradec nad Moravicí, Czech Republic, CZ, p.173-180, Marq. 2001.

KUMAR, D., KOHLI, A. Faster Simulation of Timed Petri Nets Via Distributed Simulation. In: Proceedings of the COMPSAC '97 - 21st International Computer Software and Applications Conference, p.149-152, 1997. 
LAKOS, C. A. From Coloured Petri Nets to Object Petri Nets. In: Technical Report TR94-9. Computer Science Department, University of Tasmania, 1994.

LAKOS, C. A., The Object Orientation of Object Petri Nets. In: Workshop on Object Oriented Programming and Models of Concurrency, 1995.

LEE, W. B., LAU, H. C. W. Multi-agent modeling of dispersed manufacturing networks. Expert Systems with Applications, No. 16, p.297-306, 1999.

LIRA NUÑEZ, D., JUNQUEIRA, F., MIYAGI, P. E. Process Modeling and Fault diagnosis of Flexible Assembly systems Using Petri Net. In: Proceedings of COBEM2005. $18^{\text {th }}$ International Congress of Mechanical Engineering. Ouro Preto, 2005.

MARTE, C. L. Sistemas Computacionais Distribuídos Aplicados em Automação dos Transportes. 2000. 324 p. Tese (Doutorado) - Escola Politécnica, Universidade de São Paulo. São Paulo, 2000.

MARTÍNEZ RIASCOS, L. A. Metodologia para detecção e tratamento de falhas em sistemas de manufatura através de Redes de Petri. 2002. 160p. Tese (Doutorado) - Escola Politécnica, Universidade de São Paulo. São Paulo, 2002.

MISRA, J. Distributed discret-event simulation. In: Computer Surveys, Vol. 18, No. 1, p.39-65, 1986

MIYAGI, P. E., Controle Programável - Fundamentos do Controle de Sistemas a Eventos Discretos. São Paulo: Editora Edgard Blücher, 1996.

MOORE, K. E., BRENNAN, J. E. Alpha/SIM Simulation Software Tutorial. In: Proceedings of the 1996 Winter Simulation Conference, p.632-639, 1996.

MURATA, T. Petri Nets - Properties, Analysis and Applications. In: Proceedings of the IEEE, Vol .77, No. 4, 1989.

NANKMAN, M. A., NIEUWENHUIS, L. J. M. Specification of a distributed storage system. Computer Communications, No. 19, p.30-38, 1996.

NEVISON, C. Parallel simulation of manufacturing systems: Structural factors. In Proceedings of the SCS Multiconference on Distributed Simulation 22, Vol. 1, p.17-19, 1990.

NICOL, D. M., ROY, S. Parallel Simulation of Timed Petri-Nets In: Proceedings of the 1991 Winter Simulation Conference, p.574-583, 1991. 
NKETSA, A., VALETTE, R. Rapid and modular prototyping-based Petri nets and distributed simulation for manufacturing systems. Applied Mathematics and Computation, No. 120, p. 265-278, 2001.

ORFALI, R., HARKEY, D. Client/Server programming with Java and CORBA. New York: Wiley, 1997.

PARR, G., CURRAN, K. Multiple multicast groups for multimedia on the Internet. Information and Software Technology, No. 41, p.91-99, 1999.

PAYTON, M. CORBA vs. DCOM: a Comparison. Sistemas Middleware: comparação entre CORBA e DCOM. Disponível em: $<$ http://www.cs.colorado.edu/ getrich/Classes/csci5817/Term_Papers/payton/> .

Acesso em: 24 de jul. 2003.

Peterson, J. L. Petri Net Theory and the Modeling of Systems. New Jersey: Prentice Hall Inc., 1981.

PIDD, M. An Introduction to Computer Simulation. In: Proceedings of the 1994 Winter Simulation Conference, p.7-14, 1994.

PIDD, M. Five Simple Principles of Modeling. In: Proceedings of the 1996 Winter Simulation Conference, p.721-728, 1996.

POPLAWSKI, A. L., NICOL, D. M. An investigation o out-of-core parallel discreteevent simulation. In: Proceedings of the 1999 Winter Simulation Conference, p.524-530, 1999.

POTTER, W. D. et al. Using DCOM to support interoperability in forest ecosystem management decision support systems. Computers and Electronics in Agriculture, No. 27, p. 335-354, 2000.

PUTMAN, J. Architecting with RM-ODP. New Jersey: Prentice Hall, 2001.

RAJ, G. S. A Detailed Comparison of CORBA, DCOM and Java/RMI. Sistemas Middleware: comparação entre CORBA, DCOM e Java/RMI. Disponível em: $<$ http://my.execpc.com/ gopalan/misc/compare.html>. Acesso em: 24 de jul. 2003.

REISIG, W. A Primer in Petri Design. Berlin: Springer-Verlag, 1992.

SALEH, K., PROBERT, R., HASSIB, K. The distributed object computing paradigm: concepts and applications. The Journal of Systems and Softwares, No. 47, p.125131, 1999.

SANZ, R., ALONSO, M. CORBA for control systems. In: Annual Reviews in Control, No. 25, p.169-181, 2001. 
SARGENT, R. G. Verification and Validation of Simulation Models. In: Proceedings of the 1999 Winter Simulation Conference, p. 77-87, 1994.

SCHMIDT, D. C., LEVINE, D. L., MUNGEE, S. The design of the TAO real-time object request broker. Computer Communications, No. 21, p.294-324, 1998.

SEILA, A. F. Introduction to Simulation. In: Proceedings of the 1995 Winter Simulation Conference, p.7-15, 1995.

SHI, Y., GREGORY, M. International manufacturing networks - to develop global competitive capabilities. Journal of Operations Management, No. 16, p.195-214, 1998.

SIBERTIN-BLANC, C. A Client-Server Protocol for the Composition of Petri Nets. In: Proceedings 14th International Conference on Application and Theory of Petri Nets. Chicago, Illinois, USA, p.377-396, 1993.

SINNOTT, R. O., TURNER, K. J. Applying the architectural semantics of ODP to develop a trader specification. Computer Networks and ISDN Systems, No. 29, p. 457-471, 1997.

SRINIVASAN, R., VENKATASUBRAMANIAN, V. Automating HAZOP analysis of batch chemical plant: Part I. The knowledge representation framework. Computers Chem. Enginnering, Great Britain, Vol. 22, No. 9, p.1345-1355, 1998.

VENKATESWARAN, J., JAFFERALI, M. Y. K., SON, Y-J. Distributed simulation: an enabling technology for the evaluation of virtual enterprises. In. Proceedings of the 2001 Winter Simulation Conference, p.856-862, 2001.

VILLANI, E., Abordagem Híbrida para Modelagem de Sistemas de Ar Condicionado em Edifícios Inteligentes. 2000. 154p. Dissertação (Mestrado) Escola Politécnica, Universidade de São Paulo. São Paulo, 2000.

VILLANI, E., Modelagem e analise de sistemas supervisórios híbridos. 2004. 339p. Tese (Doutorado) - Escola Politécnica, Universidade de São Paulo. São Paulo, 2004. VILLANI, E.; PASCAL, J.C.; MIYAGI, P.E.; VALETTE, R. Object oriented approach for cane sugar production: modelling and analysis. Control Engineering Practice, Oxford: Pergamon-Elsevier Science, Vol. 12, No. 10, p.1279-1289, 2004.

VILLANI, E.; PASCAL, J.C.; MIYAGI, P.E.; VALETTE, R. Petri net-based objectoriented approach for the modelling of hybrid productive systems. Nonlinear Analysis: Theory, Methods \& Applications. Amsterdam: Pergamon-Elsevier Science, Vol. 62, No. 8, p. 1394-1418, 2005. 
VILLANI, E; KANESHIRO, P. I., MIYAGI, P. E. Hybrid Stochastic Approach for the Modelling and Analysis of Fire Safety Systems. Nonlinear Analysis: Theory, Methods \& Applications. Pergamon/Elsevier Science Ltd, Amsterdam, Holanda, Vol. 65, No. 6, p.1123-1149, 2006.

VILLANI, E, MIYAGI, P. E., VALETTE, R. Landing System Validation Based on Petri Nets and a Hybrid Approach. IEEE Transactions on Aerospace and Electronic Systems, IEEE. Piscateway, NJ, USA, Vol. 42, No. 3/4, 2006. (no prelo) W3C, Extensible Markup Language (XML), World Wide Web Consortium, 2005a. Padrão XML. Disponível em: <http://www.w3.org/XML/>. Acesso em: 29 de jul. 2005.

W3C, XML Schema Part 1: Structures Second Edition, World Wide Web Consortium, 2005b. Conceitos sobre XML Schema e seu uso. Disponível em: <http://www.w3.org/TR/2004/REC-xmlschema-1-20041028/structures.html >.

Acesso em: 24 de set. 2005.

WANG, L., WU, S. Modeling with Colored Timed Object-Oriented Petri Nets for Automated Manufacturing Systems. Computers and Industrial Enginnering, Great Britain, Vol. 34, No. 2, p.463-480, 1998.

YEN-TSANG, C.; VILLANI, E.; MIYAGI, P. E. Simulador de Sistemas Híbridos. In: 8 Simpósio Internacional de Iniciação Científica (SIICUSP), São Paulo, 2000. 